\title{
Implications of Sampling Methods on Geospatial Mapping of Methane Sources
}

\author{
Dakota Wesley Oliver \\ dwo0003@mix.wvu.edu
}

Follow this and additional works at: https://researchrepository.wvu.edu/etd

\section{Recommended Citation}

Oliver, Dakota Wesley, "Implications of Sampling Methods on Geospatial Mapping of Methane Sources" (2019). Graduate Theses, Dissertations, and Problem Reports. 4038.

https://researchrepository.wvu.edu/etd/4038

This Thesis is protected by copyright and/or related rights. It has been brought to you by the The Research Repository @ WVU with permission from the rights-holder(s). You are free to use this Thesis in any way that is permitted by the copyright and related rights legislation that applies to your use. For other uses you must obtain permission from the rights-holder(s) directly, unless additional rights are indicated by a Creative Commons license in the record and/ or on the work itself. This Thesis has been accepted for inclusion in WVU Graduate Theses, Dissertations, and Problem Reports collection by an authorized administrator of The Research Repository @ WVU. For more information, please contact researchrepository@mail.wvu.edu. 


\title{
Implications of Sampling Methods on Geospatial Mapping of Methane Sources
}

\author{
Dakota W. Oliver
}

Thesis submitted to the Benjamin M. Statler College of Engineering and Mineral Resources At West Virginia University

In partial fulfillment of the requirements for the degree of

Master of Science

In

Mechanical Engineering

Derek Johnson, Ph.D., Chair

Andrew Nix, Ph.D.

Marc Besch, Ph.D.

Department of Mechanical and Aerospace Engineering

Morgantown, West Virginia

July 2019

Keywords: Methane Detection, Signal Reconstruction, Geospatial Mapping Copyright 2019 Dakota Oliver 


\title{
Abstract \\ Implications of Sampling Methods on Geospatial Mapping of Methane Sources
}

\author{
Dakota W. Oliver
}

Natural gas is deployed as an alternative fuel due to its cost and post-combustion emissions. However, methane, the main component of natural gas, is a greenhouse gas with a global warming potential (GWP) of at least 28 over 100 years. Currently, natural gas and petroleum systems are the highest emitters of methane to the atmosphere. Using conventional methods, the detection of natural gas leaks is time consuming. Currently, natural gas production sites deploy the Environmental Protection Agency's (EPA) Method 21 or optical gas imaging (OGI) for methane leak detection. Both methods require access to the natural gas site along with the time and workers necessary to conduct equipment leak checks. Industry and academia are seeking to develop and deploy mobile methane monitoring systems to geospatially identify methane emissions. There are a variety of sensor systems that can be combined to enable such monitoring but there may be implied limitations (implications) based on operating principle and sampling frequency. The goal of this research was to assess these implications and where applicable develop methods that could overcome limitations.

Using a vehicle mounted approach, two mobile methane detection systems were deployed in rural West Virginia (WV). Over the course of 90 days, a total of 43 trips were completed through Morgantown, WV and the surrounding area. During each trip, two systems were implemented simultaneously with different sampling frequencies and methane sampling methods. The slow system operated at $1 \mathrm{Hertz}(\mathrm{Hz})$ with a closed-path methane analyzer, while the fast system operated at $10 \mathrm{~Hz}$ with an open-path methane analyzer. The effects of the sampling frequency and sampling method were observed for each system. The sampling frequency effects were examined with respect to geospatial limitations and wind speed limitations. The sampling method effects were compared between the systems using peak concentrations as the primary metric.

With the sample frequency effects, the closed-path methane analyzer required a signal reconstruction to report an accurate response in real time methane concentration. Methods of signal reconstruction, consisting of sequential inversion technique (SIT), inverse fast Fourier transform (IFFT), artificial neural network (ANN), and differential coefficients method (DCM), were investigated before the DCM and ANN were applied. A performance value was defined for improvement comparisons between the initial methane signal and the reconstructed signal. An application was created in MATLAB ${ }^{\odot}$ to process the mobile methane detection data. After indicating the user defined parameters, the application created a MATLAB ${ }^{\odot}$ workspace file and Google ${ }^{\circledR}$ Earth file consisting of a visual representation of the fast, slow, and reconstructed systems to elucidate the geospatial differences. The requirements for both the fast and slow systems were investigated with the intent of an operational mobile methane detection system. Suggested improvements and potential expansions of the mobile methane detection system were discussed. 


\section{Acknowledgements}

I can say with confidence that this would not have been possible with the support of my advisor, Dr. Derek Johnson. Your help with not only advisement, but with data collection and implementation ideas allowed for this thesis to develop into its current state.

I would also like to thank my committee: Drs. Andrew Nix and Marc Besch. Without their support and guidance, this work would not be possible.

I would also like to thank my current and former laboratory colleagues: Robert Heltzel, Mahdi Darzi, Chris Ulishney, Brian Cappellini, and Amber Barr. Their help with implementation, design, and data testing allowed for success in this project. Mr. Heltzel's help with edits, suggestions, and other thought processes were valuable during the writing process. His help with data collection and setup proved indispensable. Mr. Darzi's suggestions of problem solving approaches inspired conclusions on the data. Mr. Ulishney's help with the design and construction of the mounting system was crucial for field testing. Mr. Cappellini and Ms. Barr's help with setup and tear down of field testing cannot go unnoticed. Thank you all for the time spent outside the laboratory.

I would like to thank my family; in particular, my mother, father, and sister. Their unwavering support

allowed me to find and pursue my dreams. Without your love and guidance, I would not be the man I am today.

Lastly, I would like to thank my Fiancée, Megan Pumphrey. Without her constant encouragement through the graduate school experience, my two years in Morgantown would not have been possible. She kept aligning my focus on success to motivate this work to completion. 


\section{Table of Contents}

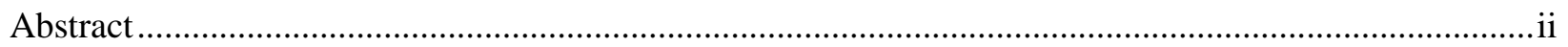

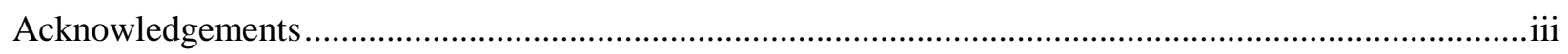

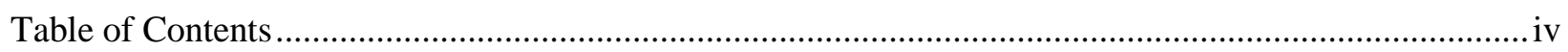

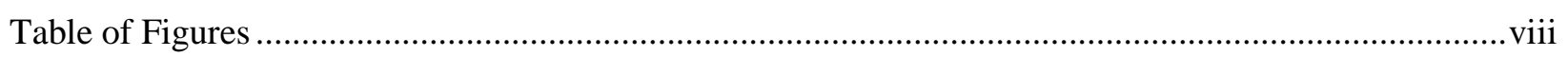

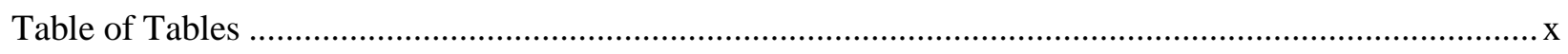

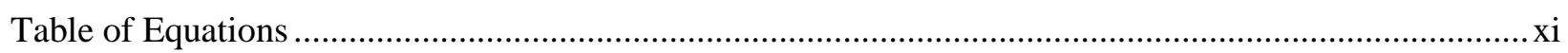

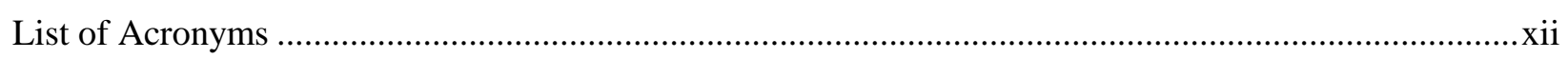

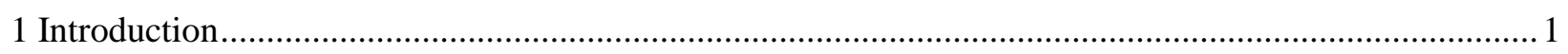

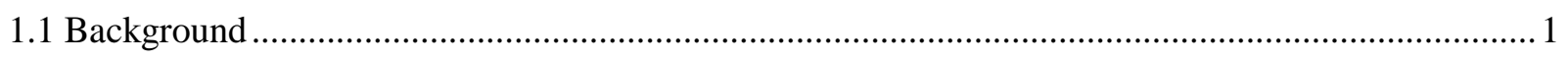

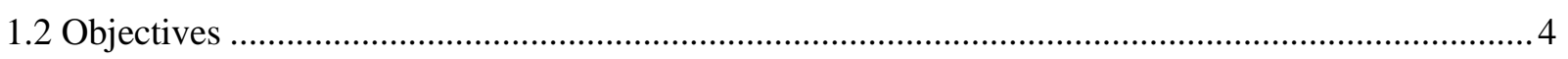

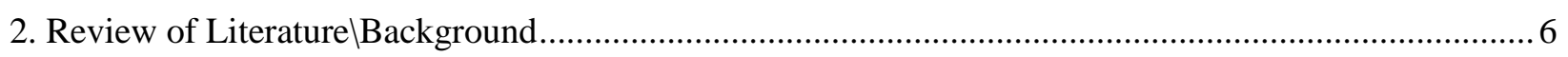

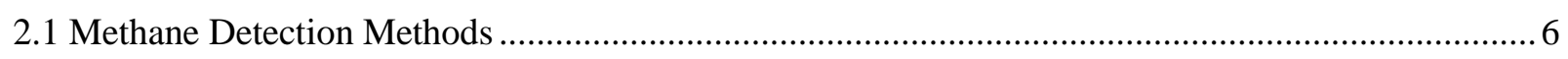

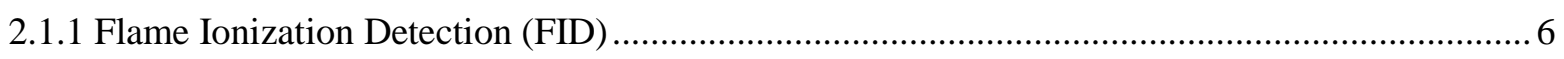

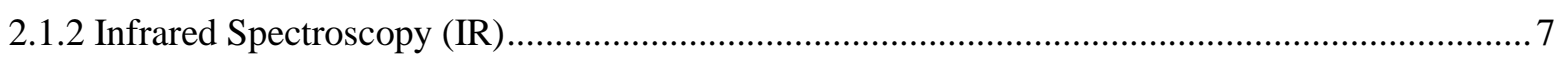

2.1.2.1 Fourier Transform Infrared Spectrometer (FTIR) ...................................................... 8

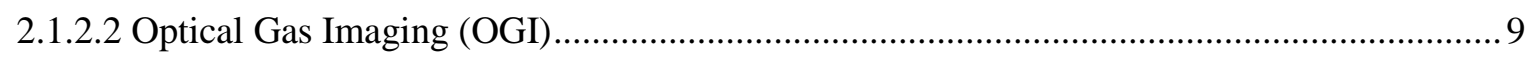

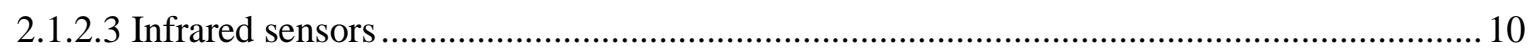

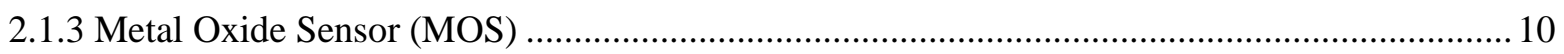

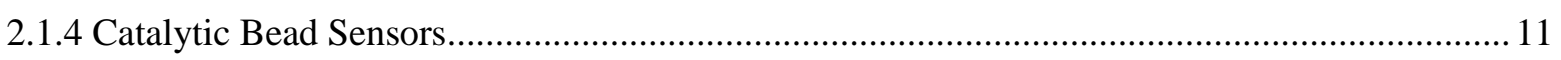

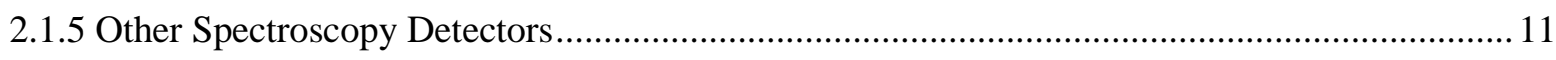

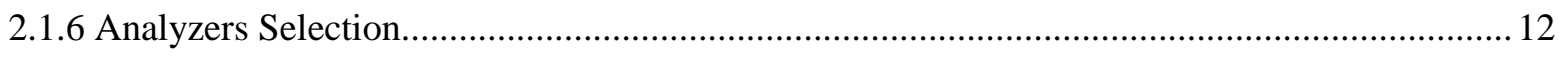

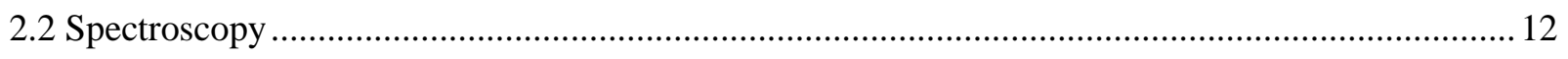

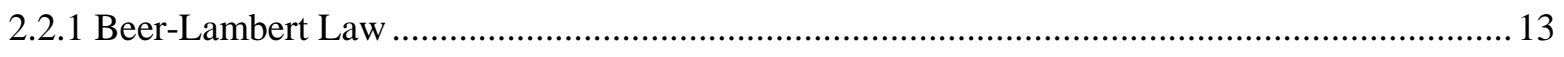

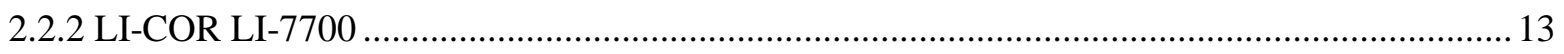

2.2.2.1 Wavelength Modulation Spectroscopy ...................................................................... 14

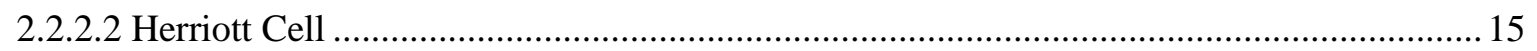

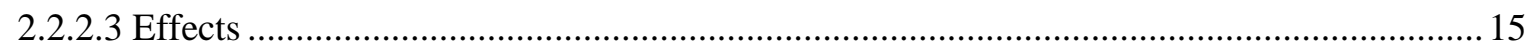

2.2.3 Los Gatos Research Ultra-Portable Greenhouse Analyzer (UGGA) ...................................... 16

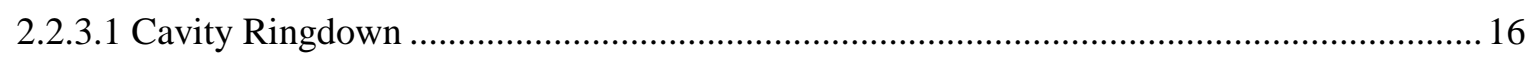

2.2.3.2 Off-Axis Integrated Cavity Output Spectroscopy …..................................................... 16

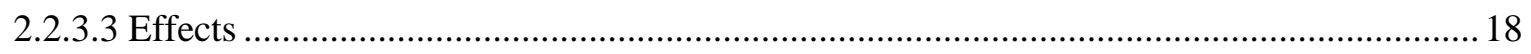

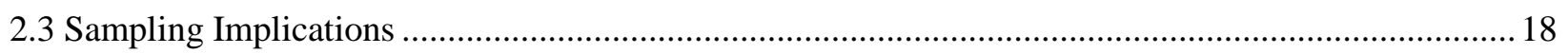

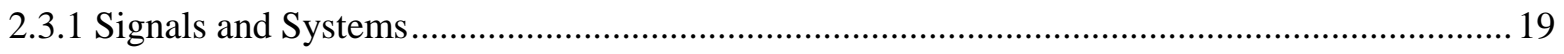




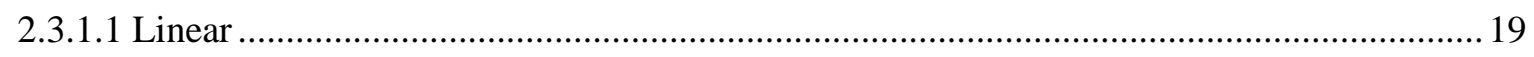

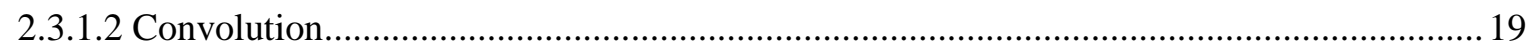

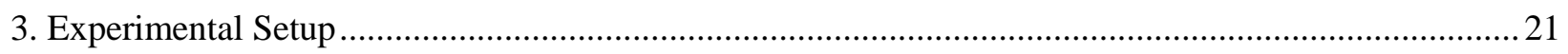

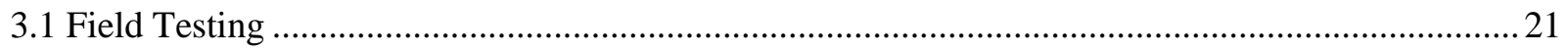

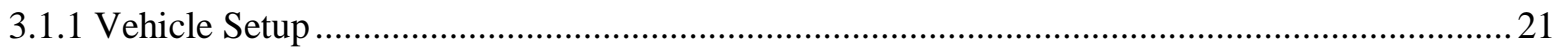

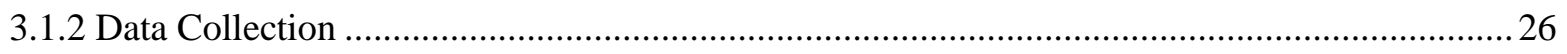

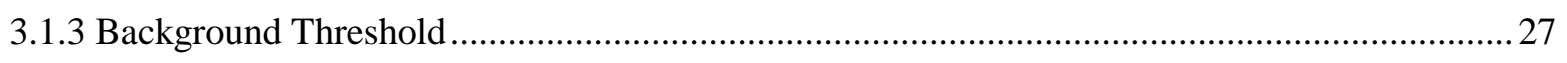

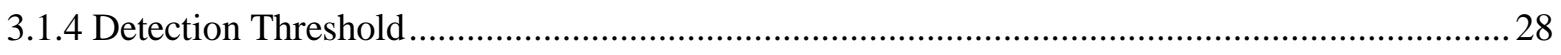

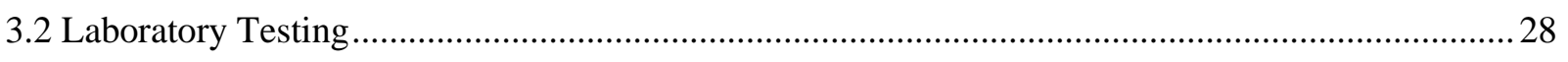

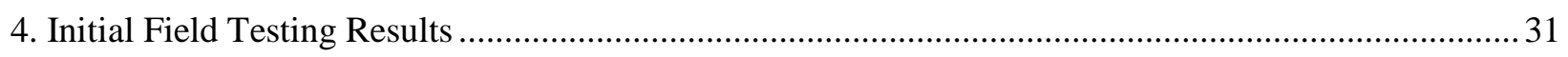

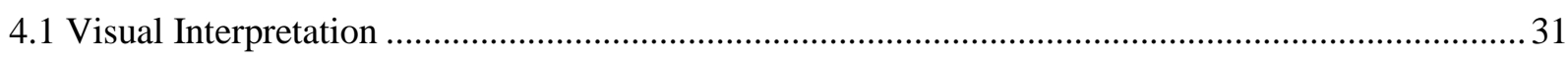

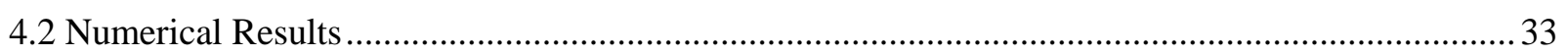

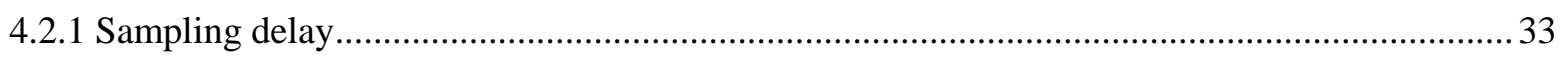

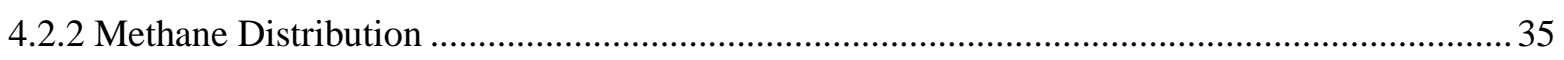

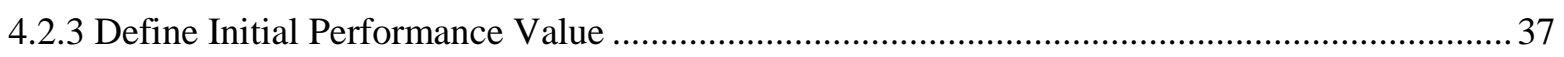

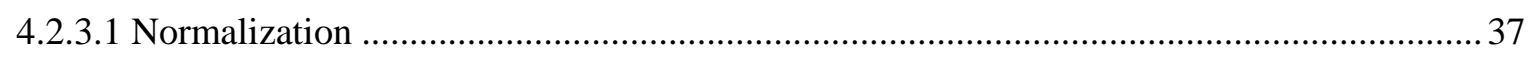

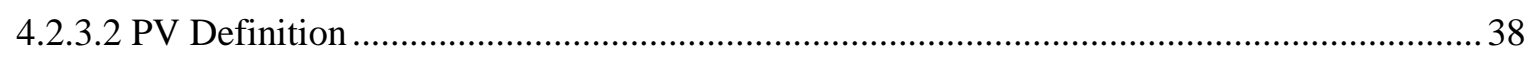

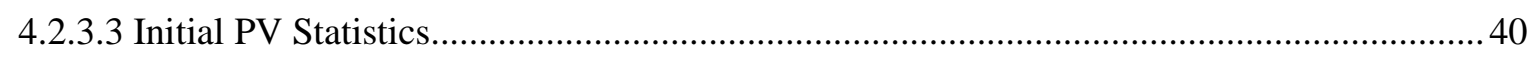

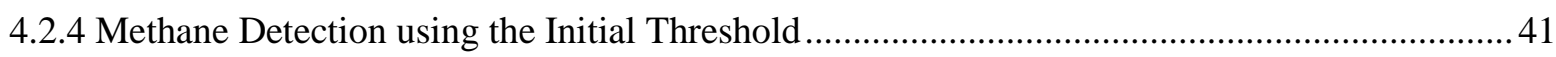

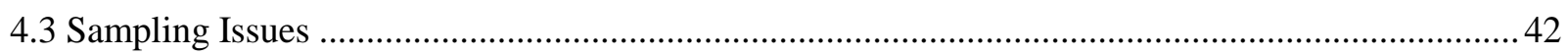

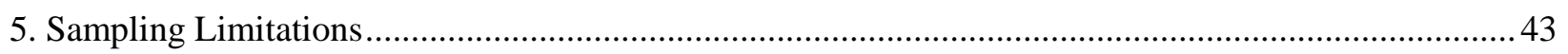

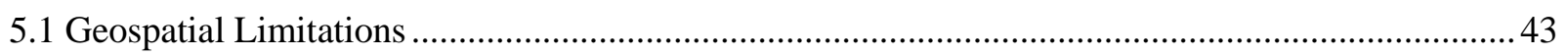

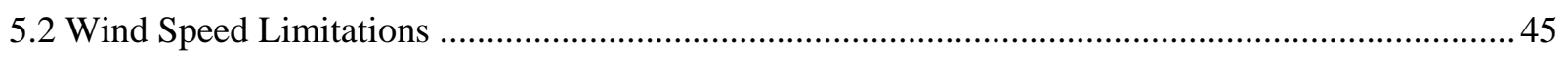

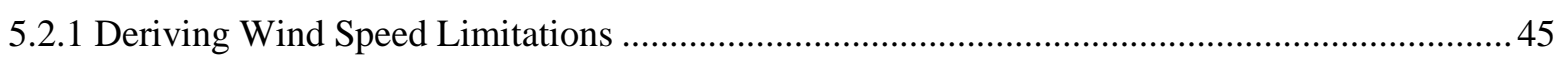

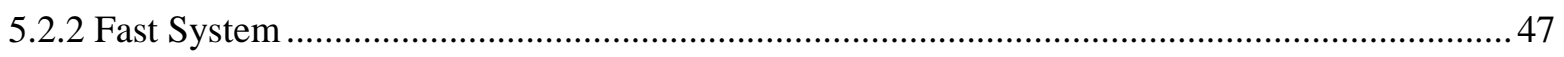

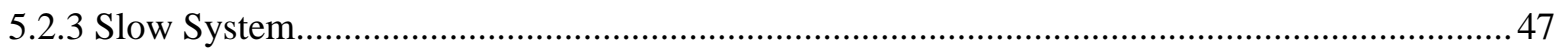

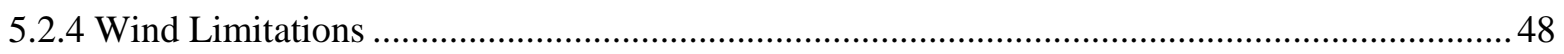

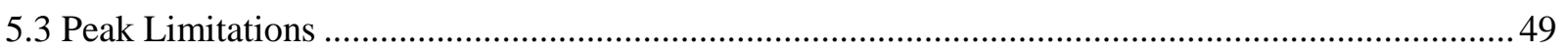

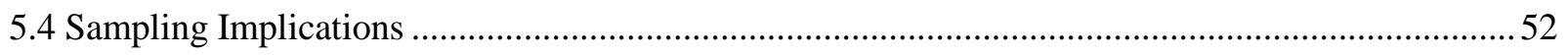

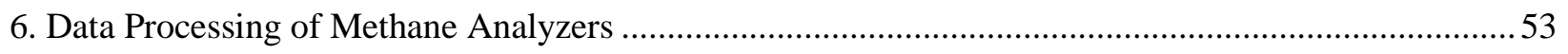

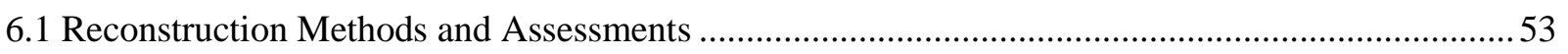

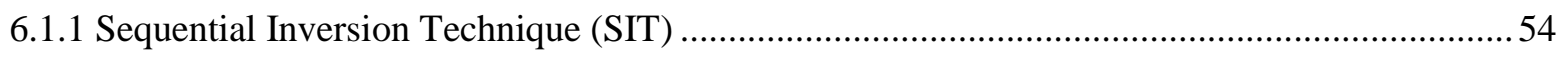

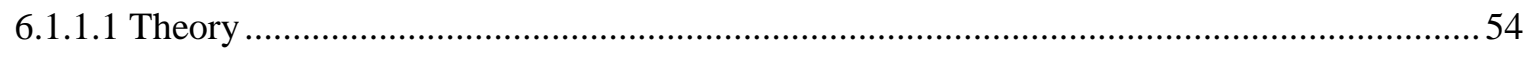

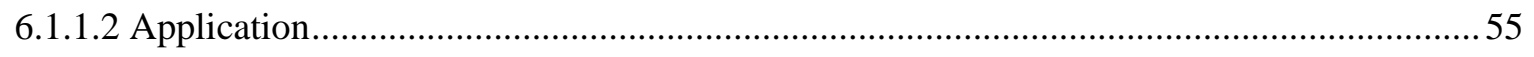

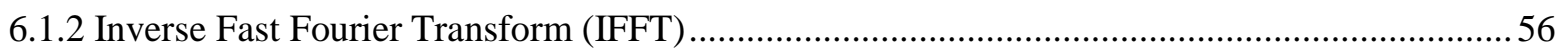




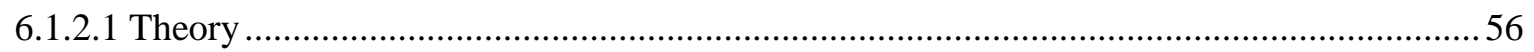

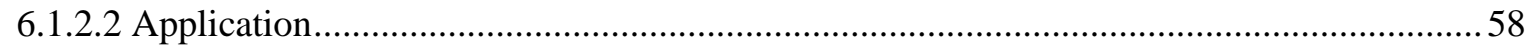

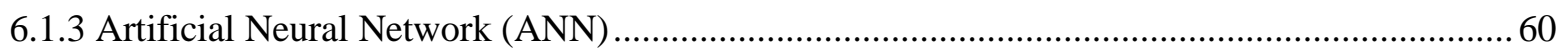

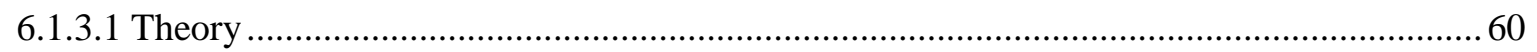

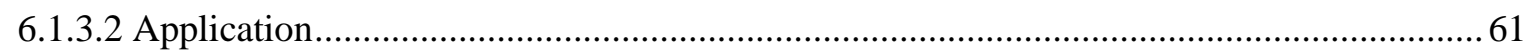

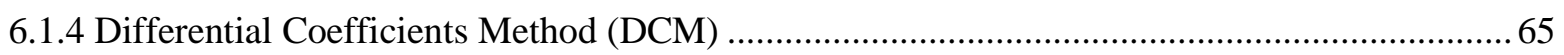

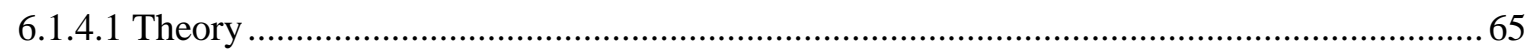

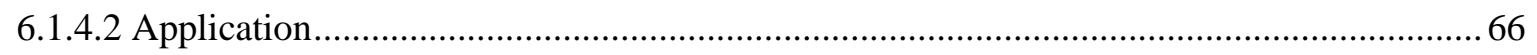

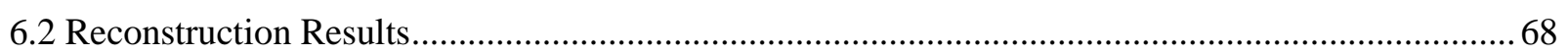

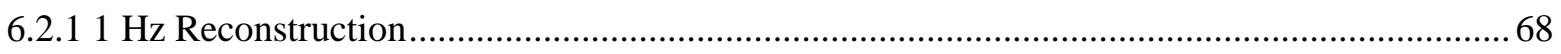

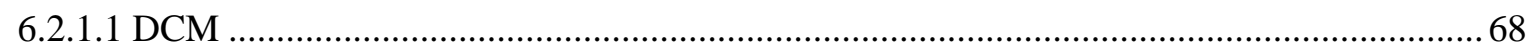

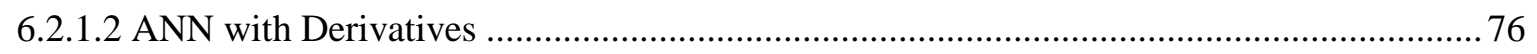

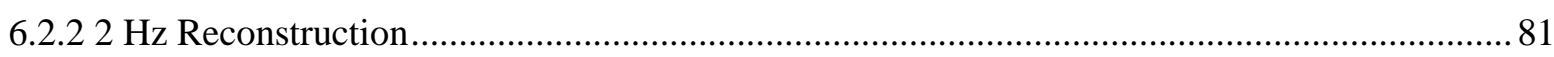

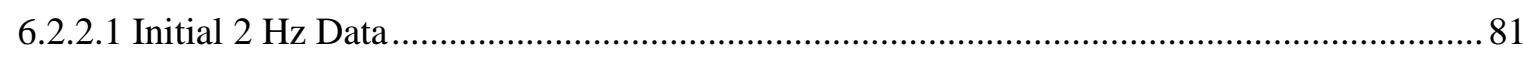

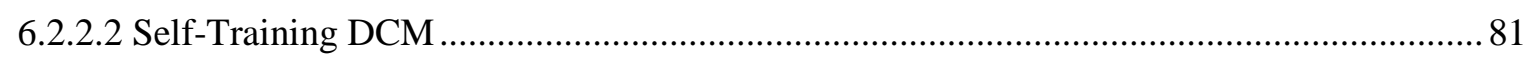

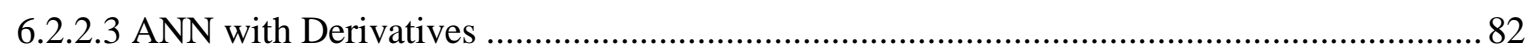

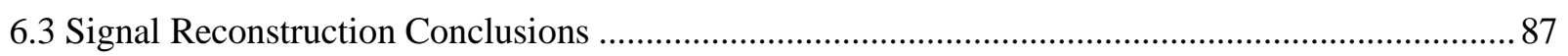

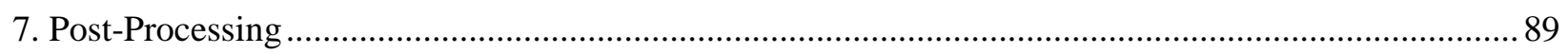

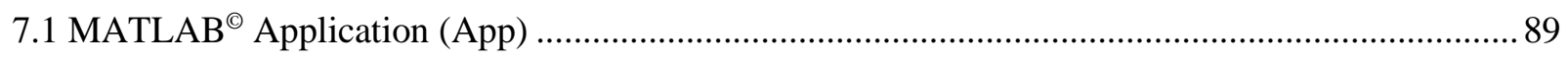

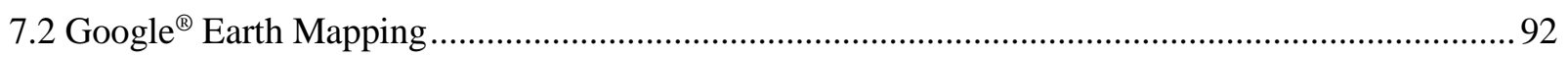

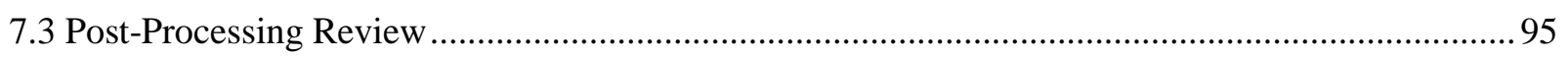

8. Conclusions, Recommendations, and Future Applications............................................................ 95

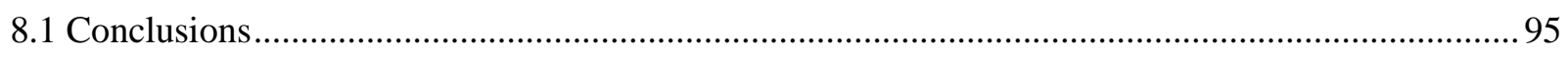

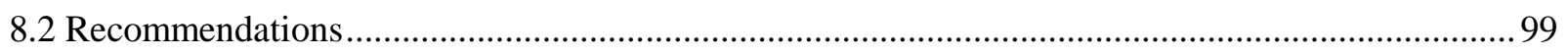

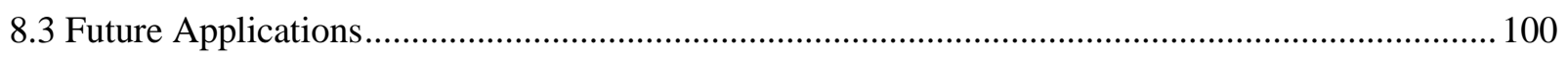

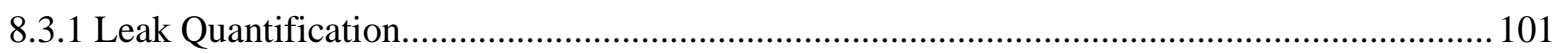

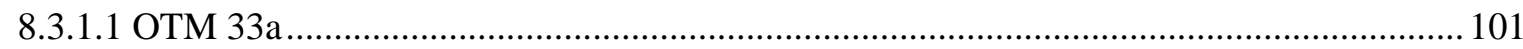

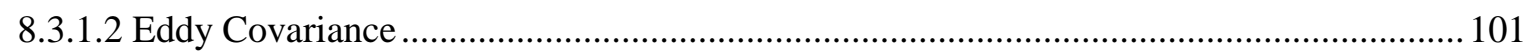

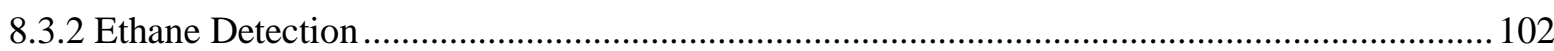

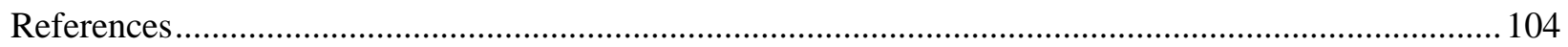

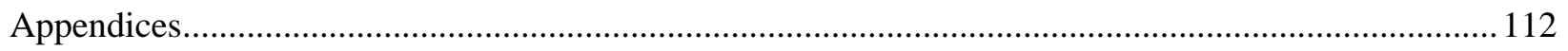

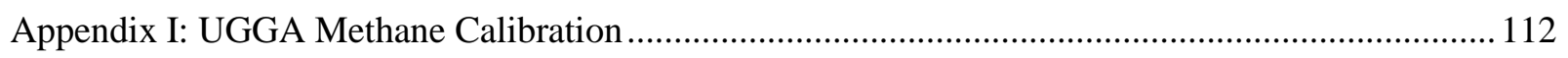

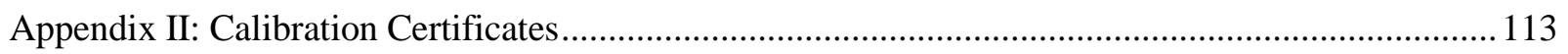

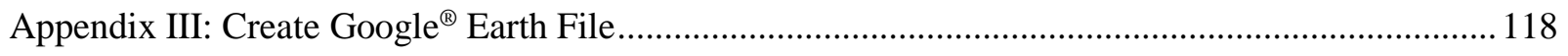

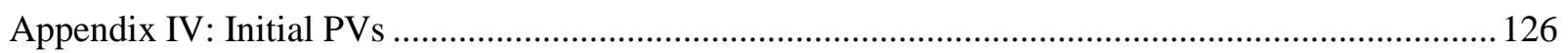




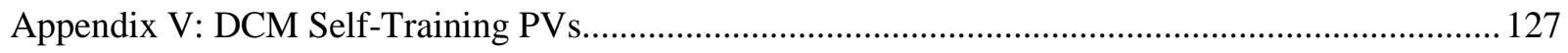

Appendix VI: Average PVs of the Self-Trained DCM Applied to Remaining Trip Files................... 128

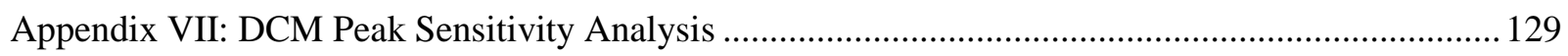

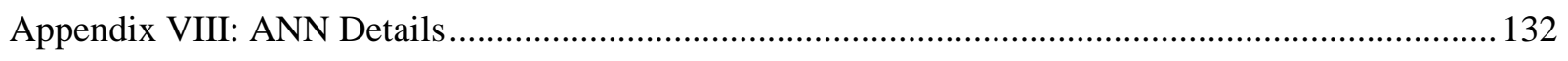

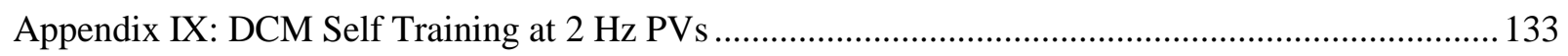




\section{Table of Figures}

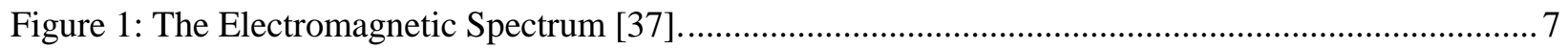

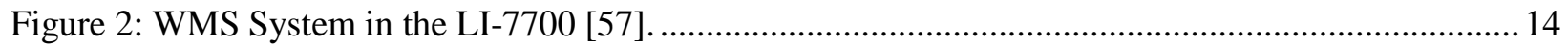

Figure 3: Modulation of the Laser Wavelength Occurring in the LI-7700 [57]...................................... 15

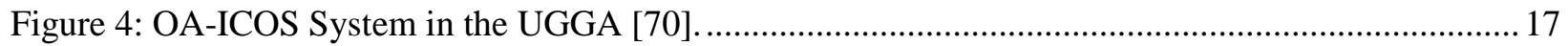

Figure 5: Testing Equipment Mounted to the Vehicle: (Left to Right) LI-COR LI-7700, LI-COR LI-7500,

Gill WindMaster, Gill WindSonic. .................................................................................................. 23

Figure 6: Small Testing Equipment Mounted to the Vehicle: (left to right) LI-COR LI-200, Los Gatos

Research Ultra-Portable Greenhouse Gas Analyzer, Omega IBTHX....................................................2

Figure 7: Design of the Mobile Methane Detection Box used for Data Collection..................................26

Figure 8: All Field Data Routes Mapped in Google ${ }^{\circledR}$ Earth..............................................................2

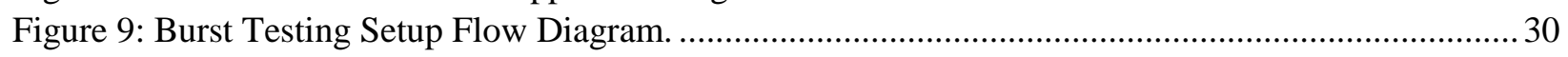

Figure 10: LI-7700 Methane Concentration Displayed in Google ${ }^{\circledR}$ Earth............................................... 32

Figure 11: UGGA Methane Concentration Displayed in Google ${ }^{\circledR}$ Earth. ................................................. 32

Figure 12: Contiguous Methane Concentrations of LI-7700 and UGGA in Time During Initial Results.. 33 Figure 13: Impulse Response of the UGGA with 101.3 ppmv Methane. Note: 1 indicates the valve is on

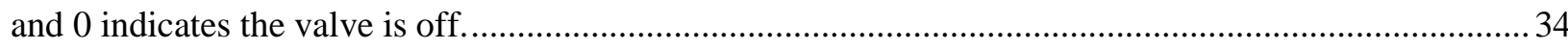

Figure 14: Impulse Response of the UGGA with 50.65 ppmv Methane. Note: 1 indicates the valve is on

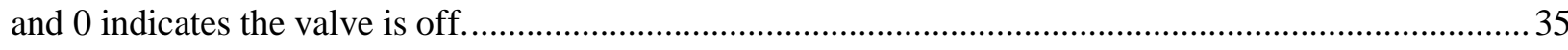

Figure 15: The Distribution of Methane Concentration for all Moving Data. Note: The total number of samples was 444,991 for $10 \mathrm{~Hz}$ LI-7700 and 44,556 for $1 \mathrm{~Hz}$ LI-7700 and UGGA............................... 36 Figure 16: A Normalized Response of the Same Methane Plume by the LI-7700 and the UGGA. Note: The methane responses were time aligned prior to normalization....................................................... 38 Figure 17: Distribution of each PV Component Contribution from the Initial Data Set. Note: The total

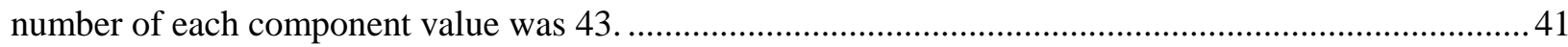

Figure 18: Geospatial Resolution of the LI-7700 at $10 \mathrm{~Hz}$ and the Time Aligned UGGA at $1 \mathrm{~Hz} \ldots \ldots \ldots . . .44$ Figure 19: Compass Rose for Wind Direction with Wind Components Corresponding to Direction [78].47 Figure 20:Wind Speeds that Violated the Limiting equation as a Function of Vehicle Speed and Total

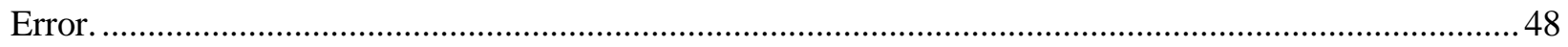

Figure 21: Trip 554, Differences in Peak Values of the LI-7700 and the UGGA. ................................. 49

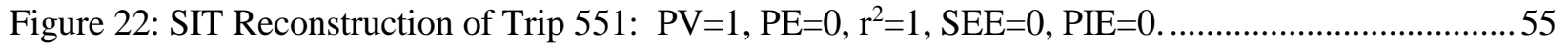
Figure 23: SIT Reconstruction of Trip 554 using Trip 551's SIT: $P V=0.111, \mathrm{PE}=0.867, \mathrm{r}^{2}=0.018, \mathrm{SEE}=1$,

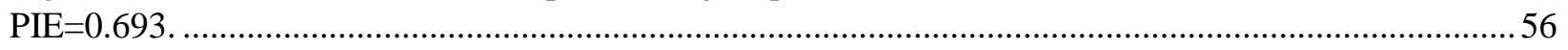

Figure 24: Determination of the Impulse Function from Two Signals.................................................58

Figure 25: Application of Impulse Response Signal to Create an Input Signal.......................................58

Figure 26: IFFT Reconstruction of Trip 551: $\mathrm{PV}=1, \mathrm{PE}=0, \mathrm{r}^{2}=1, \mathrm{SEE}=0, \mathrm{PIE}=0$.................................59

Figure 27: IFFT Reconstruction of Trip 554 using Trip 551's IFFT: $P V=0.258, P E=0.739, \mathrm{r}^{2}=0$,

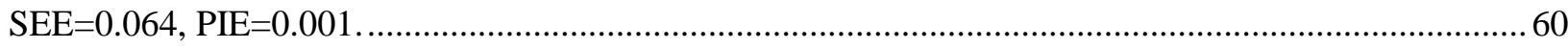

Figure 28: ANN Reconstruction of Trip 551: $P V=0.690, P E=0.394, r^{2}=0.786, S E E=0.029, P I E=0.238 .62$ Figure 29: ANN Reconstruction of Trip 554 using Trip 551's $A N N$ : $P V=0.315, P E=0.781, r^{2}=0.406$,

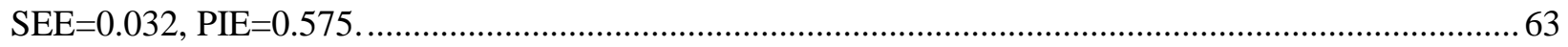

Figure 30: ANN with Derivatives Reconstruction of Trip 551: $P V=0.917, P E=0.099, \mathrm{r}^{2}=0.969$,

SEE $=0.013$, PIE $=0.177$.

Figure 31: ANN with Derivatives Reconstruction of Trip 554 using Trip 551's ANN: PV=0.716, $\mathrm{PE}=0.309, \mathrm{r}^{2}=0.816, \mathrm{SEE}=0.019, \mathrm{PIE}=0.505$. 
Figure 32: DCM Reconstruction of Trip 551: $\mathrm{PV}=0.670, \mathrm{PE}=0.540, \mathrm{r}^{2}=0.879, \mathrm{SEE}=0.020, \mathrm{PIE}=0.012 .67$ Figure 33: DCM Reconstruction of Trip 554 using Trip 551's DCM: $P V=0.511, P E=0.847, r^{2}=0.897$, $\mathrm{SEE}=0.011, \mathrm{PIE}=0.036$.

Figure 34: (Top) Distribution of the Initial PV Components. (Bottom) Distribution of the Self-Trained PV Components Note: The total count for each component was 43. ...................................................... 70

Figure 35: Trip 545, DCM Self-Trained Reconstructed UGGA: $P V=0.774, \mathrm{PE}=0.371, \mathrm{r}^{2}=0.921$,

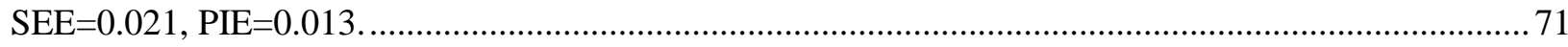

Figure 36: Trip 545, DCM Reconstructed UGGA with Trip 540: $\mathrm{PV}=0.374, \mathrm{PE}=0.544, \mathrm{r}^{2}=0.069$,

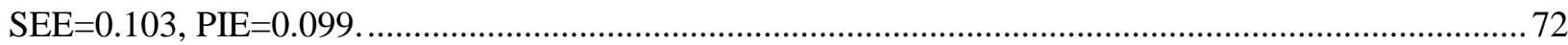

Figure 37: Trip 545, DCM Reconstructed UGGA with Trip 533: $\mathrm{PV}=0.855, \mathrm{PE}=0.362, \mathrm{r}^{2}=0.846$,

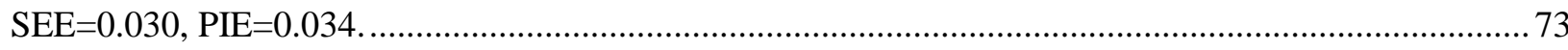

Figure 38: The Average PV of the Trip Coefficients vs the Self-Trained PV......................................... 74

Figure 39: False Reporting Rate of $10 \mathrm{~Hz}$ LI-7700 vs the Self-Trained PV of each Trip File's

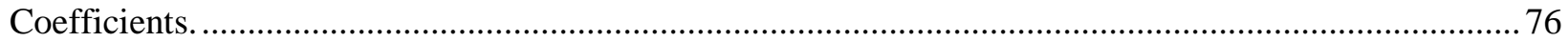

Figure 40: Reconstruction of the Training Data using ANN: $P V=0.899, \mathrm{PE}=0.143, \mathrm{r}^{2}=0.954, \mathrm{SEE}=0.022$,

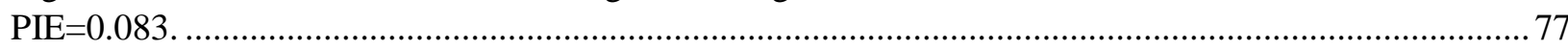

Figure 41: Reconstruction of the Validation Data using ANN: $P V=0.86, P E=0.140, \mathrm{r}^{2}=0.820$,

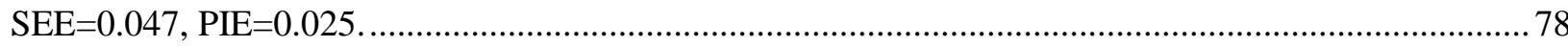

Figure 42: Trip 545, LI-7700 vs Reconstructed UGGA Self-Trained DCM at 2 Hz: PV=0.473, PE $=0.477$, $\mathrm{r}^{2}=0.222, \mathrm{SEE}=0.062, \mathrm{PIE}=0.015$.

Figure 43: Reconstruction of a Section of Training Data using ANN at $2 \mathrm{~Hz}$ : $\mathrm{PV}=0.699, \mathrm{PE}=0.362$,

$\mathrm{r}^{2}=0.759, \mathrm{SEE}=0.048, \mathrm{PIE}=0.219$.

Figure 44: Reconstruction of the Validation Data using ANN at $2 \mathrm{~Hz}: \mathrm{PV}=0.663, \mathrm{PE}=0.326, \mathrm{r}^{2}=0.565$,

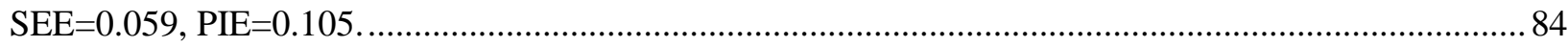

Figure 45: Methane Responses by the LI-7700, the initial UGGA, and the UGGA Reconstructed by the

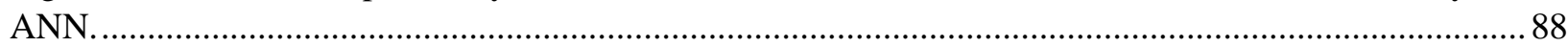

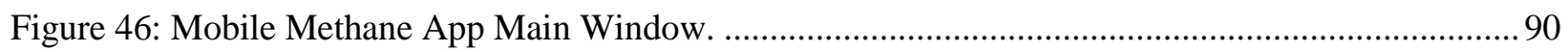

Figure 47: Overhead Display of Google ${ }^{\circledR}$ Earth Mapping. ................................................................. 93

Figure 48: Methane Concentration Mapped unto the Vehicle Route......................................................94

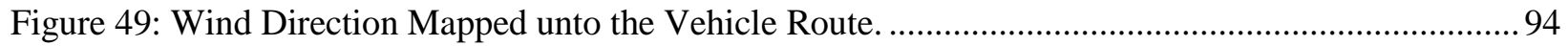

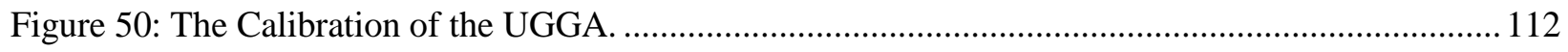

Figure 51: 101.3 ppmv Methane Bottle Calibration Certificate. ........................................................ 114

Figure 52: Ultra Zero Air Bottle Calibration Certificate. ................................................................... 115

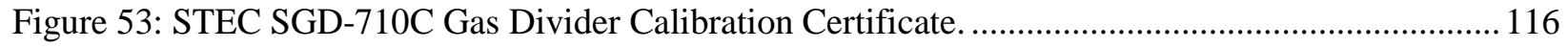

Figure 54: STEC SGD-710C Gas Divider Verification Check Sheet.................................................. 117

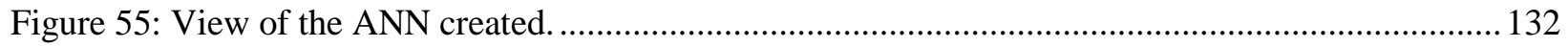




\section{Table of Tables}

Table 1: A Review of Potential Methane Analyzers for Mobile Methane Detection. ............................... 12

Table 2: Equipment Used in Mobile Methane Detection...................................................................22

Table 3: Statistical Breakdown of the PV and PV Components of the Initial Data.................................4 41

Table 4: Detection Threshold Sensitivity Analysis of the Initial Data ...................................................51

Table 5: PV Breakdown of Self-Trained Trips..................................................................................... 69

Table 6: Improvement of the PV Breakdown of Self-Trained Trips Compared to the Initial PV Breakdown.

Note: Highlighted Cells Indicated a Positive Improvement. .....................................................................69

Table 7: Peak Sensitivity Analysis of the Self-Trained Coefficients Applied to all Trip Files................... 75

Table 8: Peak Sensitivity Analysis of the ANN of the Training and Validation Data............................... 79

Table 9: Peak Sensitivity Analysis of the Training Data Before and After Reconstruction using the ANN.

Table 10: Peak Sensitivity Analysis of the Validation Data Before and After Reconstruction using the

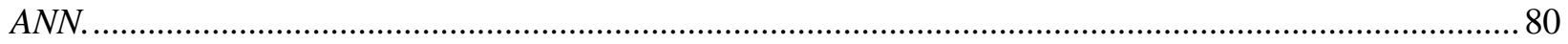

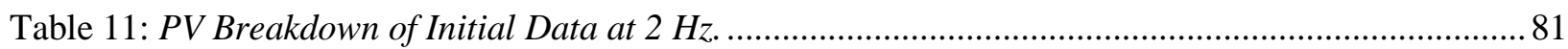

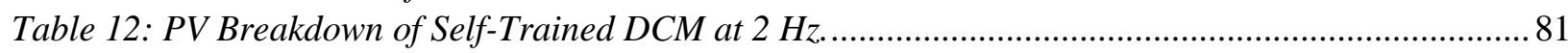

Table 13: Relative Changes of the PV Breakdown of Self-Trained Trips DCM at $2 \mathrm{~Hz}$ Compared to the 2

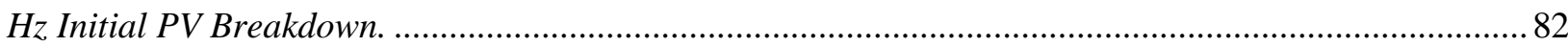

Table 14: Peak Sensitivity Analysis of all the Data Before and After Reconstruction at $2 \mathrm{~Hz}$ using the

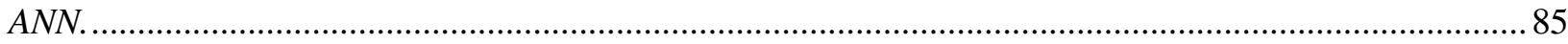

Table 15: Peak Sensitivity Analysis of the Training Data Before and After Reconstruction at $2 \mathrm{~Hz}$ using

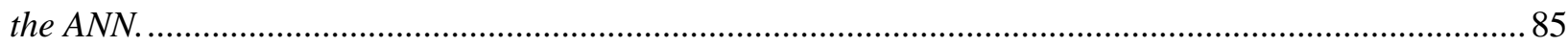

Table 16: Peak Sensitivity Analysis of the Validation Data Before and After Reconstruction at $2 \mathrm{~Hz}$ using

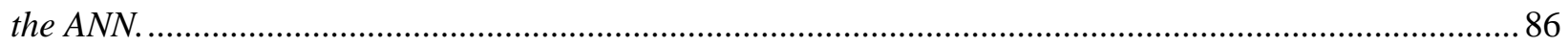

Table 17: Results of Each Detection Threshold of the Initial UGGA, UGGA Reconstructed by DCM, and

UGGA Reconstructed by ANN for $1 \mathrm{~Hz}$ LI-7700 Peaks....................................................................... 98

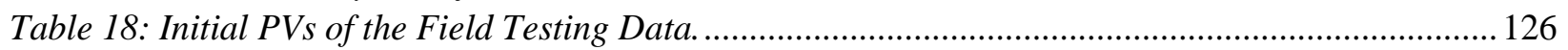

Table 19: PVs of the Field Testing Data Using DCM and Self-Training. .............................................. 127

Table 20: Average PVs and its components of the Field Testing Data Using DCM Coefficients Created.

Table 21: Detection Thresholds of DCM Reconstruction Coefficients for 2.7 ppmv and 2.6 ppmv with 10

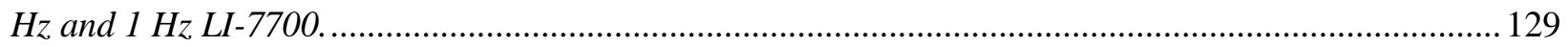

Table 22:The Best False Reporting Rates from 2.5 to 3.5 ppmv for the DCM Coefficients..................... 130

Table 23: The Best False Reporting Rates from 2.5 to 5.5 ppmv for the DCM Coefficients.................... 131

Table 24: Detailed Values of the Weights of Each Node. .................................................................... 132

Table 25: PVs of the Field Testing Data Using DCM and Self-Training at $2 \mathrm{~Hz}$................................. 133 


\section{Table of Equations}

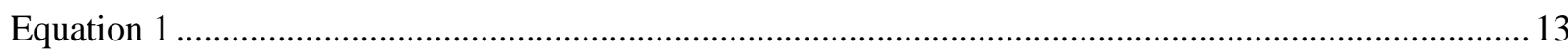

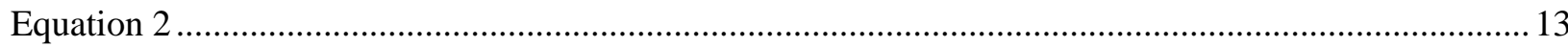

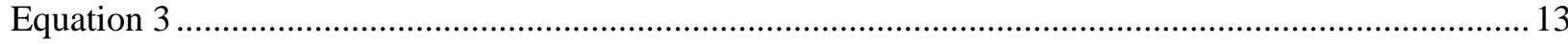

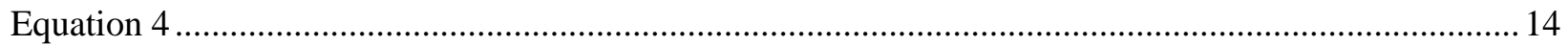

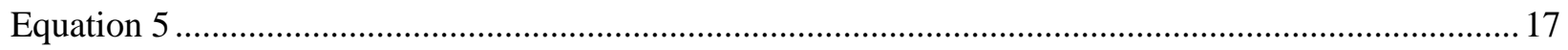

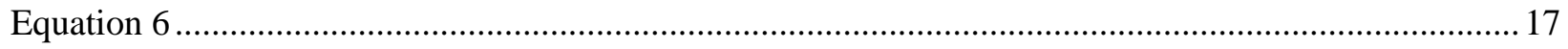

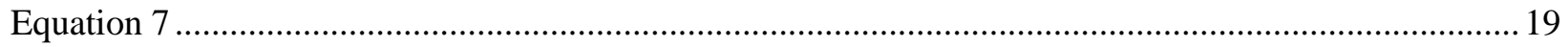

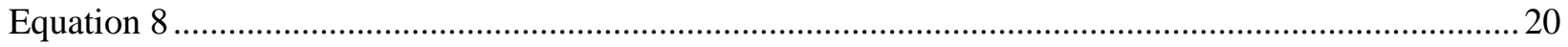

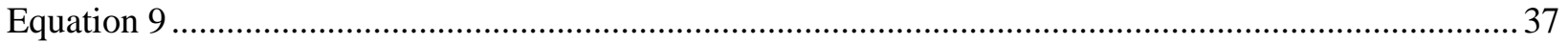

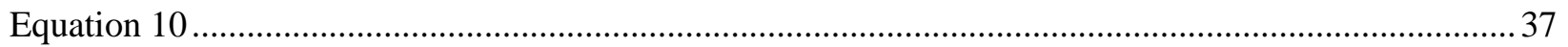

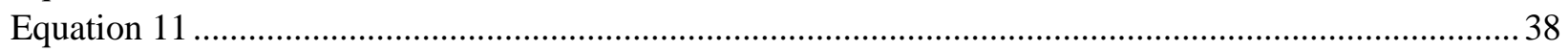

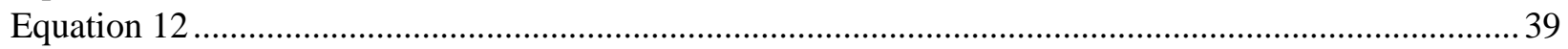

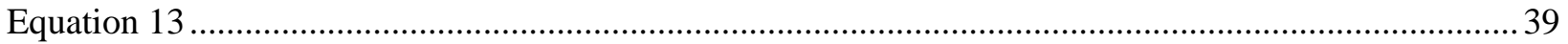

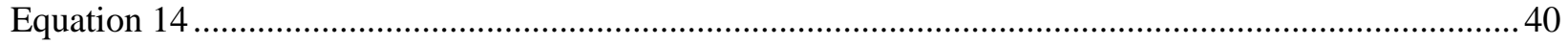

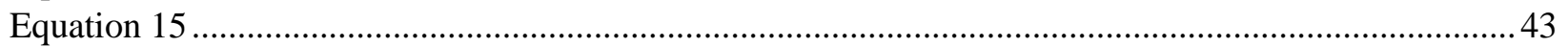

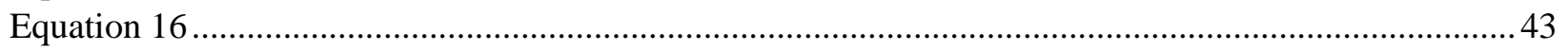

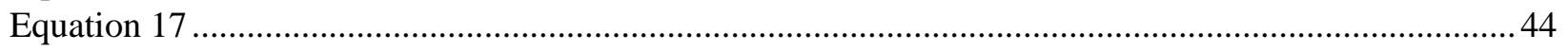

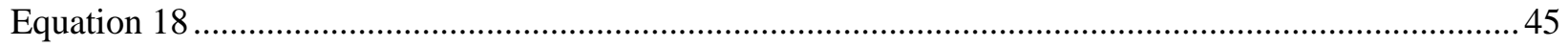

Equation 19

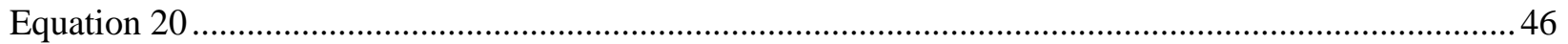

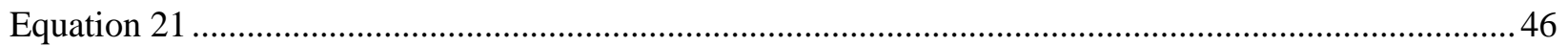

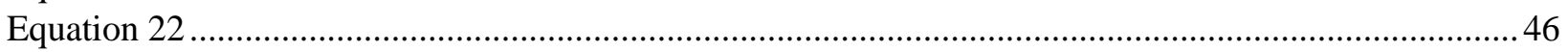

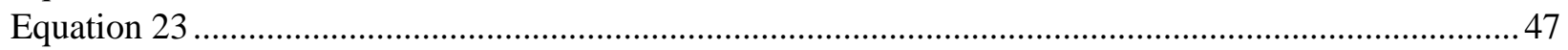

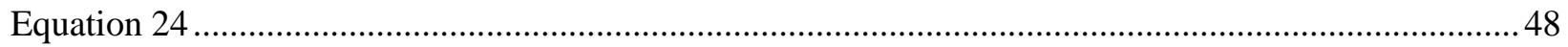

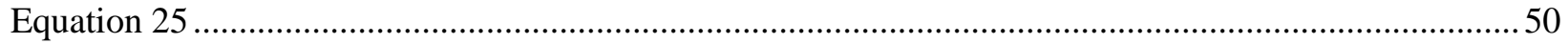

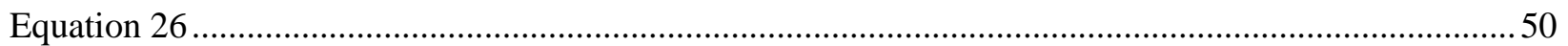

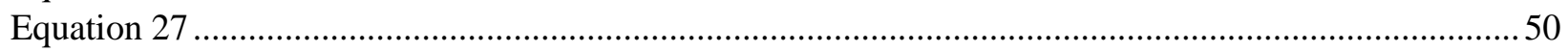

Equation 28

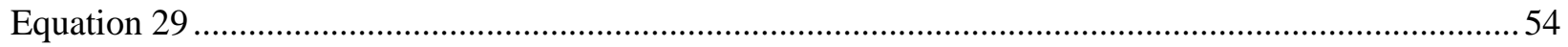

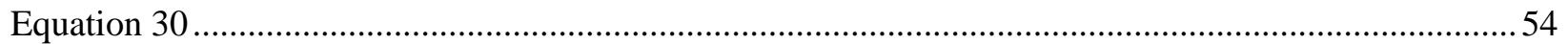

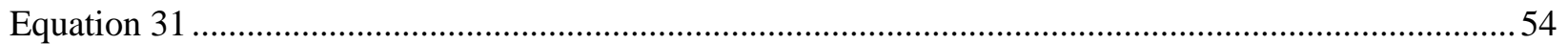

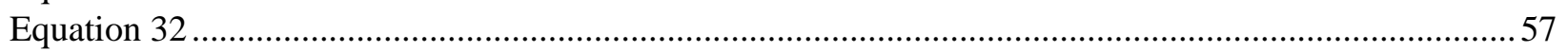

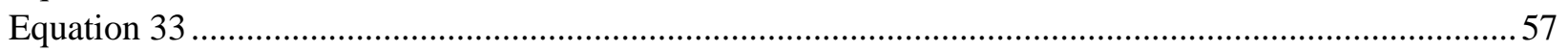

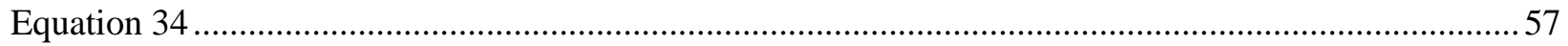

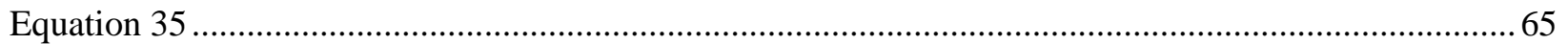

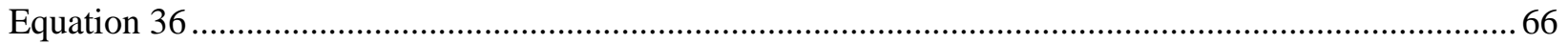




\section{List of Acronyms}

$\underline{\text { Acronym }}$

Word or Phrase

ANN

Artificial Neural Network

ARPA-E

Advanced Research Projects Agency- Energy

App

Application

BTU

British Thermal Unit

$\mathrm{CO}_{2}$

Carbon Dioxide

DCM

Differential Coefficients Method

EDF

Environmental Defense Fund

EIA

Energy Information Agency

EPA

Environmental Protection Agency

${ }^{\circ} \mathrm{F}$

Fahrenheit

FFT

Fast Fourier Transform

FID

Flame Ionization Detector

FTIR

Fourier Transform Infrared Spectroscopy

GN

Gauss-Newton

GPS

Global Positioning System

GR

Geospatial Resolution

GWP

Global Warming Potential

$\mathrm{H}_{2} \mathrm{O}$

Dihydrogen Monoxide

$\mathrm{Hz}$

Hertz

ICOS

Integrated Cavity Output Spectroscopy

IFFT

Inverse Fast Fourier Transform

IPCC

International Panel on Climate Change

IR

Infrared

$\mathrm{kph}$

Kilometer Per Hour

LM

Levenberg-Marquardt

$\mathrm{m}$

Meter

$\mathrm{mm}$

Millimeter 


\begin{tabular}{|c|c|}
\hline $\mathrm{mm}^{3}$ & Cubic Millimeter \\
\hline $\mathrm{m} / \mathrm{s}$ & Meters Per Second \\
\hline mbar & Millibar \\
\hline MOS & Metal Oxide Sensor \\
\hline $\mathrm{mph}$ & Miles Per Hour \\
\hline NIST & National Institute of Standards and Technology \\
\hline NOAA & National Oceanic \& Atmospheric Administration \\
\hline$\mu-\mathrm{m}$ & Micro-Meter \\
\hline$\mu-s$ & Micro-Second \\
\hline OA-ICOS & Off-Axis Integrated Cavity Output Spectroscopy \\
\hline OGI & Optical Gas Imaging \\
\hline OTM 33a & Other Test Method 33a \\
\hline $\mathrm{PE}$ & Peak Error \\
\hline PIE & Plume Integration Error \\
\hline ppbv & Parts Per Billion \\
\hline ppmv & Parts Per Million \\
\hline ppmv-m & Parts Per Million Meter \\
\hline PV & Performance Value \\
\hline$r^{2}$ & Linear Correlation Coefficient \\
\hline RSSI & Relative Signal Strength Indicator \\
\hline SEE & Standard Estimate of the Error \\
\hline SIT & Sequential Inversion Technique \\
\hline slpm & Standard Liter Per Minute \\
\hline UGGA & Ultra-Portable Greenhouse Gas Analyzer \\
\hline US & United States \\
\hline V & Voltage \\
\hline$W$ & Watt Per Meter Squared \\
\hline \multicolumn{2}{|l|}{$\overline{m^{2}}$} \\
\hline WMS & Wavelength Modulation Spectroscopy \\
\hline WV & West Virginia \\
\hline
\end{tabular}




\section{Introduction}

\subsection{Background}

The United States (US) produces the largest amount of natural gas in the world, with production of over 70 billion cubic feet a day [1]. In 2018, the US produced a total of 36 trillion cubic feet of natural gas [2]. According to the Energy Information Administration (EIA), the US has a surplus of natural gas for 90 years at the current consumption rate of 27.5 trillion cubic feet per year, indicating the potential long term reliance on natural gas [3].

To reduce emissions to the atmosphere, natural gas has been implemented as an alternative fuel.

Combustion of natural gas produces $27 \%$ and $46 \%$ lower carbon dioxide $\left(\mathrm{CO}_{2}\right)$, per British thermal unit (BTU), compared to petroleum and coal, respectively [4]. In 2015, both natural gas and coal created 1.5 billion metric tons of $\mathrm{CO}_{2}$, while natural gas utilization was $81 \%$ higher than coal [5].

Natural gas's capability to serve as a lower emission fuel than petroleum or coal is dependent on losses along the supply chain of its main component, methane. Global warming potential (GWP) is the energy one ton of a gas absorbs in the atmosphere compared to the energy of one ton of $\mathrm{CO}_{2}$ absorbs over a time span [6]. The International Panel on Climate Change's (IPCC) 2013 report defined methane's GWP as 28 over 100 years [7]. When breaking down the contributors to total methane emissions, the Environmental Protection Agency (EPA) reported that natural gas, petroleum, and coal systems were the largest sources of methane [8].

Models have compared the environmental impacts of natural gas leakage and production in the implementation of natural gas over other fuels $[9,10]$. To reduce radiative forcing in the atmosphere, Alvarez et al. created a model to observe the leak ratio, or ratio of natural gas leakage to total production [9]. For immediate climate benefits, natural gas could potentially replace gasoline in light-duty cars, diesel fuel in heavy-duty vehicles, and coal in power plants, with leak ratios lower than $1.6 \%, 1 \%$ and 
$3.2 \%$ of production, respectively. Zhang et al. presented a model of replacing coal with natural gas power plants for electricity generation [10]. Assuming efficiencies of $60 \%$ for natural gas and $51 \%$ for coal power plants, a leak ratio above $2 \%$ would void the environmental benefit of using a natural gas power plant over a coal power plant. The models dictated that the benefits of natural gas as an alternative fuel decreased with high natural gas leaks.

Methane detection has been a priority of several US government agencies including: National Institute of Standards and Technology (NIST), National Oceanic and Atmospheric Administration (NOAA), and Advanced Research Projects Agency - Energy (ARPA-E), and non-governmental organizations such as the Environmental Defense Fund (EDF) [11-13]. NIST and NOAA partnered to develop a field spectrometer for permanent deployment at natural gas sites [11]. ARPA-E sponsored the Methane Observation Networks with Innovative Technologies to Obtain Reductions (MONITOR) program, where 12 organizations received funding to improve methane detection and quantification systems [12]. The EDF cooperated with Stanford University to host the Mobile Monitoring Challenge where researchers deployed their methane detection and quantification systems in a competition [13].

Researchers have implemented methane detection systems to quantify natural gas emissions [14-22]. Researchers have operated vehicles with methane analyzers for methane detection [14-18, 23], methane quantification [19-21, 24, 25], and methane quantification method comparisons [22]. Picarro Inc. and Los Gatos Research have created commercially available mobile methane detection services using their closed-path methane analyzers $[26,27]$. Such systems commonly implement a methane analyzer with a pump and a sealed, or closed-path cell [14-17, 19-21, 24, 26, 27].

Phillips et al. and Jackson et al. performed methane detection using a closed-path Picarro G2301 methane analyzer sampling at 0.9 Hertz (Hz) in Boston, Massachusetts and Washington, D.C., respectively [14, 15]. Using a Picarro G112i analyzer, the isotopes of methane were identified [14]. Using both closed-path Picarro analyzers, the methane sources were predominantly associated with natural gas leaks, but required a handheld gas detector for source attribution [14]. 
Eapi et al. deployed a closed-path Picarro G2204 methane analyzer for methane detection in Tarrant, Wise, Denton, and Johnson counties in Texas [16]. They drove through plumes of methane multiple times for repeated measurements and the temporal variations were explained through atmospheric conditions only $23 \%$ of the time. Driving operation was attempted to remain at a constant 20 miles per hour (mph), or 32.19 kilometers per hour $(\mathrm{kph})$, but was limited by roadway safety. The atmospheric conditions were determined regionally from the Dallas/Fort Worth Airport and were not determined locally [16]. Analysis of the sampling method of the closed-path Picarro, local atmospheric conditions, or vehicle speed were not conducted for explaining methane concentration differences.

Atherton et al. performed methane detection in the Montney Shale in British Columbia [17]. They deployed a Los Gatos Research UltraPortable Greenhouse Gas analyzer (UGGA) for methane detection. This was a closed-path analyzer sampling at $1 \mathrm{~Hz}$. They found that $58 \%$ of methane leaks detected could likely be associated natural gas infrastructure. The probability of false identification of a methane plume was less than $0.01 \%$ but there was uncertainty in methane plume source association [17].

Von Fischer et al. and Weller et al. outfitted Google ${ }^{\circledR}$ Street View Cars with a methane analyzer for methane quantification and comparisons [22, 24]. Using controlled releases in Fort Collins, Colorado, a methane leak rate algorithm was created using the methane reported by a Picarro G2301 sampling at $2 \mathrm{~Hz}$ [24]. It was determined that wind speed did not play an effect in methane rate calculation but the methane analyzer underreported methane rates for high leak rates [24]. Comparing methane quantification to handheld methane detectors, the mobile methane system detected leaks the handheld methane analyzer was unable to determine [22]. This was assumed to be associated with the high precision of the methane analyzer. The mobile methane quantification overreported methane concentrations compared to surface flux measurements [22]. This may be associated with the implementation of methane plume size in the leak rate algorithm.

Rella et al. performed methane quantification in the Barnett Shale in Texas [19]. They collected flux methane measurements at 207 well pads using the mobile flux plane technique. Using a mast with 4-6 
ports on a vehicle, each port collected 50 seconds of gas using a pump and delivered each sample individually to the methane analyzer. The methane analyzer deployed was a Picarro G2301 methane analyzer which was a closed-path analyzer sampling at $2 \mathrm{~Hz}$ [19]. To perform the mobile flux plane technique, time alignment of each sample from a port was required [19].

Tao et al. deployed a greenhouse gas detection system in both the United States and China [23]. For methane detection, they deployed a LI-COR LI-7700 that had an open-path cell and sampled at $10 \mathrm{~Hz}$. The open-path methane analyzer was mounted to the top of their vehicle after modeling the wake zone of the vehicle [23]. Effects of the open-path sampling method were not compared to a closed-path analyzer.

In summary, natural gas has a prominent role in energy as an alternative fuel due to its availability and post-combustion emissions. However, methane is a prominent greenhouse gas that should be minimized, which requires continued advancements in detection methods. Of the mobile methane detection and quantification systems deployed in other research, analysis of the methane sampling methods was not conducted. The sampling methods of the closed-path methane analyzer were not compared to open-path methane analyzers prior to implementation in mobile methane systems. Therefore the goal of this researcher was to further examine any implications from choice of sampling method.

\subsection{Objectives}

The overall objective of this study was the evaluation of current, state-of-the-art methane analyzers and the implications of their deployment in mobile methane mapping. The application of two methane analyzers allowed for the comparison of their sampling methods when targeting the identification of methane concentrations just above ambient background. To achieve this objective, the research consisted of the following tasks:

- Conducted a literature review of currently available methane analyzers and identified their drawbacks for deployment in mobile methane detection systems. 
- Developed a high and low frequency mobile methane detection system with each methane analyzer and other equipment necessary for geospatial mapping and identification (e.g. sonic anemometer and GPS.

- Compared the initial measurement results of each sampling methodology.

- Determined the sampling limitations of each system due to sampling frequency, the methane analyzer's operational principles, and vehicle speed.

- Examined methods of reconstruction that hinder the deployment of closed-path analyzers.

- Discussed the creation of a post-processing application for simplistic data presentation.

- Described the requirements and recommendations to perform mobile methane detection under transient driving operation.

- Examined potential applications for expanding the use of the mobile methane detection system(s) and other analyzers. 


\section{Review of Literature/Background}

\subsection{Methane Detection Methods}

Currently there are many methane sensors and analyzers that use different fundamental techniques to accurately quantify the concentration of methane based on first principles and derivatives thereof. To review the potential methane analyzers, the requirements for a system were reviewed. The average atmospheric level of methane is 1.867 parts per million by volume (ppmv) [28]. Therefore, the methane analyzers must be capable of measuring low methane concentrations and include the resolution to detect subtle changes. In addition, if a device cannot operate in a moving vehicle, it is not an option for mobile methane detection applications.

To determine the best analyzer for mobile methane detection, various sensors and analyzers were reviewed and included: Flame Ionization Detector (FID), Fourier Transform Infrared Spectroscopy (FTIR), Optical Gas Imaging (OGI), Infrared (IR) sensors, Metal Oxide Sensor (MOS), catalytic bead sensors, and other spectroscopy techniques. The observed options varied in operating principles, precision, and mobility.

\subsubsection{Flame Ionization Detection (FID)}

Created in 1957 by Ian McWilliam in Australia, the FID is a measurement device for determining the hydrocarbon concentration in a sample [29]. The sample gas encounters the flame and the combustion of the sample causes the mixture to emit ions based on the mole fraction of hydrocarbons in the sample. An ion detector converts the emitted ions into a recordable signal. A source of compressed FID fuel is required for operation.

The FID requires a special calibration for each species of hydrocarbons, along with its ratio of other elements such as oxygen [30]. Oxygen in the sample distorts the flame and creates errors in the measurement if the FID is not calibrated for the amount of oxygen present in the sample [30]. The FID 
avoids errors with oxygen if the sample is separated, such as in gas chromatography which isolates the compounds in the sample.

Both Horiba Ltd. and Sensors Inc. produce commercially available emission measurement systems with FIDs for use in vehicle emissions testing. The Horiba OBS-ONE GS and the Sensors SEMTECH FID and Dual FID both only reach a precision as low as 10 ppmv of total hydrocarbons $[31,32]$. With a precision of 10 ppmv, the commercially available FIDs were unable to accurately detect subtle changes near atmospheric, background levels of methane. In addition, the Horiba and SEMTECH do not easily measure only methane directly. The FID's use in a mobile methane detection system would require a greater resolution of pure methane, onboard FID fuel storage, and methods for speciation.

\subsubsection{Infrared Spectroscopy (IR)}

IR spectroscopy encompasses the electromagnetic spectrum from 0.78 to over 1000 micro-meter $(\mu-m)$ wavelengths, as shown in Figure 1 [33]. The wide range of IR is broken into 3 parts; near-IR, mid-IR, and far-IR. Near-IR operates in the region from 0.78 to $2.5 \mu$-m and far-IR operates above $15 \mu$-m [34]. MidIR is the region between near-IR and far-IR. Some applications, such as the FTIR, operate in all IR ranges while commercially available OGI and IR products operate in the mid-IR range only [35, 36]. Despite all these analyzers using IR spectroscopy, each method was examined separately as some operating principles varied.

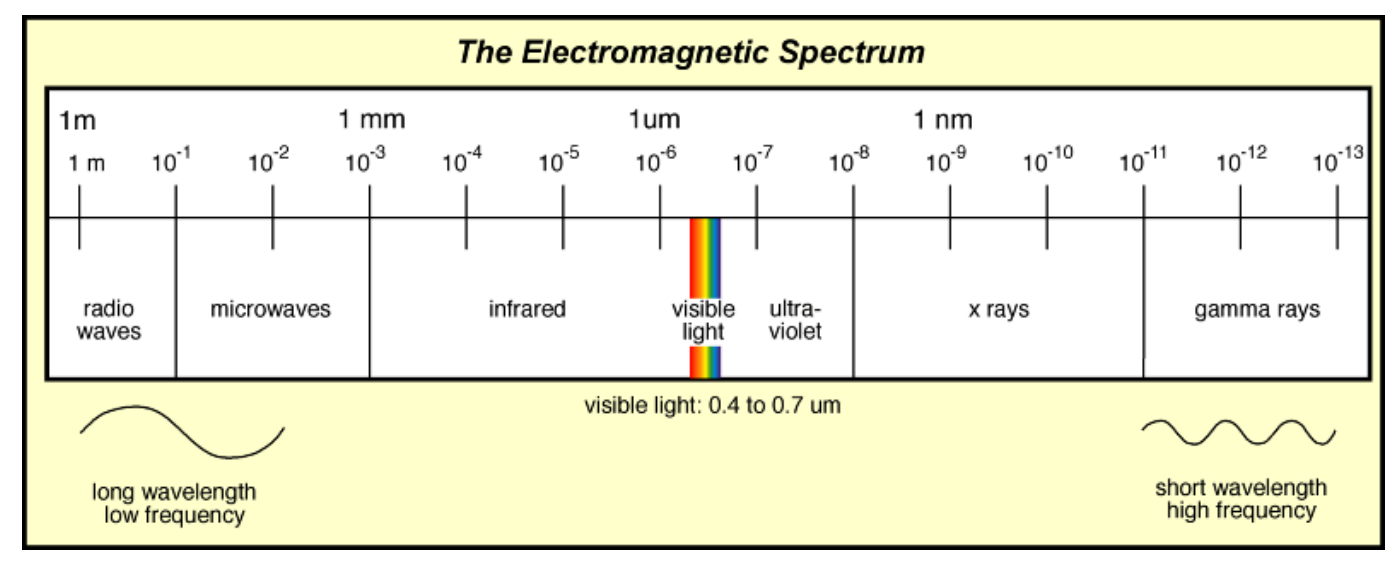

Figure 1: The Electromagnetic Spectrum [37]. 


\subsubsection{Fourier Transform Infrared Spectrometer (FTIR)}

The FTIR was created in the 1980s [33]. The development of these devices stemmed from the desire for a system that sampled at one second or less without separating the sample. The FTIR's principles are based on the absorption of infrared wavelengths in the sample. The molecules absorb certain IR wavelengths and begin rotating or vibrating due to an increase in the dipole moment of the compound. By performing a Fourier transform to the frequency domain with knowledge of the composition's coefficients, the composition of the sample is determined.

The FTIR spectrometer allows for a high reduction in reporting errors through few optical parts with a complex spectra [38]. The FTIR detects most non-diatomic gas species. However, due to a zero change of the dipole moment of diatomic molecules, they are incapable of measuring species such as oxygen and nitrogen [38]. The FTIR determines almost all compounds accurately, quickly, and without any additional processing steps so long as a general composition is known.

For applications outside the laboratory, the FTIR's main issue is maintaining an operating temperature while reporting at high precision. For the FTIR to function, the IR detector requires a cooling method, usually with liquid nitrogen [39]. Several studies implemented the use of the FTIR in mobile applications by keeping liquid nitrogen available in the vehicle $[39,40]$. However, this requires addition safety considerations similar to the fuel requirements of the FID. The MKS MultiGas 2030-HS, a mobile liquid nitrogen cooled FTIR, has a sampling frequency of $5 \mathrm{~Hz}$ but has a lower detection limit of 1 ppmv of methane [41]. To overcome liquid cooling, FTIRs are available with Peltier, or electric cooling. For example, the ARCoptix Rocket is a Peltier cooled FTIR with a lower detection limit of $10 \mathrm{ppmv}$ of methane [42]. Current commercial FTIRs' lower detection limits were not well suited for mobile methane systems. 


\subsubsection{Optical Gas Imaging (OGI)}

Using the principles of IR absorption is OGI. With OGI, a camera detects IR at a specific wavelength for the desired molecules. For example, FLIR Systems' OGI cameras use $3.3 \mu-\mathrm{m}$ wavelength filters for hydrocarbon detection [35]. If the naturally emitted IR wavelength hits the molecule, the IR is absorbed by the molecule before it reaches the detector. Using the IR detector and visual lens, the camera creates an image for the viewer to see the location of the molecules. Because of its operation, OGI requires site access with proximity to the methane source. A commercially available camera detects a methane leak rate of about 20 grams per hour with a confidence of $90 \%$ from a distance of 3 meters (m) [43].

The operator must conduct their study during optimal weather conditions. The plume should be a different temperature and radiance than the background [35]. In addition, warmer days provide better detection of methane and the use of the sky as a backdrop provides optimal leak detection [44]. This is due to the temperature difference of the surface and sky and the sky providing constant radiance different from methane. The maximum allowable distance using a OGI is a function of the differences in temperature [45].

There is no commercially available OGI capable of an output other than a picture. The OGI produces an image during operation that cannot distinguish between hydrocarbons or excess heat. This requires an operator to interpret each picture. Rebellion Photonics' is currently developing a soda-can sized OGI capable of wirelessly uploading the video stream during operation [46]. The goCGI is under development as a wearable OGI with the goal of achieving flow rate calculations using complex algorithms without user interpretation.

The OGI's use in a mobile methane detection system is limited. Because a user interprets all the images captured, this introduces the possibility of human error in source determination. In addition, commercially available OGI are not capable of speciating multi-component mixtures or numerical representations of low concentrations. These factors reduced the OGI's applicability in mobile methane detection. 


\subsubsection{Infrared sensors}

IR sensors operate using a similar principle as the OGI; however, OGI applies the IR detector to determine a picture while the sensor determines a volume concentration of the molecule. For IR sensors, an IR detector determines the quantity of the molecule based on the absorption of the IR wavelengths and is not affected by smoke [47]. However, the IR sensor cannot distinguish between molecules at some wavelengths. For example, water vapor absorbs a significant number of IR wavelengths from 2 to $8 \mu-\mathrm{m}$ [36]. This is an issue as methane has an absorption band in the $3.3 \mu-\mathrm{m}$ range. The interference of other molecules prevents the basic IR sensor from providing high accuracy measurements. Commercially available IR sensors such as, NET IRNET-P, Edinburgh Sensors Gascard NG, and Dynamet MSH$\mathrm{PS} / \mathrm{HC} / \mathrm{NC}$, operate in ranges of $0-5 \%$ concentration of methane in the sample [48-50]. All three sensors report accuracies at 50 parts per billion by volume (ppbv) but require 30 seconds to reach $90 \%$ of the target value. While their sampling frequency is $1 \mathrm{~Hz}$, the time to reach $90 \%$ would induce significant temporal and spatial delays thus diminishing the IR sensor's applicability in a mobile methane detection system. In addition, their sensor response to other hydrocarbons limited their application to specific focus on methane.

\subsubsection{Metal Oxide Sensor (MOS)}

The MOS consists of a semiconductor heated between two wires. As the heated semiconductor contacts oxygen, it adsorbs and stores oxygen the surface. Once the combustible, or reducing, gas encounters the semiconductor, the reducing gas removes the oxygen. The semiconductor resistance changes as a function of the oxygen levels on the semiconductor [51]. As such, a MOS cannot distinguish between gases that oxidize similarly [51].

Temperature, humidity, and oxygen dependence are the biggest factors in MOS operation. As the temperature increases, the amount of reducing gas detected varies [52]. In addition, water adsorbs to the semiconductor's surface and decreases the sensitivity of the MOS [52]. These two issues require external corrections based upon the temperature and humidity at the sensor. If the oxygen levels are too low, then 
the metal oxide cannot adsorb oxygen and the MOS begins to fail [51], though this would not be a concern for atmospheric monitoring. The combination of temperature, humidity, and oxygen dependence significantly increases the error in measurements.

Commercially available MOS for methane do not reach precisions lower than 100 ppmv. Winsen MQ-4 is a commercially available MOS designed for methane detection, with a range of 300-10,000 ppmv [53]. The commercially available MOS operated at orders of magnitude larger than the range required for mobile methane detection.

\subsubsection{Catalytic Bead Sensors}

Catalytic bead sensors, or pellistors, operate similarly to a MOS. Instead of the semiconductor, a bead coated in a catalyst causes the reducing gas to oxidize before its combustible range [47]. The oxidation changes the resistance which is proportional to the amount of reducing gas.

The catalytic bead sensor cannot distinguish between gases with similar combustion properties [47]. The major downfall for catalytic bead sensors is the lower detection limit which is 1000 ppmv [47]. In addition, the catalytic bead sensors have a response time up to 10 seconds, which creates sampling inaccuracies [54]. The NET NP-17SHM is a methane catalytic bead sensor, capable of detection of 0$100 \%$ of methane concentration by volume with a response time of 20 seconds to reach $90 \%$ of the target value [55]. The NP-17SHM's error, $1 \%$ of methane concentration, indicates it is not capable of meaningful detection below $1 \%$ of methane concentration by volume. The detection and response time issues limited the implementation of catalytic bead sensors in a mobile methane detection system.

\subsubsection{Other Spectroscopy Based Analyzers}

Spectroscopy is the study of radiation and matter, and it encompasses all potential methods of detection using the light spectrum. Companies have developed their own forms of spectroscopy for detecting methane. Commercially available name brands include Picarro Inc, Los Gatos Research, and LI-COR Biosciences among others. 
For methane detection, two potential methane analyzers are the Los Gatos Research Ultra-Portable Greenhouse Gas Analyzer (UGGA) and LI-COR LI-7700 (LI-7700). The UGGA operates inside a crushproof portable case designed for field conditions that uses closed-path operation. With portability, precision of $2 \mathrm{ppbv}$, and sampling frequency of $1 \mathrm{~Hz}$, the UGGA is an option for mobile methane detection [56]. The LI-7700 operates with an open-path cell, allowing for instantaneous geospatial sampling for a given plane. The LI-7700 has a precision of 5 ppbv, and sampling frequency of $10-40 \mathrm{~Hz}$ [57]. Both analyzers are capable of mobility and meet the requirements for mobile methane detection.

\subsubsection{Analyzers Selection}

A review of the potential analyzers for methane detection is shown in Table 1. Only laser spectrometers could determine atmospheric differences of methane at low concentrations and are methane specific without additional processing of the methane sample. Laser spectrometers from Los Gatos Research and LI-COR Biosciences were selected for mobile methane detection because of their varying measurement methodologies, lower detection limits, and precision.

Table 1: A Review of Potential Methane Analyzers for Mobile Methane Detection.

\begin{tabular}{|c|c|c|c|c|c|c|c|}
\hline Metric & FID & FTIR & IR & OGI & MOS & $\begin{array}{c}\text { Catalytic } \\
\text { Bead }\end{array}$ & $\begin{array}{c}\text { Laser } \\
\text { Spectrometers }\end{array}$ \\
\hline $\begin{array}{c}\text { Low } \\
\text { Concentratiol }\end{array}$ & & & & & & & \\
\hline Quantitative & & & & & & & \\
\hline $\begin{array}{l}\text { Methane } \\
\text { Specific }\end{array}$ & & & & & & & \\
\hline
\end{tabular}

\subsection{Spectroscopy}

The use of the UGGA and the LI-7700 in mobile methane detection requires a basic understanding of the spectroscopy laws and the design of each analyzer. The Beer-Lambert law explains the basis for each analyzer's design and operation. The LI-7700 uses wavelength modulation spectroscopy (WMS) in an 
open-path Herriott cell, while the UGGA uses closed-path, off-axis integrated cavity output spectroscopy (OA-ICOS) $[57,58]$.

\subsubsection{Beer-Lambert Law}

The Beer-Lambert law describes the relationship of species absorption by comparing the light intensity before and after passing through a sample. The idea of light dissipating began with works called 'Traité d'optique' by Bourguer and 'Photometria' by Lambert [59]. Beer's contributions to the idea occurred almost 100 years later [59]. The Beer-Lambert law presented a combination of their works. The BeerLambert law is:

$$
I=I_{o} e^{-\alpha}
$$

where $I$ is the received optical power, $I_{o}$ is the initial optical power, and $\alpha$ is the absorbance [59]. In addition, absorbance is:

$$
\alpha=-S(T) g\left(v-v_{0}\right) N l
$$

Where $S(T)$ is the absorption line strength as a function of temperature, $g\left(v-v_{o}\right)$ is a normalized line shape function for the line at $v_{o}, N$ is the gas density and $l$ is the path absorbance [60]. The expanded BeerLambert law is:

$$
I=I_{o} e^{-S(T) g\left(v-v_{0}\right) N l}
$$

This law is the foundation for all spectroscopy techniques as it is modified when applied in various systems.

\subsubsection{LI-COR LI-7700}

The LI-7700 implements WMS across an open-path Herriott cell. WMS benefits from the abilities of tunable lasers for laser modulation. The setup is shown in Figure 2 and features a tunable near-IR laser, 2 detectors, a Herriott cell, and reference sample. The near-IR laser requires no cooling system as it does not reach high temperatures like other IR lasers. 


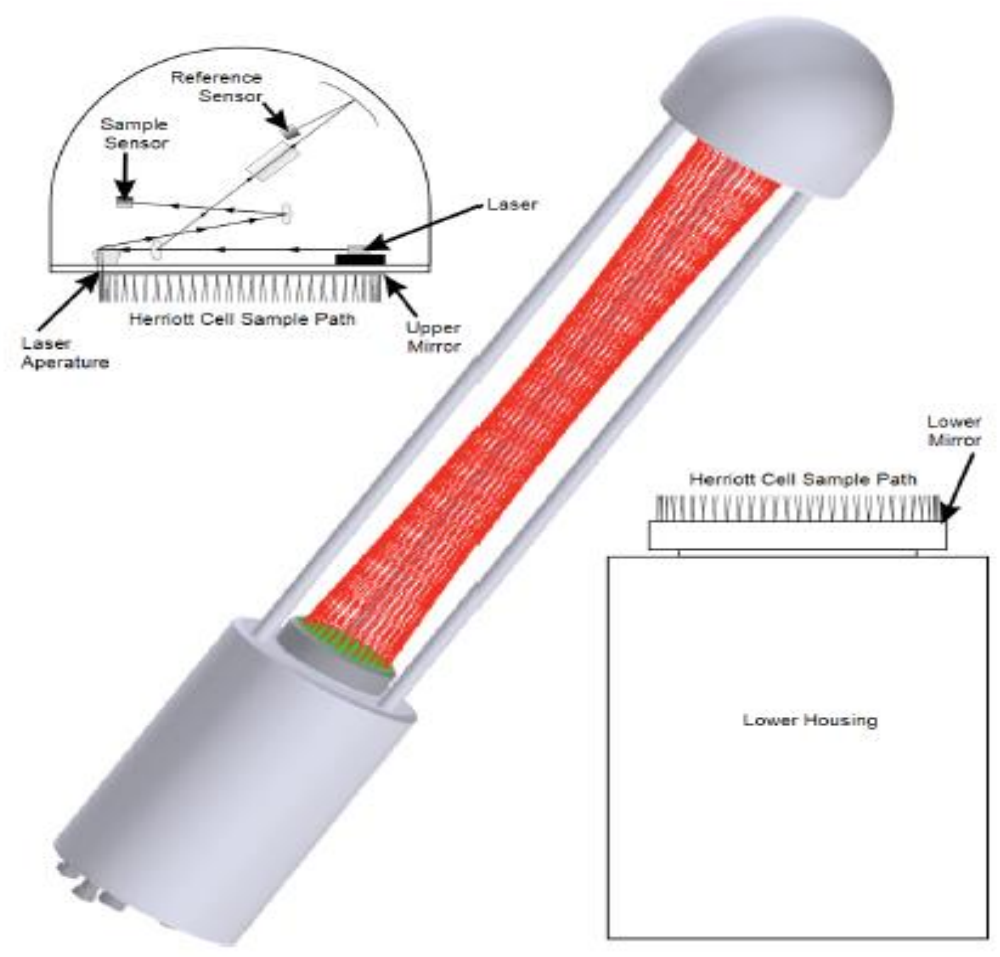

Figure 2: WMS System in the LI-7700 [57].

\subsubsection{Wavelength Modulation Spectroscopy (WMS)}

WMS is a specific version of frequency modulation where the modulation frequency is much less than the frequency's half width [61]. Modulation of the light's wavelength occurs to measure the molecular absorption in the cell. The laser followed the pattern as shown in Figure 3. The resulting waveform is proportional to the density of the volume of molecules in the cell as:

$$
\rho=K_{s}\left(\sum_{i=1}^{M} \widehat{a}[i] a_{r e f}[i]-K_{z}\right)
$$

where $K_{s}$ is the span gas value, $M$ is the number of samples, $i$ is the waveband from one to $M, \hat{a}[i]$ is the measured waveform, $a_{\text {ref }}[i]$ is the reference waveform, and $K_{z}$ is the zero value [61]. Due to the calculation of density in WMS, methane, in units of $\mu-\mathrm{mol} / \mathrm{mol}$ or $\mathrm{ppm}$, requires a temperature and pressure correction. 


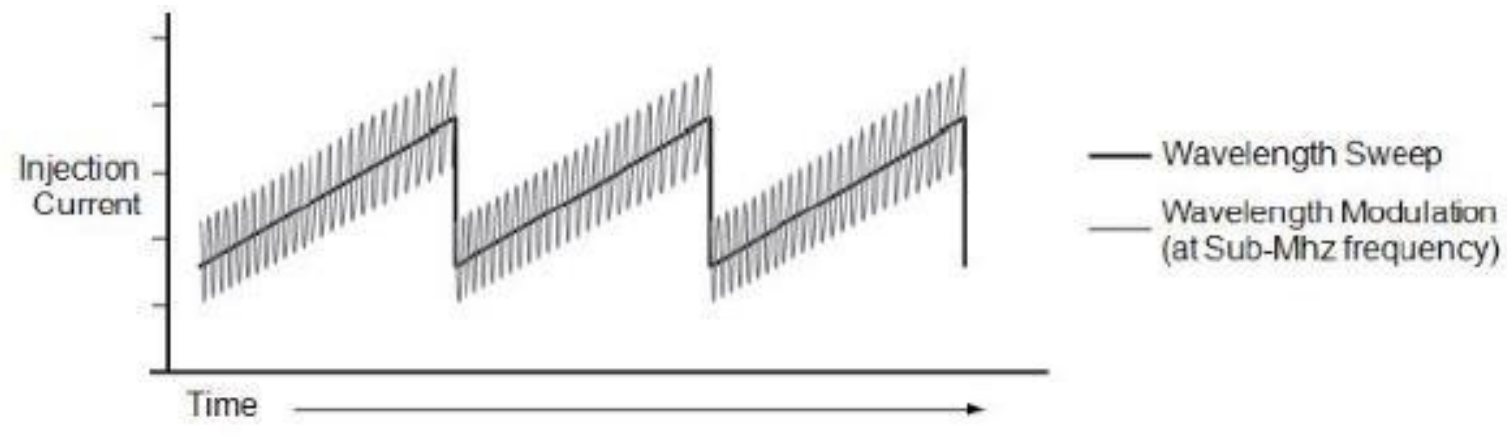

Figure 3: Modulation of the Laser Wavelength Occurring in the LI-7700 [57].

\subsubsection{Herriott Cell}

A Herriott cell is two reflective lenses opposite each other, where one lens has a portion without reflection for the source light to exit through after a designed path length [62]. The path length increases by the reflection of the light by the lens. Named for Donald R. Herriott, the cell can be either an open-path, which is accessible from all sides, or closed-path, where the inlet/outlet ports are the only path into the cell. In the case of the LI-7700, the open-path cell consists of $30 \mathrm{~m}$ total path length with just $0.5 \mathrm{~m}$ of physical path [57].

\subsubsection{Effects}

The LI-7700 had a standard sampling rate up to $40 \mathrm{~Hz}$, but it was sampled at $10 \mathrm{~Hz}$ during operation due to sampling frequency limitations of data acquisition modules [63]. At $10 \mathrm{~Hz}$, the LI-7700 had a precision of $5 \mathrm{ppbv}$ of methane. In addition, it had a measurement range of 0-40 ppmv for precise measurements [63]. The LI-7700 reported a linear error equal to $1 \%$ of the methane reading. Because of the LI-7700's high sampling frequency, open-path operation, and precision, the LI-7700 is the state-of-the-art ambient methane analyzer.

Because of the open-path operation, the implications of the LI-7700 consist of a having a relative signal strength indicator (RSSI) and measuring in parts per million-meter (ppmv-m). With the open-path cell, objects can interfere with the laser by obstructing its path. By quantifying the RSSI, the LI-7700 discloses the level of interference during operation. A minimum of 10\% RSSI was required for accurate 
measurements [64]. With the Herriott cell of $0.5 \mathrm{~m}$, the LI-7700 records the total ppmv of methane across the cell in ppmv-m. The LI-7700 averages the methane reported across the cell, thus it cannot determine the distribution of methane concentrations across the cell path.

\subsubsection{Los Gatos Research Ultra-Portable Greenhouse Analyzer (UGGA)}

The UGGA uses Los Gatos Research's patented OA-ICOS technology to quantify methane, water $\left(\mathrm{H}_{2} \mathrm{O}\right)$, and $\mathrm{CO}_{2}$. The OA-ICOS was created based on cavity ringdown spectroscopy. Both methods consist of a closed sampling cell, a diode laser, a detector, and a sampling pump. However, OA-ICOS and cavity ringdown vary in their measurement principles.

\subsubsection{Cavity Ringdown}

The cavity ringdown technique was developed during the 1980s and used a laser and a closed cell with almost perfect reflectivity [65]. It was created to reduce the number of uncertainties in the cell due to small changes in wavelength absorption over small distances. The cavity ringdown technique determines the absorption of the species by quantifying the losses, or ringdown time, during each pass of the cell. The integration of the losses determines the quantity of each species in the cell. By pairing this with a pulsed laser, cavity ringdown is a cost effective and accurate measurement technique. Currently, Picarro Inc. produces commercially available analyzers using the cavity ringdown technique, sampling at a default frequency of $1 / 5 \mathrm{~Hz}$, though higher frequencies are available $[24,66]$. The sampling rate is limited in the design of cavity ringdown spectroscopy due to physical ringdown time [67]. To increase sampling rate, the OA-ICOS was created.

\subsubsection{Off-Axis Integrated Cavity Output Spectroscopy}

Using cavity ringdown as the foundation, integrated cavity output spectroscopy (ICOS) was created by Anthony O'Keefe, the founder of Los Gatos Research. ICOS is when the laser's wavelength enters the closed-path cavity and the wavelength output from the cavity determines the losses in the cell caused by 
molecular absorption. The integration of the total signal transmitted and a previously defined baseline determine the absorption in the cell.

Normalization occurs to remove any broadening effects caused by the lasers. The signal of ICOS is:

$$
I=I_{o} T^{2} e^{-k l}\left[2 \log \left(R^{\prime}\right)\right]^{-1}
$$

where $I$ is the transmitted intensity, $I_{o}$ is the incident light intensity, $T$ is the mirror transmission, $k$ is the intra-cavity absorption per unit length, $l$ is the cavity sample length, and $R$ ' is the effective reflectivity [68]. Effective reflectivity is:

$$
\boldsymbol{R}^{\prime}=\boldsymbol{R} \boldsymbol{e}^{-\boldsymbol{k l}}
$$

where $R$ is the true mirror reflectivity [68]. The light in ICOS retraces the path throughout the cell without a delay in sampling. This allows for an increase in precision due to overlapping light passes. OAICOS uses a laser that is not aligned to the centerline axis. By changing the laser alignment, the light changes path shape and increases path length [69]. The system is shown in Figure 4.

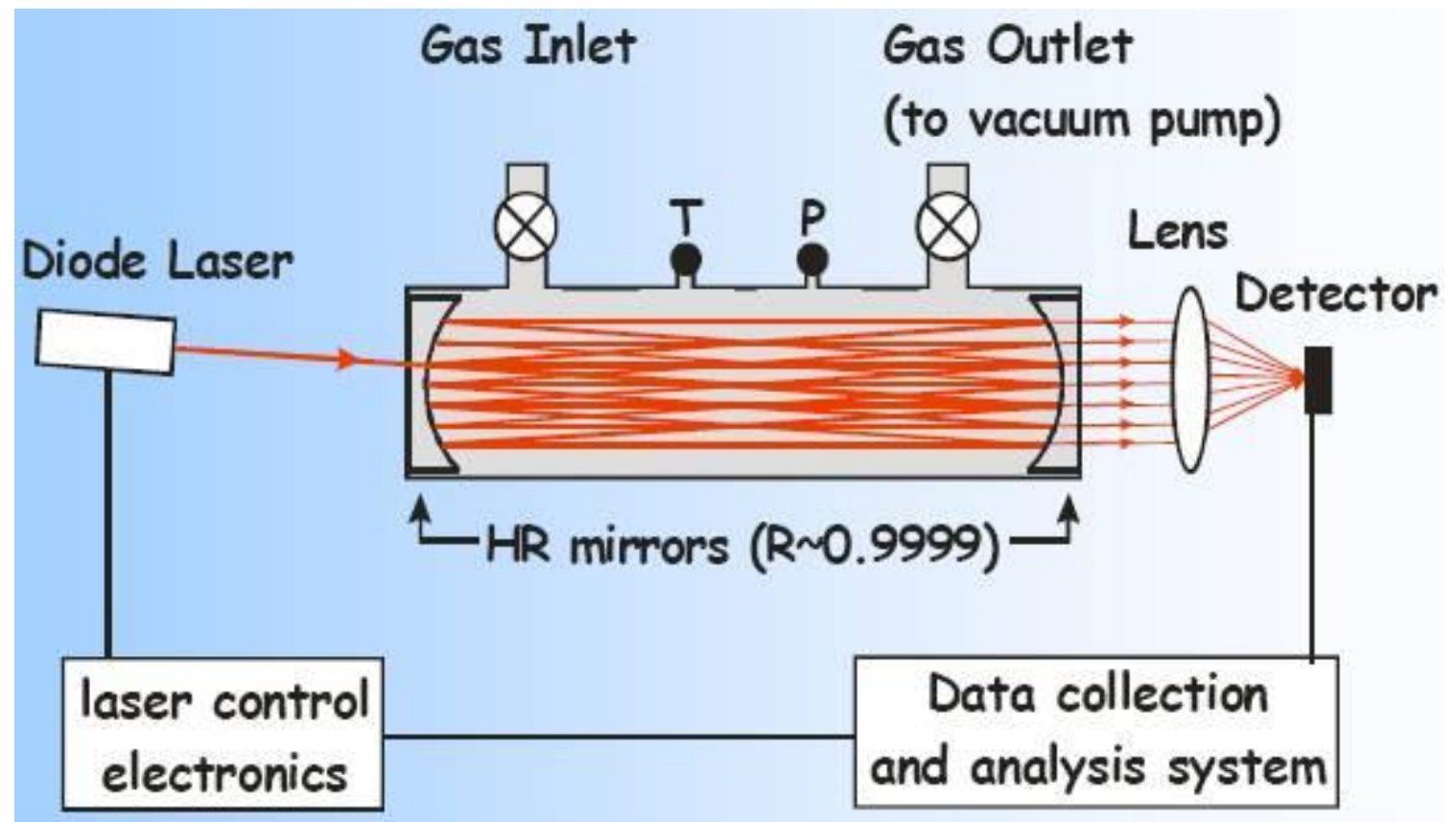

Figure 4: OA-ICOS System in the UGGA [70]. 


\subsubsection{Effects}

Due to the closed-path operation of the UGGA's OA-ICOS method, the UGGA has some benefits over other spectroscopy methods. The ICOS method allows for precise measurements. Sampling at steady state for 100 seconds, the UGGA reports a precision of 2 ppbv [56]. The UGGA has a standard operational range of 0-500 ppmv of methane but has the capability to report as high as 10,000 ppmv of methane [56]. In addition, the UGGA used in this study had a maximum sampling frequency of $1 \mathrm{~Hz}$. The Los Gatos Research Greenhouse Gas Analyzer and the Fast Methane Analyzer can report methane at up to 10 and 20 Hz, respectively $[71,72]$.

The closed-path cell of the UGGA is 343 cubic millimeters $\left(\mathrm{mm}^{3}\right)$. For the sample to reach the cell inside the portable case, the UGGA has an internal sampling line of $3.175 \mathrm{~mm}$ (millimeter) internal diameter and $1.12 \mathrm{~m}$ length. A positive displacement pump flows at a rate of 0.5 standard liter per minute (slpm) to create a vacuum in the closed cell. The vacuum pulls the sample through the cell, thus causing diffusion in the cell. The UGGA operates with a cell pressure near 140 Torr. The use of a pump creates a time delay as a function of the sample line length, both external and internal of the analyzer. The external line allowed for mounting the UGGA away from the sampling location (within a vehicle to avoid exposure to elements). Thus, the use of OA-ICOS in the closed cell creates signal processing issues when compared to the LI-7700. But because of its remote location and closed-path operation, it is not as sensitive to environmental weather conditions (i.e. rain drops, dust, or condensation on lenses).

\subsection{Sampling Implications}

The conversion of continuous operation into discrete signals creates signal processing issues. The signal processing effects of the equipment illustrates the sampling issues associated with the analyzers. The time delay and diffusion caused by the UGGA's operation impacts sampling and signal processing. Understanding basic signal terms and processes allows for the better understanding of analyzers. 


\subsubsection{Signals and Systems}

In signal processing, there are signals and systems. Systems create discrete output signals from real world continuous inputs [73]. All sensors or analyzers are systems, and their outputs are signals that are available for interpretation.

\subsubsection{Linear}

For systems to be linear, their signals must be homogenous and additive. Homogenous is when a change in amplitude of the input signal caused a change of the amplitude of the output signal [73]. A signal is additive if the sum of two input signals produced the sum of their output signals [73]. All linear systems require both attributes, but a third property is necessary for some processing techniques, shift invariance. Shift invariance is time invariance, where a change in time does not change the output signal [73]. In the UGGA and LI-7700, shift invariance is the ability to record the same signal at different operational times. Both the UGGA and the LI-7700 are examples of linear systems.

\subsubsection{Convolution}

Convolution is a mathematical operator of discrete signals. The principle is the superposition of two signals to create a third signal. Convolution sum is:

$$
\mathbf{y}[\mathbf{i}]=\sum_{\mathbf{j}=\mathbf{1}}^{\mathbf{m}} \mathbf{h}[\mathbf{j}] * \mathbf{x}[\mathbf{i}-\mathbf{j}]
$$

where $y$ is the output signal, $x$ is the input signal, $h$ is the impulse response, $i$ is the current point, and $m$ is the length of the impulse response. [74]. The impulse response is another signal, or a filter that creates the output signal. Any distortion or dilution is an impulse response and that convolutes with the input signal. For convolution to create the proper impulse response, the system must be linear and time invariant under all operating conditions. For the UGGA and LI-7700, any dilutions or other sampling effects were an impulse response that had been applied to the UGGA's or LI-7700's input signal.

Convolution has a few mathematical properties. They are communitive, associative, distributive, and transference. Communitive convolution is convolution regardless of the order of the signals. Associative 
convolution is convolution regardless of their grouping if they remained in the same order. Distributive is best shown as the equation:

$$
A(B+C)=A B+A C
$$

where convolution distributes into a grouping. Transference is a linear shift to both the input and output signal, without changing the impulse response [75]. Transference is only a change in magnitude of a signal, while the signal retained its original shape. This is important to note as normalization of signals was a transference. With all the convolution and linear properties, all the impulse responses combine to create one impulse response.

All equipment used in the mobile methane systems were systems themselves. Their outputs to the computer were the signals for interpretation. The UGGA had an impulse response due to the diffusion in the closed cell. To overcome this, the impulse response required a correction for accurate measurement. 


\section{Experimental Setup}

In order to formulate conclusions regarding limitations of methane analyzers in a mobile detection system, two experiments were designed. For mobile methane detection, both field and laboratory testing were performed to examine the various capabilities and/or limitations of each system.

\subsection{Field Testing}

Field testing required all the equipment to be deployed to a vehicle as a single unit. The equipment, data collection routes, and thresholds were determined prior to field testing. Field testing occurred in/near Morgantown, West Virginia (WV).

\subsubsection{Vehicle Setup}

The equipment was divided into two systems, fast and slow. The full breakdown of equipment is shown in Table 2. A few pieces of equipment were used in both systems. For mobile methane detection, each system (fast and slow) consisted of its own methane analyzer, sonic anemometer, and GPS. The sonic anemometer for each system quantified wind direction using vectors, where the sign indicated direction. This allowed for the determination of wind direction for potential source attribution. The GPS units quantified location for mapping of sources and vehicle speed for correcting wind speed. Each system was capable to quantify methane, determine potential source direction, and record geospatial information for mapping and user interpretation. All components were sampled at either 10 or $1 \mathrm{~Hz}$, respectively. 
Table 2: Equipment Used in Mobile Methane Detection.

\begin{tabular}{|c|c|c|c|c|c|c|}
\hline Make & Model & Output (Units) & Frequency & Range & Error & System \\
\hline $\begin{array}{c}\text { LI-COR } \\
\text { Biosciences }\end{array}$ & LI-7700 [63] & Methane (ppmv) & $\begin{array}{l}\text { Max:40 Hz } \\
\text { Used: } 10 \mathrm{~Hz}\end{array}$ & $0-40$ ppmv & $1 \%$ & \multirow{3}{*}{ Fast system } \\
\hline $\begin{array}{l}\text { Gill } \\
\text { Instruments }\end{array}$ & WindMaster [76] & $\begin{array}{l}\text { Wind Speed (two horizontal } \\
\text { components, one vertical } \\
\text { component) }(\mathrm{m} / \mathrm{s})\end{array}$ & $\begin{array}{l}\text { Max:20 Hz } \\
\text { Used:10 Hz }\end{array}$ & $0-45 \mathrm{~m} / \mathrm{s}$ & $1.5 \%$ & \\
\hline U-Blox & EVK-M8U [77] & $\begin{array}{c}\text { Position (Latitude, Longitude), } \\
\text { Speed }(\mathrm{m} / \mathrm{s})\end{array}$ & $\begin{array}{l}\text { Max:20 Hz } \\
\text { Used:10 Hz }\end{array}$ & N/A & $\begin{array}{l}2.5 \mathrm{~m} \\
0.5 \mathrm{~m} / \mathrm{s}\end{array}$ & \\
\hline $\begin{array}{l}\text { Los Gatos } \\
\text { Research }\end{array}$ & $\begin{array}{l}\text { Ultra-Portable } \\
\text { Greenhouse Gas } \\
\text { Analyzer [56] }\end{array}$ & Methane $/ \mathrm{CO}_{2} / \mathrm{H}_{2} \mathrm{O}$ (ppmv) & $\begin{array}{l}\text { Max: } 1 \mathrm{~Hz} \\
\text { Used: } 1 \mathrm{~Hz}\end{array}$ & $\begin{array}{l}.01-500 \text { ppmv (methane); } \\
0-20,000 \text { ppmv }\left(\mathrm{CO}_{2}\right) ; 0- \\
\text { 70,000 ppmv }\left(\mathrm{H}_{2} \mathrm{O}\right)\end{array}$ & $1 \%$ & \multirow{3}{*}{$\begin{array}{l}\text { Slow } \\
\text { system }\end{array}$} \\
\hline $\begin{array}{l}\text { Gill } \\
\text { Instruments }\end{array}$ & WindSonic [78] & $\begin{array}{l}\text { Wind Speed (two horizontal } \\
\text { components) }(\mathrm{m} / \mathrm{s})\end{array}$ & $\begin{array}{l}\text { Max: } 4 \mathrm{~Hz} \\
\text { Used: } 1 \mathrm{~Hz}\end{array}$ & $0-60 \mathrm{~m} / \mathrm{s}$ & $2 \%$ & \\
\hline GlobalSat & BU-353S4 [79] & $\begin{array}{c}\text { Position (Latitude, Longitude), } \\
\text { Speed }(\mathrm{m} / \mathrm{s})\end{array}$ & $\begin{array}{l}\text { Max: } 5 \mathrm{~Hz} \\
\text { Used: } 1 \mathrm{~Hz}\end{array}$ & N/A & $\begin{array}{l}2.5 \mathrm{~m} \\
0.1 \mathrm{~m} / \mathrm{s}\end{array}$ & \\
\hline $\begin{array}{c}\text { LI-COR } \\
\text { Biosciences }\end{array}$ & LI-7500 [80] & $\mathrm{CO}_{2} / \mathrm{H}_{2} \mathrm{O}(\mathrm{ppmv})$ & $\begin{array}{l}\text { Max:20 Hz } \\
\text { Used: } 10 \mathrm{~Hz}\end{array}$ & $\begin{array}{c}0-3,000 \text { ppmv }\left(\mathrm{CO}_{2}\right) ; 0-60 \\
\text { ppmv }\left(\mathrm{H}_{2} \mathrm{O}\right)\end{array}$ & $1 \%$ & \multirow{3}{*}{$\begin{array}{c}\text { Both } \\
\text { Systems }\end{array}$} \\
\hline $\begin{array}{c}\text { LI-COR } \\
\text { Biosciences }\end{array}$ & LI-200 [81] & $\begin{array}{l}\text { Solar Loading (Converts V to } \frac{W}{m^{2}} \\
\text { using ICP-CON PET-7019z [82]) }\end{array}$ & $\begin{array}{c}\text { Max: }<1 \mu-\mathrm{s} \\
\text { ICP-CON max: } 10 \mathrm{~Hz} \\
\text { ICP-CON used: } 1 \mathrm{~Hz}\end{array}$ & $0-3,000 \frac{W}{m^{2}}$ & $1 \%$ & \\
\hline Omega & iBTHX [83] & $\begin{array}{c}\text { Temperature }\left({ }^{\circ} \mathrm{F}\right), \text { Pressure } \\
\text { (mbar), Relative Humidity }(\%)\end{array}$ & $1 / 4 \mathrm{~Hz}$ & $\begin{array}{c}-40-185^{\circ} \mathrm{F} ; 10-1,100 \mathrm{mbar} \\
0-100 \%\end{array}$ & $\begin{array}{l}2.7^{\circ} \mathrm{F} ; 2 \\
\text { mbar; } 4 \%\end{array}$ & \\
\hline
\end{tabular}


Figures 5 and 6 show the full field testing setup mounted to a vehicle. All the equipment shown was mounted to the vehicle using a plate designed for accommodation of the LI-7700. The full equipment list included 2 methane analyzers, 2 sonic anemometers, 2 GPSs (not pictured), an open-path $\mathrm{CO}_{2} / \mathrm{H}_{2} \mathrm{O}$ analyzer, a pyranometer, a weather sensor, and a laptop (not pictured). The equipment mounted to the plate was designed to ensure methane detection without interfering with wind measurements. A rudimentary flat plate analysis was conducted by Ms. Rebekah Barrow (BSME, BSAE) to assess minimum clearance issues as related to vehicle wake. Lower mounted analyzers were mounted at the front of the plate while taller analyzers were mounted nearer the rear.

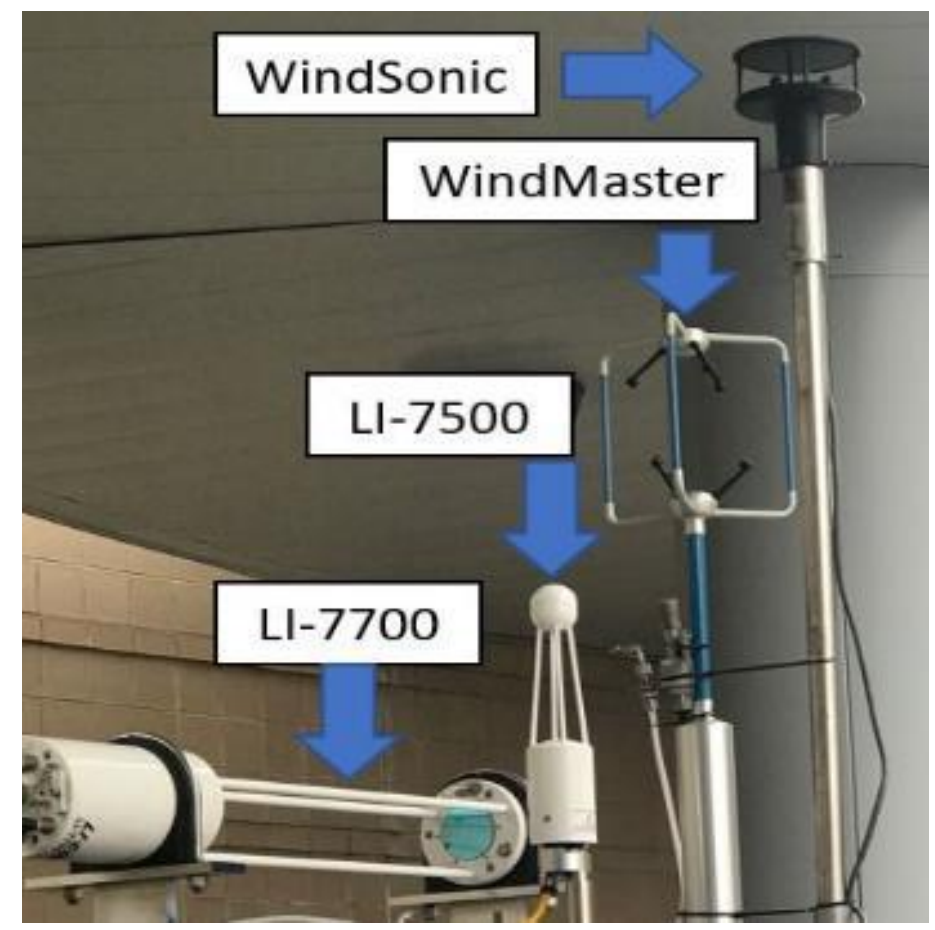

Figure 5: Testing Equipment Mounted to the Vehicle: (Left to Right) LI-COR LI-7700, LI-COR LI-7500, Gill WindMaster, Gill WindSonic.

For methane analyzers, both the LI-7700 and UGGA were presented earlier. The LI-7700 was calibrated by LI-COR Biosciences prior to its deployment. Due to the open-path operation of the LI-7700, it was required to be mounted to the plate on the outside of the vehicle. The LI-7700 was mounted in the front on the plate to reduce dispersion of the methane sample from other components. The UGGA was calibrated for methane prior to testing and is described in Appendix I. The UGGA was not calibrated for 
$\mathrm{CO}_{2}$ or water vapor prior to operation. The UGGA was mounted inside the vehicle and a $4.78 \mathrm{~m}$ line was attached outside the vehicle for sampling.

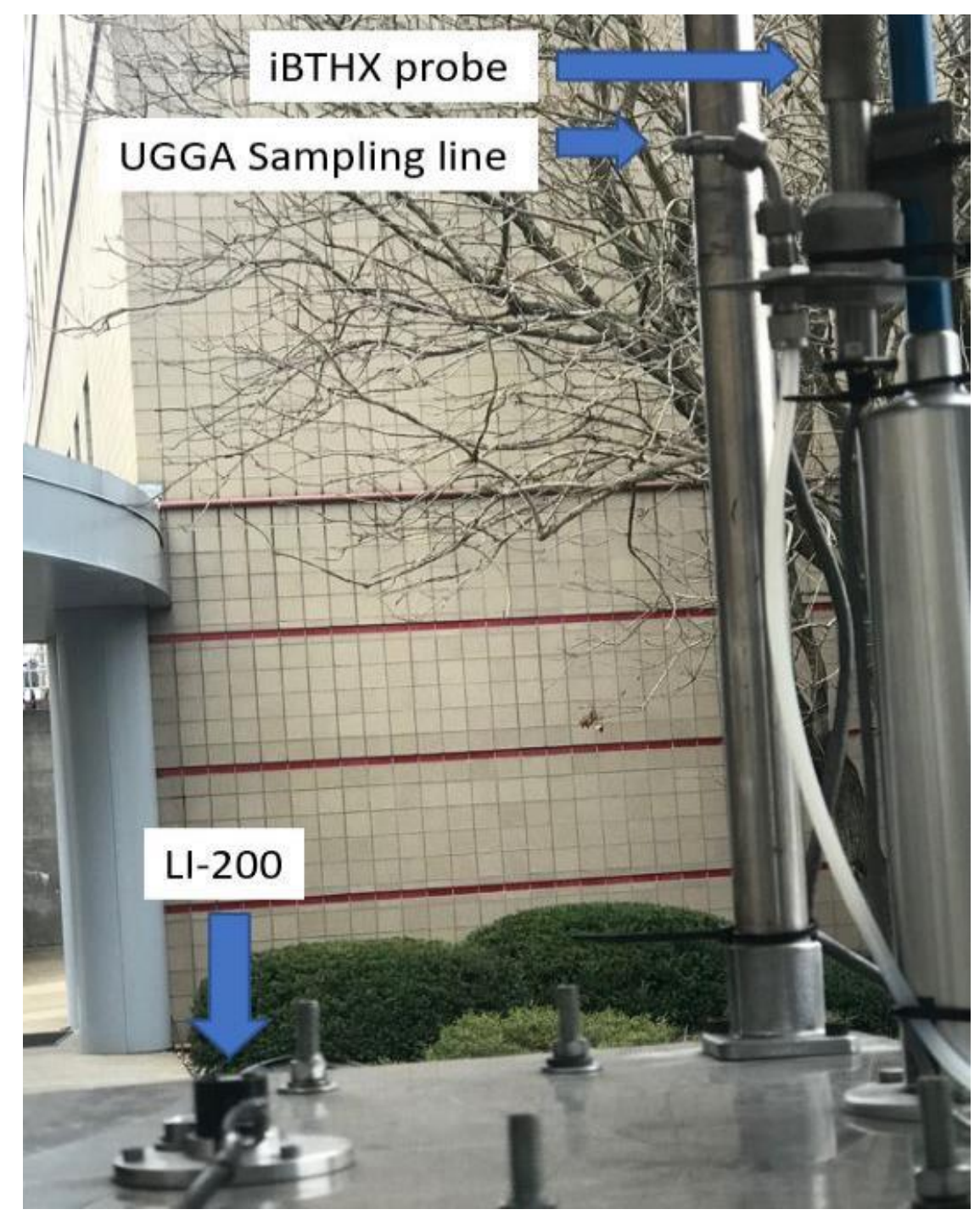

Figure 6: Small Testing Equipment Mounted to the Vehicle: (left to right) LI-COR LI-200, Los Gatos Research Ultra-Portable Greenhouse Gas Analyzer, Omega IBTHX.

Both the WindSonic 2D and the WindMaster 3D were manufactured by Gill Instruments. The WindSonic 2D only measured wind in the horizontal directions at $1 \mathrm{~Hz}$, while the WindMaster 3D was capable of measuring at speeds of up to $20 \mathrm{~Hz}$, though data collection occurred at $10 \mathrm{~Hz}$. Their north direction was aligned with the front of the vehicle, denoted as vehicle north. In addition, the WindMaster's stand was used as a mount for the UGGA sampling line and the weather sensor, as shown in Figure 6. This allowed 
for the shortest distance between the UGGA sampling line and the LI-7700 without an additional mount. The UGGA sampling inlet was therefore at the approximate height of the LI-7700 sampling plane. The two GPS units deployed were a U-Blox EVK-M8U and a GlobalSat BU-353S4. The EVK-M8U reported at a frequency of $10 \mathrm{~Hz}$, while the BU-353S4 reported at $1 \mathrm{~Hz}$. Both GPS units recorded speed in meters per second $(\mathrm{m} / \mathrm{s})$ and location in latitude and longitude coordinates. The fast system consisted of the LI7700, the WindMaster, and the U-Blox, while the slow system consisted of the UGGA, the WindSonic, and the BU-353S4.

Additional equipment included a $\mathrm{CO}_{2} / \mathrm{H}_{2} \mathrm{O}$ analyzer, a pyranometer, a weather sensor, and a laptop. The $\mathrm{CO}_{2} / \mathrm{H}_{2} \mathrm{O}$ analyzer was a LI-COR LI-7500. It implemented the same WMS as the LI-7700 except the LI7500 scanned wavelengths for $\mathrm{CO}_{2}$ and $\mathrm{H}_{2} \mathrm{O}$. The LI-7500's results were part of another ongoing study, but it was still active during data collection. The pyranometer was a LI-COR LI-200, which determined the solar loading $\left(\frac{W}{m^{2}}\right)$. The weather sensor was an Omega iBTHX which was used to record ambient pressure in millibar (mbar), temperature $\left({ }^{\circ} \mathrm{F}\right)$, and relative humidity $(\%)$. Using the Omega and the LI200 , the weather conditions were defined as they played a role in methane transport. The atmospheric stability class was calculated using the LI-200 and Omega but these items were not used in this mobile methane detection research. However, they were installed to collect additional data that can be used in future research projects focused on quantification. A computer using an in-house developed data acquisition software, Scimitar, recorded all the data and displayed it for the user in real time. The fast system's sampling frequency was limited by Scimitar due to its maximum sampling frequency of $10 \mathrm{~Hz}$. Once the equipment was mounted, it was wired accordingly for data acquisition.

For all the equipment to communicate to the computer in an orderly fashion, a mobile methane detection box was created. It was designed to receive all analog and digital inputs from the equipment and connected to the computer with a single USB and ethernet cable, as shown in Figure 7. Ports consisting of USB, ethernet, DB9, BNC connectors, and a terminal block were mounted to the sides of the box. Inside the box, separate cables were connected to the appropriate communication or power method. The 
implementation of the mobile methane detection box was created to simplify the setup and data collection. Once the vehicle had the equipment mounted and connected, it was ready for data collection.

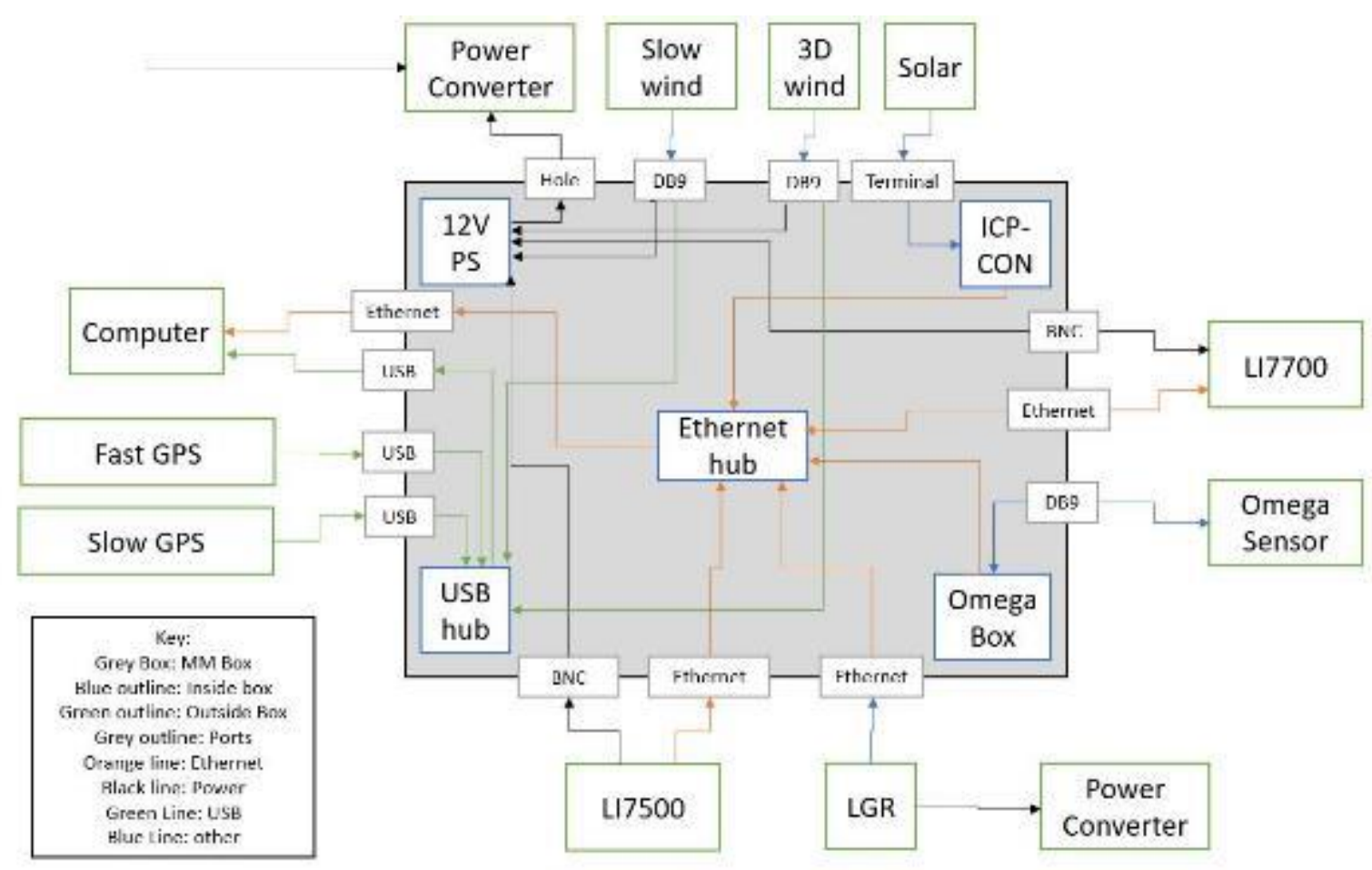

Figure 7: Design of the Mobile Methane Detection Box used for Data Collection.

\subsubsection{Data Collection}

Data collection began in January 2019 and continued into February 2019. Over the course of two months, the field testing equipment was applied to the vehicle totaling 8 days, 43 trip files, and over 15 hours of data. This yielded over 540,000 methane values at $10 \mathrm{~Hz}$ and 54,000 at $1 \mathrm{~Hz}$. The number of days proved the systems robustness as it was exposed to various weather conditions during numerous tests. Because the UGGA was mounted inside the vehicle, it did not experience any sampling losses due to weather. However, the use of the LI-7700's analyzer was hindered based on weather conditions when condensation occurred on the Herriot cell lenses.

The system was operated primarily near the Morgantown, WV area. Most of the urban driving throughout Morgantown detected few sources of methane. Due to the abundance of natural gas wells in the area and 
other methane sources (e.g. coal mines), rural driving outside city limits was shown to be an ideal region for mobile methane system evaluation. Figure 8 displays all routes taken during field data collection. Note, that in many cases routes were repeated when methane sources were identified as a method to compare and increase data samples collected under different conditions. The routes passed through Cassville, Core, and Pentress, WV and Mt. Morris and Point Marion, Pennsylvania.

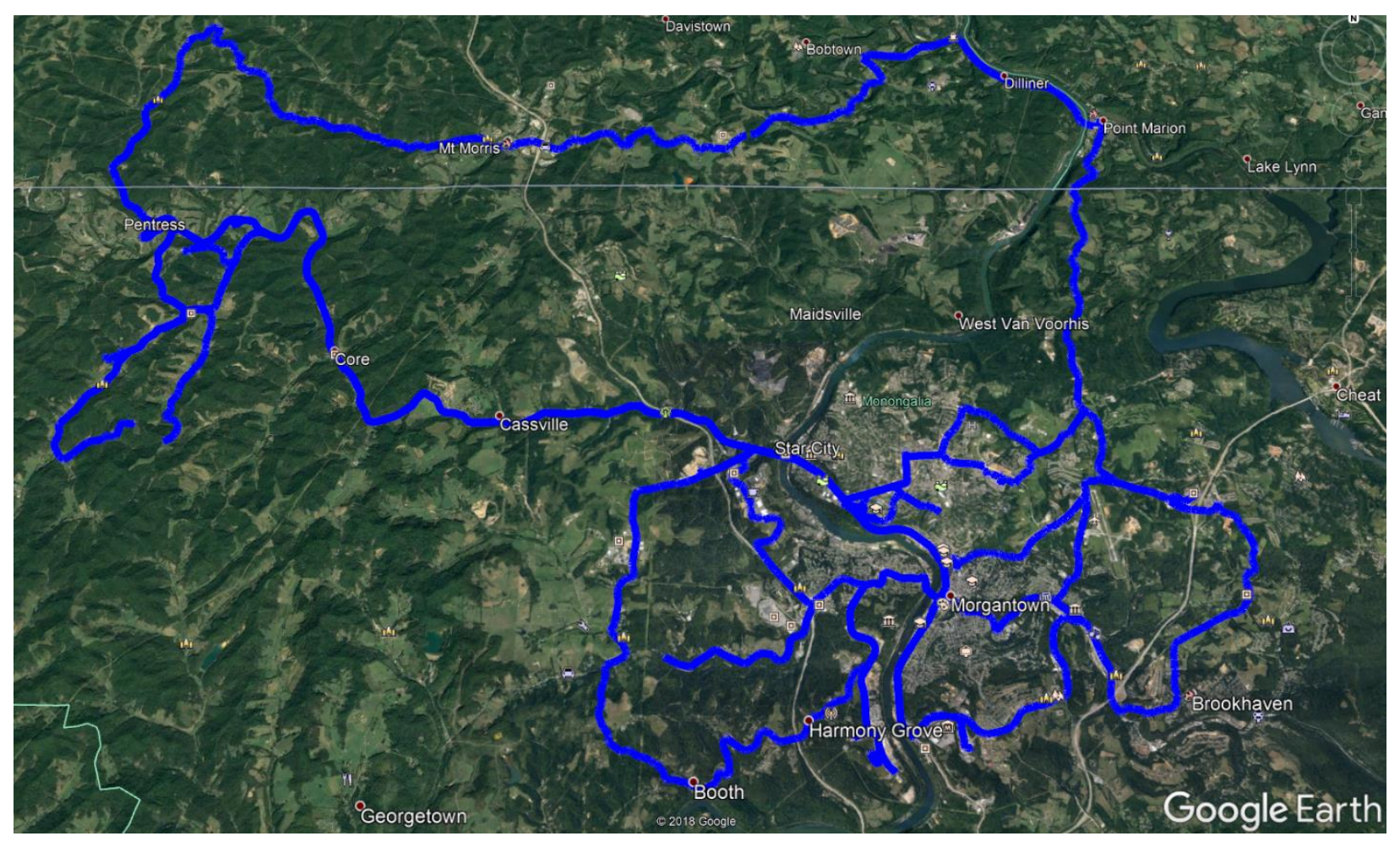

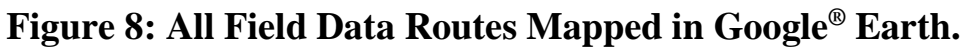

\subsubsection{Background Threshold}

Because methane disperses from high concentrations to low concentrations, small methane concentrations above background may indicate larger methane sources upwind. The dispersion of methane was a function of the wind in transport and the weather conditions. By pairing methane readings above background with the wind direction, methane detection may be able to lead to potential source attribution. For methane detection, a background threshold was required to determine if methane concentrations were elevated. 
In Phillips et al., the mode of the data collected during transient operation was considered the background threshold [14]. In Eapi et al., the national average methane concentration of 1.867 ppmv was used as the background threshold $[16,28]$. Atherton et al. defined the background threshold as the lowest methane concentration every 300 seconds [17]. In Fischer et al., a moving average of a two minute time period was used as the background threshold [24]. In addition, they noted that the use of a constant methane background threshold was not representative of real world operation in both time and space.

For initial results, the background threshold was set to be the lowest $5 \%$ of each trip data, identical to the methods performed by Brantley et al. [84]. The 5\% background threshold was believed to contain the background concentration during data collection while allowing for varying background concentrations. The background threshold would only remove the lowest $5 \%$ of points, but concentrations less than $1 \%$ of the maximum background corrected concentration were considered background as well.

\subsubsection{Detection Threshold}

A detection threshold was required to determine if elevated methane concentrations, or peaks, were potential methane sources. Phillips et al. implemented $2.5 \mathrm{ppmv}$ as the threshold for source attribution, which was the $90^{\text {th }}$ percentile value of their total data set [14]. Eapi et al. used 3 ppmv as the detection threshold because it was at least 1 ppmv greater than their background [16]. Atherton et al. used the ratio of $\mathrm{CO}_{2}$ to methane for three seconds to determine detection thresholds [17]. Fischer et al. used $110 \%$ of the background value as their detection threshold [24]. During research and evaluation, the initial detection threshold of 3 ppmv was selected. Note that the UGGA's background was zeroed to the LI7700's background due to different calibrations.

\subsection{Laboratory Testing}

In the laboratory, the UGGA was exposed to a set volume flow rate of methane for a set duration. The full laboratory setup design, shown in Figure 9, included a three-way valve, relay, ICP-CON PET-7019Z, power supply, STEC SGD-710C gas divider, 101.3 ppmv methane bottle, and zero-air bottle. Appendix II 
contains the calibration certificates, with uncertainties and errors, for the methane bottle, zero-air bottle, and the SGD-710C gas divider.

Using the methane bottle, the air bottle, and the gas divider, a controlled flow rate of methane with a known concentration was delivered to the UGGA. Prior to reaching the UGGA, a three-way valve and relay were connected to an ICP-CON PET-7019Z's digital output, which separated the flow into bursts of various lengths. After the three-way valve, a t-fitting was used as a flooded probe to provide the UGGA with a flow rate in excess of its sample flow rate. The sample flow rate of the UGGA was $0.5 \mathrm{slpm}$. The arrangement enabled background sampling when not exposed to a burst. Using Scimitar, the valve control and the response from the UGGA were recorded. The concentrations of methane delivered to the UGGA were spaced far enough apart that the UGGA had enough time to reach background prior to the sampling of the next burst. 


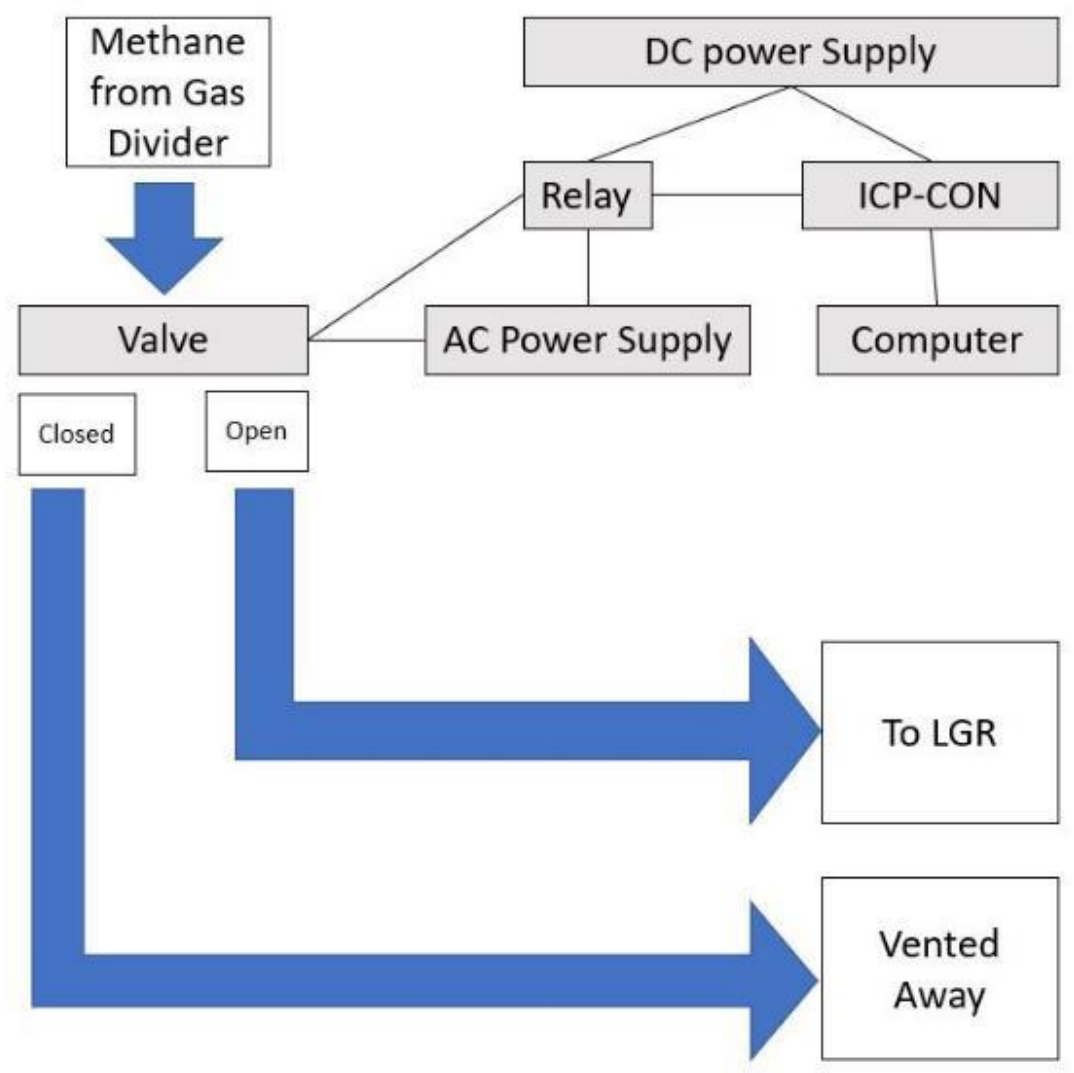

Figure 9: Burst Testing Setup Flow Diagram.

The tests performed consisted of 101.3 and 50.65 ppmv methane concentrations. The $101.3 \mathrm{ppmv}$ concentration was used as it was the concentration used in calibration of the UGGA. The 50.65 ppmv was used as it was above the range of the LI-7700. Despite the use of two separate concentrations of methane, the response curves had the same shape but varied in magnitude. These tests confirmed the UGGA's time invariant response. 


\section{Initial Field Testing Results}

Using the initial field testing results, disparity between the LI-7700 and the UGGA became apparent. A mapping of the initial tests depicted the implications of the UGGA's closed-path operation. In order to statistically compare the analyzer responses, a performance value (PV) was later defined. Over the 15 hours of data collection, 12 hours consisted of data where the vehicle was in motion. Any values of vehicle speed that were lower than the GPS vehicle speed error were defined as stationary and the remaining points were defined as mobile.

\subsection{Visual Interpretation}

Using MATLAB ${ }^{\odot}$ and Google ${ }^{\circledR}$ Earth, the trip files collected during field testing were mapped. The MATLAB $^{\odot}$ code, shown in Appendix III, created a Google ${ }^{\circledR}$ Earth file of the trip. The path taken was mapped with methane concentration extruded upwards to depict the concentration, with higher concentration having taller extrusions. In addition, the color scale ranged for each analyzer in each file with blue as the background methane concentration and red as the maximum methane concentration.

A trip section is mapped in Figures 10 and 11. Figure 10 displays the LI-7700's response to a suspected methane plume, and the Figure 11 displays the UGGA's response to the same plume of methane. Note, the Google ${ }^{\circledR}$ Earth mapping extrudes based on the ratio of methane concentration to the peak of methane in the analyzer's response. Here, Figure 11 has a higher extrusion of background methane because the UGGA underreports the methane peak of the LI-7700.

Despite both peaks being represented with red, the LI-7700's response was 8.69 ppmv above background and the UGGA's methane concentration was only 1.02 ppmv above background. The lower UGGA peak value and its shift in location highlighted the diffusion and delay associated with its closed-path operation. Figure 12 depicts both the mapped views of Figures 10 and 11 on a graph for a comparison of the responses in time. 


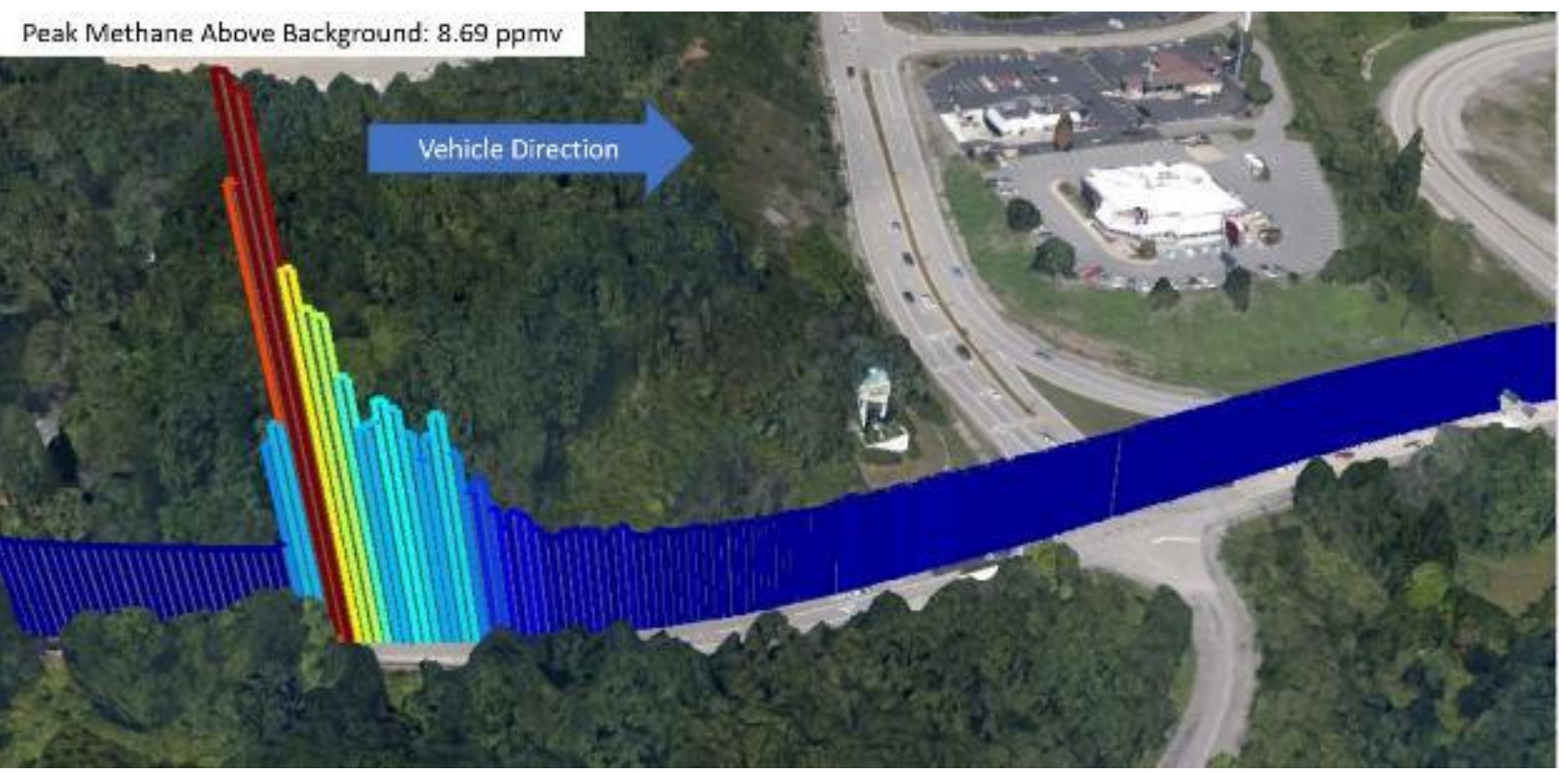

Figure 10: LI-7700 Methane Concentration Displayed in Google ${ }^{\circledR}$ Earth. $^{-}$

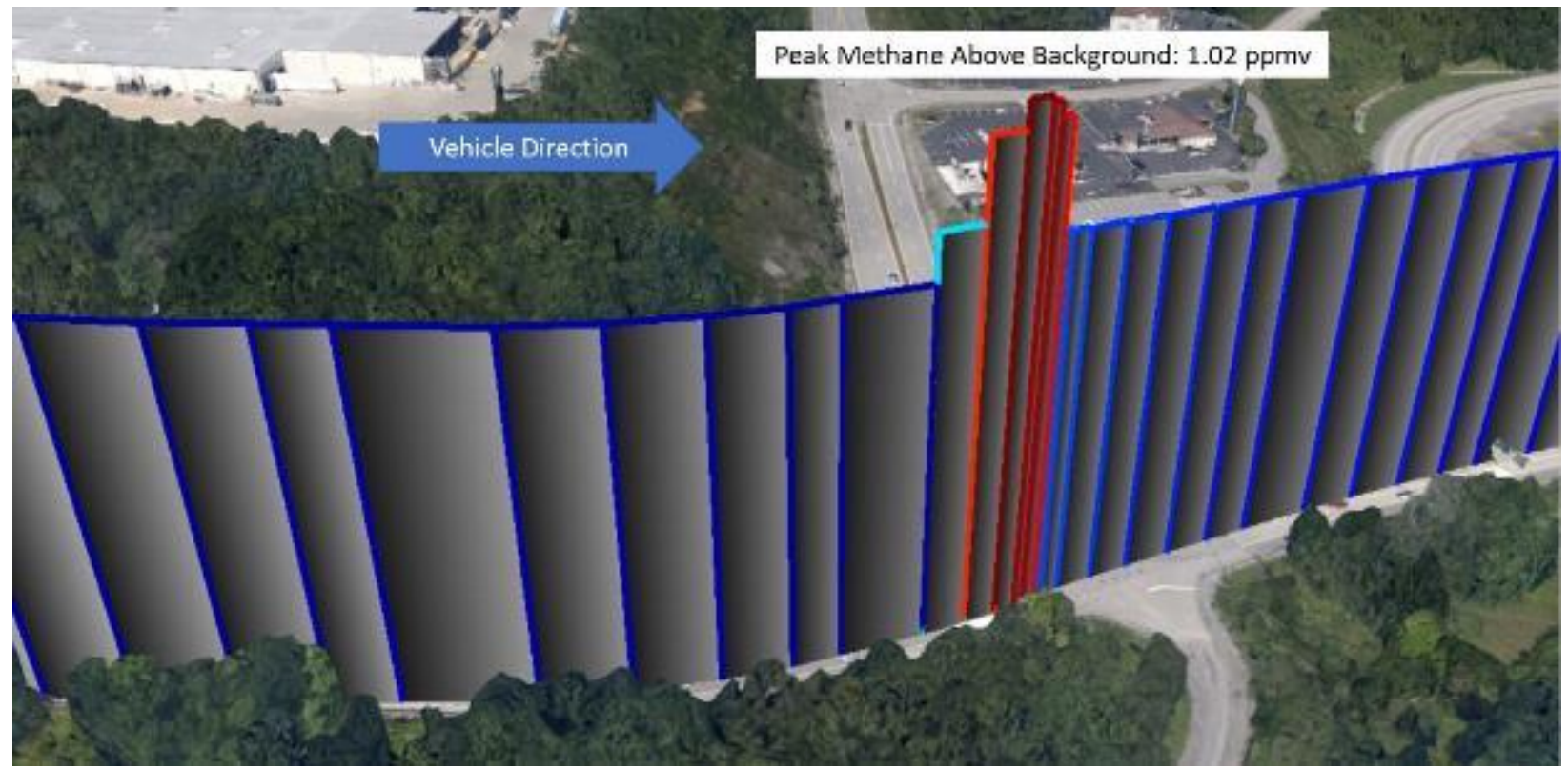

Figure 11: UGGA Methane Concentration Displayed in Google ${ }^{\circledR}$ Earth. 


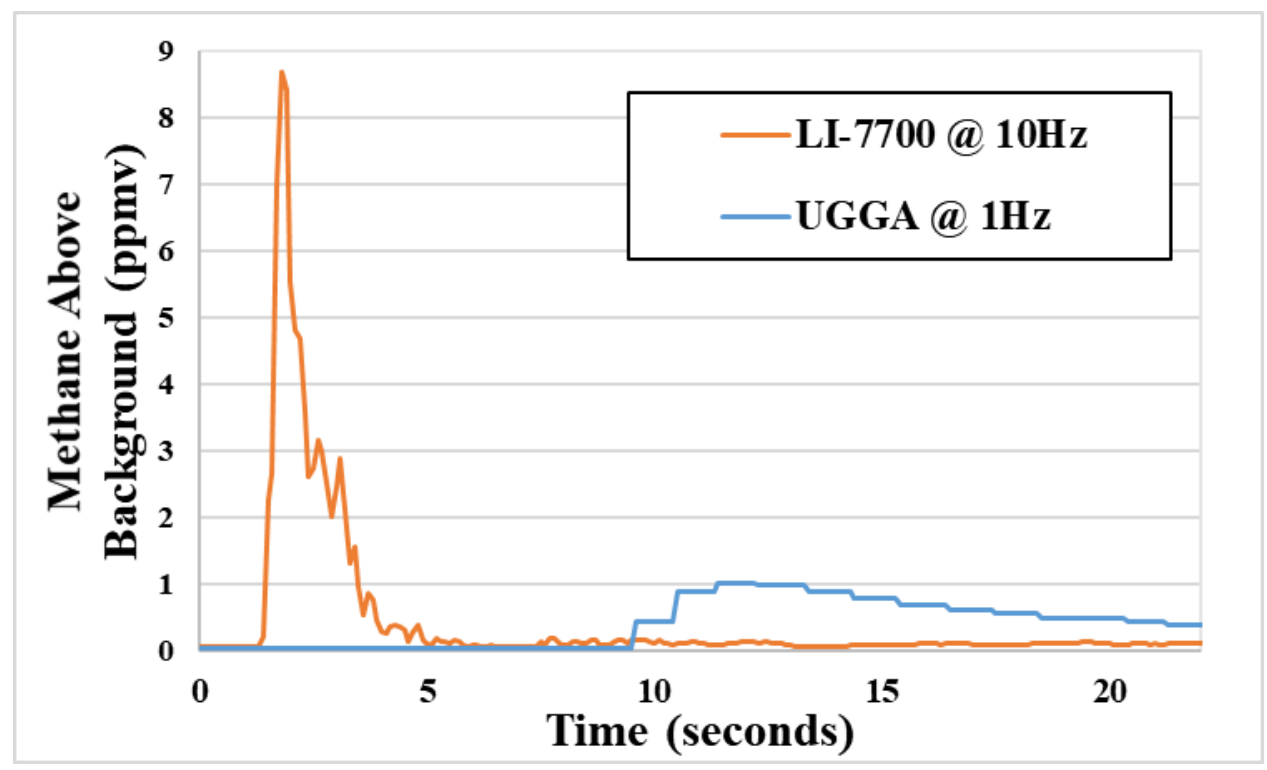

\section{Figure 12: Contiguous Methane Concentrations of LI-7700 and UGGA in Time During Initial Results.}

This introduced a peak error and plume integration error. The peak error was the difference in peak methane concentrations. The plume integration error was the integrated amount of methane over the entire trip (i.e. the area under a methane versus distance or methane versus time curve). Both errors were significant in determining the analyzer's accuracy. To determine the response time of the UGGA, laboratory testing was required.

\subsection{Numerical Results}

Apparent from the visual interpretations of the LI-7700 and UGGA's responses during operation, the UGGA required a time delay correction prior to any statistical comparison due to its sampling method. Once the time shift was applied, a PV was established to compare the analyzer responses.

\subsubsection{Sampling delay}

Using the same external $4.78 \mathrm{~m}$ length and $3.175 \mathrm{~mm}$ internal diameter line from field testing, along with the internal $1.12 \mathrm{~m}$ length line and $3.175 \mathrm{~mm}$ internal diameter line inside the UGGA, the sampling delay of the line was calculated to be 5.6 seconds for a constant sample rate of $0.5 \mathrm{slpm}$. The calculation of the delay assumed no flow loss through the lines. However, the exact dimensions of all fittings and 
connections were not easily quantified, so the time delay was measured experimentally to ensure accuracy.

The UGGA was exposed to a concentration of methane for a length of time using a valve. The UGGA was allowed to return to a background value between tests. With the knowledge of the valve opening time, the delay time of the UGGA was measured. Each methane concentration duration at its respective concentration was separated into individual files. Files for each of the $101.3 \mathrm{ppmv}$ and $50.65 \mathrm{ppmv}$ concentrations were processed using $\operatorname{MATLAB}^{\odot}$. The impulse responses for both concentrations are shown in Figures 13 and 14. Both concentrations of methane illustrated the same delay time of about 9 seconds that concurred with the delay shown in Figures 10, 11 and 12. The method assumed no loss of flow through the lines. In addition, the time calculated was the time to reach the cell and did not include the response time of the UGGA. Note that delay was limited to an integer value due to the sampling frequency of $1 \mathrm{~Hz}$. The small stagger in the impulse responses was associated with the calibration of the UGGA.

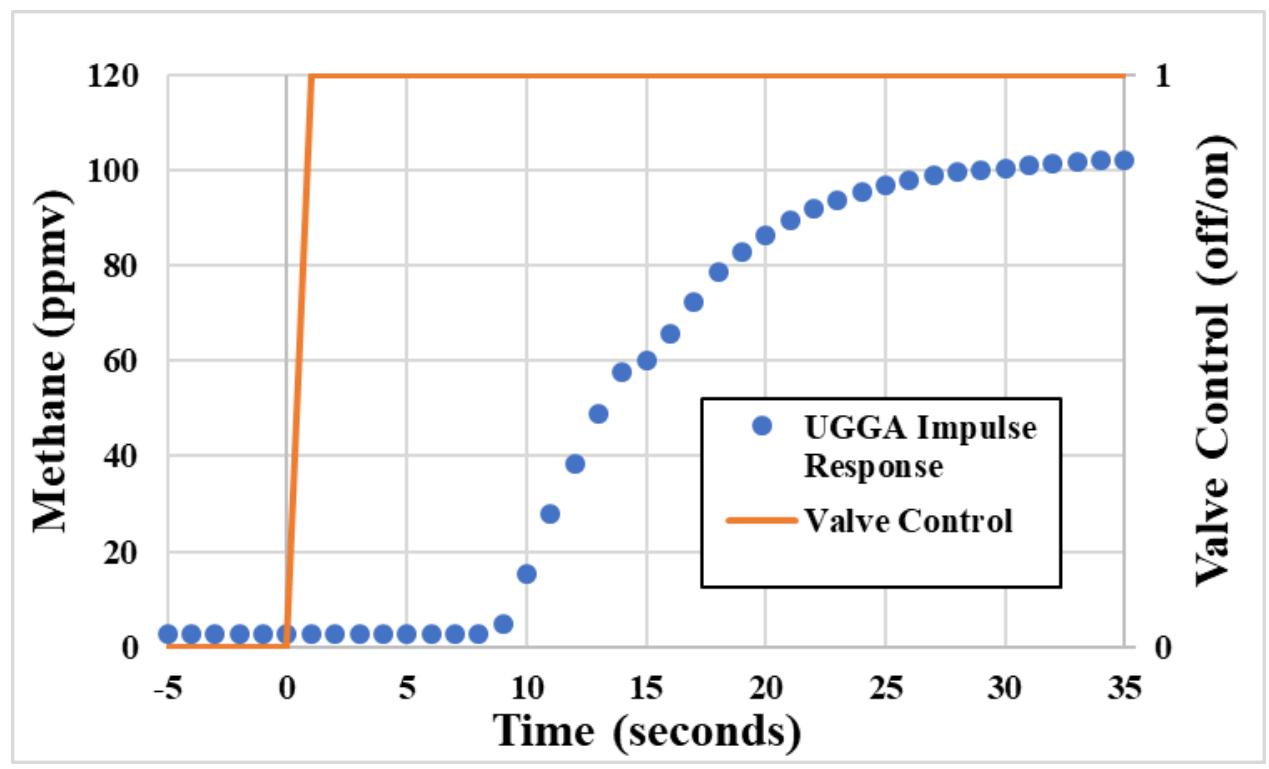

Figure 13: Impulse Response of the UGGA with 101.3 ppmv Methane. Note: 1 indicates the valve is on and 0 indicates the valve is off. 


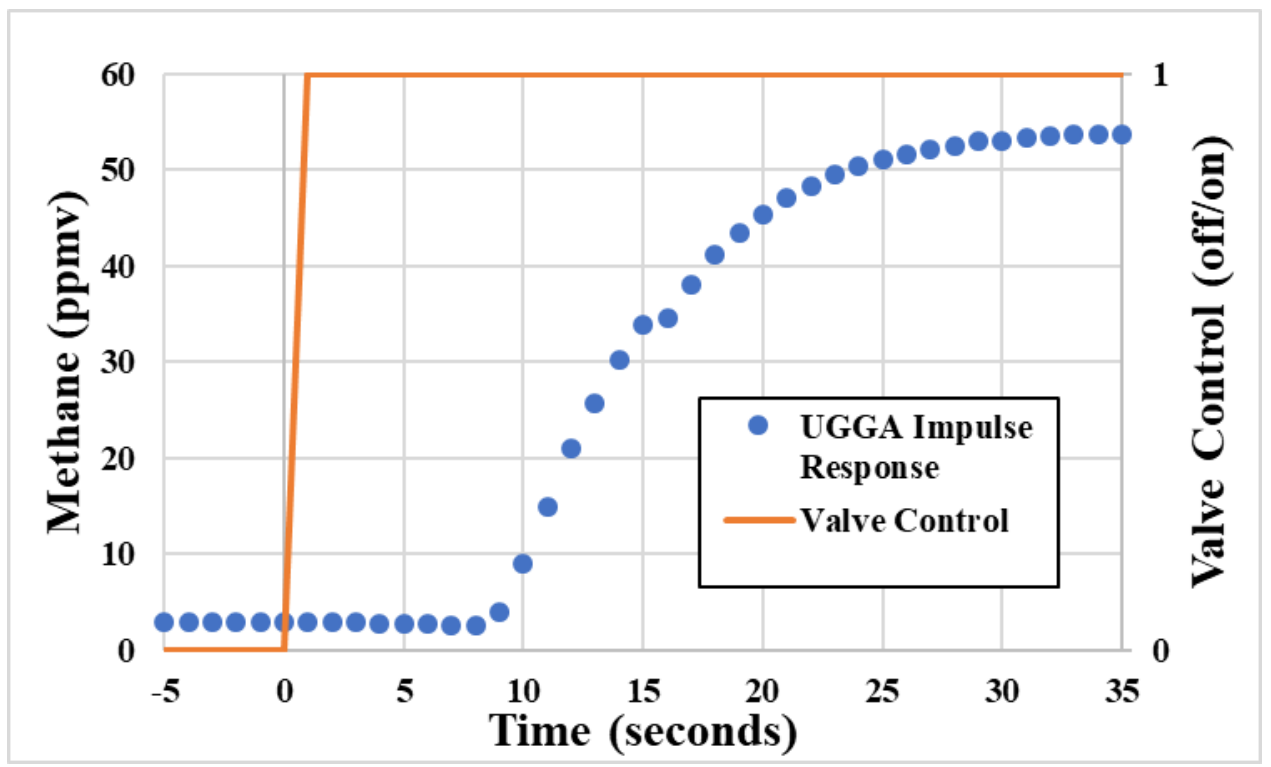

Figure 14: Impulse Response of the UGGA with 50.65 ppmv Methane. Note: 1 indicates the valve is on and 0 indicates the valve is off.

\subsubsection{Methane Distribution}

Assuming the lowest 5\% of methane was background for both the UGGA and LI-7700, any points above background indicated a potential methane plume. Figure 15 displays the frequency of methane concentration during all 12 hours of moving data on a log scale. The LI-7700 reported $89 \%$ of its methane concentrations below 3 ppmv at both 10 and $1 \mathrm{~Hz}$. The UGGA reported $79 \%$ of its methane concentration below 3 ppmv. 


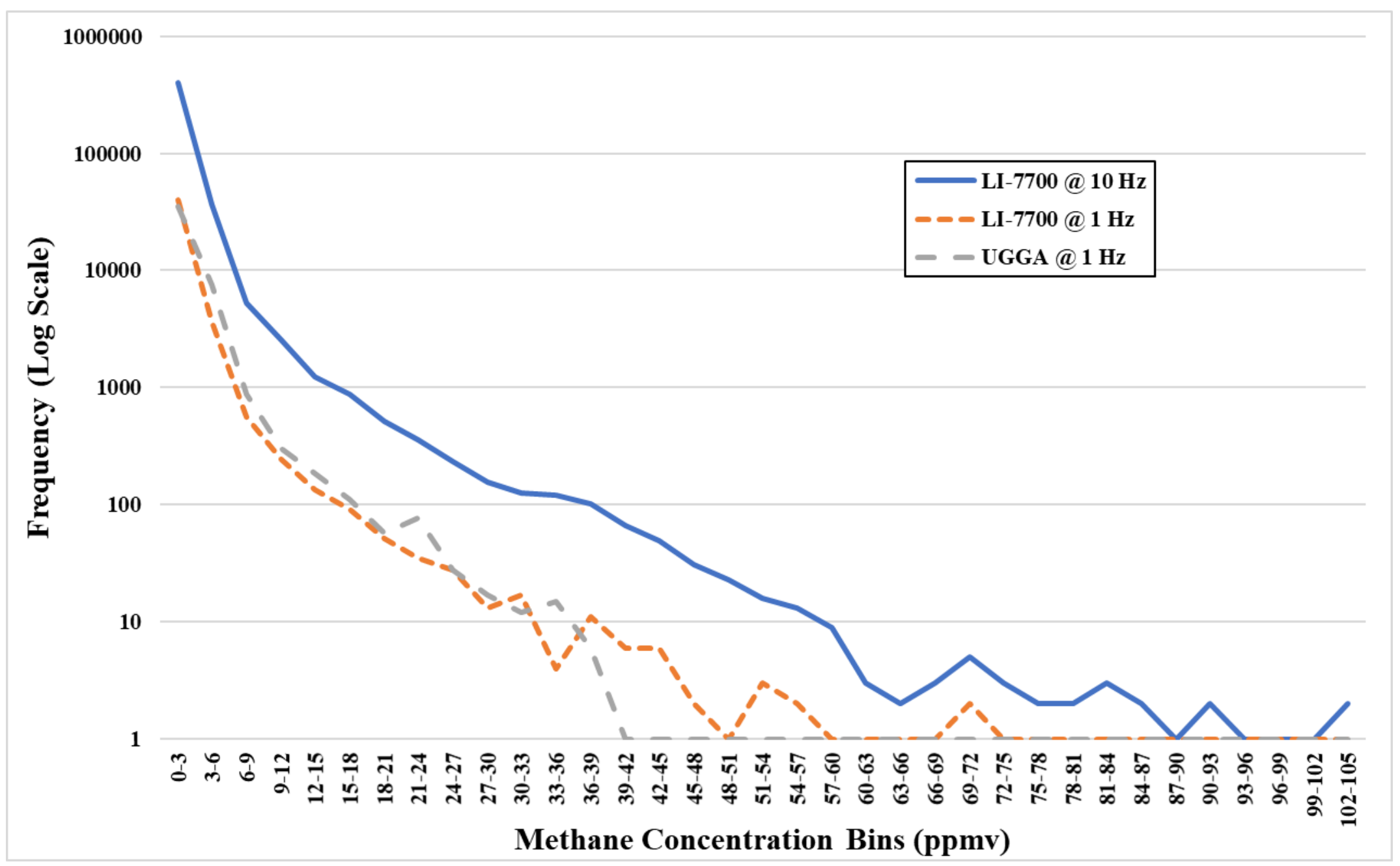

Figure 15: The Distribution of Methane Concentration for all Moving Data. Note: The total number of samples was 444,991 for $10 \mathrm{~Hz}$ LI7700 and 44,556 for $1 \mathrm{~Hz}$ LI-7700 and UGGA. 


\subsubsection{Define Initial Performance Value}

The comparison between the LI-7700 and the UGGA required a PV to conduct statistical comparisons. Prior to implementing the PV, normalization of the signals was performed. Using the normalized methane signals, a PV was defined and assigned for each initial trip file.

\subsubsection{Normalization}

Time alignment and normalization were required prior to the implementation of a PV. Laboratory flow testing of the UGGA quantified the sample delay time. Because each analyzer reported a different background due to their varying calibrations, the normalization corrected each analyzer to its own respective background. With the methane time aligned, a normalization was applied as shown:

$$
\begin{aligned}
& U G G A_{\text {norm }}(t)=\left(U G G A(t)-U G G A_{\text {Background }}\right) /\left(\max (L I 7700)-L_{17700} \text { Background }\right)
\end{aligned}
$$

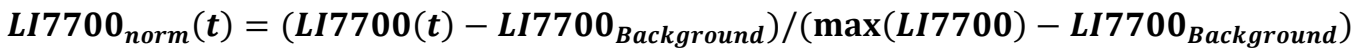

where $t$ is the time in the signal, $U G G A_{\text {norm }}(t)$ and $L I 770_{\text {norm }}(t)$ are the new normalized signals of the UGGA and LI-7700, UGGA(t) and LI7700(t) are the original signals of the UGGA and LI-7700, $U G G A_{\text {Background }}$ and $L I 7700_{\text {Background }}$ are the background threshold value of the UGGA and LI-7700, and $\max (U G G A, L I 7700)$ is the maximum methane concentration between either the UGGA's or LI-7700's signal. Figure 16 displays the normalized version of the methane plume in Figures 10, 11, and 12. This normalization corrected both signals by removing their respective background thresholds and dividing based on the maximum of the LI-7700's methane signal. All normalized points below 0.01 were considered background to remove methane concentrations near the background threshold. 


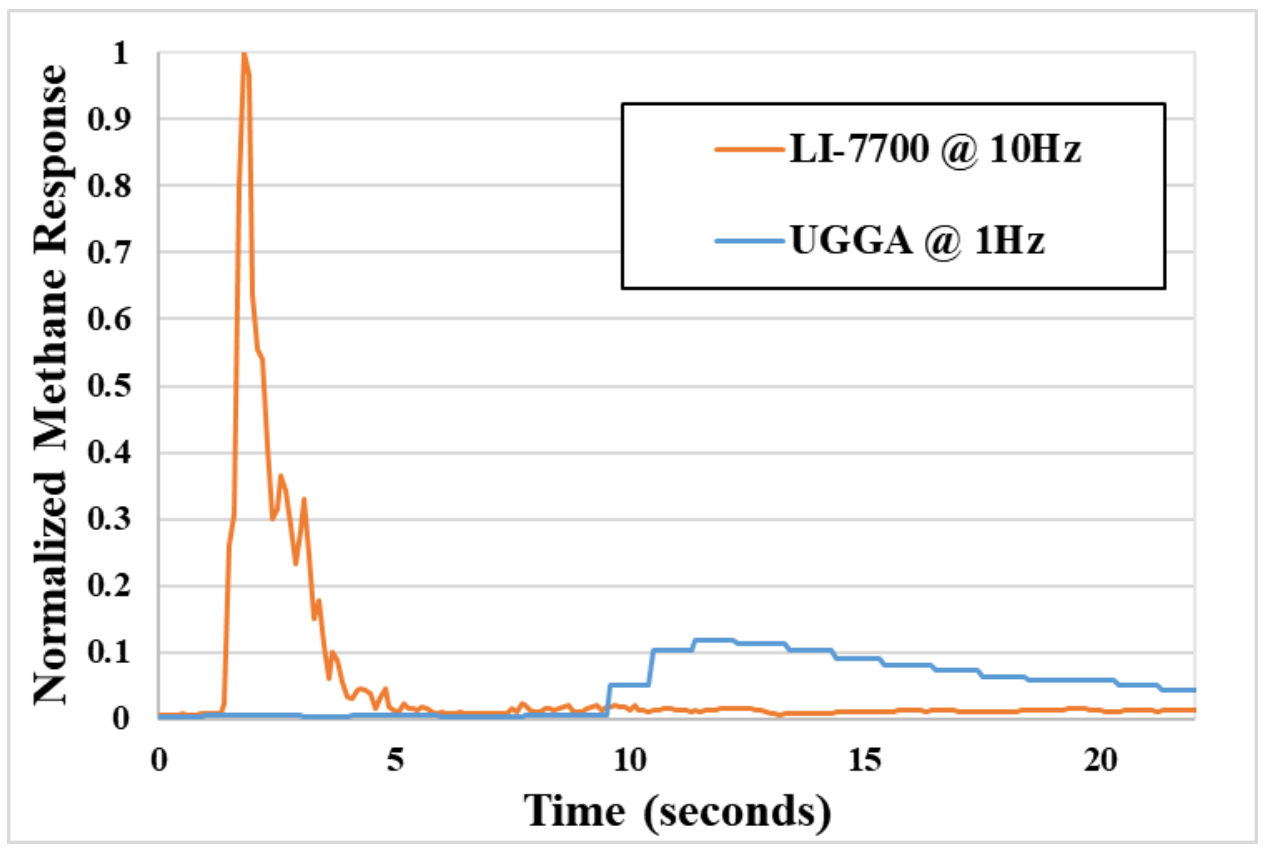

Figure 16: A Normalized Response of the Same Methane Plume by the LI-7700 and the UGGA. Note: The methane responses were time aligned prior to normalization.

\subsubsection{PV Definition}

In order to compare the differences between the UGGA's and LI-7700's normalized methane responses, a performance value (PV) was created for each trip file. The PV quantified the correlation between the UGGA and the LI-7700's signal. The implementation of the normalized methane responses bounded the PV between zero and one. A PV of one indicated that the UGGA perfectly matched the LI-7700's methane response. Four metrics were combined to create a single PV. The PV was defined as:

$$
P V=W_{P E} *(1-P E)+W_{R 2} * r^{2}+W_{S E E} *(1-S E E)+W_{P I E} *(1-P I E)+
$$

Where $P E$ is the peak error, $r^{2}$ is coefficient of determination, $S E E$ is the standard estimate of the error, PIE is the plume integration error, and $W$ is the weight of each component.

The peak error (PE) was the average of the percent error of the peak of each plume given by Equation 12: 


$$
P E=\frac{\sum_{i=1}^{n} \frac{\left|\max (U(S(i): E(i)))-\max \left(U_{U G G A}(S(i): E(i))\right)\right|}{\max (U(S(i): E(i)))}}{n}
$$

where $n$ is number of plumes, $i$ is the ith plume, $U(S(i): E(i))$ is the LI-7700 concentration between the start and end of the plume, and $U_{U G G A}(S(i): E(i))$ is the concentration between the start and end of the plume. A plume was defined as contiguous elevated methane concentrations with five seconds of background between each plume. A peak was the maximum methane concentration in a given plume. By using the maximum value, PE compared the true maximums of each interval. Five seconds of background between each range allowed the LI-7700 to fluctuate without starting a new interval. Peaks that were not perfectly time aligned were credited despite inaccurate location. A PE of zero indicated perfect peak matching.

The coefficient of determination $\left(\mathrm{r}^{2}\right)$ served as a measure to quantify the variance between the two variables. In this application, $\mathrm{r}^{2}$ quantified the variance between the LI-7700 and the UGGA's normalized methane responses. The $\mathrm{r}^{2}$ was calculated by squaring the linear correlation coefficient. An $\mathrm{r}^{2}$ of zero indicated that there was not a linear association between the methane responses and an $\mathrm{r}^{2}$ of one indicated a perfect linear association between methane responses.

The standard error of the estimate (SEE) was the calculation of combined error from each point as given by Equation 13:

$$
S E E=\sqrt{\frac{\sum_{t=1}^{n}\left(U(t)-U_{U G G A}(t)\right)^{2}}{n}}
$$

where $n$ is the number of points in the data file, $t$ is the current time step, $U(t)$ is the LI-7700's signal at the point $t$, and $U_{U G G A}(t)$ is the UGGA's signal at the point $t$. The SEE included an implementation of the squaring of the difference, or sum squared error, creating only non-negative numbers. This was useful for determining magnitude of error but not direction of error. Any exact responses from the LI-7700 and UGGA resulted in a SEE of zero. 
The plume integration error (PIE) was percent error of integrated signals. The integration was the total amount of methane reported across the entire data file. PIE is given by Equation 14.

$$
P I E=\left|\frac{\int U(t)-\int U_{U G G A}(t)}{\int U(t)}\right|
$$

where $\int U(t)$ is the integrated LI-7700 signal, and $\int U_{U G G A}(t)$ is the integrated UGGA signal. The PIE term accounted for the total amount of methane in the data file but did not account for when the methane plume occurred in the data file.

The normalization of the methane signals for the use of PV required the implementation of varying weights between each PV component. To calculate the weights for each component, the variance of each component in the initial data was used to determine the weight for each component. Each component's weight was its variance divided by the sum of all the variances, which limited the PV calculation from zero to one. Variance in each PV component was selected to attribute a higher weight to components that had higher variance between each trip file.

\subsubsection{Initial PV Statistics}

Prior to comparisons, the LI-7700 was down sampled to $1 \mathrm{~Hz}$ using a forward average to match the UGGA. In addition, the four PV components were calculated for each trip file to determine the associated weights from the variances. Table 3 depicts a statistical breakdown of the 43 trip files including the average, variance, maximum, minimum, and each associated weight of each component of the PV. The SEE and PIE were shown to be $1 \%$ and $11 \%$ of the total variance, respectively. The lower variance led to lower weighting in the PV calculation. Using the calculated weights, the average, variance, maximum, and minimum of the PV was calculated and is shown in Table 3. Appendix IV contains all the PVs and their components along with the maximum methane concentration from each methane analyzer for each trip file. Table 3 shows that peak error was the largest source of variance between the data, which was of significant concern since methane peaks were one of the most common methods to detect a potential source of methane in other research programs $[14,16,24]$. 
Table 3: Statistical Breakdown of the PV and PV Components of the Initial Data.

\begin{tabular}{|c|c|c|c|c|c|}
\hline & PE & $\mathbf{r}^{\mathbf{2}}$ & SEE & PIE & PV \\
\hline AVG & 0.602 & 0.544 & 0.070 & 0.083 & 0.512 \\
\hline VAR & 0.061 & 0.040 & 0.001 & 0.013 & 0.030 \\
\hline W & 0.53 & 0.35 & 0.01 & 0.11 & \\
\hline MAX & 0.953 & 0.981 & 0.136 & 0.500 & 0.939 \\
\hline MIN & 0.071 & 0.274 & 0.017 & 0.003 & 0.217 \\
\hline
\end{tabular}

For a further breakdown, Figure 17 depicts the contribution distribution of the PV components. The SEE and PIE were shown to contribute at least 0.9 during over $79 \%$ and $86 \%$ of the trip files, respectively. Equally weighted PV components would have skewed the PV to high values due to the distribution of SEE and PIE.

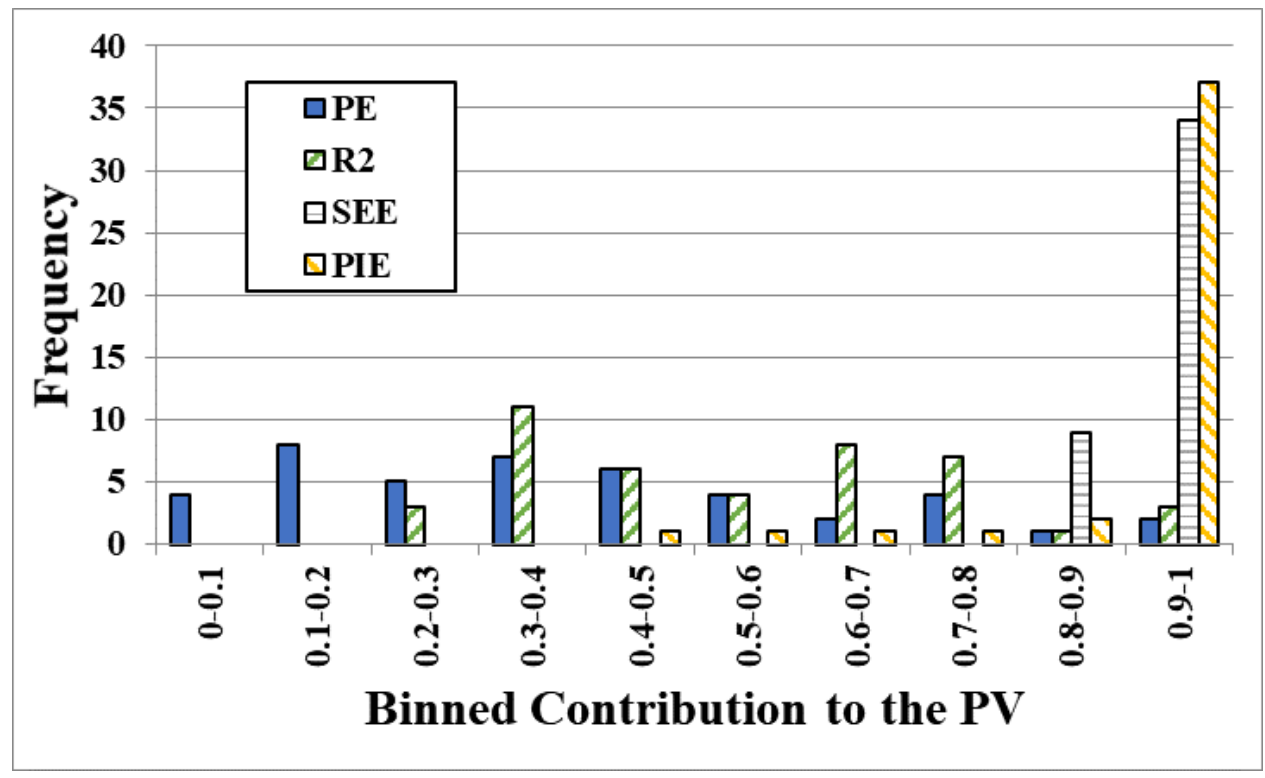

Figure 17: Distribution of each PV Component Contribution from the Initial Data Set. Note: The total number of each component value was 43.

\subsubsection{Methane Detection using the Initial Threshold}

To detect elevated levels of methane, the detection threshold of 3 ppmv was implemented with initial data after the UGGA's background was zeroed to the LI-7700's background. These plumes were defined as contiguous methane concentrations above the background threshold and were separated by five seconds 
of background concentration between plumes. During data collection, a plume of methane was detected 363 times. Of the 363 sections, the LI-7700 at $10 \mathrm{~Hz}$ recorded above the 3 ppmv detection threshold in 112 plumes. Compared to the LI-7700 at $10 \mathrm{~Hz}$, the UGGA reported zero false positive plumes. A false positive plume was denoted as a plume where the UGGA detected a peak and the LI-7700 did not detect a peak above the detection threshold. The UGGA reported 45 false negative plumes. A false negative plume was denoted as a plume where the UGGA did not report a methane peak but the LI-7700 reported a peak methane concentration above the detection threshold.

When down sampled to $1 \mathrm{~Hz}$, the LI-7700 reported above the threshold 97 times. Compared to the LI7700 at $1 \mathrm{~Hz}$, the UGGA reported 0 false positives and 30 false negatives. The detection threshold failures did not account for the error associated between the peak concentrations. It was theorized that the false negatives reported by the UGGA were associated with small width, low methane concentrations whereby the smearing effect associated with its sampling method, averaged values below the peak threshold. A sensitivity analysis of the threshold quantity was required to determine if the 3 ppmv detection threshold reduced uncertainty in methane detection.

\subsection{Sampling Issues}

Using the initial data, it was shown that time alignment alone did not correct the UGGA to match the LI7700. The PVs indicated issues with the UGGA in detecting peak methane concentrations, total methane concentrations, and signal matching. As shown, the UGGA's sampling method created a smearing effect in the methane signal, associated with diffusion in the cell.

The UGGA's advantages for its closed cell operation were diminished with a misrepresented signal. An accurate UGGA signal with time correction did not experience the weather, mounting, and range concerns of the LI-7700. To determine the sampling implications of using each system, the limitations due to sampling frequency, the methane analyzer's operational principles, and vehicle speed were further examined. 


\section{Sampling Limitations}

A closer investigation into sampling limitations was conducted. This included geospatial, wind, and peak limitations associated with the sampling methods and frequencies of the methane detection systems. The collective limitations were observed to determine if any corrections were required for either methane detection systems.

\subsection{Geospatial Limitations}

Geospatial limitations were a concern when combining discrete sampling methods with moving vehicle speeds. The distance between sampling locations of the analyzer as a function of vehicle speed was defined as geospatial resolution (GR). The GR contained the methane sample, but its location occurred within the current and previous sample. With differing sampling frequencies, the LI-7700 and the UGGA experienced different GR in m, which was defined by Equation 15:

$$
\boldsymbol{G R}=\frac{V S_{\text {avg }}}{\omega}
$$

where $V S_{\text {avg }}$ is the average vehicle speed in kilometers per hour $(\mathrm{kph})$, and $\omega$ is the sampling frequency in Hz. Figure 18 displays the GR of the LI-7700 and UGGA as a function of vehicle speed. Time alignment did not affect the GR, but time alignment did affect the error or uncertainty in geospatial location. Geospatial location error (GLE) was the distance between the sample being encountered and the analyzer's recorded response. GLE, as a function of GR, is:

$$
G L E=G R *\left(t_{\text {delay }}+t_{\text {response }}\right)
$$

where $t_{\text {delay }}$ is the delay time and $t_{\text {response }}$ is the response time of the analyzer. Because of its closed-path operation, the UGGA's GLE experienced a sampling and response delay. The LI-7700 did not experience the delay time due to its open-path sampling method. With time alignment, the GLE of the UGGA was reduced to the response time within the cell. 


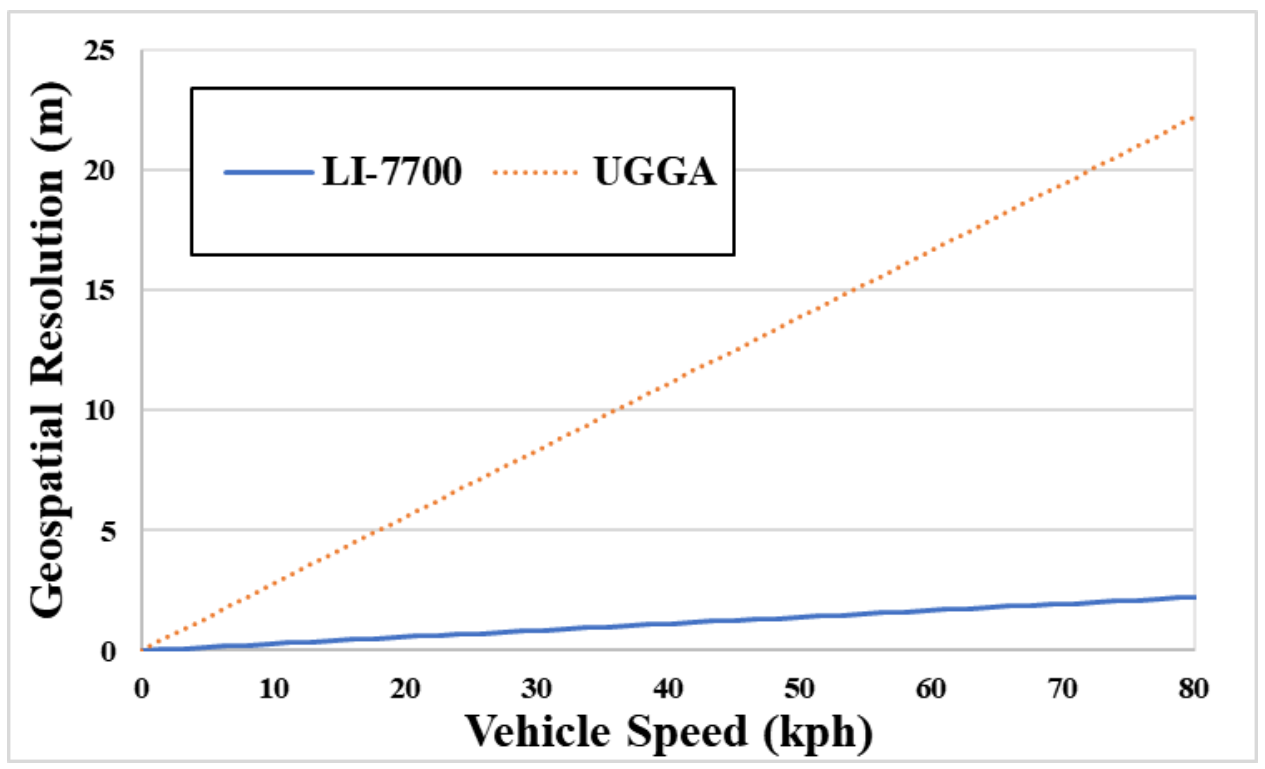

Figure 18: Geospatial Resolution of the LI-7700 at $10 \mathrm{~Hz}$ and the Time Aligned UGGA at $1 \mathrm{~Hz}$. Implementation of closed-path methane analyzers in mobile methane detection applications required a time delay correction to reduce GLE to only be a function of response time. A speed limit proposed as a function of sampling frequency prevented excessive GR values to time corrected analyzers. A constant speed limit of $36 \mathrm{kph}$ at $1 \mathrm{~Hz}$ resulted in a GR of $10 \mathrm{~m}$. To achieve a GR of $10 \mathrm{~m}$, the speed limit, in kph, as a function of sampling frequency, in $\mathrm{Hz}$, is:

$$
S L_{10}=36 * \omega
$$

Other researchers have implemented closed-path analyzers during driving operations with time corrections. Von Fischer et al. limited their vehicle speed to $70 \mathrm{kph}$ with a methane analyzer sampling at 2 $\mathrm{Hz}$ [24]. Their vehicle speed limit produced a GR of $9.83 \mathrm{~m}$ after they applied a response time correction. Phillips et al. did not impose a speed limit to their Picarro G2112-i, but did correct for the response time of the methane analyzer [14]. The newest version of the Picarro G2112-i has a standard sampling rate of $1 / 2 \mathrm{~Hz}$ [85]. A vehicle speed limit of $18 \mathrm{kph}$ would be required to maintain a GR of $10 \mathrm{~m}$. Eapi et al. imposed a speed limit of $20 \mathrm{mph}$, or $32.19 \mathrm{kph}$, while implementing a Picarro G2204 with a sampling frequency of $1 / 3 \mathrm{~Hz}$ [16]. The GR of using the Picarro G2204 at $32.19 \mathrm{kph}$ was $26.82 \mathrm{~m}$. 
The geospatial limitations associated with sampling methods and frequencies was shown to impact the sampling distance between points. To reduce the GR distance to $10 \mathrm{~m}$, a speed limit as a function of sampling frequency should be employed.

\subsection{Wind Speed Limitations}

While the goal of this research was to assess system implications for methane mapping, others seek to include source attribution as a capability. Methane plumes were created from atmospheric diffusion and downwind advection. If a wind direction can be accurately determined, attribution may be possible. However, the effects of driving the vehicle may reduce this capability since atmospheric wind speed may be small compared to that induced by vehicle operation. In addition, there was error associated with the measurements of wind speed and vehicle speed (GPS speed error).

\subsubsection{Deriving Wind Speed Limitations}

The sonic anemometers reported wind speed vectors that used the sign of each component to indicate direction and the value to indicate magnitude. The wind speed error was based on the wind components reported by the anemometer. The wind speed error is:

$$
W S_{\sigma}=\sigma_{W S} * \sqrt{U^{2}+V^{2}+W^{2}}
$$

where $\sigma_{W S}$ is the error of the anemometer, $U$ is the wind speed component from the north and south direction $V$ is the east and west wind component, and $W$ is the vertical wind component, if available. Recall, the north direction was aligned to the front of the vehicle. Because the error was based on the reported wind speed, high vehicle speeds increased the wind speed error.

As vehicle speeds increased, the $W$ approached zero. If the WindMaster was outside the wake zone, then the WindMaster reported an angle of attack of near zero relative to the center of the anemometer. The angle of attack was the angle between of the vertical wind component and the vehicle north wind component. There are naturally small vertical wind components created from turbulent eddies within the 
boundary layer. By including a 3D anemometer, one can compare these eddies to the upward wind component to ensure that the sampling components are placed outside of the vehicle wake zone.

To calculate the wind direction, the $U$ component must be corrected for vehicle speed. The corrected wind speed is:

$$
U_{\text {corr }}=U-V s
$$

where $V s$ is the vehicle speed as reported by the GPS units. Due to the sonic anemometer and GPS containing errors in reporting, the corrected vehicle north wind speed with error is:

$$
U_{c o r r, \sigma}=(U-V S) \pm \sqrt{W S_{\sigma}^{2}+\sigma_{G P S}^{2}}
$$

where $\sigma_{G P S}$ is the error of the GPS's vehicle speed calculation. The corrected north wind speed component contained a range of potential values due to the uncertainty associated with error propagation. The points in time where wind direction cannot be determined are based on the limiting equations:

$$
\begin{array}{r}
|(U-V S)| \leq \sqrt{W S_{\sigma}^{2}+\sigma_{G P S}{ }^{2}} \\
|V| \leq \sigma_{W S} * \sqrt{U^{2}+V^{2}}
\end{array}
$$

The limiting equation did not describe the magnitude of the wind direction range, but only determined wind with a directional range that contained two quadrants. Figure 19 displays a compass rose with each quadrant occurring every $90^{\circ}$ and the sign that corresponds to each wind direction. For example, if the sonic anemometer reports a wind from the south-east and Equation 21 holds, then the wind could originate from either the south-east or north-east. Note that if the wind speed error was larger than the east and west wind direction, then the east and west direction cannot be determined. To determine cases where wind direction cannot be estimated, each component in both systems was further analyzed. 


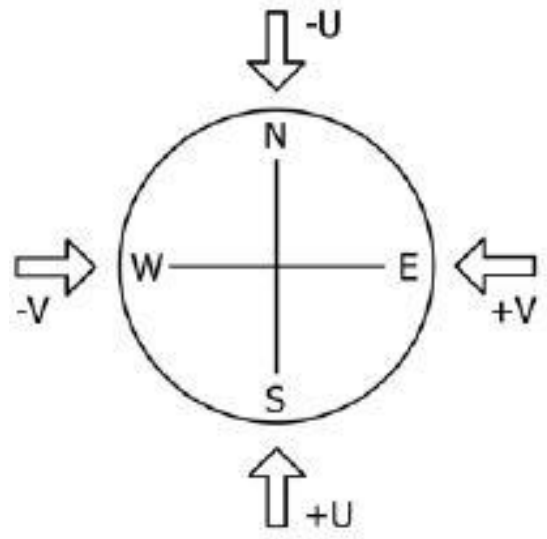

Figure 19: Compass Rose for Wind Direction with Wind Components Corresponding to Direction [78].

\subsubsection{Fast System}

The fast system consisted of the WindMaster and the U-Blox EVK-M8U. Both recording at $10 \mathrm{~Hz}$, the WindMaster and U-Blox EVK-M8U were paired with the LI-7700 for methane detection. The WindMaster had an error of $1.5 \%$ between $0-30 \mathrm{~m} / \mathrm{s}$ of wind [76]. The EVK-M8U had a constant speed error of $0.5 \mathrm{~m} / \mathrm{s}$ [77]. With $\sigma_{W S}=0.015$ and at moving speeds, the limiting equation is:

$$
|(U-V s)| \leq \sqrt{\left(0.015 * \sqrt{U^{2}+V^{2}}\right)^{2}+0.5^{2}}
$$

Moving speeds were defined as all values above the GPS vehicle speed error. Equation 21 held true for $20.5 \%$ of moving operation and Equation 22 held true for $16.4 \%$ of moving operation. When both rules were applied, the general wind direction quadrant could not be determined in $33.9 \%$ of the moving data for the fast system.

\subsubsection{Slow System}

The slow system consisted of the WindSonic and the BU-353S4. Both recording at $1 \mathrm{~Hz}$, the WindSonic and BU-353S4 were paired with the UGGA for methane detection. The WindSonic had an error of 2\% [78]. The BU-353S4 had a constant speed error of $0.1 \mathrm{~m} / \mathrm{s}$ [79]. In this case, $\sigma_{W S}=0.02$ and $\sigma_{G P S}=0.1$. With $\sigma_{W S}=0.02$ and at moving speeds, the limiting equation is: 


$$
|(U-V s)| \leq \sqrt{\left(0.02 * \sqrt{U^{2}+V^{2}}\right)^{2}+0.1^{2}}
$$

Equation 21 held true for $19.7 \%$ of moving operation and Equation 22 held true for $3.5 \%$ of operation. The slow system had fewer points that violated the limiting equation than the fast system due in part to the higher accuracy of the slower GPS unit. When both rules were applied, the general wind direction quadrant could not be determined in $22.6 \%$ of the moving data from the slow system.

\subsubsection{Wind Limitations}

The fast system and the slow system were observed collectively to determine rules for operation. Figure 20 displays the points that violated the limiting equation for both the fast and slow system. The wind direction was still able to be estimated for $66.1 \%$ and $77.4 \%$ of the data for the fast and slow systems, respectively. Prior to processing data, no rules for reducing errors can be inferred; however, because wind speed error increased as vehicle speed increased, the minimum required wind speed in the north direction increased as vehicle speed increased.

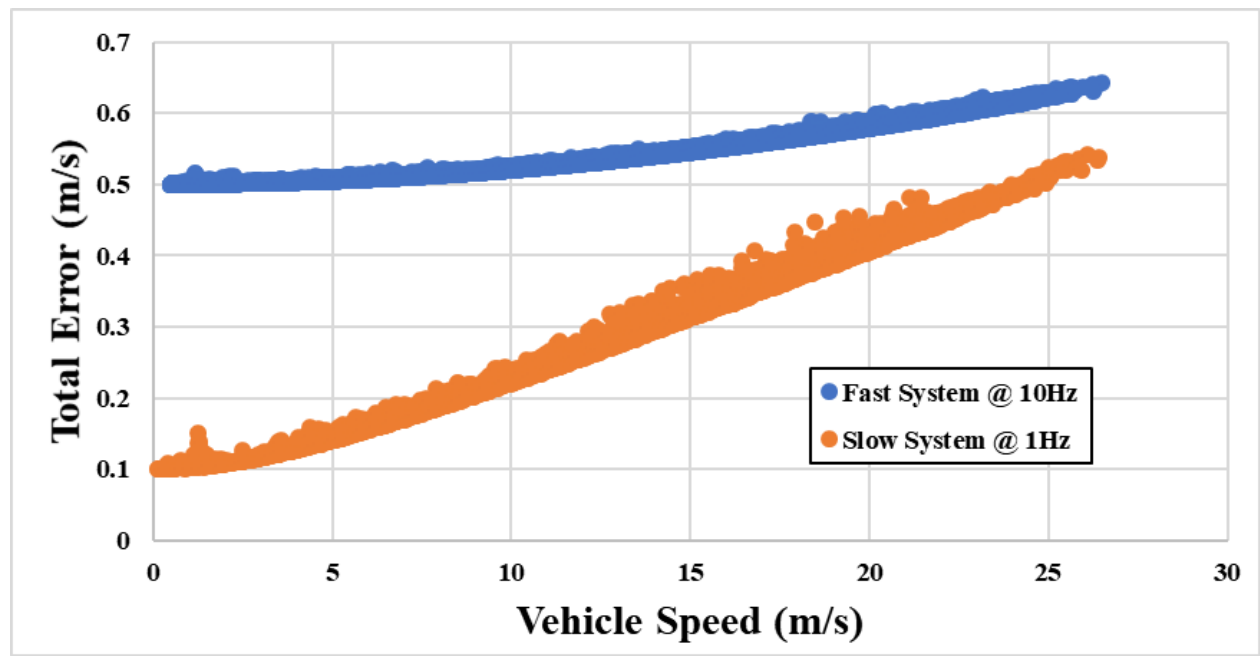

Figure 20:Wind Speeds that Violated the Limiting equation as a Function of Vehicle Speed and Total Error. 


\subsection{Peak Limitations}

The peak error associated with the initial PV displayed the UGGA's success at reporting peak methane concentrations. Recall, peak error was the average of the relative errors between the maximum methane concentration reported by each analyzer for the plumes in a trip file. Figure 21 displays 100 seconds of the methane response above the background threshold of each analyzer for a plume in trip 554. Note that the peak UGGA methane response was only $11 \%$ of the LI-7700's peak methane response and the UGGA was not time aligned.

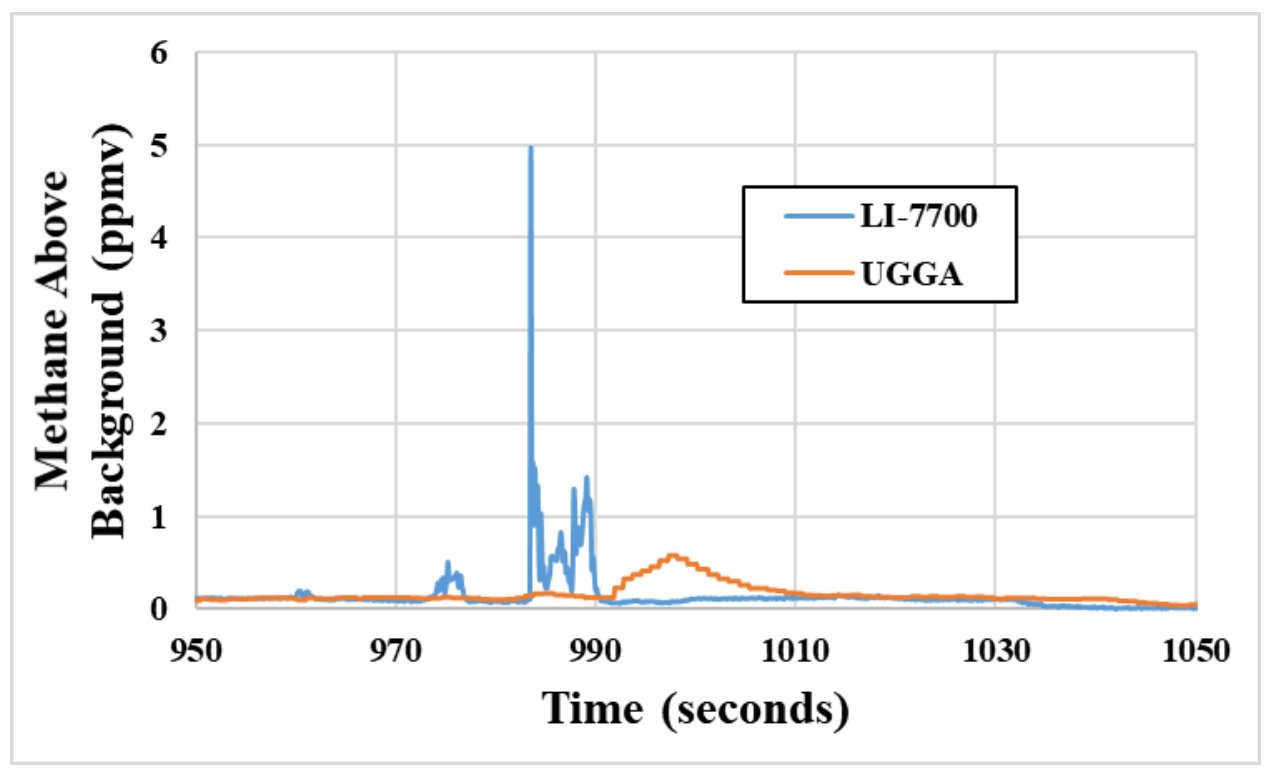

Figure 21: Trip 554, Differences in Peak Values of the LI-7700 and the UGGA.

Because of the differences in the peak values of the LI-7700 and the UGGA, a sensitivity analysis was performed on the detection threshold. There were 363 possible methane plumes identified. These plumes were defined as contiguous methane concentrations above the background threshold and were separated by 5 seconds of background concentration between plumes. Ranging from 2.5 ppmv to $3.5 \mathrm{ppmv}$, the detection threshold was varied to determine if both the LI-7700 and the UGGA indicated the same potential methane sources. Table 4 depicts the sensitivity analysis of the detection threshold using the LI7700's data at both 10 and $1 \mathrm{~Hz}$. Table 4 includes the total number of peaks detected by the LI-7700, the 
false positives and false negatives reported by the UGGA, along with the false positive rate, false negative rate, and false reporting rate. The false positive rate is:

$$
\frac{F P}{T N}
$$

where $F P$ is the number of false positive plumes reported by the UGGA and $T N$ is total negative detection plumes by the LI-7700. The false negatives rate is:

$$
\frac{F N}{T P}
$$

where $F N$ is the number of false negative plumes reported by the UGGA and $T P$ is the number of total positive detection plumes by the LI-7700. The false reporting rate was:

$$
\frac{F N+F P}{T N+T P}
$$

$T N$ and $T P$ represent the total number of plumes.

For the initial 3 ppmv, the UGGA reported a false negative rate of $40.2 \%$ and $30.9 \%$ for 10 and $1 \mathrm{~Hz} \mathrm{LI}-$ 7700 peaks, respectively. Because the UGGA reported no false positives with any detection threshold, the best detection threshold was determined by minimizing the false negative rate. The best detection thresholds were $2.7 \mathrm{ppmv}$ for $10 \mathrm{~Hz}$ and $2.6 \mathrm{ppmv}$ for $1 \mathrm{~Hz}$. The best false negative rates were $34.7 \%$ and $24.3 \%$ for the 10 and $1 \mathrm{~Hz}$, respectively. The UGGA reported numerous false negatives that indicated the necessity for a correction to the UGGA to sharpen the diffuse signal.

The peak limitations highlighted the tendency of the UGGA to significantly underreport the peak methane concentration as compared to the LI-7700. The peak error only accounted for the maximum in the range, but Figure 21 depicted local peaks that the UGGA was unable to detect. A change in detection sensitivity can reduce the false negative rate but was not enough to warrant the implementation of the UGGA without an external correction since it would still under report possible methane sources by nearly $25 \%$. 
Table 4: Detection Threshold Sensitivity Analysis of the Initial Data.

\begin{tabular}{|c|c|c|c|c|c|c|c|c|c|c|c|}
\hline Detection Threshold (ppmv) & 2.5 & 2.6 & 2.7 & 2.8 & 2.9 & 3 & 3.1 & 3.2 & 3.3 & 3.4 & 3.5 \\
\hline $\begin{array}{c}\text { LI-7700 Peaks Detected } \\
\text { @ } 10 \mathrm{~Hz}\end{array}$ & 150 & 136 & 124 & 121 & 115 & 112 & 108 & 104 & 103 & 100 & 97 \\
\hline False Positives by UGGA & 0 & 0 & 0 & 0 & 0 & 0 & 0 & 0 & 0 & 0 & 0 \\
\hline False Positive Rate & 0 & 0 & 0 & 0 & 0 & 0 & 0 & 0 & 0 & 0 & 0 \\
\hline False Negatives by UGGA & 56 & 49 & 43 & 44 & 43 & 45 & 43 & 44 & 47 & 46 & 45 \\
\hline False Negative Rate & 0.373 & 0.360 & 0.347 & 0.364 & 0.374 & 0.402 & 0.398 & 0.423 & 0.456 & 0.460 & 0.464 \\
\hline False Reporting Rate & 0.154 & 0.135 & 0.118 & 0.121 & 0.118 & 0.124 & 0.118 & 0.121 & 0.129 & 0.127 & 0.124 \\
\hline Detection Threshold (ppmv) & 2.5 & 2.6 & 2.7 & 2.8 & 2.9 & 3 & 3.1 & 3.2 & 3.3 & 3.4 & 3.5 \\
\hline $\begin{array}{c}\text { LI-7700 Peaks Detected } \\
\text { @ } 1 \mathrm{~Hz}\end{array}$ & 125 & 115 & 109 & 102 & 100 & 97 & 91 & 88 & 85 & 82 & 81 \\
\hline False Positives by UGGA & 0 & 0 & 0 & 0 & 0 & 0 & 0 & 0 & 0 & 0 & 0 \\
\hline False Positive Rate & 0 & 0 & 0 & 0 & 0 & 0 & 0 & 0 & 0 & 0 & 0 \\
\hline False Negatives by UGGA & 31 & 28 & 28 & 25 & 28 & 30 & 26 & 28 & 29 & 28 & 29 \\
\hline False Negative Rate & 0.248 & 0.243 & 0.257 & 0.245 & 0.280 & 0.309 & 0.286 & 0.318 & 0.341 & 0.341 & 0.358 \\
\hline False Reporting Rate & 0.085 & 0.077 & 0.077 & 0.069 & 0.077 & 0.083 & 0.072 & 0.077 & 0.080 & 0.077 & 0.080 \\
\hline
\end{tabular}




\subsection{Sampling Implications}

The geospatial, wind speed, and peak limitations presented guidelines for mobile methane detection applications. The geospatial limitations indicated the necessity for time alignment and a vehicle speed limit based on sampling frequency. The wind speed limitations suggested rules of thumb in order to estimate wind direction of a plume while driving. The peak limitations illustrated the errors in the methane reported by the UGGA. The weather, mounting, and interference drawbacks associated with the open-path LI-7700 could be alleviated with an UGGA, if a method to correct the underreported methane response was applied. To overcome this limitation, signal reconstruction methods were examined to correct the UGGA's signal to recreate a sharpened response. 


\section{Data Processing of Methane Analyzers}

During the detection threshold sensitivity analysis, the UGGA proved it was unable detect the same peaks as the LI-7700. A reconstruction technique with time delay correction was required to correct the UGGA methane response. There exist numerous reconstruction methods and the following were investigated: Sequential Inversion Technique (SIT), Inverse Fast Fourier Transform (IFFT), Artificial Neural Networks (ANN), and the Differential Coefficients Methods (DCM). The results of the UGGA's reconstruction were assessed by comparing relative improvements in the PV for various reconstruction methods and sampling frequencies.

\subsection{Reconstruction Methods and Assessments}

Signal reconstruction was divided into two major categories, forward or backward. Forward reconstruction used the input signal to determine the potential output signal. Ganesan and Clark performed a forward reconstruction with the input signal consisting of vehicle emissions and the output signal consisted of the analyzer output [86]. By comparing the forward reconstruction to the actual analyzer input, the analyzer's response was predicted. Backward reconstruction attempted to recreate the input signal using the analyzer's output signal. All the reconstruction methods observed were backwards reconstructions, as the UGGA's input signal was the desired result.

In order to recreate the UGGA's input signal, the LI-7700 was implemented as the best method of measuring instantaneous methane. Because of the weather, mounting, and interference effects with the LI7700's open-path operation, a corrected UGGA would allow for the removal of the LI-7700 during operation. Prior to reconstruction, the methane signals were time aligned and normalized. Each methods' theory was investigated and applied to determine their potential success for UGGA reconstruction. 


\subsubsection{Sequential Inversion Technique (SIT)}

\subsubsection{Theory}

The SIT was detailed in Madireddy and Clark [87]. There exist coefficients, $C_{j}$, where $j$ ranged from one to the length of the signal. Beginning with an input, $U\left(t_{i}\right)$, and output signal, $Y\left(t_{i}\right)$, where $t_{i}$ is the $i t h$ value in the signal's time, SIT follows the following pattern:

$$
\begin{gathered}
Y(1)=C_{1} * U(1) \\
Y(2)=C_{1} * U(2)+C_{2} * U(1) \\
Y(3)=C_{1} * U(3)+C_{2} * U(2)+C_{3} * U(1)
\end{gathered}
$$

and so on. Expanding the SIT becomes:

$$
\boldsymbol{Y}\left(\boldsymbol{t}_{\boldsymbol{i}}\right)=\boldsymbol{C}_{1} * U\left(\boldsymbol{t}_{i}\right)+C_{2} * U\left(t_{i-1}\right)+C_{3} * U\left(t_{i-2}\right)+\cdots+C_{k} * U\left(t_{i-k+1}\right)
$$

where $i$ is the value in seconds ranging from one to the length of the signals and $k$ is the ith term in the sequence of coefficients. For example, given $U=[3,2,0,1]$ and $\mathrm{Y}=[9,0,5,12]$ results in $\mathrm{C}=[3,-2,3$, 1]. The SIT provides an exact solution for the given input and output signals under the correct conditions.

The SIT began to fail due to two reasons: roundoff error and varying lengths of the two signals. Each concurrent $C_{j}$ uses the previous $C_{j}$ s beginning at $t_{i}=1$. Because $C_{l}$ uses in the determination of all other $C_{j} \mathrm{~s}$, it plays a major role in the error association of too large or small $C_{j} \mathrm{~s}$. If the initial $C_{l}$ is too high or too low, other $C_{j}$ s increase error through values that are too high or low. Madireddy and Clark determined that signal reconstruction began to fail when $C_{l}$ fell below a threshold of 0.137 [87].

Because of the structure of the SIT, the length of the signals impact reconstruction. Madireddy and Clark proved that the reconstruction using SIT began to fail after about 100 seconds due to the compounding of errors [87]. When the coefficients and the signals are different lengths, the SIT requires a filtering or padding method. 


\subsubsection{Application}

Using field data, an individual set of coefficients were created for each data file. With individual creation for each file, the SIT was capable of reconstruction with almost zero error. The coefficients perfectly recreated the file used to derive the coefficients. Down sampling the LI-7700 to $1 \mathrm{~Hz}$ and performing the SIT, Figure 22 depicts the reconstruction of trip 551. The PV of the SIT's reconstruction was one. The only errors associated with SIT were the rounding errors created due to calculation precision.

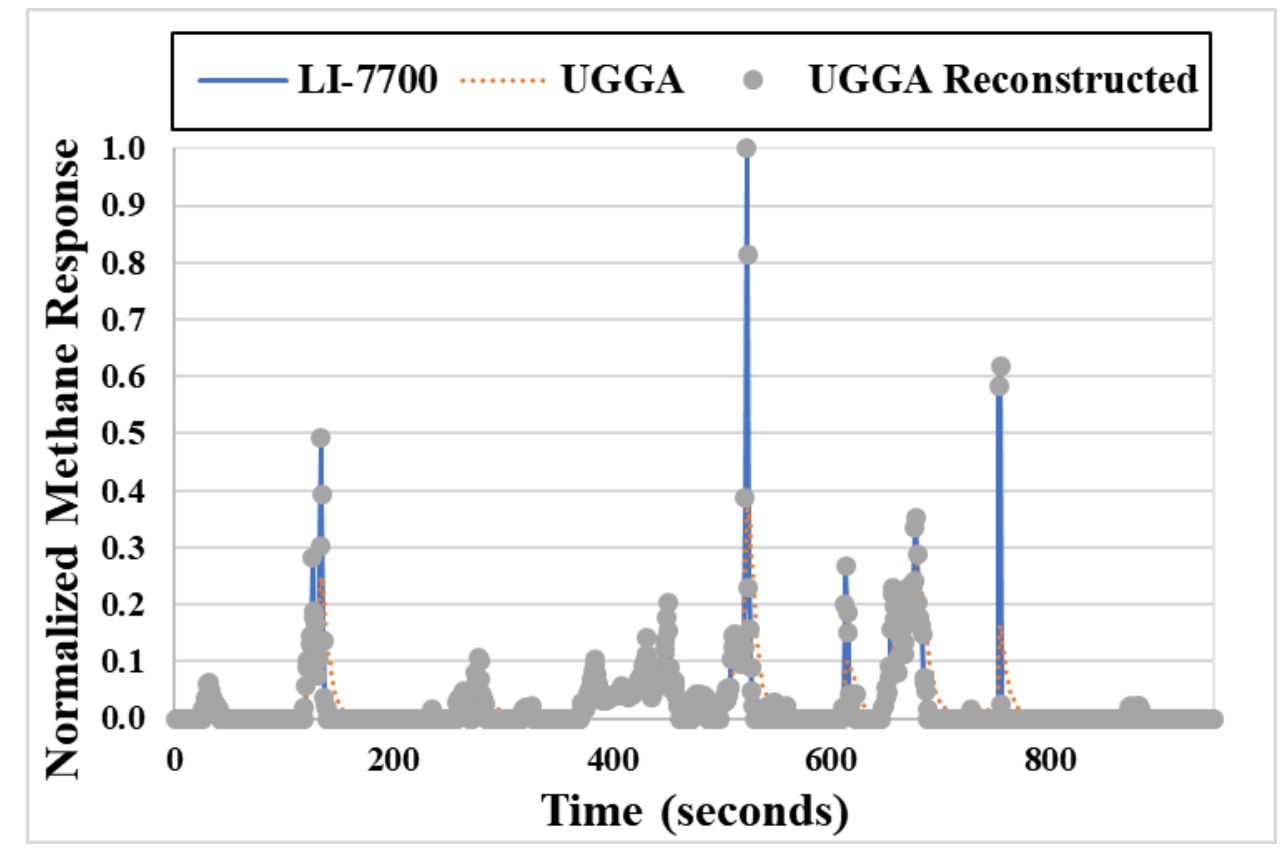

Figure 22: SIT Reconstruction of Trip 551:

$P V=1, P E=0, r^{2}=1, S E E=0, P I E=0$.

In order to remove the LI-7700 from operation, the SIT was applied to other files. Due to varying signal lengths, either the SIT coefficients or the UGGA signal were padded both before and after with zeros to ensure the same signal length. Figure 23 displays a section from the application of trip 551's SIT to trip 554. This resulted in a PV of 0.111 , or a decrease of $73.4 \%$. Due to the zero padding, the SIT reconstruction did not affect over half the trip points. Because of the transient nature of the mobile methane detection, the SIT was not implemented. 


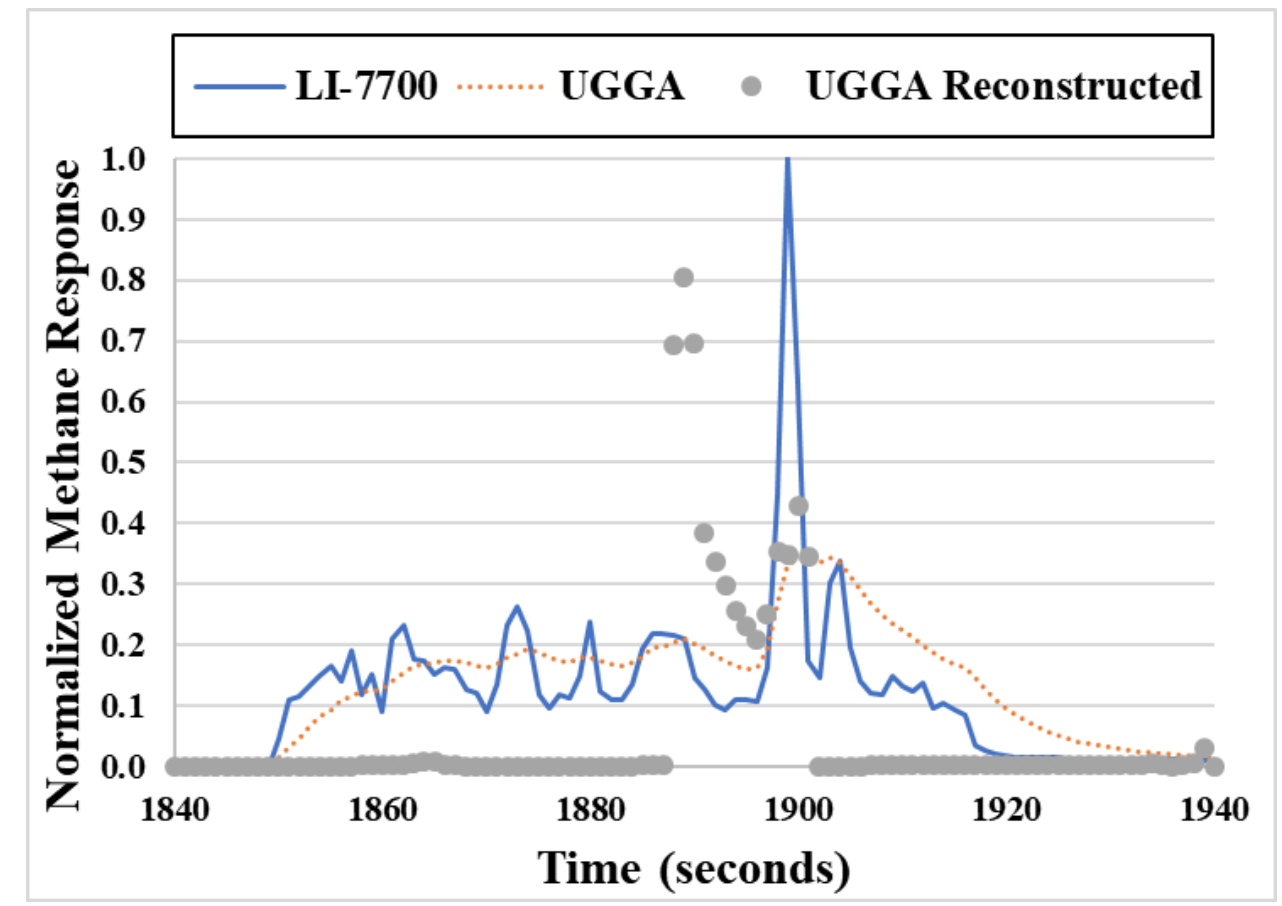

Figure 23: SIT Reconstruction of Trip 554 using Trip 551's SIT: $\mathrm{PV}=0.111, \mathrm{PE}=0.867, \mathrm{r}^{2}=0.018, \mathrm{SEE}=1, \mathrm{PIE}=0.693$.

\subsubsection{Inverse Fast Fourier Transform (IFFT)}

\subsubsection{Theory}

Recall that convolution is the compounding of two signals, the input signal and the impulse response, in the time domain. Convolution in the time domain is the same as multiplication of signals in the frequency domain. Multiplying signals in the frequency domain is simpler than performing convolution in the time domain.

A Fast Fourier Transform (FFT) or IFFT transform the signals from the time domain to the frequency domain or vice versa. The FFT of a signal is the real and the imaginary parts both using: 


$$
\begin{aligned}
& \operatorname{Re} X[k]=\sum_{i=0}^{N-1} x[i] * \cos \left(\frac{2 \pi k i}{N}\right) \\
& \operatorname{Im} X[k]=\sum_{i=0}^{N-1} x[i] * \sin \left(\frac{2 \pi k i}{N}\right)
\end{aligned}
$$

where $X[k]$ is the frequency domain signal with both real and imaginary parts, $x[i]$ is the time domain signal, $N$ is the number of points in $x[i]$, and $\mathrm{k}$ is frequency ranging from one to $N / 2$ [88]. To perform the IFFT in the frequency domain, the signal must be recreated from both the real and imaginary parts:

$$
x[i]=\sum_{k=0}^{N / 2} \operatorname{Re} \bar{X}[k] * \cos \left(\frac{2 \pi k i}{N}\right)+\sum_{i=0}^{N / 2} \operatorname{Im} \bar{X}[k] * \sin \left(\frac{2 \pi k i}{N}\right)
$$

where $\bar{X}[k]$ is the amplitude of the wave of the real or imaginary part [88]. As an example, FFT applied to the signal $[3,2,0,1]$ resulted in the signal $[1.5,0.75+0.25 \mathrm{i}, 0,0.75-0.25 \mathrm{i}]$ in the frequency domain. When the IFFT was applied to the new frequency domain signal, the original $[3,2,0,1]$ was returned. The IFFT method contains two sections, solving for the impulse response and applying the impulse response.

The convolution in the time domain allows for the reconstruction of the output signal. Convolution in the time domain requires the impulse response. The flowchart in Figure 24 displays how to solve for the impulse response. Starting with both an input and output signal, FFT transforms the signals to the frequency domain. The division of the frequency domain input and output signals results in the impulse response in the frequency domain. Performing IFFT on the impulse response in the frequency domain creates the time domain impulse response. 


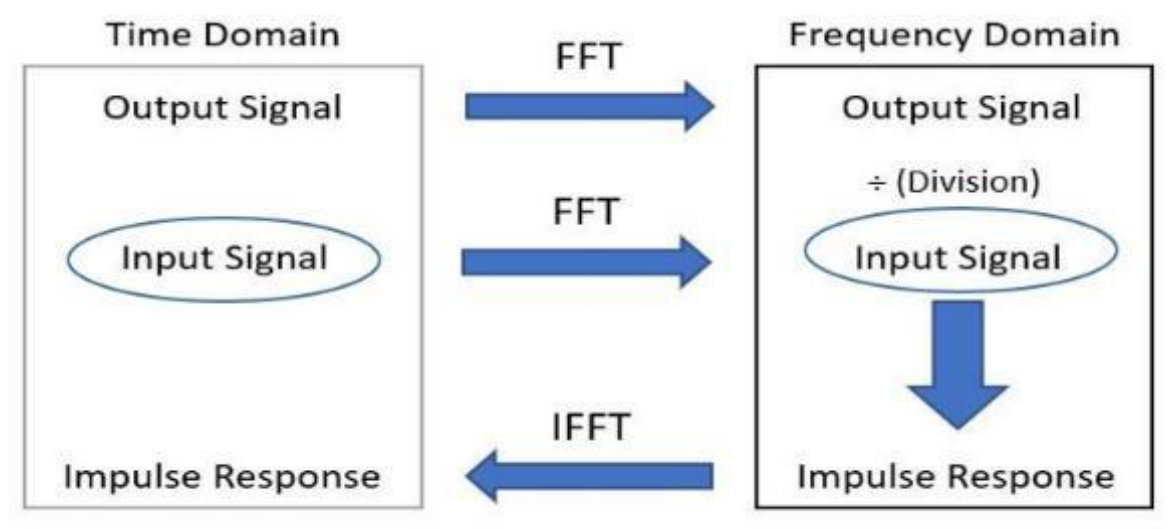

Figure 24: Determination of the Impulse Function from Two Signals.

Figure 25 displays the method to determine the original input using the newly found impulse response. After converting both the output signal and impulse response to the frequency domain, division occurs between the signals. This division solves for the input in the frequency domain. The use of an IFFT results in the original input signal.

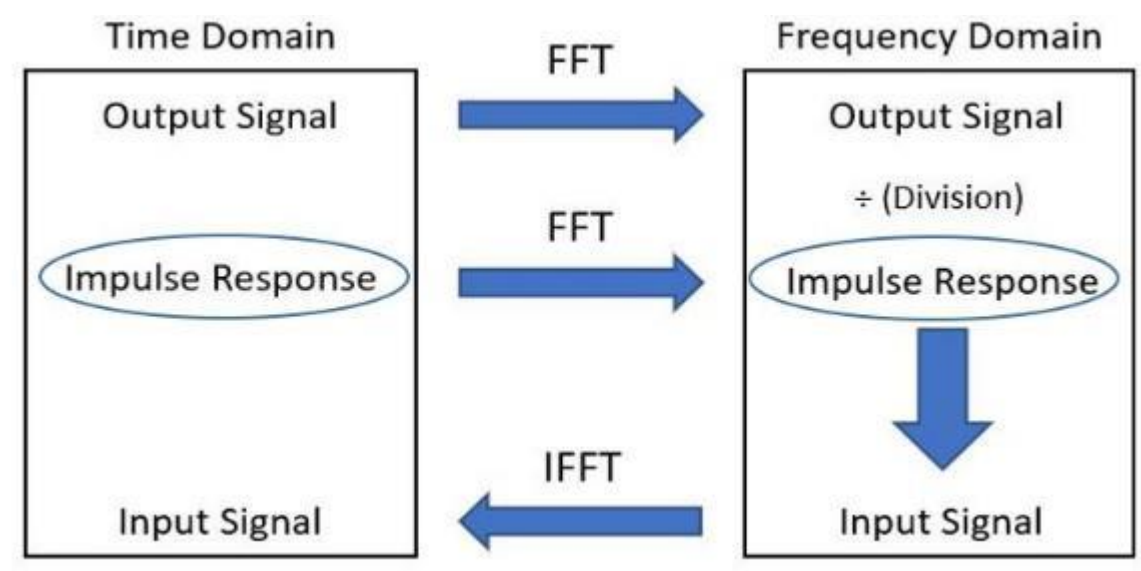

Figure 25: Application of Impulse Response Signal to Create an Input Signal.

\subsubsection{Application}

Using the field data accumulated, an impulse response was created for each data file. With individual creation for each file, the IFFT showed it was capable by reconstructing with almost zero error. Down sampling the LI-7700 and performing the IFFT, Figure 26 depicts the reconstruction of trip 551 which resulted in a PV of one. 


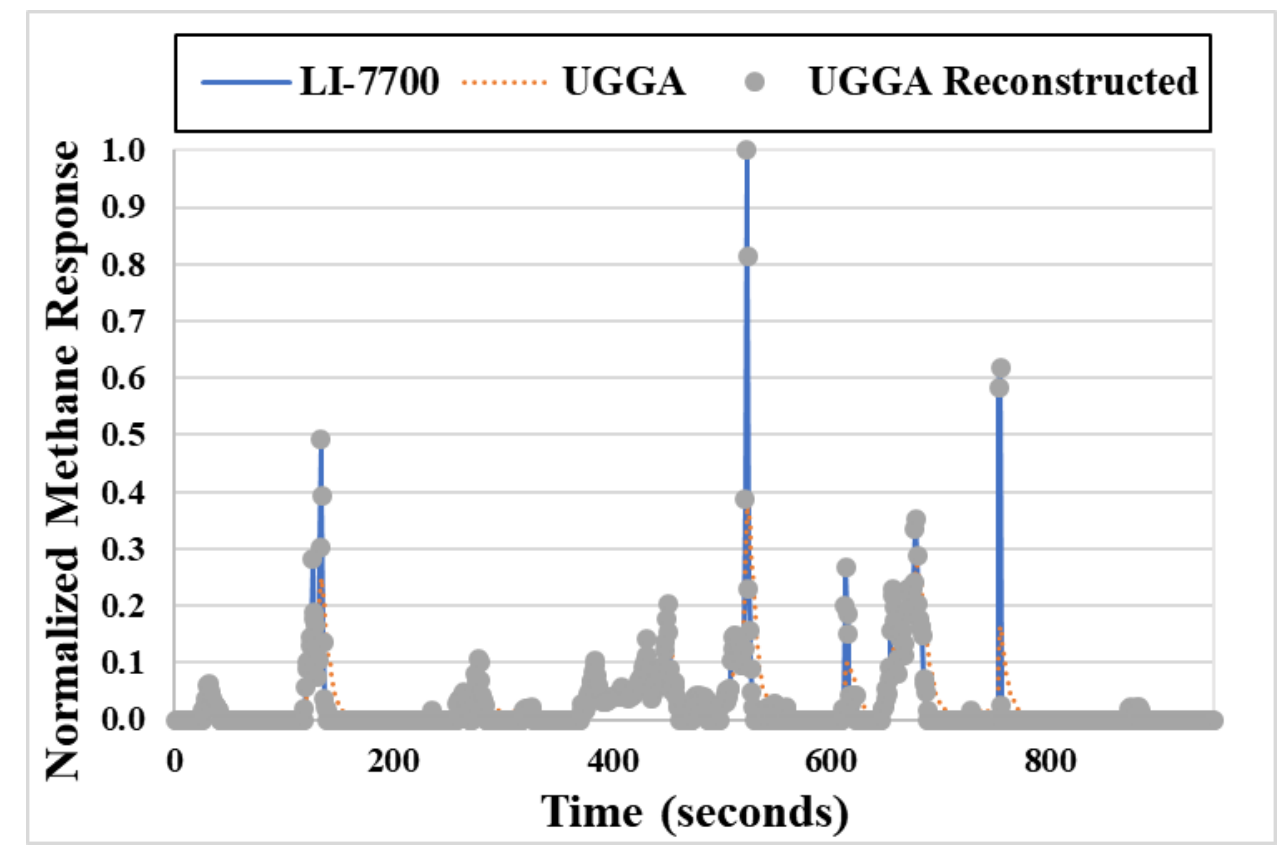

Figure 26: IFFT Reconstruction of Trip 551:

$\mathrm{PV}=1, \mathrm{PE}=0, \mathrm{r}^{2}=1, \mathrm{SEE}=0, \mathrm{PIE}=0$

To eliminate the need for continuous open-path measurements, the IFFT was applied to other files. The IFFT was applied on other files after the signal length was changed to match the impulse response. Figure 27 displays a section of the application of trip 551's IFFT to trip 554. With a PV of 0.258 , the PV decreased by $38.1 \%$ from reconstruction compared to the original. Due to the zero padding, the IFFT reconstruction did not accurately represent over half the points. To implement the IFFT, each plume of the UGGA would require an impulse response to be created prior to implementation without the LI-7700. The IFFT could be applied to mobile methane systems when both the UGGA and LI-7700 were in operation. To implement the UGGA without the LI-7700, the IFFT was not applicable. 


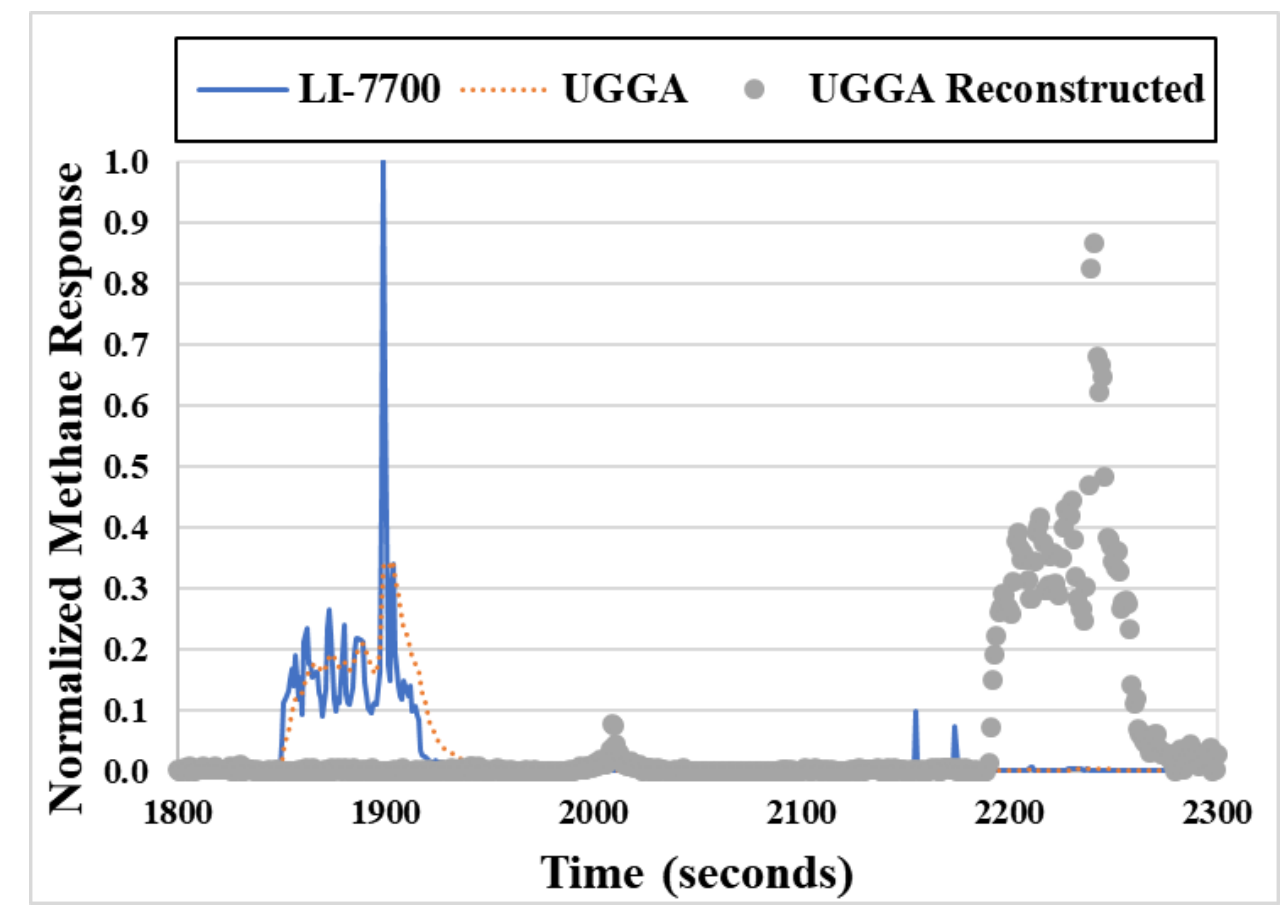

Figure 27: IFFT Reconstruction of Trip 554 using Trip 551's IFFT: $P V=0.258, P E=0.739, r^{2}=0$, SEE$=0.064$, PIE=0.001.

\subsubsection{Artificial Neural Network (ANN)}

\subsubsection{Theory}

In summary, an ANN is a response network that determines an output with given inputs. It models the brain, which uses neurons to send signals and modify them until it reaches its goal. An ANN is a combination of neuron layers that consists of a set number of neurons [89]. The neurons are a transfer function with a coefficient, which change the input and passes the output to next neuron. Once it has gone through all neurons, then evaluation of the output occurs.

To achieve the coefficients, the ANN must be trained with an input and output combination. This allows for the neural network to train to the given output based on the input. Once the neural network receives the simulated output, then comparison of the simulated output and true output ensue. The training method changes the coefficients with respect to the simulated and true outputs. Training continues for a set number of steps or until the ANN reaches a solution. An evaluation function determines the success of the ANN's training. 


\subsubsection{Application}

An ANN was created in $\mathrm{MATLAB}^{\odot}$ to calculate a correction to the UGGA. The ANN was designable by the user, consisting of neurons, transfer functions, or training iterations as desired. An option was a function fitting ANN, which would not allow the user to define its function, but instead determine the transfer function through its error calculation. The function fitting ANN calculated the best transfer function and reported its results.

To train for reconstruction, the ANN was supplied with only points in time where the LI-7700's signal was above background. Once a result was found, the ANN was applied to the whole data set. Two function fitting networks ANNs were created with 10 nodes and trained for 10,000 iterations. Because the ANN was created using MATLAB $^{\odot}$ 's deep learning toolbox, the training of the ANN is terminated before 10,000 iterations if the training function does not improve the ANN. In addition, the LevenbergMarquardt backpropagation (LM) was implemented as the training method. LM is a combination of Gauss-Newton method (GN) and gradient-based decent [90]. As the ANN was far away from the solution, LM performed similar to gradient based. As the ANN approached the solution, LM performed similar to GN. GN minimized the sum of squared error by assuming the space was a quadratic locally [90]. The use of LM as the training function required the implementation of sum squared error as the evaluation function.

Two ANNs were created using a single file as training and applied to other files to determine the applicability of each ANNs inputs. The first ANN performed reconstruction with only the UGGA's methane signal as input. Figure 28 depicts an example of the ANN performance on trip 551. The ANN produced a PV of 0.69 or increase of $25.7 \%$. 


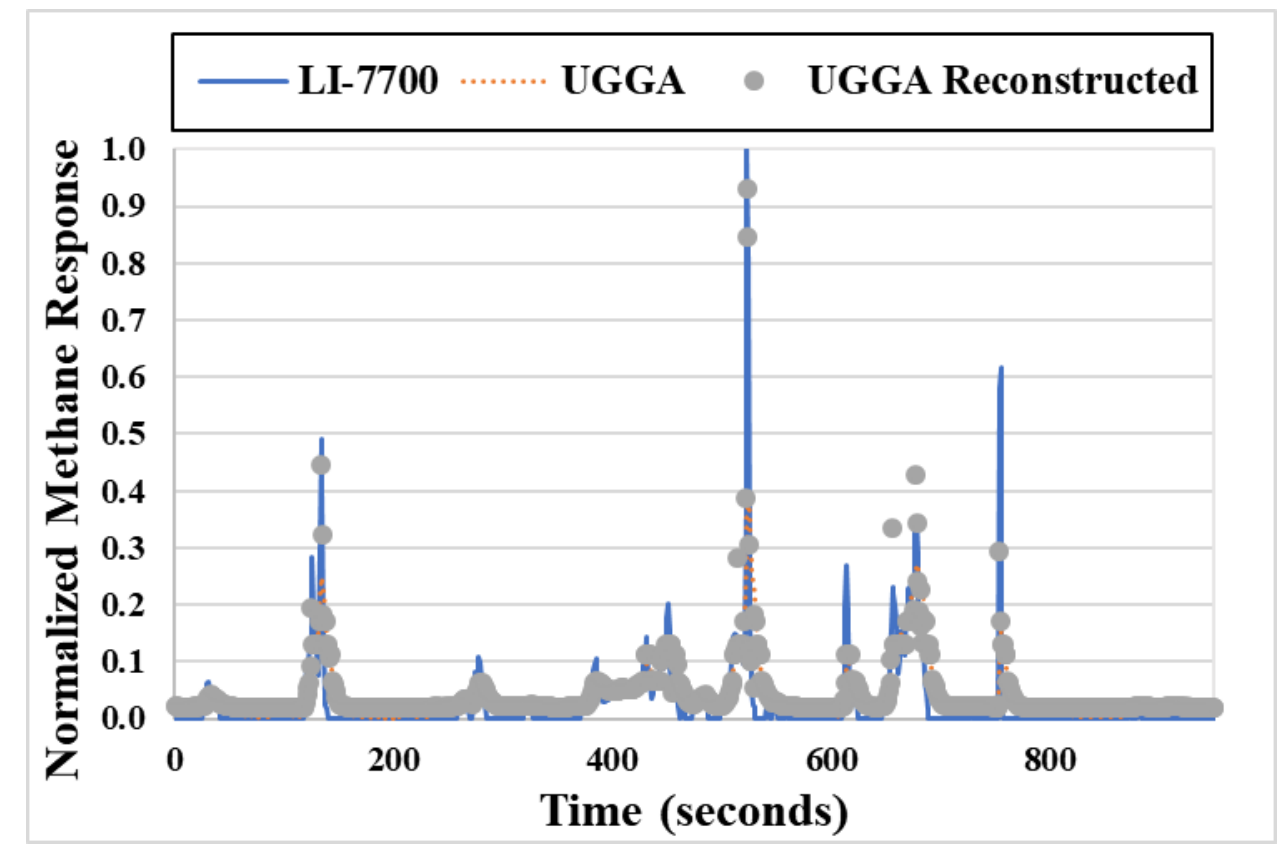

Figure 28: ANN Reconstruction of Trip 551:

$\mathrm{PV}=0.690, \mathrm{PE}=0.394, \mathrm{r}^{2}=0.786, \mathrm{SEE}=0.029, \mathrm{PIE}=0.238$.

Trip 551's ANN was applied to trip 554. A section of the results is shown in Figure 29. The application of the ANN to a different data set produced a PV of 0.315 , or a decrease of $24.5 \%$. The application of the ANN to a data set required more inputs for better success. 


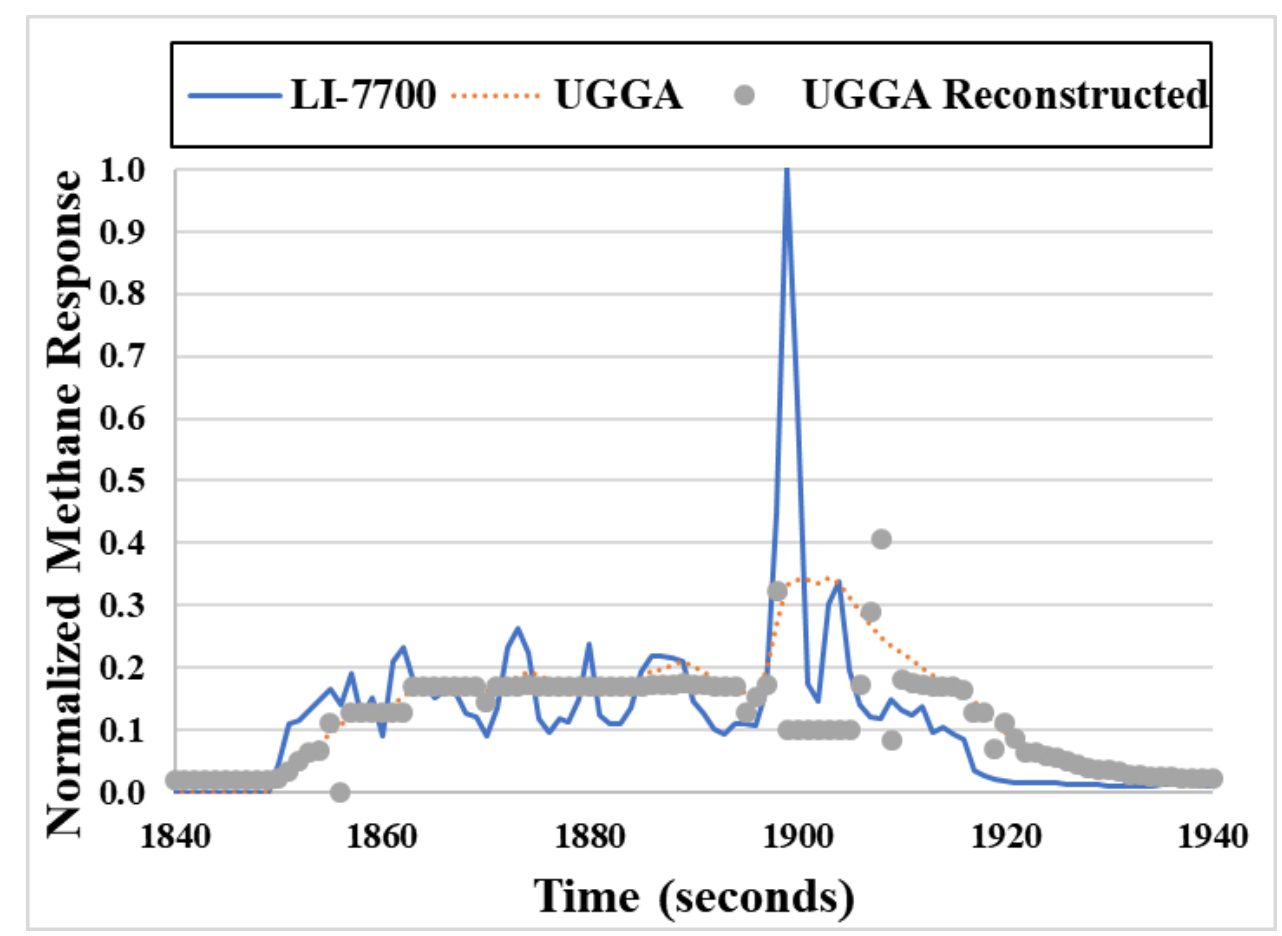

Figure 29: ANN Reconstruction of Trip 554 using Trip 551's ANN: $\mathrm{PV}=0.315, \mathrm{PE}=0.781, \mathrm{r}^{2}=0.406, \mathrm{SEE}=0.032, \mathrm{PIE}=0.575$.

The second ANN consisted of the UGGA's methane and the derivatives of the UGGA's methane. The ANN was provided with the first three derivatives of the UGGA's signal. The derivatives were calculated using a backwards approximation. The derivatives used were based on the differentials used in the DCM. Figure 30 depicts an example of the ANN with derivatives of trip 551. The ANN's performance PV was 0.917 , or an increase of $67 \%$. 


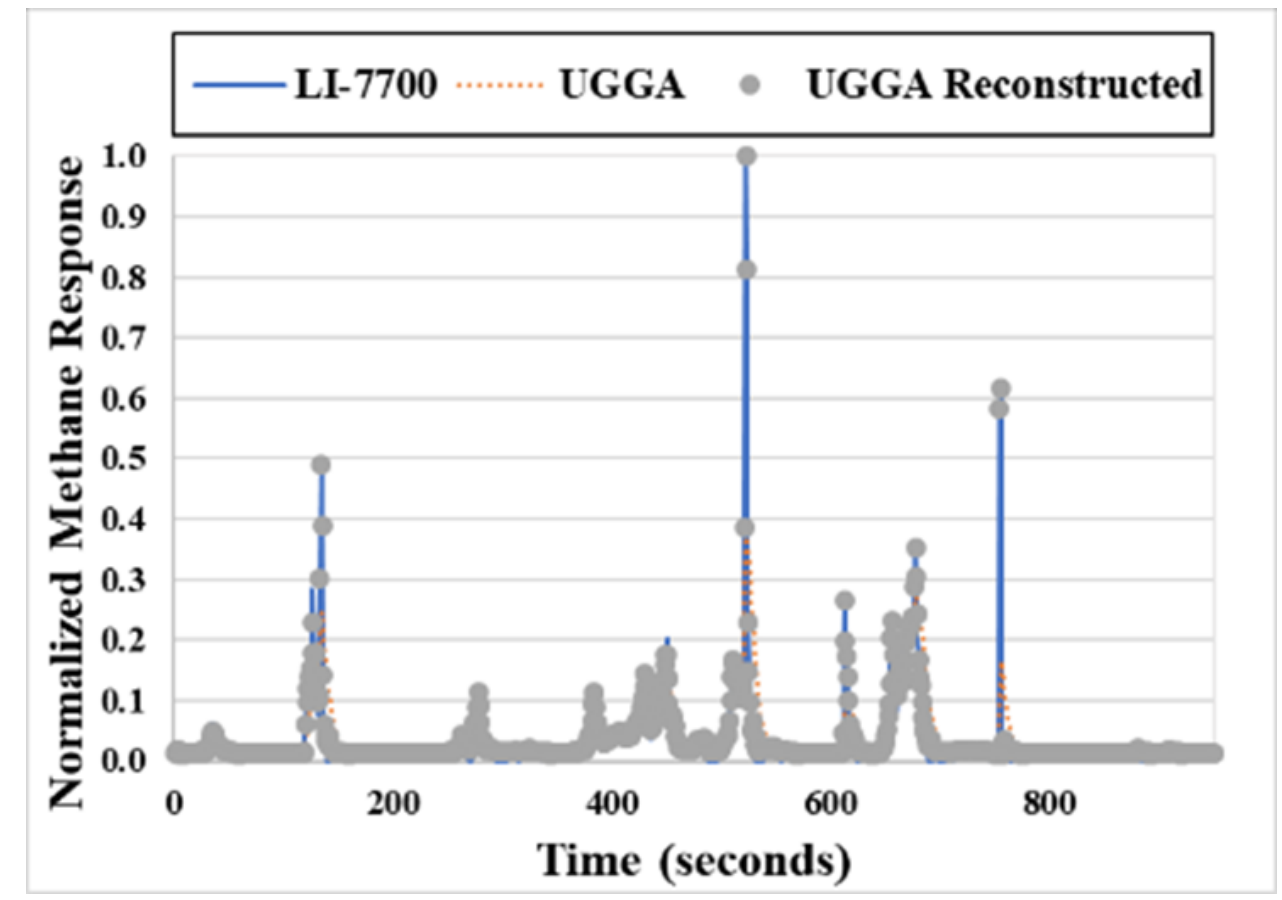

Figure 30: ANN with Derivatives Reconstruction of Trip 551: $\mathrm{PV}=0.917, \mathrm{PE}=0.099, \mathrm{r}^{2}=0.969, \mathrm{SEE}=0.013, \mathrm{PIE}=0.177$.

A section of the application of trip 551's ANN to trip 554 is shown in Figure 31. The PV of the application of the ANN was 0.716 , or an increase of $71.7 \%$. The ANN with derivatives improved the PVs better than the first ANN. An ANN with derivatives was created and applied to all the data. The creation of an ANN would allow for the implementation of the UGGA without the LI-7700. The total results of the ANN were investigated to determine if it was applicable for mobile methane detection. 


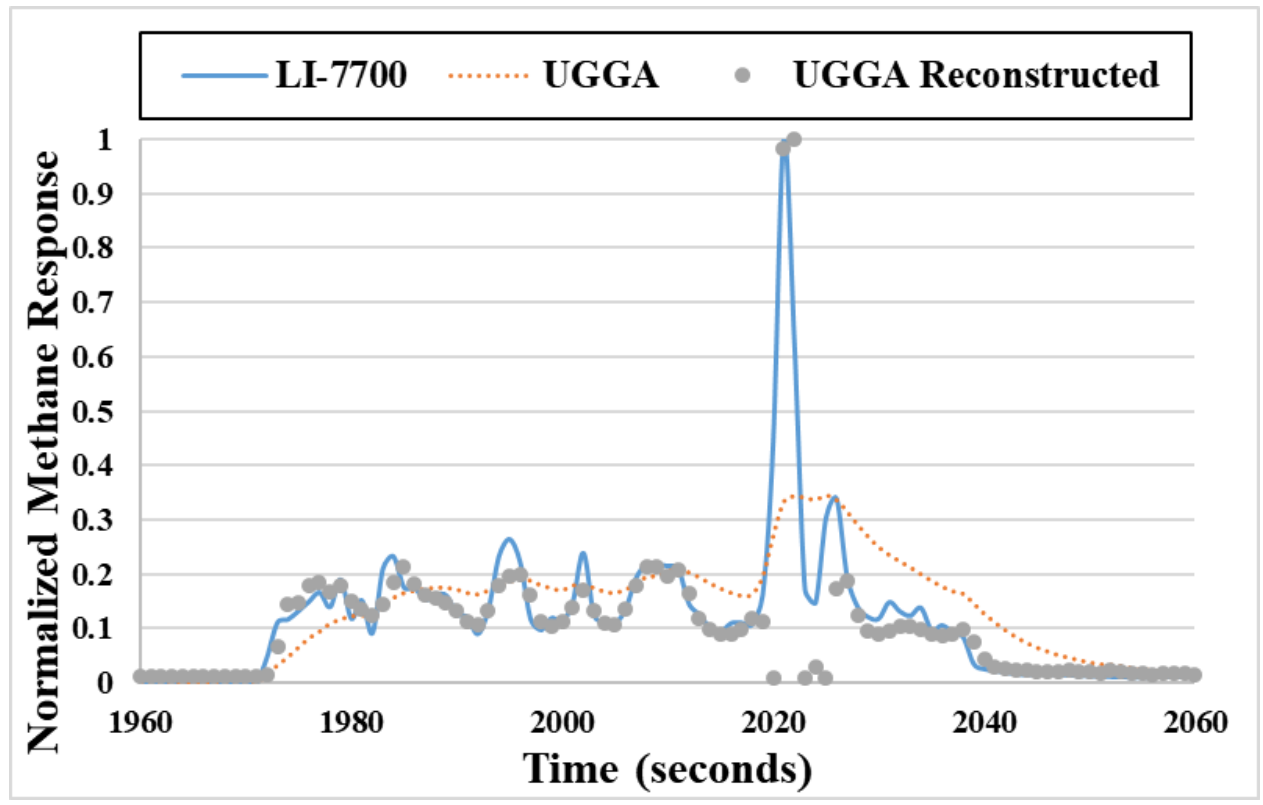

Figure 31: ANN with Derivatives Reconstruction of Trip 554 using Trip 551's ANN:

$\mathrm{PV}=0.716, \mathrm{PE}=0.309, \mathrm{r}^{2}=0.816, \mathrm{SEE}=0.019, \mathrm{PIE}=0.505$.

\subsubsection{Differential Coefficients Method (DCM)}

\subsubsection{Theory}

The DCM was introduced by Ajtay and Welienman for the reconstruction of vehicle emissions [91]. The DCM was founded on dispersion associated with mixing and transport. It used the principle of differentials to recreate a signal. If $U(t)$ was the input signal and $Y(t)$ was the output, then differentials of $Y(t)$ were $Y^{\prime}(t), Y^{\prime \prime}(t)$ and so on. Assuming a linear combination of first two differentials and the output to create the input, DCM is:

$$
U(t)=Y(t)+a_{1} Y^{\prime}(t)+a_{2} Y^{\prime \prime}(t)
$$

where $t$ is the time step in the signal. Madireddy and Clark compared the results of using more than two differentials and determined that for vehicle emissions more than three differentials did not contribute significantly to a better solution [92]. DCM of multiple differentials is: 


$$
U(t)=\sum_{i=0}^{n} a_{i} Y^{[i]}(t)
$$

Where $n$ is the number of differentials desired, $a_{i}$ are the coefficients and $Y^{[i]}(t)$ are the differentials of the output signal.

Madireddy and Clark's analysis of the DCM was performed by observing the differential effects and initial constants [92]. Madireddy and Clark did not implement a coefficient for the constant which reduced the effect of the initial output signal. In addition, Madireddy and Clark determined that the third derivative accounted for rounding errors and that the backwards derivative was the best for consistency.

\subsubsection{Application}

The DCM was examined since the UGGA experienced diffusion in the cell. In this application, $a_{0}$ was solvable and the DCM consisted of three backwards differential terms. The solving option for the various $a_{i}$ was an average least squared error, through varying the $a_{i}$ linearly. Average least squared error was the minimization of the average squared error differences. The training set for the DCM was reduced to methane concentrations above background of the LI-7700. After training, the coefficients were applied to the entire data file. The DCM applied to trip 551 is shown in Figure 32. The DCM created a PV of 0.670 for a $22 \%$ increase from the initial PV of trip 551. 


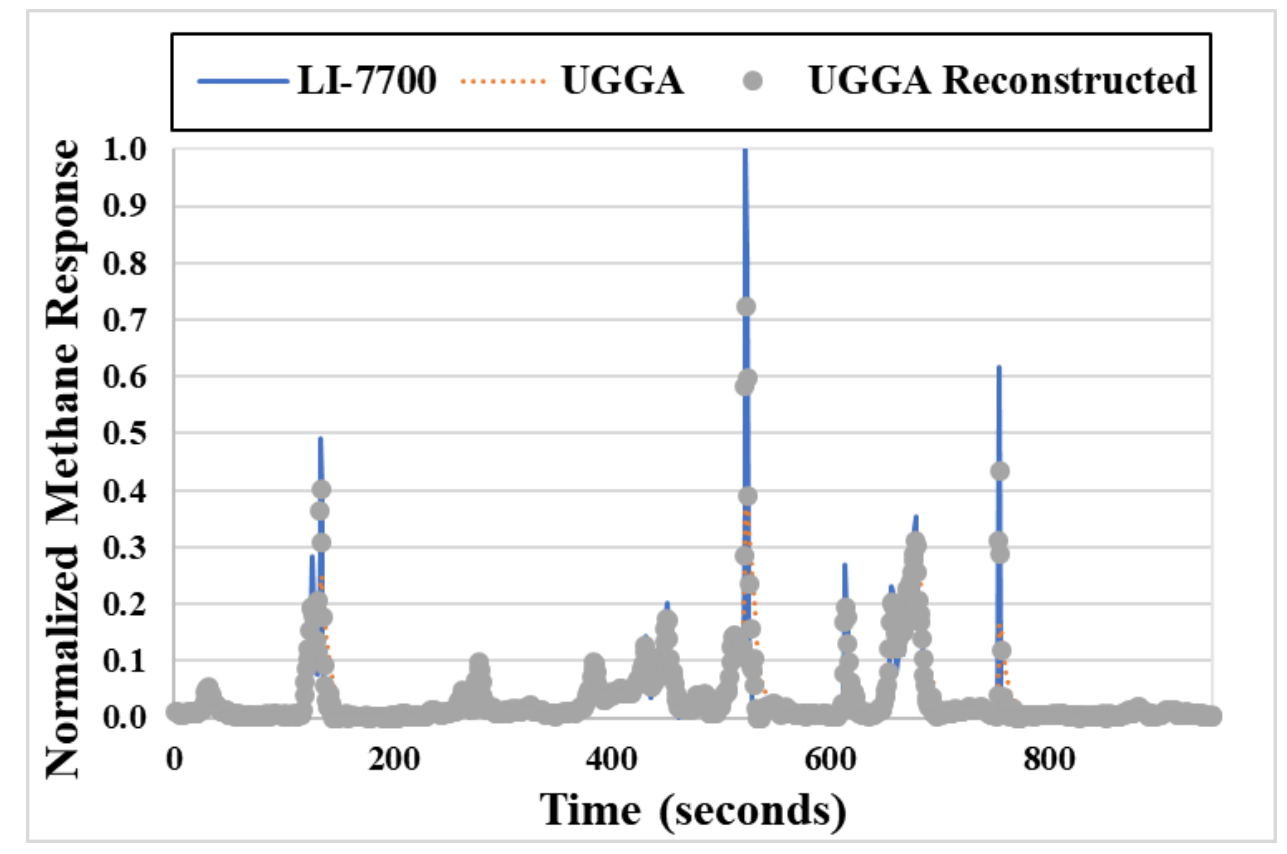

Figure 32: DCM Reconstruction of Trip 551:

$P V=0.670, P E=0.540, r^{2}=0.879$, SEE $=0.020, P I E=0.012$.

Applying the DCM coefficients of trip 551 to trip 554 is shown in Figure 33. The PV was 0.511 which was a $22 \%$ increase from the original PV of trip 554. Since DCM had the ability to define a set of coefficients and apply them to any set, it allowed for its implementation to all sets without the LI-7700's signal. The DCM was investigated further for its application in methane reconstruction. 


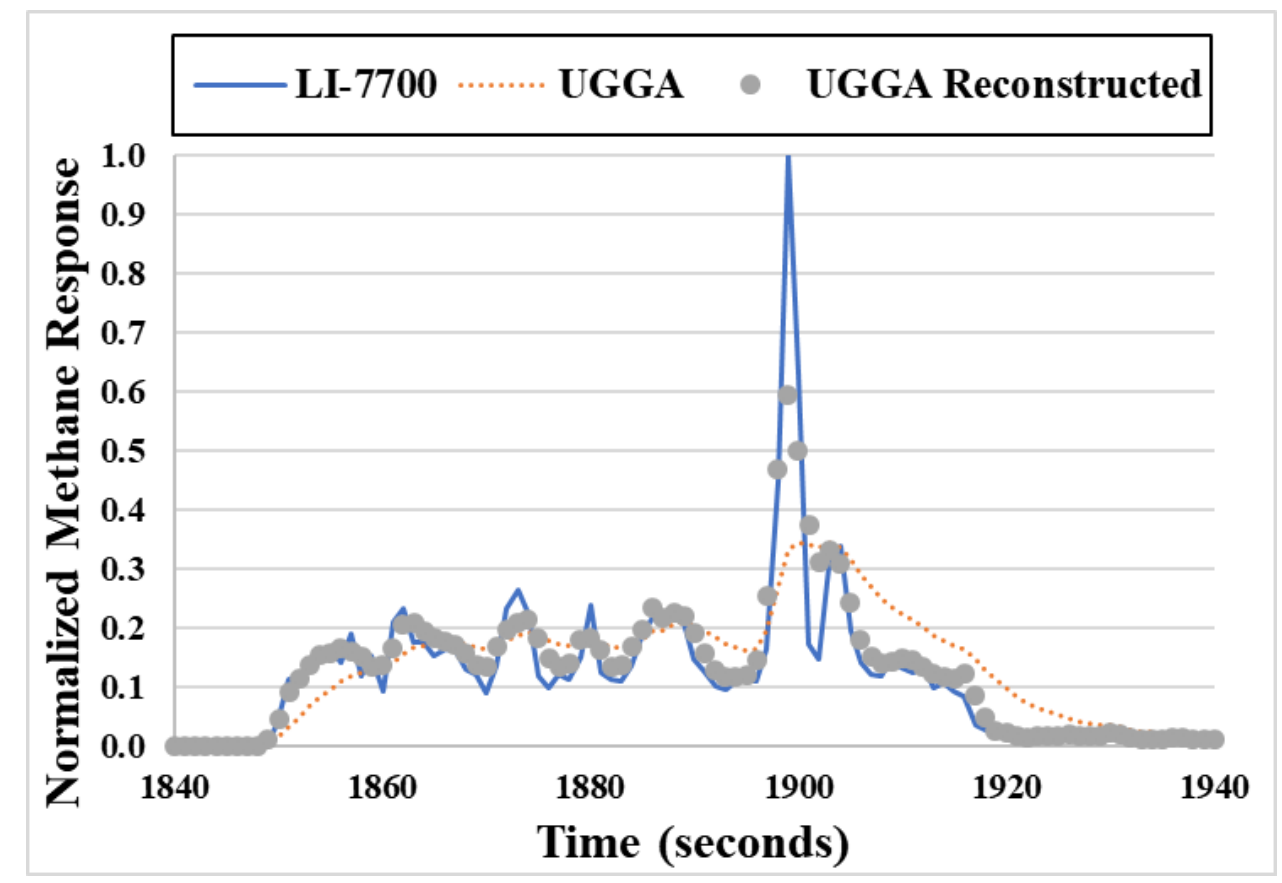

Figure 33: DCM Reconstruction of Trip 554 using Trip 551's DCM: $\mathrm{PV}=0.511, \mathrm{PE}=0.847, \mathrm{r}^{2}=0.897, \mathrm{SEE}=0.011, \mathrm{PIE}=0.036$.

\subsection{Reconstruction Results}

The PV of all mobile methane data sets was determined at various frequencies. Both DCM and ANN with derivatives were attempted. The results were compared at $1 \mathrm{~Hz}$. An attempt to up sample and reconstruct the UGGA was detailed.

\subsection{1 $1 \mathrm{~Hz}$ Reconstruction}

The LI-7700 was down sampled to $1 \mathrm{~Hz}$ which allowed for reconstruction of the UGGA's methane signal. To perform down sampling, forward averages of the LI-7700 were taken. Using the PV defined previously, the success of reconstruction was compared between the reconstructed and original signals.

\subsubsection{DCM}

\subsection{Self-Training}

Using the DCM, all 43 files were self-trained. Because the least squared error used in DCM was computed iteratively, the PV was limited by boundaries of the coefficients. The range was defined as -5 to 
5 for $a_{0}$ and -15 to 15 for $a_{1}, a_{2}$, and $a_{3}$ with precision to two decimal places. During the calculation of 172 total coefficients, only one coefficient reached its boundary.

Using the coefficient search range of the DCM, Table 5 displays the average, standard deviation, maximum, and minimum of the PV and its components. It was observed that the average PV of the trip files was 0.644. Table 6 displays the breakdown of the improvement from implementing the DCM to the trip files. The average PV increased by 0.132 , or a $25 \%$ percent increase compared to the initial PV. The PV was shown to vary across all files. All the PVs and their breakdowns for self-training are given in Appendix V.

Table 5: PV Breakdown of Self-Trained Trips.

\begin{tabular}{|c|c|c|c|c|c|}
\hline & PE & $\mathbf{r}^{\mathbf{2}}$ & SEE & PIE & PV \\
\hline AVG & 0.453 & 0.696 & 0.069 & 0.079 & 0.644 \\
\hline VAR & 0.093 & 0.067 & 0.005 & 0.019 & 0.043 \\
\hline MAX & 0.945 & 0.996 & 0.327 & 0.599 & 0.978 \\
\hline MIN & 0.000 & 0.024 & 0.010 & 0.000 & 0.312 \\
\hline
\end{tabular}

Table 6: Improvement of the PV Breakdown of Self-Trained Trips Compared to the Initial PV Breakdown. Note: Highlighted Cells Indicated a Positive Improvement.

\begin{tabular}{|c|c|c|c|c|c|}
\hline & PE & $\mathbf{r}^{2}$ & SEE & PIE & PV \\
\hline AVG & -0.149 & 0.152 & -0.002 & -0.004 & 0.133 \\
\hline VAR & 0.190 & 0.271 & 0.057 & 0.132 & 0.160 \\
\hline MAX & 0.272 & 0.680 & 0.220 & 0.376 & 0.564 \\
\hline MIN & -0.665 & -0.495 & -0.073 & -0.488 & -0.143 \\
\hline
\end{tabular}


In observance of Tables 4 and 5, a distribution of the PV components is shown in Figure 34. Each component's zero to one performance impact was binned into 0.1 sections. Compared to the initial PV components, PE's largest bin increased from $0.1-0.2$ to $0.9-1$ and $\mathrm{r}^{2}$ 's largest bin increased from 0.3-0.4 to 0.8-0.9.

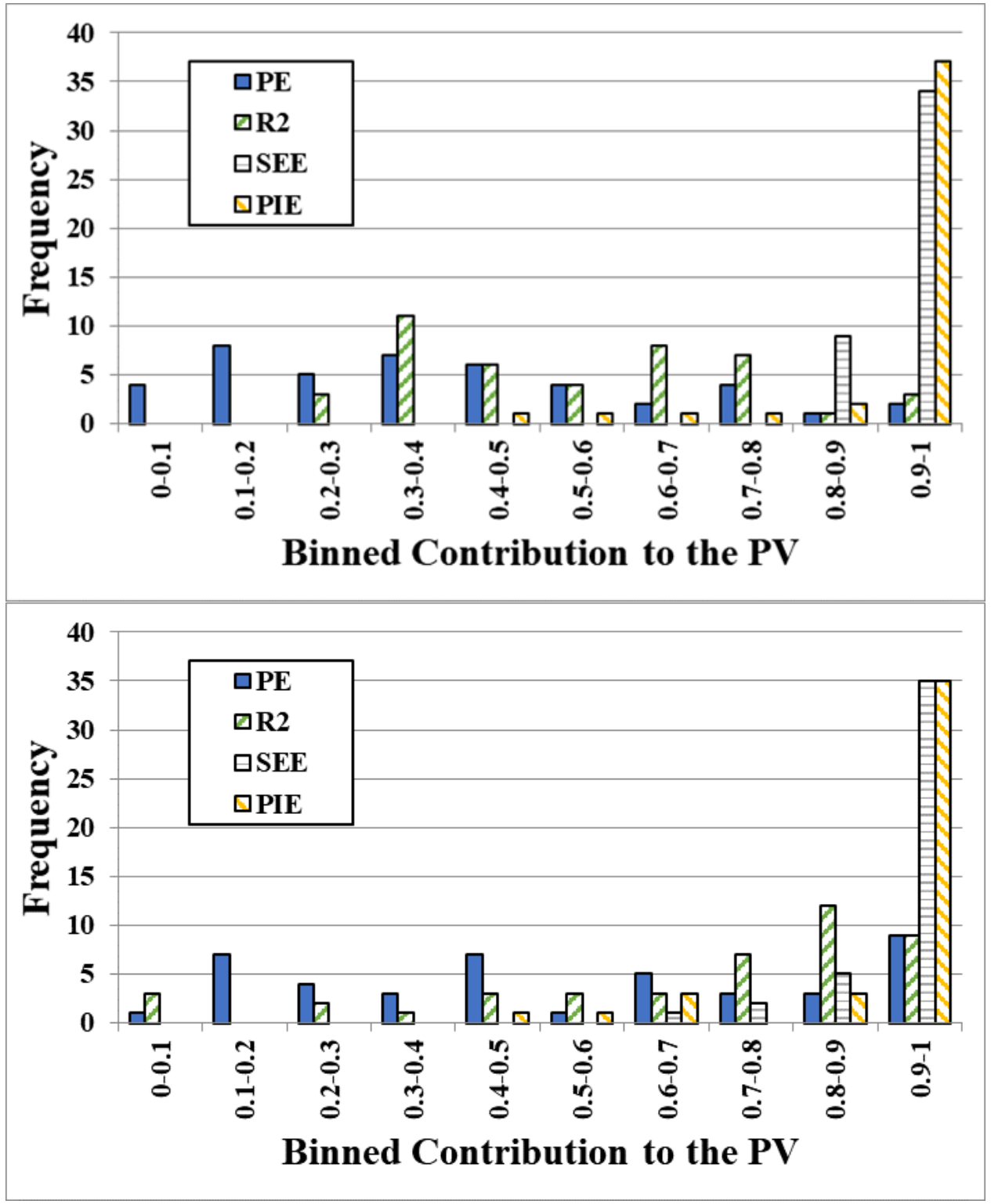

Figure 34: (Top) Distribution of the Initial PV Components. (Bottom) Distribution of the SelfTrained PV Components Note: The total count for each component was 43. 
To illustrate the effects of the DCM on the UGGA, Figure 35 displays trip 545 that was self-trained. Trip 540's PV was 0.774 , or a $13.8 \%$ increase from trip 545's initial PV. The DCM coefficients calculated were available for application to other files.

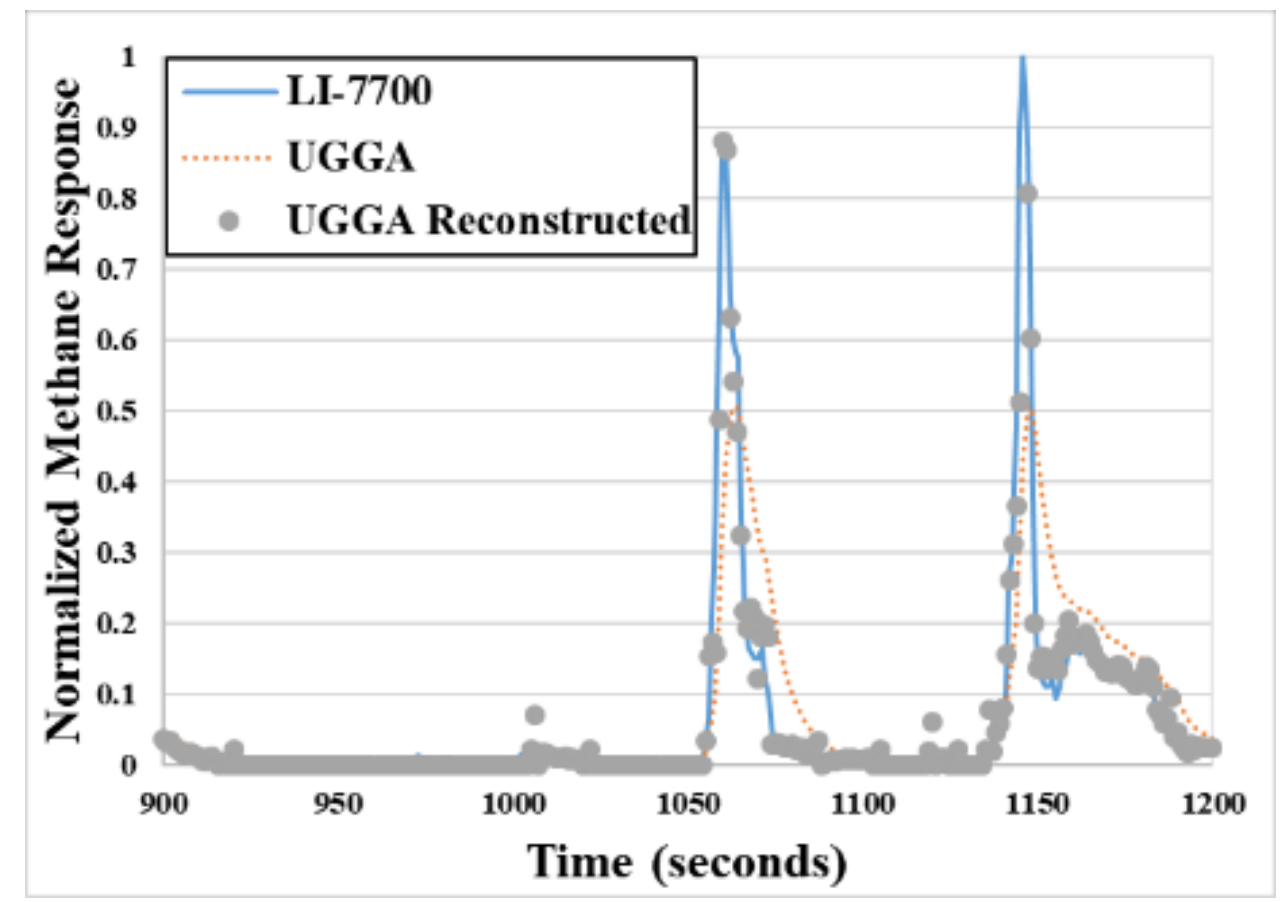

Figure 35: Trip 545, DCM Self-Trained Reconstructed UGGA: $P V=0.774$, PE$=0.371, r^{2}=0.921$, SEE$=0.021$, PIE $=0.013$.

\subsection{Applying DCM Coefficients}

During DCM training, each trip generated a unique set of coefficients. To determine the suitability of each set of coefficients, all sets of coefficients were applied to the remaining 42 trip files that did not create them. Appendix VI displays the average PV and its components from each DCM coefficients to all 43 trip files. The best set of coefficients were created from trip 552 which improved the average PV to 0.692 for a $35 \%$ increase of the average initial PV. Five of the 43 trips improved the average PV by at least $30 \%$ and 25 trips improved the average PV by at least $20 \%$.

Examples of the coefficient application is shown in Figures 36 and 37. Figure 36 displays trip 545 trained with the coefficients from trip 540. Trip 540's self-trained PV was 0.312. When applied to trip 545, the PV decreased by 0.262 , or a $41.2 \%$ decrease from trip 545's initial PV. Figure 37 displays trip 545 
trained with the coefficients from trip 533 applied for DCM reconstruction. Trip 533's self-trained PV was 0.843 . When applied to trip 545 , the PV increased by 0.219 which is a $34.4 \%$ increase compared to trip 545's initial PV.

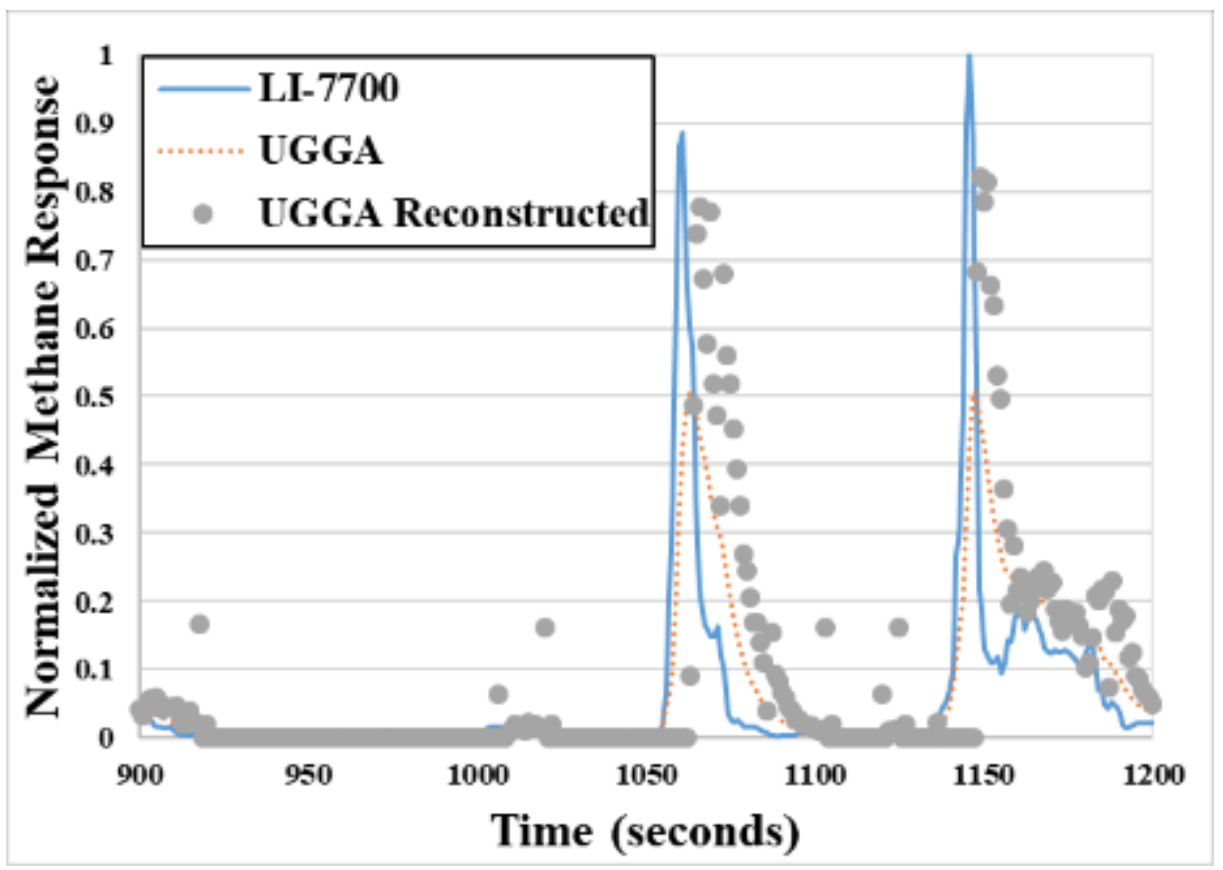

Figure 36: Trip 545, DCM Reconstructed UGGA with Trip 540: $\mathrm{PV}=0.374, \mathrm{PE}=0.544, \mathrm{r}^{2}=0.069, \mathrm{SEE}=0.103, \mathrm{PIE}=0.099$. 


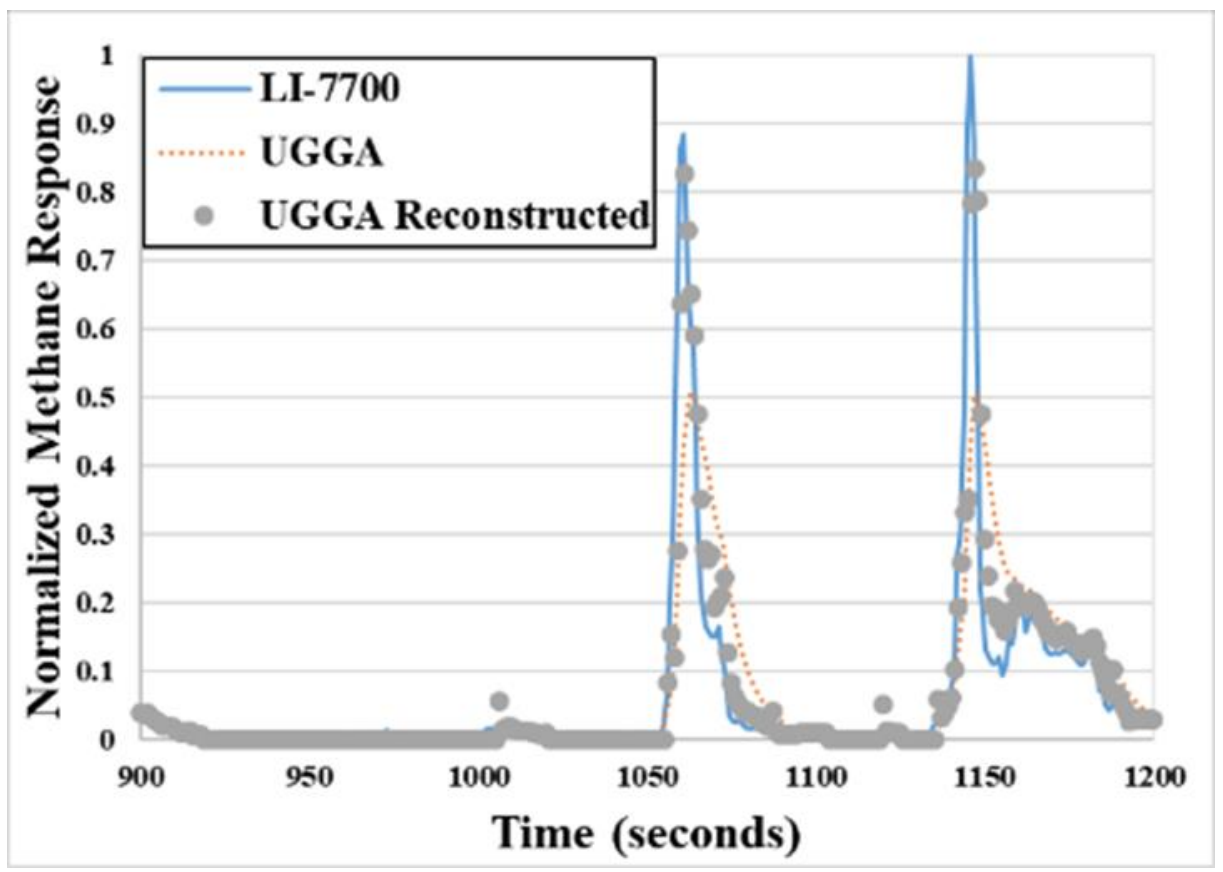

Figure 37: Trip 545, DCM Reconstructed UGGA with Trip 533: $\mathrm{PV}=0.855, \mathrm{PE}=0.362, \mathrm{r}^{2}=0.846, \mathrm{SEE}=0.030, \mathrm{PIE}=0.034$.

The best applied DCM coefficients were not associated with the best PVs from self-training. Figure 38 displays a weak correlation between the self-trained PV and the average PV of the 43 files of each selftrained coefficients. The PV increased from the implementation of DCM, but the best PV coefficients did not guarantee the best average PVs from reconstruction. To judge the success of the DCM coefficients, a peak sensitivity analysis was conducted. 


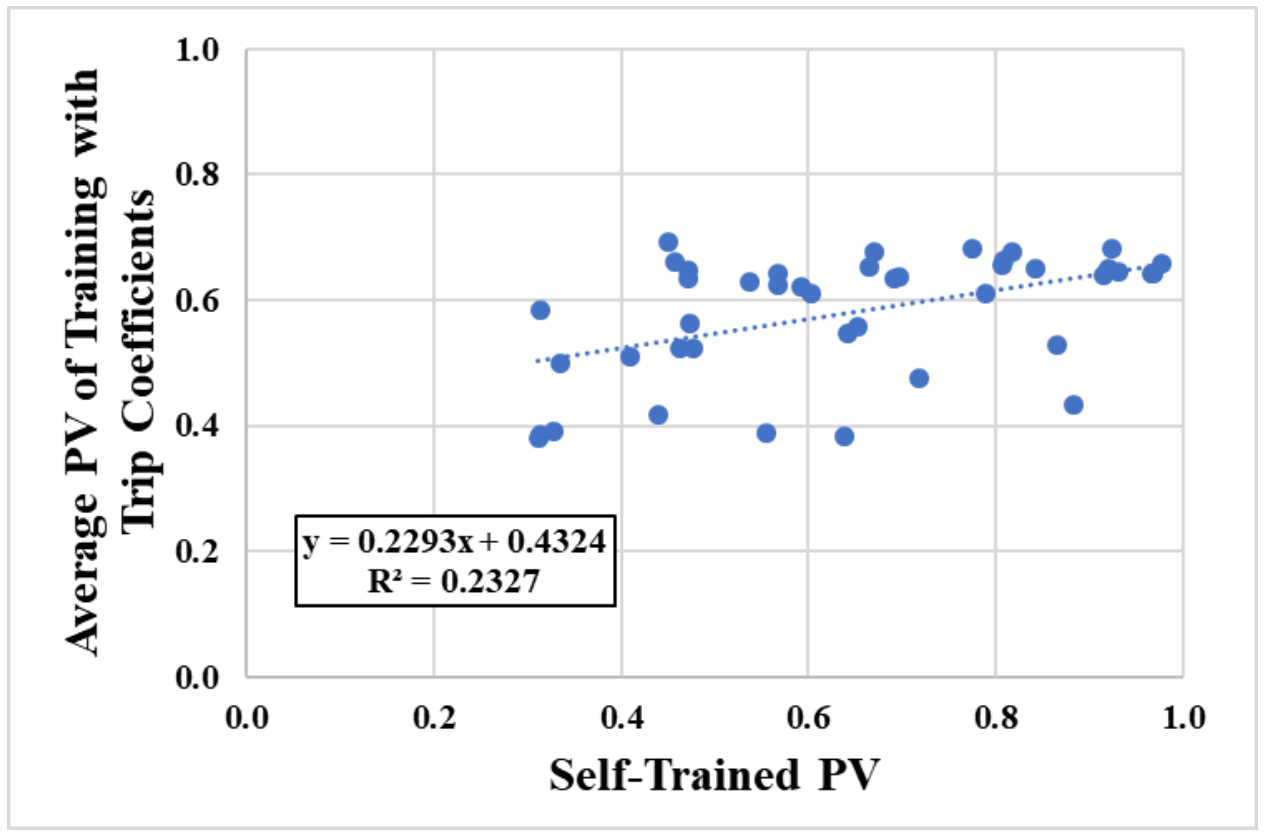

Figure 38: The Average PV of the Trip Coefficients vs the Self-Trained PV.

\subsection{Detection Threshold Sensitivity Analysis}

To determine the peak finding ability of the DCM coefficients, the recreated plumes using the DCM coefficients were subjected to detection threshold sensitivity analysis. To convert the UGGA reconstructed normalized methane to a ppmv concentration, the inverse of the UGGA normalization was applied. The denormalized methane concentrations are shown in equations 37 and 38. The UGGA's background was the LI-7700's background due to the zeroing of backgrounds between analyzers.

$$
\begin{gathered}
U G G A(t)=U G G A_{\text {norm }}(t) *\left(\max (L I 7700)-L I 7700_{\text {Background }_{1}}\right)+U G G A_{\text {Background }_{\text {ack }}} \\
L I 7700(t)=L I 7700_{\text {norm }}(t) *\left(\max (L I 7700)-L I 7700_{\text {Background }}\right)+L I 7700_{\text {Background }}
\end{gathered}
$$

Using all 43 trip file coefficients, all 363 plumes were reconstructed. The initial sensitivity values were observed for each file. Appendix VII contains each trip coefficient's false reporting, false positive, and false negative rates for 2.7 ppmv detection of the $10 \mathrm{~Hz}$ LI-7700 peaks, and 2.6 ppmv detection of the 1 Hz LI-7700 peaks. Of the 43 sets of coefficients, only one file did not improve the false negative rate; however, every set of coefficients created false positives. A detection sensitivity was conducted to investigate for improved detection thresholds. 
Using the initial range of 2.5 to $3.5 \mathrm{ppmv}$, detection threshold sensitivity analysis was performed.

Appendix VII contains each DCM coefficient's best threshold and false reporting, false positive, and false negative rates at 10 and $1 \mathrm{~Hz}$. Table 7 displays the best trip coefficients with their minimum false reporting rate at the minimum detection threshold. To determine the best threshold, the false reporting rate was minimized because reconstruction created false positives by the UGGA while lowering the false negative rate. For $10 \mathrm{~Hz}$ LI-7700 peaks, the detection threshold of 3.5 ppmv reduced the false reporting rate by $57.6 \%$ from the initial threshold of 2.7 ppmv. For $1 \mathrm{~Hz}$ LI-7700 peaks, the detection threshold of 3.4 ppmv reduced the false reporting rate by $75.3 \%$ from the initial threshold of $2.6 \mathrm{ppmv}$.

The bounds were adjusted to 2.5 to $5.5 \mathrm{ppmv}$ to determine if a better local minimum was available. The larger sensitivity analysis bound results are included in Appendix VII and the best are shown in Table 7. The best false reporting rates were 0.039 and 0.019 for 10 and $1 \mathrm{~Hz}$, respectively. The 5.2 ppmv detection threshold for $10 \mathrm{~Hz}$ resulted in a decrease of the false reporting rate by $67 \%$. Because other mobile methane systems determine enhanced concentrations of methane near 2-3 ppmv, a detection threshold outside the initial 2.5 ppmv to 3.5 ppmv was not recommended.

Table 7: Peak Sensitivity Analysis of the Self-Trained Coefficients Applied to all Trip Files.

\begin{tabular}{|c|c|c|c|c|}
\hline $\begin{array}{c}\text { Sensitivity } \\
\text { Range }\end{array}$ & $\begin{array}{c}\text { LI-7700 } \\
\text { Frequency }\end{array}$ & $\begin{array}{c}\text { Minimum False } \\
\text { Reporting Rate }\end{array}$ & $\begin{array}{c}\text { Minimum Detection } \\
\text { Threshold }\end{array}$ & $\begin{array}{c}\text { Minimum Trip } \\
\text { Coefficients }\end{array}$ \\
\hline \multirow{2}{*}{ 2.5-3.5 ppmv } & 10 & 0.050 & 3.5 & 575 \\
\cline { 2 - 5 } & 1 & 0.019 & 3.4 & 550 \\
\hline \multirow{2}{*}{ 2.5-5.5 ppmv } & 10 & 0.039 & 5.2 & 542 \\
\cline { 2 - 5 } & 1 & 0.019 & 3.4 & 550 \\
\hline
\end{tabular}

Figure 39 displays a weak correlation between the self-trained PV and the false reporting rate of the trip coefficients. The DCM coefficients improved the peak sensitivity but were not predictable based on their PV. 


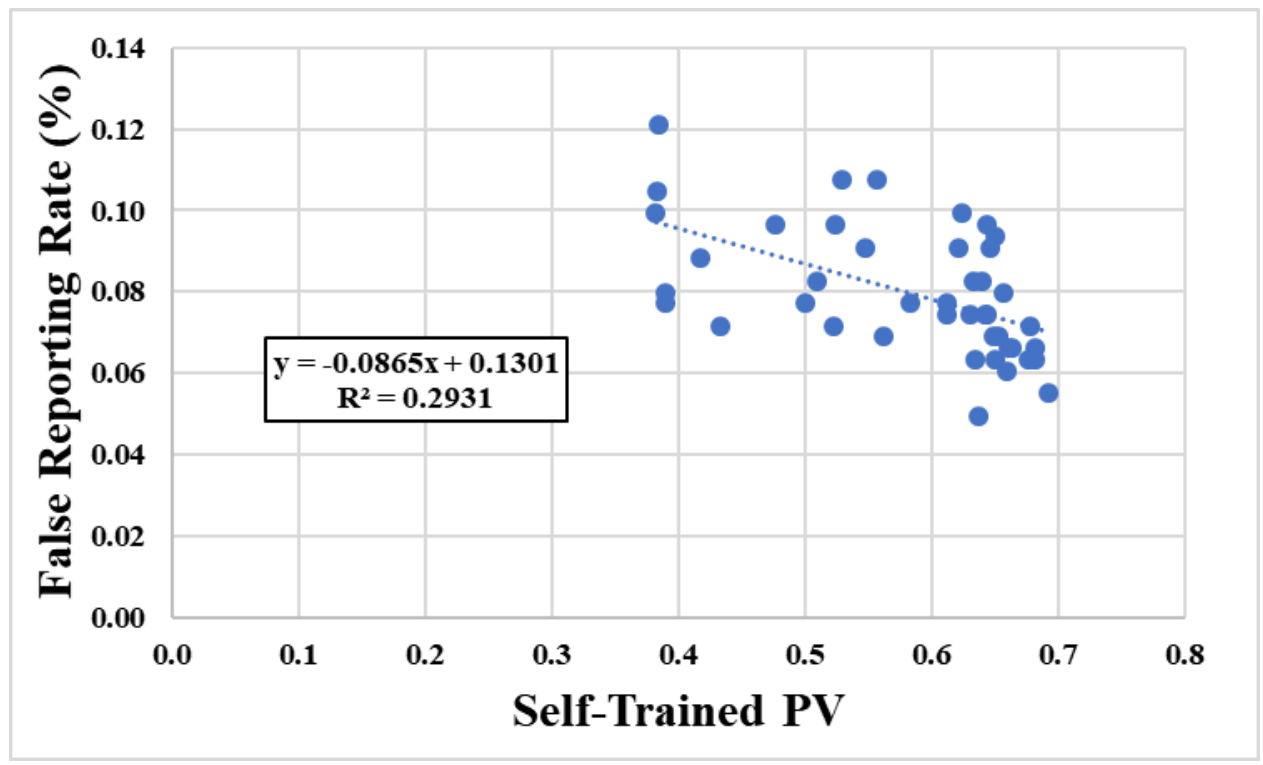

Figure 39: False Reporting Rate of 10 Hz LI-7700 vs the Self-Trained PV of each Trip File's Coefficients.

\subsubsection{ANN with Derivatives}

\subsection{ANN Determination}

An ANN was created from the function fitting network defined previously. For the data input, all the normalized trip data were split into training data and validation data sets using the holdout crossvalidation method. The holdout method performed a simple split of the data into training and validation sets using a splitting ratio. The conventional splitting ratio used in the holdout method was $2 / 3$ training data $[93,94]$. Dobbin and Simon tested various holdout method ratios and determined that 2/3 training data resulted in near optimal mean squared error of their data set [93]. To achieve a holdout ratio near 2/3 training data, the data was split to ensure that the ANN was trained with almost $70 \%$ of the total methane plumes.

Using the training data, the ANN was trained using LM and 10,000 iterations. Figure 40 displays a section of the training data reconstructed using the ANN. The PV of the reconstruction of the training data was 0.899. For comparison, the average initial PV of the trip files used for the training data was 0.512 . 
The PV increased from the ANN by 75.6\%. Appendix VIII contains details regarding the ANN including the structure, transfer functions, and weighting applied.

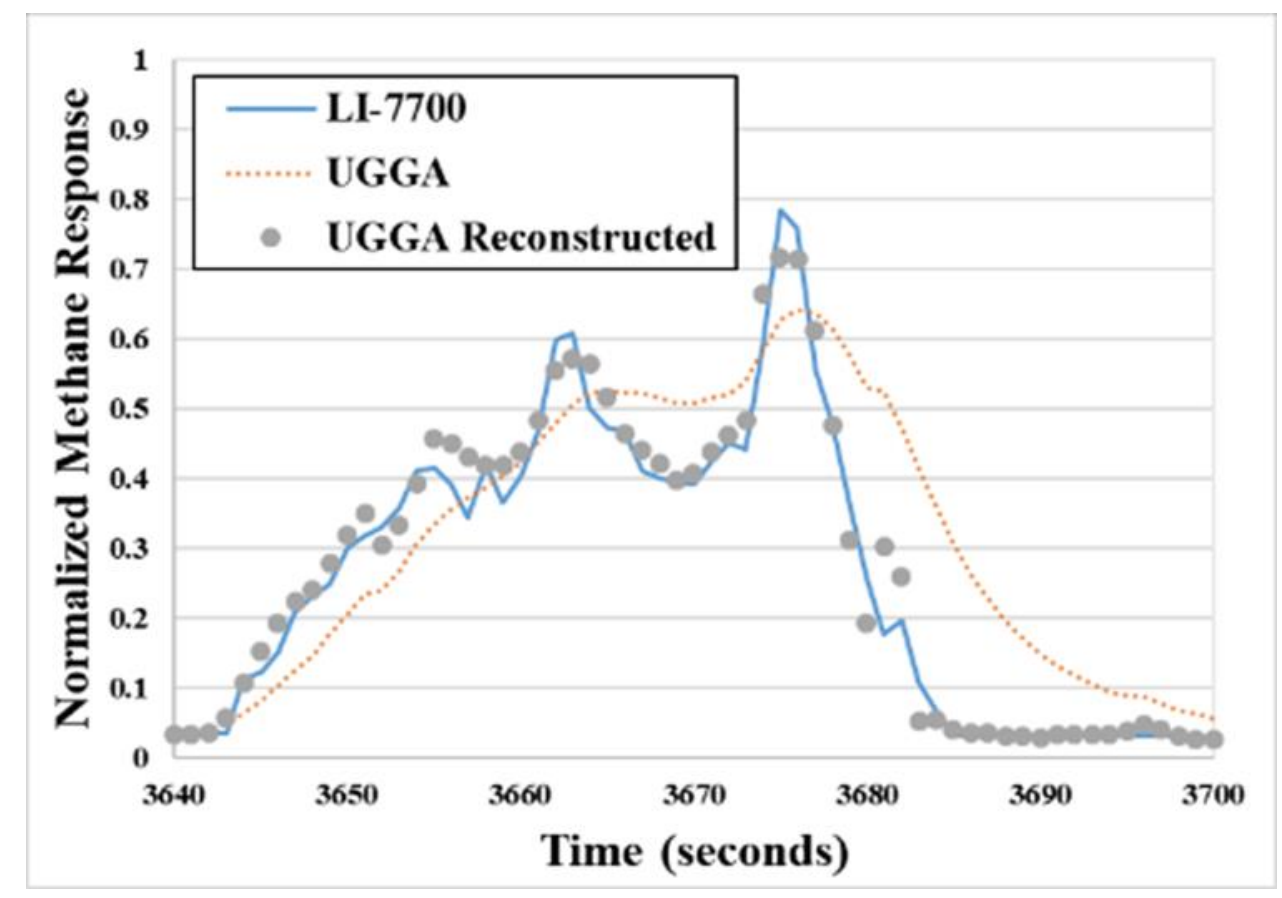

Figure 40: Reconstruction of the Training Data using ANN: $\mathrm{PV}=0.899, \mathrm{PE}=0.143, \mathrm{r}^{2}=0.954, \mathrm{SEE}=0.022, \mathrm{PIE}=0.083$.

\subsection{Applying ANN}

Once the ANN was trained, the ANN was validated using the validation data set. Figure 41 displays a section of the validation data reconstructed using the ANN. The PV of reconstruction of the validation set was 0.86 . For comparison, the average initial PV of the trip files used for the training data was 0.511 . The validation data PV increased by $68.3 \%$. To determine the success in peak finding, a detection threshold sensitivity was conducted. 


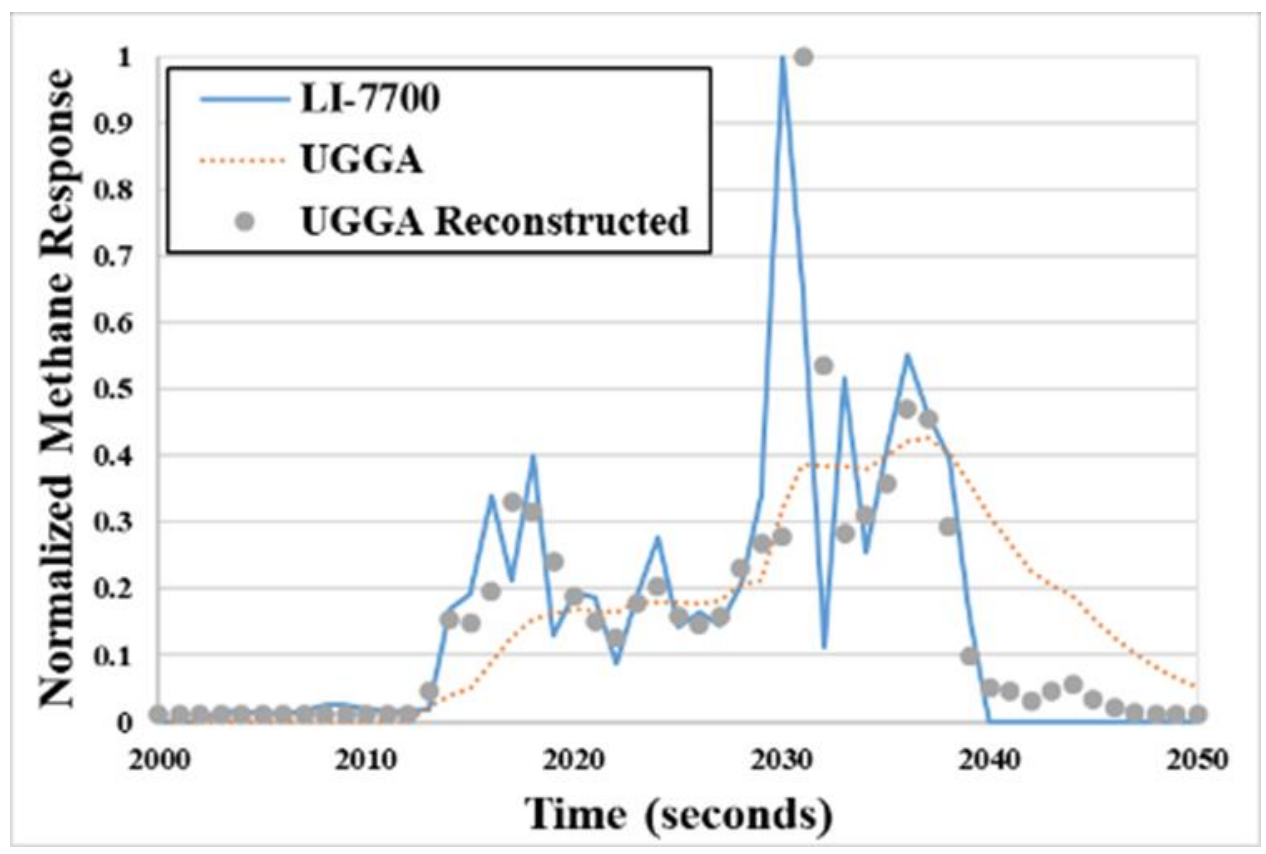

Figure 41: Reconstruction of the Validation Data using ANN:

$\mathrm{PV}=0.86, \mathrm{PE}=0.140, \mathrm{r}^{2}=0.820, \mathrm{SEE}=0.047, \mathrm{PIE}=0.025$.

\subsection{Detection threshold Sensitivity Analysis}

To determine the peak finding ability of the ANN, the recreated plumes using ANN were subjected to detection threshold sensitivity analysis. To convert the UGGA reconstructed normalized methane to a ppmv concentration, the inverse of the UGGA normalization was applied.

The initial sensitivity values of $2.7 \mathrm{ppmv}$ and $2.6 \mathrm{ppmv}$ were observed for 10 and $1 \mathrm{~Hz}$ LI-7700 peaks. The ANN created the false negative rates of 0.169 and 0.059 which was a reduction by $51.3 \%$ and $75.72 \%$. The ANN created false positives that increased the false reporting rate by 0.006 and 0.011 . A detection sensitivity was conducted to investigate for improved detection thresholds.

Using the initial range of 2.5 to $3.5 \mathrm{ppmv}$, detection threshold sensitivity analysis was performed using the reconstructed methane created by the ANN. Table 8 displays the best detection threshold for 10 and 1 Hz. The false reporting rates of 0.061 and 0.017 resulted in a decrease of $48.3 \%$ and $77.9 \%$ from the initial detection thresholds of 2.7 and 2.6 ppmv for 10 and $1 \mathrm{~Hz}$, respectively. 
Table 8: Peak Sensitivity Analysis of the ANN of the Training and Validation Data.

\begin{tabular}{|c|c|c|c|c|c|}
\hline $\begin{array}{c}\text { Sensitivity } \\
\text { Range }\end{array}$ & $\begin{array}{c}\text { LI-7700 } \\
\text { Frequency }\end{array}$ & $\begin{array}{c}\text { Minimum } \\
\text { False } \\
\text { Reporting } \\
\text { Rate }\end{array}$ & $\begin{array}{c}\text { False Positive } \\
\text { Rate }\end{array}$ & $\begin{array}{c}\text { False Negative } \\
\text { Rate }\end{array}$ & $\begin{array}{c}\text { Minimum } \\
\text { Detection } \\
\text { threshold }\end{array}$ \\
\hline $\begin{array}{c}\mathbf{2 . 5 - 3 . 5} \\
\text { ppmv }\end{array}$ & 10 & 0.061 & 0.004 & 0.216 & 3.5 \\
\cline { 2 - 6 } & 1 & 0.017 & 0.007 & 0.047 & 3.3 \\
\hline
\end{tabular}

To confirm the successful training of the ANN, both the training and validation data were subjected to detection threshold sensitivity analysis. In order to draw comparisons, the peaks of the validation set of the UGGA prior to reconstruction were observed. Table 9 displays the peak sensitivity of the training data for both the UGGA and reconstructed UGGA using the ANN. With the expanded search range, the false reporting rate decreased by $53.4 \%$ and $78.6 \%$ for 10 and $1 \mathrm{~Hz}$, respectively. Table 10 displays the peak sensitivity of the validation data for both the UGGA and reconstructed UGGA. With the search range of 2.5 to 3.5 ppmv, the false reporting rate decreased by $38.5 \%$ and $71.4 \%$ for 10 and $1 \mathrm{~Hz}$, respectively. For $1 \mathrm{~Hz}$ of the validation data, the ANN only created two errors out of 111 plumes. 
Table 9: Peak Sensitivity Analysis of the Training Data Before and After Reconstruction using the ANN.

\begin{tabular}{|c|c|c|c|c|c|c|c|c|c|}
\hline \multirow[b]{2}{*}{$\begin{array}{l}\text { Sensitivity } \\
\text { Range }\end{array}$} & \multirow[b]{2}{*}{$\begin{array}{c}\text { LI-7700 } \\
\text { Frequency }\end{array}$} & \multicolumn{4}{|c|}{ UGGA } & \multicolumn{4}{|c|}{ UGGA Reconstructed } \\
\hline & & $\begin{array}{l}\text { Minimum } \\
\text { False } \\
\text { Reporting } \\
\text { Rate }\end{array}$ & $\begin{array}{l}\text { Minimum } \\
\text { Detection } \\
\text { Threshold }\end{array}$ & $\begin{array}{c}\text { False } \\
\text { Positive } \\
\text { Rate }\end{array}$ & $\begin{array}{c}\text { False } \\
\text { Negative } \\
\text { Rate }\end{array}$ & $\begin{array}{l}\text { Minimum } \\
\text { False } \\
\text { Reporting } \\
\text { Rate }\end{array}$ & $\begin{array}{l}\text { Minimum } \\
\text { Detection } \\
\text { Threshold }\end{array}$ & $\begin{array}{c}\text { False } \\
\text { Positive } \\
\text { Rate }\end{array}$ & $\begin{array}{c}\text { False } \\
\text { Negative } \\
\text { Rate }\end{array}$ \\
\hline \multirow{2}{*}{$\begin{array}{l}2.5-3.5 \\
\text { ppmv }\end{array}$} & 10 & 0.107 & 2.8 & 0 & 0.355 & 0.052 & 3.5 & 0.005 & 0.203 \\
\hline & 1 & 0.056 & 2.8 & 0 & 0.222 & 0.012 & 3.3 & 0.010 & 0.019 \\
\hline \multirow{2}{*}{$\begin{array}{l}2.5-5.5 \\
\text { ppmv }\end{array}$} & 10 & 0.103 & 4.7 & 0 & 0.317 & 0.048 & 3.7 & 0.000 & 0.214 \\
\hline & 1 & 0.056 & 2.8 & 0 & 0.222 & 0.012 & 3.3 & 0.010 & 0.019 \\
\hline
\end{tabular}

Table 10: Peak Sensitivity Analysis of the Validation Data Before and After Reconstruction using the ANN.

\begin{tabular}{|c|c|c|c|c|c|c|c|c|c|}
\hline & & \multicolumn{4}{|c|}{ UGGA } & \multicolumn{3}{|c|}{ UGGA Reconstructed } \\
\cline { 3 - 9 } $\begin{array}{c}\text { Sensitivity } \\
\text { Range }\end{array}$ & $\begin{array}{c}\text { LI-7700 } \\
\text { Frequency }\end{array}$ & $\begin{array}{c}\text { Minimum } \\
\text { False } \\
\text { Reporting } \\
\text { Rate }\end{array}$ & $\begin{array}{c}\text { Minimum } \\
\text { Detection } \\
\text { Threshold }\end{array}$ & $\begin{array}{c}\text { False } \\
\text { Positive } \\
\text { Rate }\end{array}$ & $\begin{array}{c}\text { False } \\
\text { Negative } \\
\text { Rate }\end{array}$ & $\begin{array}{c}\text { Minimum } \\
\text { False } \\
\text { Reporting } \\
\text { Rate }\end{array}$ & $\begin{array}{c}\text { Minimum } \\
\text { Detection } \\
\text { Threshold }\end{array}$ & $\begin{array}{c}\text { False } \\
\text { Positive } \\
\text { Rate }\end{array}$ & $\begin{array}{c}\text { False } \\
\text { Negative } \\
\text { Rate }\end{array}$ \\
\hline $\begin{array}{c}\mathbf{2 . 5 - 3 . 5} \\
\text { ppmv }\end{array}$ & 10 & 0.117 & 3.1 & 0 & 0.317 & 0.072 & 2.9 & 0 & 0.186 \\
\cline { 2 - 10 } & 1 & 0.063 & 3.4 & 0 & 0.226 & 0.018 & 3.4 & 0 & 0.065 \\
\hline
\end{tabular}




\subsection{2 $2 \mathrm{~Hz}$ Reconstruction}

\subsubsection{Initial $2 \mathrm{~Hz}$ Data}

As discussed earlier, faster sampling rates are available for closed-path analyzers. The goal was to include a $5 \mathrm{~Hz}$ version of the UGGA (methane and ethane) in these analyses, but the analyzer was not available due to construction delays of the analyzer. However, the up sampling of the current UGGA was conducted to understand any implications. Linear interpolation was required to create the $2 \mathrm{~Hz}$ signal and its derivatives for the UGGA. The LI-7700 was down sampled to $2 \mathrm{~Hz}$ using a forward average. Table 11 presents the PV and its components of the initial data at $2 \mathrm{~Hz}$.

Table 11: PV Breakdown of Initial Data at $2 \mathrm{~Hz}$.

\begin{tabular}{|c|c|c|c|c|c|}
\hline & PE & $\mathbf{r}^{\mathbf{2}}$ & SEE & PIE & PV \\
\hline AVG & 0.692 & 0.215 & 0.085 & 0.101 & 0.346 \\
\hline VAR & 0.053 & 0.058 & 0.002 & 0.018 & 0.027 \\
\hline MAX & 0.979 & 0.949 & 0.216 & 0.531 & 0.774 \\
\hline MIN & 0.100 & 0.000 & 0.019 & 0.005 & 0.079 \\
\hline
\end{tabular}

\subsubsection{Self-Training DCM}

Using the 43 trips, $2 \mathrm{~Hz}$ reconstruction was attempted using the DCM. The coefficients were limited to the same search space as $1 \mathrm{~Hz}$, despite the increased computational time with a longer signal. Table 12 shows the average, variance, maximum and minimum of the 43 trips with each trips PV and components presented in Appendix IX. The average PV was 0.037 higher than the initial data at $2 \mathrm{~Hz}$. Table 13 displays the improvement of the PV at $2 \mathrm{~Hz}$ compared to the initial PVs at $1 \mathrm{~Hz}$.

Table 12: PV Breakdown of Self-Trained DCM at $2 \mathrm{~Hz}$.

\begin{tabular}{|c|c|c|c|c|c|}
\hline & PE & $\mathbf{r}^{2}$ & SEE & PIE & PV \\
\hline AVG & 0.602 & 0.221 & 0.098 & 0.220 & 0.383 \\
\hline VAR & 0.068 & 0.069 & 0.003 & 0.073 & 0.028 \\
\hline MAX & 0.957 & 0.939 & 0.263 & 0.955 & 0.790 \\
\hline MIN & 0.019 & 0.000 & 0.020 & 0.000 & 0.114 \\
\hline
\end{tabular}


Table 13: Relative Changes of the PV Breakdown of Self-Trained Trips DCM at $2 \mathrm{~Hz}$ Compared to the $2 \mathrm{~Hz}$ Initial PV Breakdown.

\begin{tabular}{|c|c|c|c|c|c|}
\hline & PE & $\mathbf{r}^{\mathbf{2}}$ & SEE & PIE & PV \\
\hline AVG & -0.082 & 0.007 & 0.013 & 0.121 & 0.033 \\
\hline VAR & 0.014 & 0.013 & 0.001 & 0.057 & 0.001 \\
\hline MAX & -0.023 & -0.009 & 0.047 & 0.424 & 0.015 \\
\hline MIN & -0.081 & 0.000 & 0.001 & -0.005 & 0.035 \\
\hline
\end{tabular}

A section of trip 545 at $2 \mathrm{~Hz}$ is shown in Figure 42 with a PV of 0.473 . The DCM provided only a $10.7 \%$ improvement at $2 \mathrm{~Hz}$ and thus was not investigated further. It was noticed that $2 \mathrm{~Hz}$ reconstruction was not properly time aligned. Because time alignment was only available at $1 \mathrm{~Hz}, 2 \mathrm{~Hz}$ reconstruction experienced errors in PV calculation.

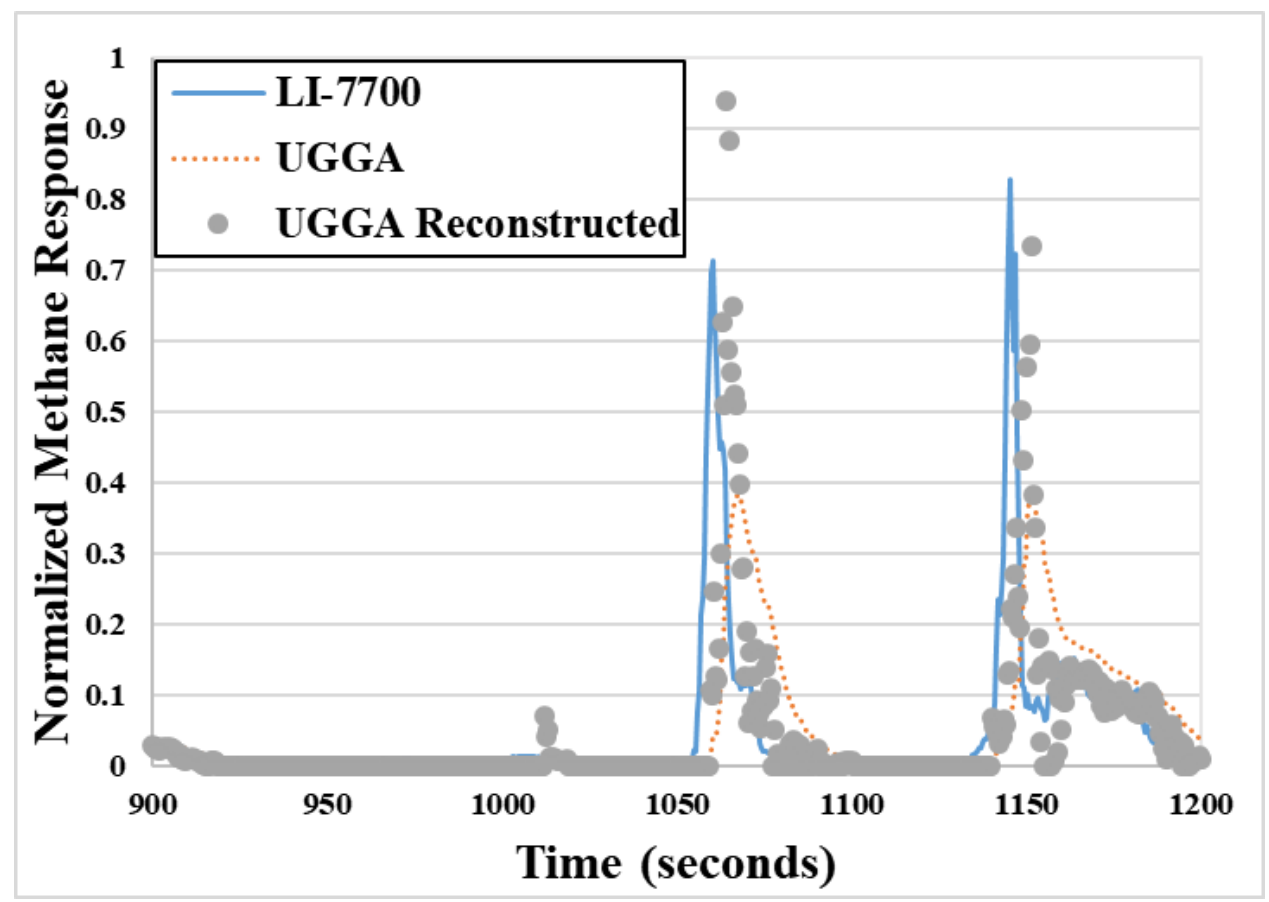

Figure 42: Trip 545, LI-7700 vs Reconstructed UGGA Self-Trained DCM at 2 Hz: $\mathrm{PV}=0.473, \mathrm{PE}=0.477, \mathrm{r}^{2}=0.222, \mathrm{SEE}=0.062, \mathrm{PIE}=0.015$.

\subsubsection{ANN with Derivatives}

Using all the collected trip data at $2 \mathrm{~Hz}$, the data was split into training and validation data. A different ANN was trained and validated for $2 \mathrm{~Hz}$ using the same setup parameters. Figure 43 displays a section of 
the training data at $2 \mathrm{~Hz}$. The $2 \mathrm{~Hz} \mathrm{PV}$ for the initial data was 0.354 and the $\mathrm{PV}$ of the $2 \mathrm{~Hz}$ training data was 0.699 . The improvement was an increase of $97.5 \%$.

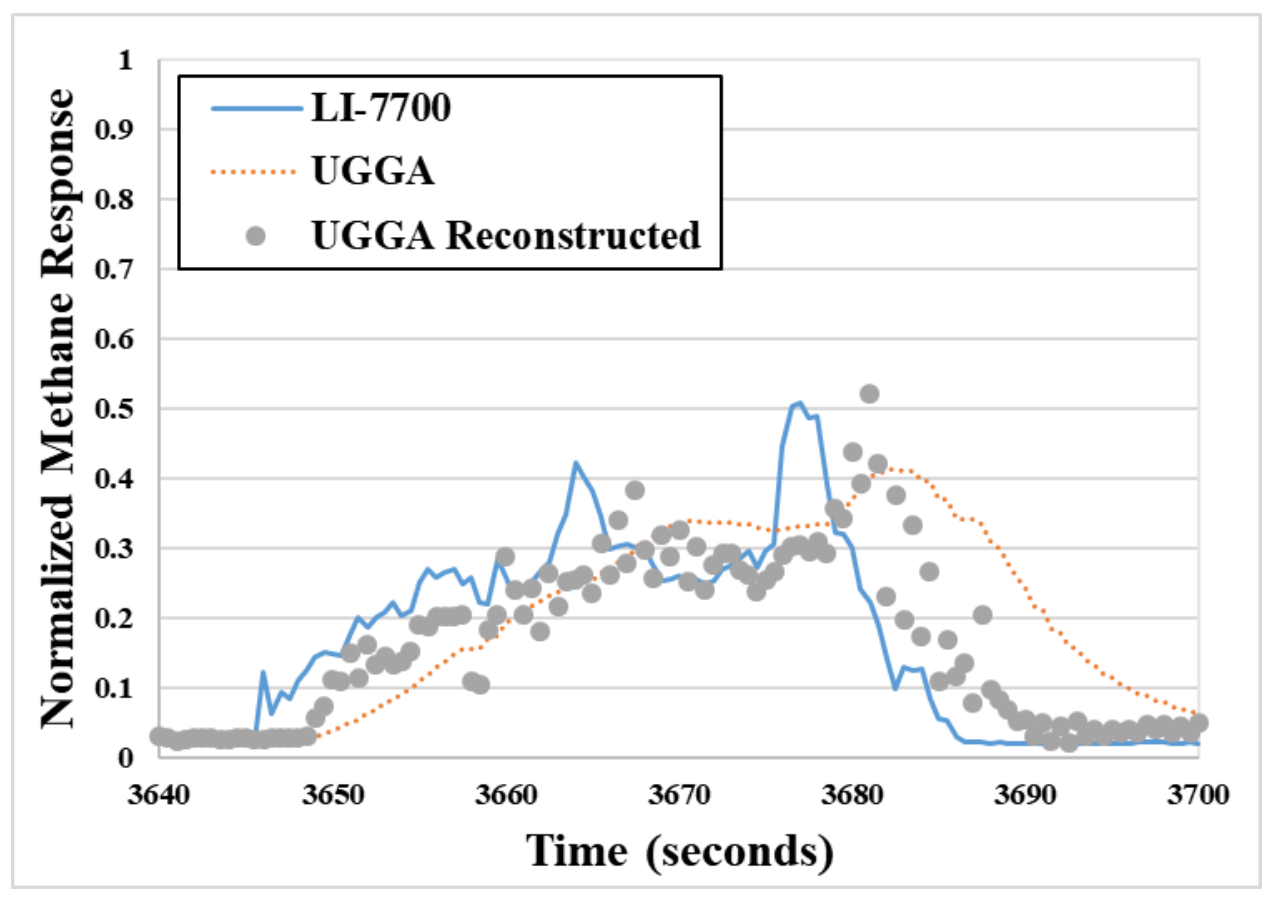

Figure 43: Reconstruction of a Section of Training Data using ANN at 2 Hz: $P V=0.699, P E=0.362, r^{2}=0.759$, SEE $=0.048, P I E=0.219$.

Figure 44 displays a section of the validation data at $2 \mathrm{~Hz}$. The $2 \mathrm{~Hz} \mathrm{PV}$ for the initial data was 0.335 and the PV of the $2 \mathrm{~Hz}$ validation data was 0.663 . The improvement was an increase of $97.9 \%$. The ANN at 2 $\mathrm{Hz}$ displayed the time alignment issue and up sampling issues as the DCM; however, the improvement of the training and validation data using the ANN led to the implementation of the detection threshold sensitivity analysis at $2 \mathrm{~Hz}$. 


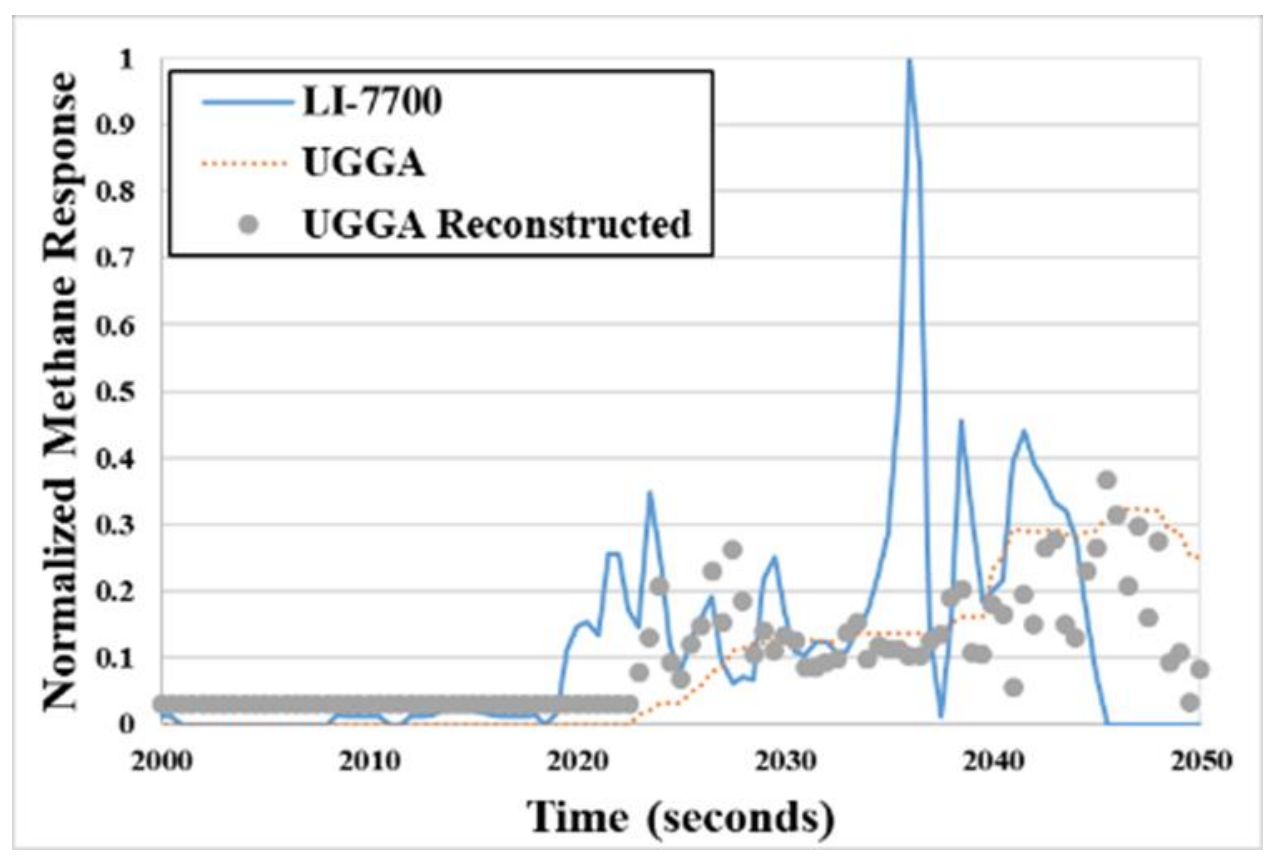

Figure 44: Reconstruction of the Validation Data using ANN at $2 \mathrm{~Hz}$ : $P V=0.663, P E=0.326, r^{2}=0.565$, SEE $=0.059, P I E=0.105$.

To determine the optimal detection threshold, detection threshold sensitivity analysis was conducted.

Tables 14, 15, and 16 display the results of detection threshold sensitivity analysis for the entire data, testing data, and validation for the UGGA and reconstructed UGGA. The $2 \mathrm{~Hz}$ ANN created more false positives and negatives during reconstruction which increased the false positive, false negative, and false reporting rate from reconstruction. 
Table 14: Peak Sensitivity Analysis of all the Data Before and After Reconstruction at $2 \mathrm{~Hz}$ using the ANN.

\begin{tabular}{|c|c|c|c|c|c|c|c|c|c|}
\hline \multirow[b]{2}{*}{$\begin{array}{c}\text { Sensitivity } \\
\text { Range }\end{array}$} & \multirow[b]{2}{*}{$\begin{array}{l}\text { LI-7700 } \\
\text { Frequency }\end{array}$} & \multicolumn{4}{|c|}{ UGGA } & \multicolumn{4}{|c|}{ UGGA Reconstructed } \\
\hline & & $\begin{array}{c}\text { Minimum } \\
\text { False } \\
\text { Reporting } \\
\text { Rate }\end{array}$ & $\begin{array}{l}\text { Minimum } \\
\text { Detection } \\
\text { Threshold }\end{array}$ & $\begin{array}{c}\text { False } \\
\text { Positive } \\
\text { Rate }\end{array}$ & $\begin{array}{c}\text { False } \\
\text { Negative } \\
\text { Rate }\end{array}$ & $\begin{array}{c}\text { Minimum } \\
\text { False } \\
\text { Reporting } \\
\text { Rate }\end{array}$ & $\begin{array}{l}\text { Minimum } \\
\text { Detection } \\
\text { Threshold }\end{array}$ & $\begin{array}{c}\text { False } \\
\text { Positive } \\
\text { Rate }\end{array}$ & $\begin{array}{c}\text { False } \\
\text { Negative } \\
\text { Rate }\end{array}$ \\
\hline \multirow{2}{*}{$\begin{array}{c}2.5-3.5 \\
\text { ppmv }\end{array}$} & 10 & 0.118 & 2.7 & 0 & 0.347 & 0.242 & 3.5 & 0.124 & 0.567 \\
\hline & 2 & 0.069 & 2.8 & 0 & 0.245 & 0.215 & 3.5 & 0.128 & 0.519 \\
\hline \multirow{2}{*}{$\begin{array}{l}2.5-5.5 \\
\text { ppmv }\end{array}$} & 10 & 0.113 & 4.7 & 0 & 0.500 & 0.157 & 5.2 & 0.014 & 0.663 \\
\hline & 2 & 0.058 & 5.3 & 0 & 0.368 & 0.113 & 5.5 & 0.026 & 0.589 \\
\hline
\end{tabular}

Table 15: Peak Sensitivity Analysis of the Training Data Before and After Reconstruction at $2 \mathrm{~Hz}$ using the ANN.

\begin{tabular}{|c|c|c|c|c|c|c|c|c|c|}
\hline \multirow[b]{2}{*}{$\begin{array}{c}\text { Sensitivity } \\
\text { Range }\end{array}$} & \multirow[b]{2}{*}{$\begin{array}{c}\text { LI-7700 } \\
\text { Frequency }\end{array}$} & \multicolumn{4}{|c|}{ UGGA } & \multicolumn{4}{|c|}{ UGGA Reconstructed } \\
\hline & & $\begin{array}{c}\text { Minimum } \\
\text { False } \\
\text { Reporting } \\
\text { Rate }\end{array}$ & $\begin{array}{l}\text { Minimum } \\
\text { Detection } \\
\text { Threshold }\end{array}$ & $\begin{array}{c}\text { False } \\
\text { Positive } \\
\text { Rate }\end{array}$ & $\begin{array}{c}\text { False } \\
\text { Negative } \\
\text { Rate }\end{array}$ & $\begin{array}{l}\text { Minimum } \\
\text { False } \\
\text { Reporting } \\
\text { Rate }\end{array}$ & $\begin{array}{l}\text { Minimum } \\
\text { Detection } \\
\text { Threshold }\end{array}$ & $\begin{array}{c}\text { False } \\
\text { Positive } \\
\text { Rate }\end{array}$ & $\begin{array}{c}\text { False } \\
\text { Negative } \\
\text { Rate }\end{array}$ \\
\hline \multirow{2}{*}{$\begin{array}{c}2.5-3.5 \\
\text { ppmv }\end{array}$} & 10 & 0.107 & 2.8 & 0 & 0.355 & 0.274 & 3.5 & 0.155 & 0.661 \\
\hline & 2 & 0.056 & 2.8 & 0 & 0.222 & 0.246 & 3.5 & 0.153 & 0.620 \\
\hline \multirow{2}{*}{$\begin{array}{c}2.5-5.5 \\
\text { ppmv }\end{array}$} & 10 & 0.103 & 4.7 & 0 & 0.531 & 0.155 & 5.2 & 0.010 & 0.787 \\
\hline & 2 & 0.056 & 2.8 & 0 & 0.222 & 0.103 & 5.5 & 0.009 & 0.706 \\
\hline
\end{tabular}


Table 16: Peak Sensitivity Analysis of the Validation Data Before and After Reconstruction at 2 Hz using the ANN.

\begin{tabular}{|c|c|c|c|c|c|c|c|c|c|}
\hline \multirow[b]{2}{*}{$\begin{array}{c}\text { Sensitivity } \\
\text { Range }\end{array}$} & \multirow[b]{2}{*}{$\begin{array}{c}\text { LI-7700 } \\
\text { Frequency }\end{array}$} & \multicolumn{4}{|c|}{ UGGA } & \multicolumn{4}{|c|}{ UGGA Reconstructed } \\
\hline & & $\begin{array}{c}\text { Minimum } \\
\text { False } \\
\text { Reporting } \\
\text { Rate }\end{array}$ & $\begin{array}{l}\text { Minimum } \\
\text { Detection } \\
\text { Threshold }\end{array}$ & $\begin{array}{c}\text { False } \\
\text { Positive } \\
\text { Rate }\end{array}$ & $\begin{array}{c}\text { False } \\
\text { Negative } \\
\text { Rate }\end{array}$ & $\begin{array}{l}\text { Minimum } \\
\text { False } \\
\text { Reporting } \\
\text { Rate }\end{array}$ & $\begin{array}{l}\text { Minimum } \\
\text { Detection } \\
\text { Threshold }\end{array}$ & $\begin{array}{c}\text { False } \\
\text { Positive } \\
\text { Rate }\end{array}$ & $\begin{array}{c}\text { False } \\
\text { Negative } \\
\text { Rate }\end{array}$ \\
\hline \multirow{2}{*}{ 2.5-3.5 ppmv } & 10 & 0.117 & 3.1 & 0 & 0.317 & 0.153 & 3.3 & 0.042 & 0.359 \\
\hline & 2 & 0.063 & 3.4 & 0 & 0.226 & 0.135 & 3.4 & 0.063 & 0.323 \\
\hline
\end{tabular}




\subsection{Signal Reconstruction Conclusions}

The reconstruction methods of SIT, IFFT, ANN, and DCM were examined to create a sharp UGGA methane response to match the LI-7700 and therefore reduce false negatives (i.e. missed plumes). The SIT and IFFT were determined to be unusable in mobile methane systems without continued operation of the LI-7700. Both the DCM and ANN were investigated further at 1 and $2 \mathrm{~Hz}$.

At $1 \mathrm{~Hz}$, the DCM was applied using the average least squared error to determine the DCM coefficients. Using the 43 trip files, each file was trained for a unique set of coefficients. The average PV improvement of the trip files was an increase of $25 \%$. All 43 sets of coefficients were applied to all 43 trip files. The best set of coefficients improved the average PV of the trip files by $35 \%$. Performing detection threshold sensitivity analysis, the best DCM coefficients resulted in a decrease in the false reporting rate by $67 \%$ and $75.3 \%$ for 10 and $1 \mathrm{~Hz}$ peaks, respectively. The best detection threshold for the LI-7700 peaks at 10 $\mathrm{Hz}$ was 5.2 ppmv. Due to the observance of other mobile methane system's detection thresholds, the detection threshold should remain between 2.5 ppmv and 3.5 ppmv.

An ANN was created as a function fitting network with 10 nodes and 10,000 iterations. Using the holdout cross validation ratio of $70 \%$ training, all the trip files were split into training and validation data. The PV of the training data improved by $75.6 \%$ and the PV of validation data improved by $68.3 \%$. The total PV increased by the initial detection thresholds of $2.7 \mathrm{ppmv}$ and $2.6 \mathrm{ppmv}$ for $10 \mathrm{~Hz}$ and $1 \mathrm{~Hz} \mathrm{LI}-7700$ peaks resulted in decreases of the false negative rate by $51.3 \%$ and $75.7 \%$ but created false positives.

Performing detection threshold sensitivity analysis, the best detection thresholds resulted in a decrease in the false reporting rate by $48.3 \%$ and $77.9 \%$ for 10 and $1 \mathrm{~Hz}$ peaks, respectively. The best detection thresholds were 3.5 ppmv and 3.3 ppmv.

At $2 \mathrm{~Hz}$, the DCM was trained and resulted in an increase of the average PV by $10.7 \%$. An ANN trained and resulted in an increase of the validation data by $97.9 \%$. The $2 \mathrm{~Hz}$ ANN increased the detection 
threshold. The $2 \mathrm{~Hz}$ data was shown to create false positives and increase the number of false negatives and thus limited the up sampling ability of the UGGA.

Using the reconstruction results, both the DCM and ANN produced improvements to the PV. The DCM required different coefficients to optimize both PV and detection thresholds; however, the ANN improved the validation set for both the PV and detection thresholds. At $1 \mathrm{~Hz}$ peaks, the ANN improved the average PV by $72.6 \%$ while reducing false negatives by $80.7 \%$.

To apply signal reconstruction without the LI-7700, the UGGA was not required to be normalized, reconstructed, and denormalized. Instead, the reconstruction was applied the methane signal reported by the UGGA after time alignment. Figure 45 displays denormalized methane responses of the LI-7700, the initial UGGA and the UGGA reconstructed by the ANN. Using the reconstruction methods, a postprocessing application was created for future works.

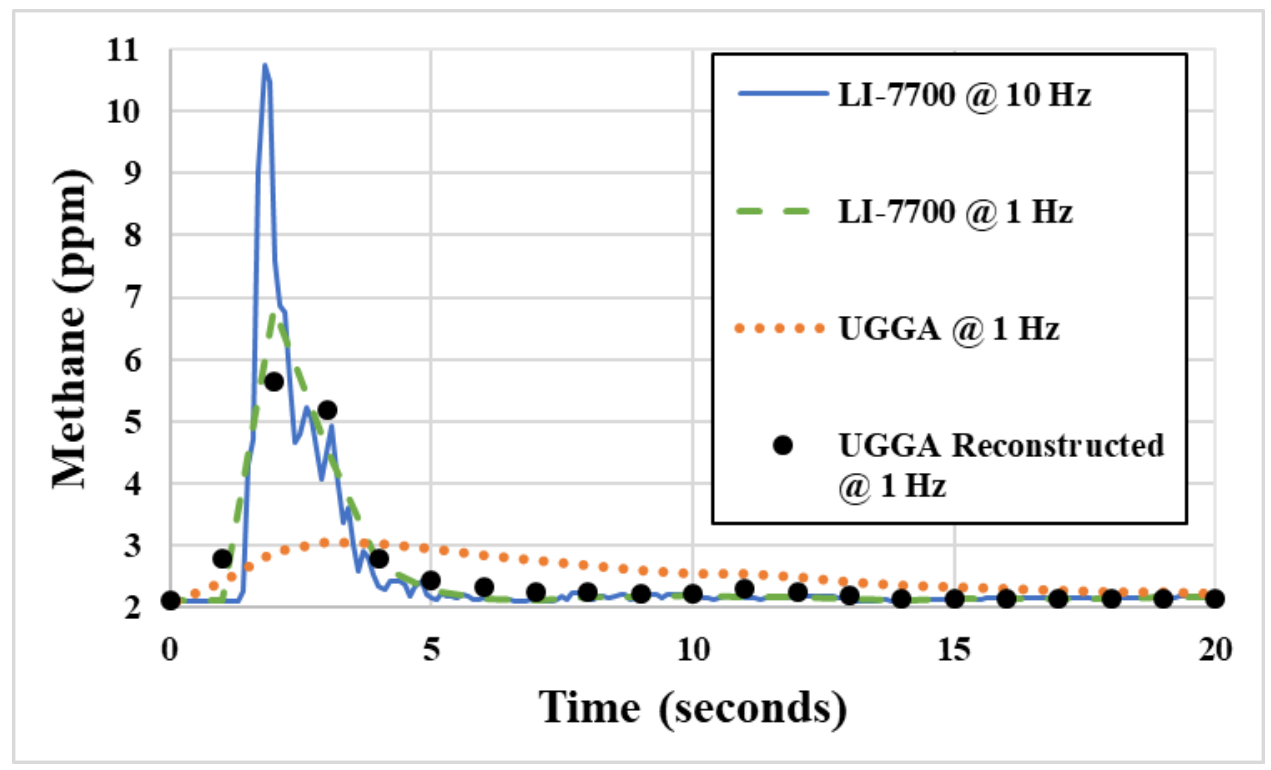

Figure 45: Methane Responses by the LI-7700, the initial UGGA, and the UGGA Reconstructed by the ANN. 


\section{Post-Processing}

Using $\mathrm{MATLAB}^{\odot}$, an application (app) called Mobile Methane was created to simplify processing trip data after collection. Once completed, the application created a Google ${ }^{\circledR}$ Earth Map file (.kmz) for a visual representation of the data collected with a MATLAB ${ }^{\odot}$ workspace file (.mat) saving important variables. This ease of access was designed for a simplified and user friendly processing. Note, such an application could prove beneficial in identifying possible sources of methane emissions if wind direction can be estimated and locations of natural gas sites can be mapped respective to the driving trace.

\subsection{MATLAB ${ }^{\odot}$ Application (App)}

MATLAB $^{\odot}$ 's application designer allowed for the design and implementation of data presentation for the mobile methane detection into a seamless application. Using Scimitar's Mobile Methane setup (valid .xml parameter tree), data were processed in the Mobile Methane. While data were not required to be collected using Scimitar's Mobile Methane setup, the data must be labelled similarly with similar units in Microsoft Excel.

For machines using $\mathrm{MATLAB}^{\odot}$, the user can install and execute the Mobile Methane app. By selecting the apps tab and running Mobile Methane, the initial startup window appears, as displayed in Figure 46. There are a few options to perform in Mobile Methane with a dialog box to view and receive messages from the app. The dialog box, denoted "Reports", begins with instructions on how to use Mobile Methane. Any user unfamiliar with the app is able to read the reports and begin processing Mobile Methane data. As shown, Figure 46 contains 3 options, "Create Mobile Methane", "Load Mobile Methane", or "Apply .mat to Create Mobile Methane" and the choice of file type. The app requires the choice between an excel file (.xls) or Scimitar file (.tz) on the main app window before any operation is performed. 


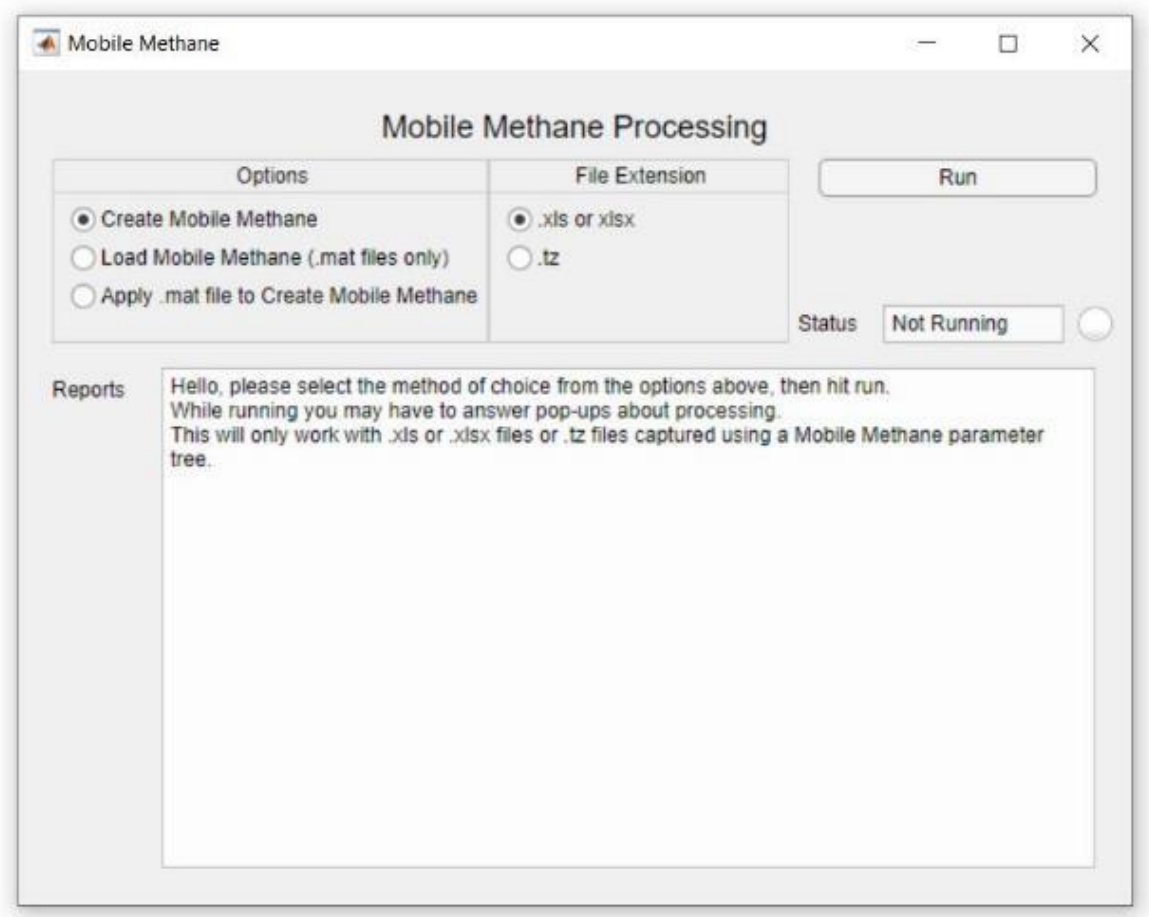

Figure 46: Mobile Methane App Main Window.

"Create Mobile Methane" is the basis for Mobile Methane. After pressing the run button, the app prompts questions, via a new window, asking the user's preferences. It begins by asking if the user would like to perform a KML package including a KML file creation and UGGA Reconstruction. A KML file creation attempts to plot all data of the trip to Google ${ }^{\circledR}$ Earth. UGGA reconstruction attempts to reconstruct the UGGA's original signal to the LI-7700's signal. If the user declines to perform a KML package, then the user is prompted to select the KML package pieces individually.

The app prompts the user to determine if they are processing multiple files combined, multiple files separated, or a single file. Multiple files combined is a combination of all the files into single trip file with a name combining all the trip files. Multiple files separated processes multiple files using the initial user prompts. If a multiple files option is selected but the user only selects a single file, then Mobile Methane processes the file as if the user selected single file option.

Next, the user is asked the frequency for reconstruction at either $1 \mathrm{~Hz}, 2 \mathrm{~Hz}, 5 \mathrm{~Hz}$ or $10 \mathrm{~Hz}$. The $5 \mathrm{~Hz}$ and $10 \mathrm{~Hz}$ reconstruction frequencies were added to Mobile Methane for future use that may implement a 
higher frequency methane analyzer. Once ready, a file selector appears asking for the files desired with the extension selected earlier.

Because Mobile Methane was used to process all trip data, reconstruction methods and options are available to the user's discretion. If reconstruction was selected, then the user is prompted to indicate the reconstruction method, number of derivatives. The reconstruction methods consist of the DCM and ANN. The maximum number of derivatives available is four.

After reconstruction, if the KML file creation was selected, then the user is prompted to enter the detection threshold desired. The default detection threshold is 3 ppmv. A Google ${ }^{\circledR}$ Earth mapping, if selected, and a MATLAB ${ }^{\odot}$ workspace save file are saved with the name of the file. This allows the user to see the mobile methane detection path and review the data file.

"Load Mobile Methane" requires a MATLAB ${ }^{\odot}$ workspace save file previously created. If there is not a MATLAB $^{\odot}$ workspace file available, Mobile Methane fails. If there is an available MATLAB $^{\odot}$ workspace file, then the app prompts the user to select a file with the extension .mat. Using the MATLAB $^{\odot}$ workspace window, data from the processed Mobile Methane MATLAB $^{\odot}$ workspace file appears. It contains data on reconstruction, mapping, user inputs, and sampling distance. The reconstruction data consists of the method chosen information, the reconstructed points, the coefficients or network of the method, and the PV breakdown. Mapping consists of all the data used for Google ${ }^{\circledR}$ Earth map creation. Sampling distance data contains various sampling frequency limitation data. All the data saved were used for comparisons.

“Apply .mat to Create Mobile Methane” allows the user to take a processed Mobile Methane MATLAB ${ }^{\odot}$ workspace file and apply its training data to another Mobile Methane trip file. This combines the steps of both "Create Mobile Methane" and "Load Mobile Methane". Following the same initial steps as Create Mobile Methane, the app requires all the same prompts except reconstruction-based prompts. Using the $\mathrm{MATLAB}^{\odot}$ workspace file, the app imports the reconstruction options and applies them to the new file. 
Instead of training the new file based on itself, the app simply reconstructs the new file using the completed training coefficients or signal defined in the MATLAB ${ }^{\odot}$ workspace file. If reconstruction was not attempted in the $\mathrm{MATLAB}^{\odot}$ workspace file chosen, then Mobile Methane fails. Once completed, the app creates a Google ${ }^{\circledR}$ Earth file, if selected, and a MATLAB ${ }^{\odot}$ workspace file using the full name of the original file with the addition of '_tr_' and the last 3 characters from the MATLAB $^{\odot}$ workspace file. This allows the user to know which file trained the newly created Mobile Methane.

\subsection{Google ${ }^{\circledR}$ Earth Mapping}

After the Mobile Methane app processes a file, a Google ${ }^{\circledR}$ Earth file is created. Contained in the Google ${ }^{\circledR}$ Earth file is the data of the newly processed file shown visually in Google ${ }^{\circledR}$ Earth.

Once the Google ${ }^{\circledR}$ Earth file is open, the user is taken to an overview the route, as shown in Figure 47. This window displays the full route for the viewer with the route options in the left window called Places. Using the Places window, the user has access to nine selectable routes under the file consisting of fast, slow, and reconstructed systems. When initially loaded, the LI-7700 concentration is displayed. Due to being selectable, the user can view multiple routes at the same time if desired. 


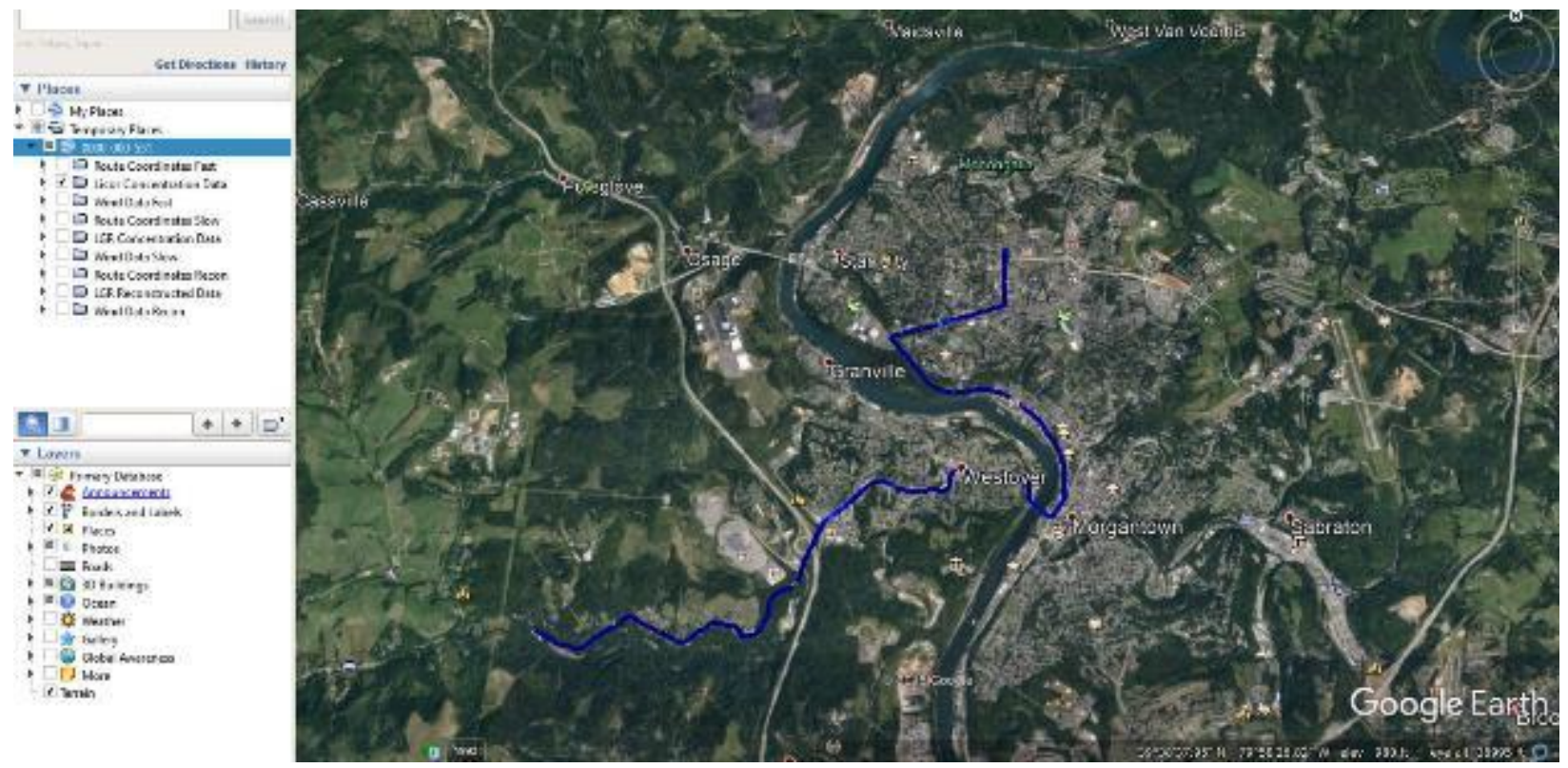

Figure 47: Overhead Display of Google ${ }^{\circledR}$ Earth Mapping.

The methane concentration, wind direction, and path are plotted for fast, slow, and reconstructed routes. The fast route plots the data recorded from the LI-7700 and WindMaster at the points recorded by the EVK-M8U, while the slow route plots the UGGA and WindSonic at the points recorded by the BU353S4. The reconstructed route plots the attempted reconstruction of the UGGA with the WindSonic and $\mathrm{BU}$ at the reconstructed frequency.

Each data set contains a selectable wind direction, methane concentration, and the path. This allows better viewing due to multiple routes overlaying on each other. Figure 48 shows the fast route's LI-7700 concentration. The methane concentrations of the LI-7700, UGGA, and reconstructed UGGA are mapped as displayed in Figure 48. The maximum point in the file is always red while any points below the detection threshold implemented are blue. After changing selections, Figure 49 shows the wind direction arrows of the $1 \mathrm{~Hz}$ route. The wind direction data from the WindMaster and WindSonic in each route is similar to Figure 49. The wind arrow only depicts direction, as wind speed is noted in the description; however, Google ${ }^{\circledR}$ Earth does not depict wind arrows at locations where the limiting equations were violated. 


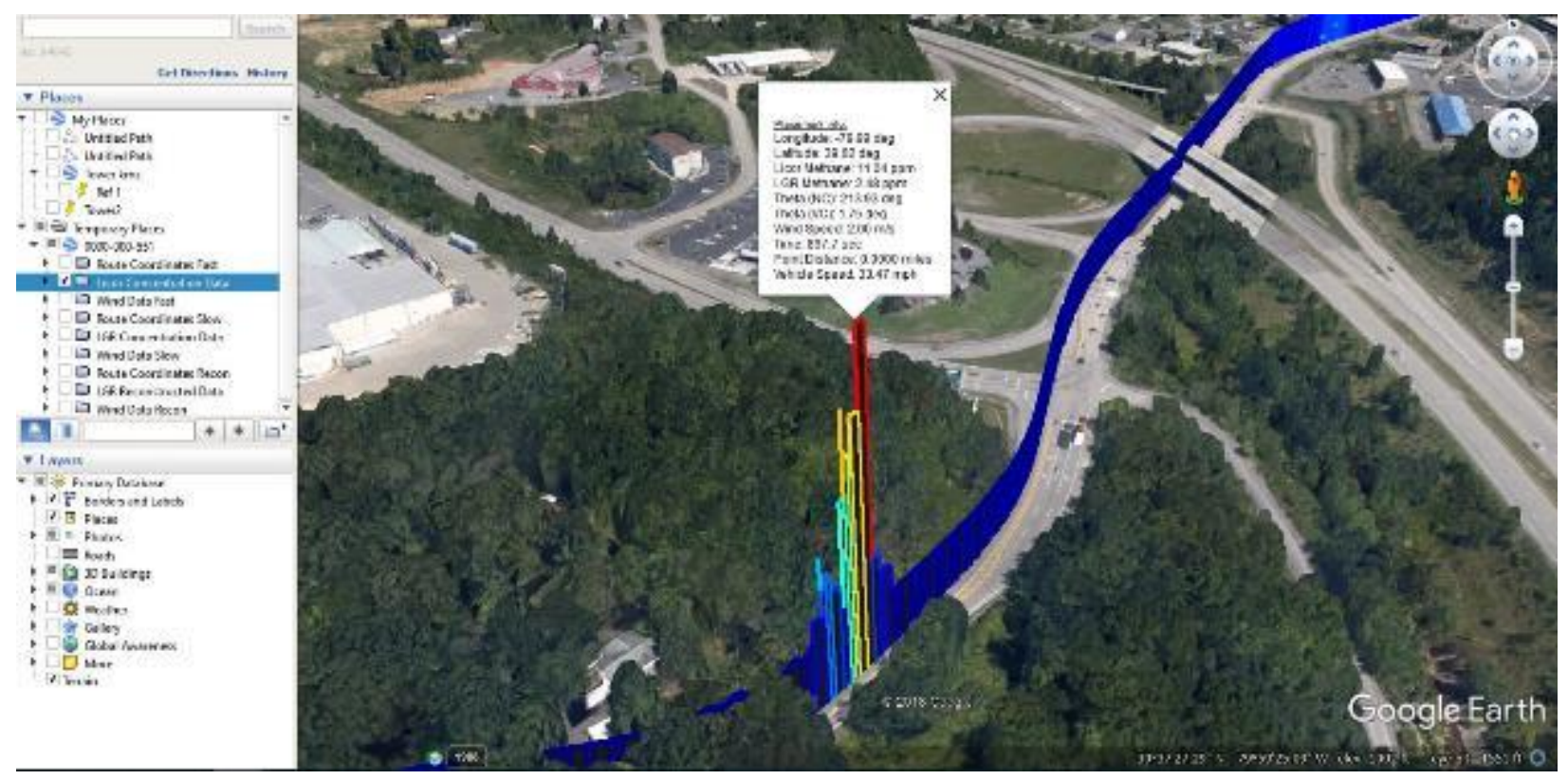

Figure 48: Methane Concentration Mapped unto the Vehicle Route.

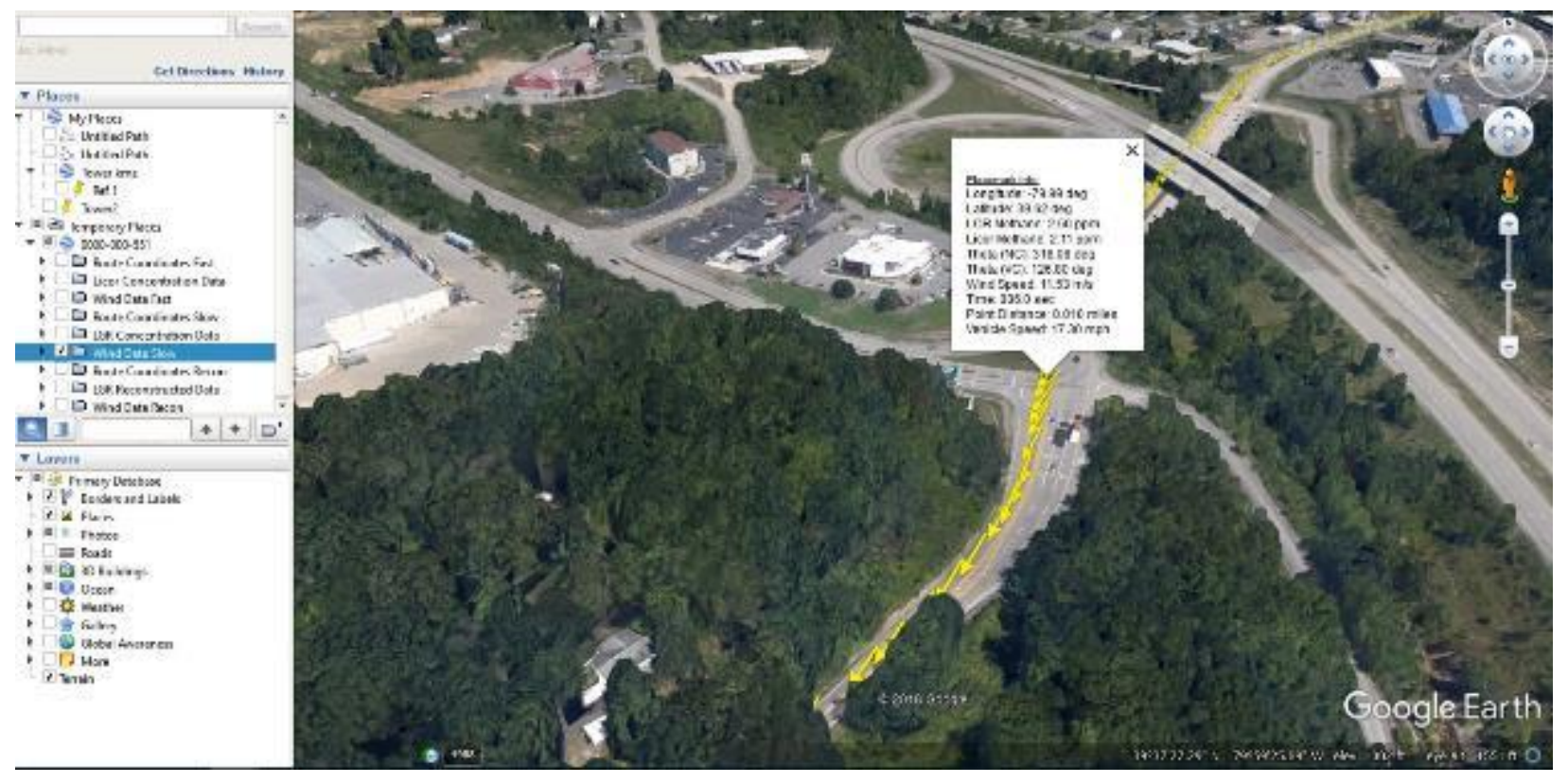

Figure 49: Wind Direction Mapped unto the Vehicle Route.

Due to multiple points laying near or occasionally on top of each other, each point in all the data sets has a description point. To access the description, click on a point in the route desired and a text box appears depicting the qualitative data for the points. Figures 48 and 49 contain examples of the description box. 
Mobile Methane's implementation allows the user to input the file, select choices, and let the app process the data. Any data required is saved for later use and the path is mapped onto a Google ${ }^{\circledR}$ Earth file.

\subsection{Post-Processing Review}

Using MATLAB ${ }^{\odot}$ and Google ${ }^{\circledR}$ Earth, the reconstruction of the UGGA was simplified. A MATLAB ${ }^{\odot}$ application processed the trip data, reconstructed the UGGA and created a Google ${ }^{\circledR}$ Earth File. In Google ${ }^{\circledR}$ Earth, the trip was visible as a path, methane concentration, and wind direction for the fast, slow, and reconstructed systems. Using the limiting equation and detection thresholds defined earlier, the elevated methane plumes with proper wind conditions were displayed for convenient methane detection. With the simplification in post-processing, the requirements and recommendations of its implementations can be determined.

\section{Conclusions, Recommendations, and Future Applications}

\subsection{Conclusions}

While natural gas may yield lower $\mathrm{CO}_{2}$ from combustion compared to coal and petroleum, methane is a potent greenhouse gas with a GWP of 28 over 100 years [95]. To combat methane emissions, researchers have worked on improving methane detection processes. The application of two mobile methane detection systems were compared in the ability to identify methane plumes near atmospheric levels.

Various analyzers and sensors were reviewed and included FID, FTIR, OGI, IR, MOS, catalytic bead sensors, and spectroscopy techniques. After review, the methane analyzers selected for each system were the LI-7700 and the UGGA, which represent nearly the state-of-the-art in both open- and closed-path approaches. The open-path WMS at $10 \mathrm{~Hz}$ of the LI-7700 and the closed-path OA-ICOS at $1 \mathrm{~Hz}$ of the UGGA allowed for near atmospheric levels of detection. Each system consisted of a methane analyzer, a sonic anemometer, and a GPS. Both systems were deployed simultaneously in the Morgantown, WV surrounding area for a total of 15 hours. 
During initial field testing, it was apparent that the LI-7700 and the UGGA reported different methane concentrations. After time alignment, the UGGA reported lower concentrations (by up to 94.6\%) and had a smeared methane response when compared to the LI-7700. Using the statistics of the data recorded by both systems a performance value (PV) was defined to quantify the comparison between the methane responses. The average PV of the initial data set was 0.512 , with 3 ppmv was defined as the initial detection threshold for determining methane sources. Of the 363 plumes, the UGGA had a false negative rate of $40.2 \%$. This meant that the slower, closed-path system would have "missed" $40 \%$ of possible plumes detected by a fast, open-path analyzer. The initial data led to the investigation of the limitations of the systems.

Each system was observed with respect to geospatial, wind, and peak limitations. Geospatial limitations were associated with GR and required a speed limit if a certain GR was required. Because of the influence of sampling frequency, the LI-7700's GR was a tenth that of the UGGA. The wind limitations consisted of the wind error calculation in the correction of wind speed during vehicle speeds. It was determined that the $33.9 \%$ and $22.6 \%$ of the moving data for the fast system and slow system could not determine the wind direction quadrant. The peak limitations observed the effect of the detection threshold. Using a sensitivity analysis, the best detection threshold was determined to be $2.6 \mathrm{ppmv}$ for $1 \mathrm{~Hz}$, but the UGGA still reported a false negatives rate of $24.3 \%$. As a reminder, a false negative meant that the UGGA did not identify a plume based on a given threshold even though the open-path system did identify a possible plume.

The UGGA was shown to require a correction method to detect methane reported by the LI-7700. The SIT, IFFT, ANN, and DCM reconstruction methods were investigated to correct the UGGA to match the LI-7700's methane response at $1 \mathrm{~Hz}$. The DCM and ANN were investigated to reduce the number of false negatives reported by the UGGA while removing the LI-7700 from operation.

The DCM was trained using linear least squares for each trip and resulted in an average PV of 0.644 . The coefficients created from each trip were applied to all trip files. The best average PV of the coefficient 
application was 0.692. A total of 42 of the 43 sets of DCM coefficients resulted in a decrease in false negative rate for the detection threshold of $2.6 \mathrm{ppmv}$, but all sets yielded unacceptable false positives rates. A detection threshold sensitivity analysis determined that the best trip coefficients resulted in a false reporting rate decrease of $75.3 \%$ for the LI-7700 at $1 \mathrm{~Hz}$.

A function fitting ANN was created with 10 nodes, 10,000 training iterations, and 70\% training holdout cross validation. The ANN was trained and improved the PV of the validation data by $68.3 \%$. The ANN reduced the false negative rate by $75.7 \%$ for 2.6 ppmv detection threshold at $1 \mathrm{~Hz}$ LI-7700 peaks. The creation of false positives at the initial detection thresholds by the ANN led to detection threshold sensitivity analysis. The threshold of 3.3 ppmv resulted in a decrease of 24 false negatives and increase of 2 false positives for the LI-7700's peaks at $1 \mathrm{~Hz}$. The optimal detection threshold of the validation data reduced the UGGA to report only two false negatives with the LI-7700 peaks at $1 \mathrm{~Hz}$.

Table 17 shows each detection threshold's results for the DCM and ANN with the initial UGGA for methane detection for $1 \mathrm{~Hz}$ LI-7700 peaks. Observing the initial detection threshold, the sensitivity analysis optimized detection threshold, the DCM optimized detection threshold, and the ANN optimized detection threshold, the ANN had the lowest false negative and false reporting rate for 3, 2.6, and 3.3 ppmv detection thresholds. The DCM reported the lowest false negative and false reporting rate for 3.4 ppmv. 
Table 17: Results of Each Detection Threshold of the Initial UGGA, UGGA Reconstructed by DCM, and UGGA Reconstructed by ANN for $1 \mathrm{~Hz}$ LI-7700 Peaks.

\begin{tabular}{|c|c|c|c|}
\hline $\begin{array}{c}\text { Detection } \\
\text { Threshold }\end{array}$ & $\begin{array}{c}\text { UGGA } \\
\text { system }\end{array}$ & $\begin{array}{c}\text { False } \\
\text { Negative } \\
\text { Rate }\end{array}$ & $\begin{array}{c}\text { False } \\
\text { Reporting } \\
\text { Rate }\end{array}$ \\
\hline \multirow{3}{*}{$3 \mathrm{ppm}$} & Initial UGGA & 0.309 & 0.083 \\
\cline { 2 - 4 } & DCM UGGA & 0.188 & 0.072 \\
\cline { 2 - 4 } $2.6 \mathrm{ppm}$ & ANN UGGA & 0.103 & 0.033 \\
\hline & Initial UGGA & 0.243 & 0.077 \\
\cline { 2 - 4 } & DCM UGGA & 0.199 & 0.099 \\
\cline { 2 - 4 } $3.4 \mathrm{ppm}$ & ANN UGGA & 0.078 & 0.096 \\
\hline & Initial UGGA & 0.341 & 0.077 \\
\cline { 2 - 4 } & DCM UGGA & 0.037 & 0.019 \\
\cline { 2 - 4 } & ANN UGGA & 0.049 & 0.017 \\
\hline \multirow{3}{*}{$3.3 \mathrm{ppm}$} & Initial UGGA & 0.341 & 0.08 \\
\cline { 2 - 4 } & DCM UGGA & 0.059 & 0.028 \\
\cline { 2 - 4 } & ANN UGGA & 0.047 & 0.017 \\
\hline
\end{tabular}

A $2 \mathrm{~Hz}$ reconstruction was investigated for the DCM and ANN. The DCM resulted in a 10\% PV improvement and the ANN resulted in a 97.9\% PV improvement. The ANN was subjected to detection threshold sensitivity analysis. The $2 \mathrm{~Hz}$ ANN created false positives and increased the false negatives. Up sampling to perform reconstruction was limited to the highest sampling frequency of the analyzers.

An application was created to process the mobile methane data. Using $\operatorname{MATLAB}^{\odot}$, the application reconstructed the UGGA signal to match the LI-7700 and created a Google ${ }^{\circledR}$ Earth map displaying the methane concentrations and wind direction at the sampled location. The application allowed for the implementation of the UGGA without the LI-7700.

Of the reconstruction methods, the UGGA reconstructed with the ANN increased the PV of the validation set by $68.3 \%$. After detection sensitivity analysis, the false negatives of the ANN validation set decreased by 9 compared to the LI-7700 peaks at $1 \mathrm{~Hz}$. The application of the ANN allowed for the UGGA to be implemented with improved detection threshold capabilities. 


\subsection{Recommendations}

The implementation of a closed-path methane detection system had errors that require correction. The methane analyzer sampling method and frequency, vehicle speed, and other components defined the ability in methane source attribution.

The LI-7700, an open-path methane analyzer, displayed a sharp methane response compared to the UGGA. Its implementation in mobile methane systems was limited by mounting and interference effects associated with open-path analyzers. In cases without these concerns, the open-path analyzer presents the best option for mobile methane detection; however, if mounting or interference issues are presented, then the open-path analyzer cannot be implemented without loss of data. The LI-7700 is capable of up to 40 $\mathrm{Hz}$, but sampling frequency of the GPS limits the application in mobile methane detection.

The UGGA, a closed-path methane analyzer, displayed a response delay and a smearing effect compared to the LI-7700. With time alignment, a corrected closed-path methane analyzer did not encounter the interference effects associated with open-path operation. The use of a closed-path methane analyzer required a post processing correction to reduce the false negatives reported.

If a closed-path analyzer is used for methane detection, an external correction should be applied to time align and improve the methane response signal. Without correction, the closed-path analyzer reports lower values compared to the open-path analyzer. The ANN reconstructed the UGGA's signal by improving both the PV and detection threshold. An ANN under the correct conditions, can be created and trained for signal reconstruction of a closed-path methane analyzer. To confirm that other closed-path analyzers operate similarly to the UGGA, the analyzers must be deployed compared to an open-path analyzer. Atherton et al. and Brantley et al. deployed a UGGA that will experience the same sampling limitations due to their OA-ICOS [17, 84]. Phillips et al., Jackson et al., Eapi et al., Fischer et al., Rella et al., Albertson et al., Brantley et al., and Weller et al. deployed various Picarro methane analyzers that operate on cavity ringdown spectroscopy $[14-16,19-22,24]$. The Picarro methane analyzers should 
experience similar sampling limitations due to its closed-path operation and its relation to OA-ICOS.

Other works may have underreported methane concentrations or missed methane plumes due to the implementation of a closed-path analyzer.

Vehicle speed and sampling frequency are the major components in the GR between points. The closedpath analyzer at $1 \mathrm{~Hz}$ created sampling location inaccuracies in geospatial limitations due to the response delay. Time alignment is required with the implementation of a closed-path analyzer.

With the $1 \mathrm{~Hz}$ UGGA, the recommended vehicle speed is $36 \mathrm{kph}$. Methane analyzers with a lower sampling frequency than $1 \mathrm{~Hz}$ will yield higher geospatial uncertainty in sampling location than the UGGA. Los Gatos Research currently produces a methane analyzer that samples at $20 \mathrm{~Hz}$ frequency [72]. A GPS and anemometer would be required to operate at $20 \mathrm{~Hz}$ to prevent linear interpolation of data. The higher sampling frequency methane analyzer would allow for higher vehicle speeds at the GR of $10 \mathrm{~m}$.

For a continuation of this work, a closer analysis into the combined effects of vehicle speed, sampling rate, and methane responses is required. Due to the vehicle speed forcing a flow over the sampling line of a closed-path methane analyzer, the analyzer may experience inaccuracies due to an increase of pressure in the cell. Future works should monitor cell pressure for its effects on the methane response through sampling, mounting, and operating conditions. Cell pressure could be used as a metric for the removal of data when it varies dramatically.

The recommendations of a mobile methane system present the suggestions after conclusions were drawn. For implementing the mobile methane detection, these recommendations pose as guides and points to consider for researchers working in this area.

\subsection{Future Applications}

There are other applications that could be implemented with the mobile methane detection system. The applications consist of two major categories, leak quantification and ethane detection. Leak quantification 
consists of potential methods of indirect quantification methods that may be implemented from the system. Details of each topic include the overview with the requirements and adaptions required of the mobile methane system.

\subsubsection{Leak Quantification}

Leak quantification is the next progression following leak detection. Given the same vehicle setup, determining the rate of the leak is imperative in determining the severity of the leak. Mobile Methane simply determines the sampled location, not the leak source location. Using an indirect quantification method, such as Other Test Method 33a (OTM 33a), or Eddy Covariance, calculation of leak rates could be determined.

\subsubsection{OTM 33a}

OTM33a was a project sponsored by the EPA in order to create a top-down methane quantification method [21]. Using a vehicle mounted system, OTM 33a attempts to quantify the leak rate. OTM 33a begins by mapping the detected methane with wind direction along the vehicle path. After a leak is determined to be downwind, OTM 33a begins trying to discover the leak by applying gaussian dispersion techniques. With knowledge of the leak, OTM 33a gives a leak rate from the source.

OTM33a's implementation would not be a difficult one. The inner workings of OTM 33a could be coded into Mobile Methane. Because the app only maps moving data to the Google ${ }^{\circledR}$ Earth file, the stationary data could be applied with OTM 33a if the leak criteria was met. Despite this, OTM 33a's execution on may be limited without further research. Using leak testing and an adaption of OTM 33a, a modified OTM 33a could be paired with a mobile methane detection system for leak detection and quantification.

\subsubsection{Eddy Covariance}

The eddy covariance method is meteorological technique that observes the fluxes of the gas desired. Many environmental scientists deploy these in search of $\mathrm{CO}_{2}$ and methane effects from the environment. The fluxes in eddy covariances are the small changes in the atmosphere over the course of a set period of 
time. By performing long sampling periods, the average of a section of time provides a snapshot of the environmental effects.

Eddy covariance has been attempted for source detection of $\mathrm{CO}_{2}[96]$. By observing the background meteorological effects over a long period of time, the background effects could be removed for source location and quantification. Long periods of time usually consist of days at a time with half an hour averaging at a minimum.

Mobile methane detection with eddy covariance is limited due to having to expose the sensors for a long period of time. If the background knowledge of the site was available via an eddy covariance setup near the leak, then mobile methane detection could be deployed for around half an hour for potential source detection. Using the mobile methane detection equipment already deployed, a simple coding of the eddy covariance method would allow for stationary data to be observed. Completing a drive by the site could indicate where to position the vehicle for eddy covariance.

\subsubsection{Ethane Detection}

Natural gas's composition is primarily methane, but the next largest component is ethane. Ethane is a hydrocarbon extracted from natural gas for its conversion to plastics [97, 98]. Despite its other applications, ethane is still used as a fuel in natural gas.

Because ethane's sources vary from methane, ethane detection indicates natural gas leaks. Ethane's creation consists only of anthropogenic sources. This varies from methane, which consists of both anthropogenic sources and biological sources. With multiple sources, not all methane sources are contributed to natural gas equipment however coexistence of ethane and methane is attributed to natural gas.

With ethane's uses and its distinguishing source ability, ethane analyzers provide insight to potential natural gas leaks [99]. The market for methane and ethane analyzers currently only consists of closed-path ethane analyzers [100]. An open-path analyzer provides sharp signal that does not experience averaging 
impulse responses upon it. A methane/ethane analyzer's application to Mobile Methane would allow for instantaneous ethane detection.

Using the LI-7700 paired with methane/ethane analyzer, an ethane signal could be recreated. Ethane could be discovered if the UGGA was replaced with a methane/ethane analyzer. Using a method such as IFFT or SIT, an accurate reconstruction could create an instant open-path signal of ethane. Reconstruction using IFFT allows for a signal that is easily invertible to recreate an ethane signal.

An adaption of Mobile Methane's code would simply require reconstruction to be performed, inverted, then applied to ethane. While the apps base operation is methane detection, it could be extended to include ethane. 


\section{References}

[1] EIA, "United States remains the world's top producer of petroleum and natural gas hydrocarbons," EIA. [Online]. Available: https://www.eia.gov/todayinenergy/detail.php?id=36292.

[2] EIA, “U.S. Natural Gas Gross Withdrawls,” EIA, 2019. [Online]. Available: https://www.eia.gov/dnav/ng/hist/n9010us2A.htm.

[3] EIA, "How much natural gas does the United States have, and how long will it last?," EIA, 2018. [Online]. Available: https://www.eia.gov/tools/faqs/faq.php?id=58\&t=8.

[4] EIA, "How much carbon dioxide is produced when different fuels are burned?," EIA. [Online]. Available: https://www.eia.gov/tools/faqs/faq.php?id=73\&t=11.

[5] EIA, "Energy-related CO2 emissions from natural gas surpass coal as fuel use patterns change," EIA. [Online]. Available: https://www.eia.gov/todayinenergy/detail.php?id=27552.

[6] EPA, "Understanding Global Warming Potentials," EPA. [Online]. Available: https://www.epa.gov/ghgemissions/understanding-global-warming-potentials\#Learn why.

[7] G. Myhre et al., "Anthropogenic and Natural Radiative Forcing. In: Climate Change 2013: The Physical Science Basis.," Contribution of Working Group I to the Fifth Assessment Report of the Intergovernmental Panel on Climate Change [Stocker, T.F., D. Qin, G.-K. Plattner, M. Tignor, S.K. Allen, J. Boschung, A. Nauels, Y. Xia, V. Bex and P.M. Midgley (eds.)]. Cambridge University Press, Cambridge, United Kingdom and New York, NY, USA. 659, 2013.

[8] EPA, “Overview of Greenhouse Gases," EPA. [Online]. Available: https://www.epa.gov/ghgemissions/overview-greenhouse-gases.

[9] R. A. Alvarez, S. W. Pacala, J. J. Winebrake, W. L. Chameides, and S. P. Hamburg, "Greater focus needed on methane leakage from natural gas infrastructure," PNAS, vol. 109, no. 17, pp. 6435-6440, 2012.

[10] X. Zhang, N. P. Myhrvold, and K. Caldeira, "Key factors for assessing climate benefits of natural gas versus coal electricity generation," Environ. Res. Lett., vol. 9, no. 11, 2014.

[11] S. Coburn et al., "Regional trace-gas source attribution using a field-deployed dual frequency comb spectrometer," Optica, vol. 5, no. 4, p. 320, 2018. 
[12] ARPA-E, "MONITOR," ARPA-E. [Online]. Available: https://arpae.energy.gov/?q=programs/monitor.

[13] Stanford School of Earth Energy and Environmental Sciences, "Mobile Monitoring Challenge," Stanford University. [Online]. Available: https://methane.stanford.edu/.

[14] N. Phillips et al., "Mapping urban pipeline leaks: Methane leaks across Boston," Environ. Pollut., vol. 173, pp. 1-4, 2013.

[15] R. B. Jackson et al., "Natural gas pipeline leaks across Washington, DC," Environ. Sci. Technol., vol. 48, no. 3, pp. 2051-2058, 2014.

[16] G. R. Eapi, M. S. Sabnis, and M. L. Sattler, "Mobile measurement of methane and hydrogen sulfide at natural gas production site fence lines in the Texas Barnett Shale," J. Air Waste Manag. Assoc., vol. 64, no. 8, pp. 927-944, 2014.

[17] E. Atherton et al., "Mobile measurement of methane emissions from natural gas developments in northeastern British Columbia, Canada," Atmos. Chem. Phys., vol. 17, no. 20, pp. 12405-12420, 2017.

[18] SCAQMD, "Mobile Methane Measurement Surveys.” [Online]. Available: https://www.aqmd.gov/home/news-events/community-investigations/aliso-canyon-update/airsampling/mobile-methane-measurement-surveys.

[19] C. W. Rella, T. R. Tsai, C. G. Botkin, E. R. Crosson, and D. Steele, "Measuring emissions from oil and natural gas well pads using the mobile flux plane technique," Environ. Sci. Technol., vol. 49, no. 7, pp. 4742-4748, 2015.

[20] J. D. Albertson et al., "A Mobile Sensing Approach for Regional Surveillance of Fugitive Methane Emissions in Oil and Gas Production,” Environ. Sci. Technol., vol. 50, no. 5, pp. 24872497, 2016.

[21] H. L. Brantley, E. D. Thoma, W. C. Squier, B. B. Guven, and D. Lyon, "Assessment of methane emissions from oil and gas production pads using mobile measurements," Environ. Sci. Technol., vol. 48, no. 24, pp. 14508-14515, 2014.

[22] Z. D. Weller et al., "Vehicle-Based Methane Surveys for Finding Natural Gas Leaks and Estimating Their Size: Validation and Uncertainty," Environ. Sci. Technol., vol. 52, pp. 11922 11930, 2018. 
[23] L. Tao, K. Sun, D. J. Miller, D. Pan, L. M. Golston, and M. A. Zondlo, "Low-power, open-path mobile sensing platform for high-resolution measurements of greenhouse gases and air pollutants,” Appl. Phys. B Lasers Opt., vol. 119, no. 1, pp. 153-164, 2015.

[24] J. C. Von Fischer et al., "Rapid, Vehicle-Based Identification of Location and Magnitude of Urban Natural Gas Pipeline Leaks,” Environ. Sci. Technol., vol. 51, no. 7, pp. 4091-4099, 2017. D. R. Caulton et al., "Quantifying uncertainties from mobile-laboratory-derived emissions of well pads using inverse Gaussian methods," Atmos. Chem. Phys., vol. 18, no. 20, pp. 15145-15168, 2018.

[26] Picarro Inc, "Picarro Drive," Picarro Inc. [Online]. Available: https://naturalgas.picarro.com/overview\#drive.

[27] ABB, "MobileGuard.” [Online]. Available: https://heathus.com/wpcontent/uploads/MobileGuard.pdf.

[28] Earth System Research Laboratory, "Trends in Atmospheric Methane," NOAA. [Online]. Available: https://www.esrl.noaa.gov/gmd/ccgg/trends_ch4/.

[29] I. G. McWilliam and R. A. Dewar, "Flame Ionization Detector for Gas Chromatography," Nature, vol. 181, p. 760, 1958.

[30] W. K. Cheng, T. Summers, and N. Collings, “THE FAST-RESPONSE FLAME IONIZATION DETECTOR,” Prog. Energy Combust. Sci., vol. 24, pp. 89-124, 1998.

[31] Horiba, “OBS-ONE GS Unit," Horiba. [Online]. Available: https://www.horiba.com/en_en/products/detail/action/show/Product/obs-one-gs-unit-28/.

[32] Sensors, "SEMTECH FID and DUAL FID Specifications.," Sensors. .

[33] D. A. Skoog, F. J. Holler, and S. R. Crouch, "Chapter 16 An Introduction to Infrared Spectrometry," in Principles of Instrumental Design Seventh Edition, C. Learning, Ed. 2017, pp. 398-411.

[34] D. A. Skoog, F. J. Holler, and S. R. Crouch, "Chapter 17 Applications of Infrared Spectroscopy," in Principles of Instrumental Design Seventh Edition, Cengage Learning, Ed. 2017, pp. 412-436.

[35] FLIR, "Infrared Cameras for Gas Leak Detection," FLIR, 2017. [Online]. Available: https://www.flir.com/globalassets/imported-assets/document/17-2691-ins-ogi-gf-series-familybrochure_revise_final_v2_lwrez.pdf. 
[36] T. Dinh, I. Choi, Y. Son, and J. Kim, "Sensors and Actuators B : Chemical A review on nondispersive infrared gas sensors: Improvement of sensor detection limit and interference correction," Sensors Actuators B. Chem., vol. 231, pp. 529-538, 2016.

[37] V. DiVenere, "The Electromegnetic Spectrum," Columbia University. [Online]. Available: http://www.columbia.edu/ vjd1/electromag_spectrum.htm.

[38] D. A. Skoog, F. J. Holler, and S. R. Crouch, "Chapter 7 Components of Optical Instruments," in Principles of Instrucmental Design, Cengage Learning, 2017, pp. 148-195.

[39] B. Daham et al., "Application of a Portable FTIR for Measuring On-road Emissions," SAE Tech. Pap., 2005.

[40] A. R. Korb, P. Dybwad, W. Wadsworth, and J. W. Salisbury, "Portable Fourier transform infrared spectroradiometer for field measurements of radiance and emissivity," Opt. Soc. Am., vol. 35, no. 10, pp. 1679-1692, 1996.

[41] MKS, "MultiGas 2030-HS High Speed (5 Hz) FTIR Gas Analyzer,” MKS. [Online]. Available: https://www.mksinst.com/f/multigas-2030-hs-ftir-continuous-gas-analyzer.

[42] ARCoptix, "FT-IR Rocket," ARCoptix. [Online]. Available: http://www.arcoptix.com/IR_infrared_spectrometer.htm.

[43] A. P. Ravikumar, J. Wang, M. Mcguire, C. S. Bell, D. Zimmerle, and A. R. Brandt, ““ Good versus Good Enough?' Empirical Tests of Methane Leak Detection Sensitivity of a Commercial Infrared Camera," Environ. Sci. Technol., vol. 52, pp. 2368-2374, 2018.

[44] A. P. Ravikumar, J. Wang, and A. R. Brandt, "Are Optical Gas Imaging Technologies Effective For Methane Leak,” Environ. Sci. Technol., vol. 51, pp. 718-724, 2016.

[45] Y. Zeng and J. Morris, "Detection limits of optical gas imagers as a function of temperature differential and distance," J. Air Waste Manag. Assoc., vol. 69, no. 3, pp. 351-361, 2018.

[46] Rebellion Photonics, "PORTABLE METHANE DETECTION SYSTEM," ARPA-E. [Online]. Available: https://arpa-e.energy.gov/?q=slick-sheet-project/portable-methane-detection-system.

[47] X. Liu et al., "A Survey on Gas Sensing Technology,” Sensors, vol. 12, no. 7, pp. 9635-9665, 2012.

[48] NET, “IRNET-P,” NET. [Online]. Available: http://www.nenvitech.com/wpcontent/uploads/2018/06/DS3706-IRNET-P-32-methane-Rev-8.pdf. 
[49] Edinburgh Sensors, "Gascard NG," Edinburgh Sensors. [Online]. Available:

https://edinburghsensors.com/products/oem/gascard-ng/.

[50] Dynamet, "Dynamet MSH," Dynamet. [Online]. Available: https://www.dynament.com/_webedit/uploaded-files/All Files/Data/tds0123.pdf.

[51] A. Dey, "Materials Science \& Engineering B Semiconductor metal oxide gas sensors : A review," Mater. Sci. Eng. B, vol. 229, pp. 206-217, 2018.

[52] C. Wang, L. Yin, L. Zhang, D. Xiang, and R. Gao, "Metal Oxide Gas Sensors: Sensitivity and Influencing Factors," Sensors, vol. 10, pp. 2088-2106, 2010.

[53] Winsen, "Flammable Gas Sensor (Model: MQ-4," Winsen. [Online]. Available: https://cdn.sparkfun.com/datasheets/Sensors/Biometric/MQ-4 Ver1.3 - Manual.pdf.

[54] J. E. Thompson, "Crowd-sourced Air Quality Studies: A Review of the Literature \& Portable Sensors," Trends Envirnomental Anal. Chem., vol. 11, pp. 23-34, 2016.

[55] NET, "NP-18SHM \& NP-18SHP,” NET. [Online]. Available: http://www.nenvitech.com/wpcontent/uploads/2016/04/DS3347-rev.-2-NP-18SHM-NP-18SHP-.pdf.

[56] Los Gatos Research, “GHG Analyzer Travels Anywhere,” Los Gatos Research. [Online]. Available: https://www.ecotech.com/wp-content/uploads/2015/03/LGR-UltraPortable-GGADatasheet.pdf.

[57] LI-COR, "LI-7700 Manual,” LI-COR. [Online]. Available: https://www.licor.com/documents/18warrx05laaa1zo9s0pepmjk0cgiqm3.

[58] Los Gatos Research, "Ultra-Portable Greenhouse Gas Analyzer User Manual," Los Gatos Research, 2014. [Online]. Available: https://www.ecotech.com/wpcontent/uploads/2015/03/UltraPortable-GGA-User-Manual-Rev-1.01.pdf.

[59] R. Di Capua, F. Offi, and F. Fontana, "Check the Lambert - Beer - Bouguer law : a simple trick to boost the confidence of students toward both exponential laws and the discrete approach to experimental physics Check the Lambert - Beer - Bouguer law : a simple trick to boost the con fi dence of," Eur. J. Phys., vol. 35, 2014.

[60] D. F. Swinehart, “The Beer-Lambert Law,” J. Chem. Educ., vol. 39, no. 7, pp. 333-335, 1962.

[61] J. A. Silver, "Frequency-modulation spectroscopy for trace species detection: theory and comparison among experimental methods," Appl. Opt., vol. 31, no. 6, pp. 707-717, 1992. 
[62] D. R. Herriott and H. J. Schulte, "Folded Optical Delay Lines," Appl. Opt., vol. 4, no. 8, p. 883, 1965.

[63] LI-COR, "LI-7700 Specifications*," LI-COR. [Online]. Available: https://www.licor.com/env/products/gas_analysis/LI-7700/specifications.html.

[64] D. McDermitt et al., "A new low-power, open-path instrument for measuring methane flux by eddy covariance,” Appl. Phys. B Lasers Opt., vol. 102, no. 2, pp. 391-405, 2011.

[65] A. O'Keefe and D. A. G. Deacon, “Cavity ring-down optical spectrometer for absorption measurements using pulsed laser sources," Rev. Sci. Instrum., vol. 54, no. 2544, 1988.

[66] Picarro Inc, "Picarro G2301," Picarro Inc. [Online]. Available: https://www.picarro.com/support/library/documents/co2_ch4_and_h2o_gas_concentration_analyz er_g2301_data_sheet.

[67] A. O'Keefe, "Integrated cavity output analysis of ultra-weak absorption," Chem. Phys. Lett., vol. 293, no. 5, pp. 331-336, 1998.

[68] A. O'Keefe, J. J. Scherer, and J. B. Paul, “cw Integrated cavity output spectroscopy," Chem. Phys. Lett., vol. 307, pp. 343-349, 1999.

[69] D. Herriot, H. Kogelnik, and R. Kompfner, "Off-Axis Paths in Spherical Mirror Interferometers," Appl. Opt., vol. 3, no. 4, pp. 523-526, 1964.

[70] PEER, “QCL Whispering Gallery Mode Sensor,” PEER. [Online]. Available: http://www.peeri.org/OV/qclWGM.htm.

[71] I. Leifer, C. Melton, M. Gupta, and B. Leen, "Mobile Monitoring of Methane Leakage," Gases Instrum., no. July/August, pp. 20-24, 2014.

[72] LGR, "Fast Methane Analyzer," LGR. [Online]. Available: http://www.lgrinc.com/documents/LGR_FMA_Datasheet.pdf.

[73] S. W. Smith, "Chapter 5: Linear Systems," in The Scientist and Engineer's Guide to Digital Signal Processing, 1998, pp. 87-106.

[74] S. W. Smith, "Chapter 6: The Delta Function and Impulse Response," in The Scientist and Engineer's Guide to Digital Signal Processing, 1998, pp. 107-122.

[75] S. W. Smith, "Chapter 7: Properties of Convolution," in The Scientist and Engineer's Guide to Digital Signal Processing, 1998, pp. 123-140. 
[76] GILL, "WindMaster \& WindMaster Pro Sonic Anemometer User Manual," GILL. [Online]. Available: http://gillinstruments.com/data/manuals/WindMaster-and-Windmaster-Pro-Manual.pdf.

[77] U-blox, "NEO-M8U Data Sheet,” U-Blox, 2018. [Online]. Available: https://www.ublox.com/sites/default/files/NEO-M8U-04B_DataSheet_\%28UBX-15015679\%29.pdf.

[78] GILL, "WindSonic User Manual,” GILL, 2006.

[79] GlobalSat, “GPS Mouse User's Guide V1.0.” [Online]. Available: https://www.globalsat.com.tw/ftp/download/GMouse_Win_UsersGuide-V1.0.pdf.

[80] LI-COR, "LI-7500A/RS Open-path CO2/H2O Gas Analyzer," LI-COR. [Online]. Available: https://www.licor.com/env/support/LI-7500RS/topics/specifications.html.

[81] LI-COR, “LI-200R Pyranometer,” LI-COR. [Online]. Available: https://www.licor.com/env/products/light/pyranometer.html.

[82] ICP-DAS, “PET-7019Z," ICP-DAS. [Online]. Available: http://www.icpdas.com/products/Remote_IO/pet-7000/pet-7019.htm.

[83] Omega, "Barometric Pressure, Temperature, Humidity Virtual Recorder," Omega. [Online]. Available: https://www.omega.com/das/pdf/IBTX_IBTHX.pdf.

[84] H. L. Brantley, E. D. Thoma, W. C. Squier, B. B. Guven, and D. Lyon, "Assessment of methane emissions from oil and gas production pads using mobile measurements," Environ. Sci. Technol., vol. 48, no. 24, pp. 14508-14515, 2014.

[85] Picarro Inc, “G2132-i Isotope Analyzer.” [Online]. Available: https://www.picarro.com/products/g2132_i_isotope_analyzer.

[86] B. Ganesan and N. N. Clark, "Relationships Between Instantaneous and Measured Emissions in Heavy Duty Applications,” SAE Trans. J. FUELS Lubr., vol. 110, no. 724, pp. 1798-1806, 2016.

[87] M. R. Madireddy and N. N. Clark, "Sequential inversion technique and differential coefficient approach for accurate instantaneous emissions measurement," Int. J. Engine Res., vol. 7, no. 6, pp. 437-446, 2006.

[88] S. W. Smith, "Chapter 8: The Discrete Fourier Transform," in The Scientist and Engineer's Guide to Digital Signal Processing, 1998, pp. 141-168.

[89] van M. Gerven, “Computational Foundations of Natural Intelligence,” Front. Comput. Neurosci, vol. 11, no. 112, 2017. 
[90] H. P. Gavin, "The Levenberg-Marquardt algorithm for nonlinear least squares curve-fitting problems," 2019. [Online]. Available: http://people.duke.edu/ hpgavin/ce281/lm.pdf.

[91] D. Ajtay and M. Weilenmann, "Compensation of the Exhaust Gas Transport Dynamics for Accurate Instantaneous Emission Measurements," Environ. Sci. Technol, vol. 38, no. 19, pp. 5141-5148, 2004.

[92] M. R. Madireddy and N. N. Clark, "Attempts to enhance the differential transient emissions from heavy-duty vehicles of Engine Research,” Int. J. Engine Res., vol. 10, no. 1, pp. 65-70, 2008.

[93] K. K. Dobbin and R. M. Simon, "Optimally splitting cases for training and testing high dimensional classifiers," BMC Med. Genomics, vol. 4, no. 1, p. 31, 2011.

[94] V. Gholami, K. W. Chau, F. Fadaee, J. Torkaman, and A. Ghaffari, "Modeling of groundwater level fluctuations using dendrochronology in alluvial aquifers," J. Hydrol., vol. 529, no. March 2019, pp. 1060-1069, 2015.

[95] IPCC, "Climate Change 2007: The Physical Science Basis. Contribution of Working Group I to the Fourth Assessment Report of the Intergovernmental Panel on Climate Change. [S. Solomon, D. Qin, M. Manning, Z. Chen, M. Marquis, K.B. Averyt, M. Tignor and H.L. Miller.” Cambridge University Press. Cambridge, United Kingdom 996 pp., 2007.

[96] J. L. Lewicki et al., "Detection of CO2 leakage by eddy covariance during the ZERT project's CO2 release experiments," Energy Procedia, vol. 1, no. 1, pp. 2301-2306, 2009.

[97] EIA, "Hydrocarbon Gas Liquids Explained," EIA, 2018. [Online]. Available: https://www.eia.gov/energyexplained/index.php?page=hgls_uses.

[98] The Essential Chemical Industry-online, "Ethene (Ethylene)," The Essential Chemical Industryonline, 2017. [Online]. Available: http://www.essentialchemicalindustry.org/chemicals/ethene.html.

[99] T. I. Yacovitch et al., "Mobile Laboratory Observations of Methane Emissions in the Barnett Shale Region,” Environ. Sci. Technol., vol. 49, no. 13, pp. 7889-7895, 2015.

[100] D. Kim-hak, D. Fleck, J. Yiu, Z. Lin, and G. Lucic, "Fugitive Methane Emission Identification and Source Attribution: Ethane-to- Methane Analysis using a Portable Cavity Ring-Down Spectroscopy Analyzer," Picarro. [Online]. Available: https://www.picarro.com/sites/default/files/EGU-AGU 2017 Ethane-Methane Poster.pdf. 


\section{Appendices}

\section{Appendix I: UGGA Methane Calibration}

The UGGA required calibration prior to operation. On December 12, 2018, the UGGA was internally

calibrated at 101.3 ppmv methane. To perform calibration, the 101.3 ppmv methane bottle and Teflon line were required. Using a T fitting, a separate line was used to prevent a pressured system, where excess methane could vent to the atmosphere. Using the internal computer of the UGGA, the UGGA's calibration steps were performed. Figure 50 depicts a section of the UGGA's calibration screen with the time and date of the last calibration.

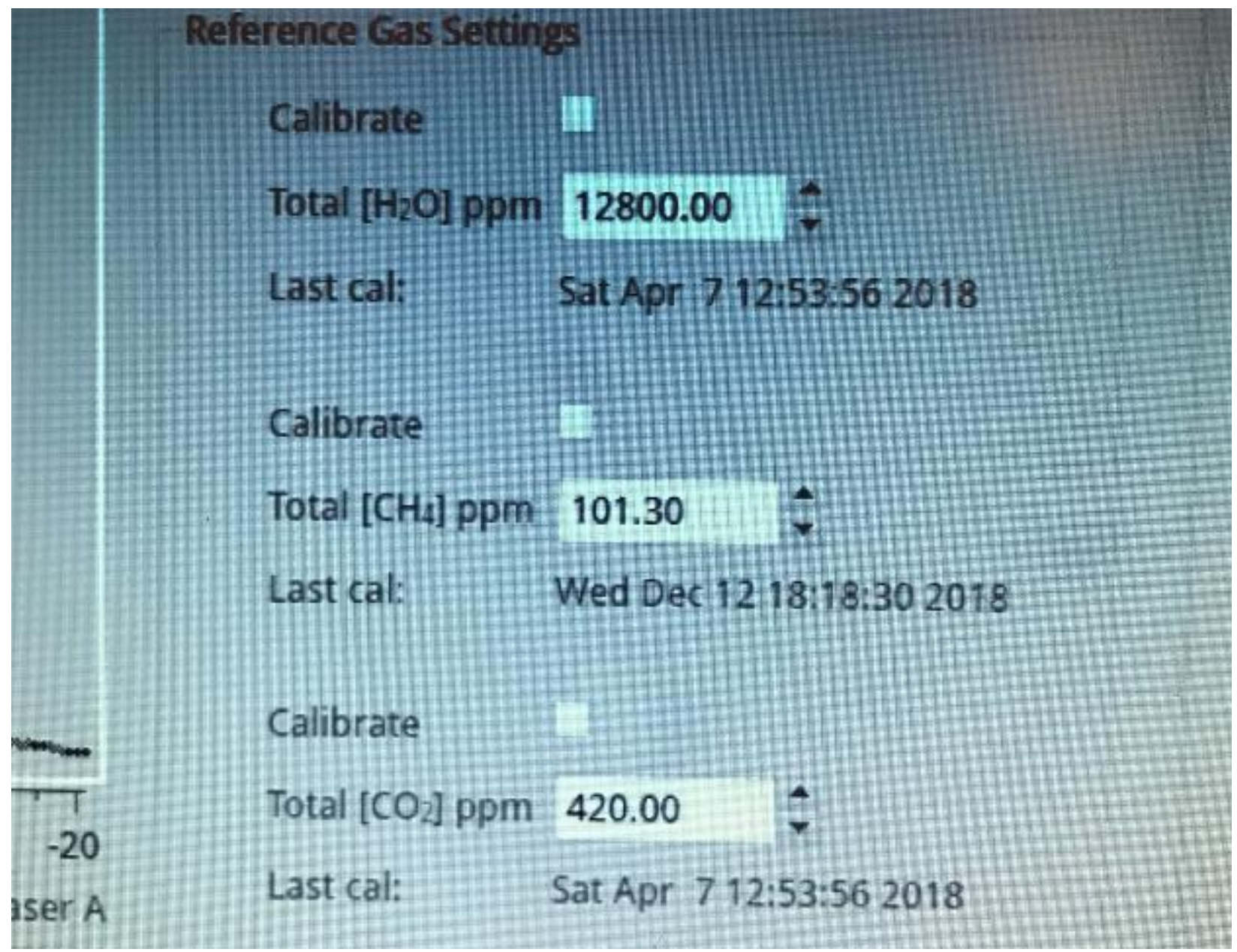

Figure 50: The Calibration of the UGGA. 


\section{Appendix II: Calibration Certificates}

All the calibrated equipment was used for either burst testing or calibration. The calibration certificates of the gas bottles used are supplied. In addition, the calibration certificate of the gas divider is also provided. Figure 51 depicts the 101.3 ppmv of methane calibration certificate. The 101.3 ppmv methane had an uncertainty of $0.9 \%$. Figure 52 is the ultra-zero air calibration certificate. The ultra-zero air bottle had an error less than 0.1 ppmv of methane. Figure 53 shows the calibration sheet used for the STEC SGD-710C gas divider. The gas divider had an uncertainty of 0.048 liters per minute. Figure 54 depicts the gas divider verification check sheet. The gas divider has a maximum error less than $1 \%$. 


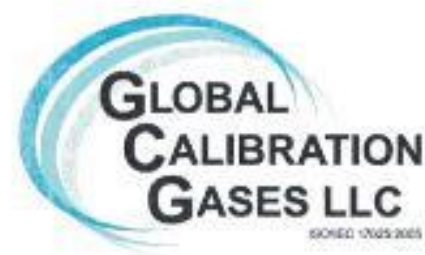

EPA Protocol

Gas Mixture

$\begin{array}{llll}\text { Customer: } & \text { Wilson Supply } & \text { Reference\#: } & \text { 091518CL-BB } \\ \text { CGA: } & 590 & \text { Certification Date: } & 09 / 20 / 2018 \\ \text { Customer PO\#: } & 144705-1 & \text { Expiration Date: } & 09 / 20 / 2026 \\ \text { Cylinder \#: } & \text { EB0067295 } & \text { Pressure, psig: } & 2000\end{array}$

Mothod: This standard was anslyzed ackersing to EPA Traceability Protcoal foe Assay and Certification of Gaseous Caloration Standsros. Procedure G1 (May 2012)

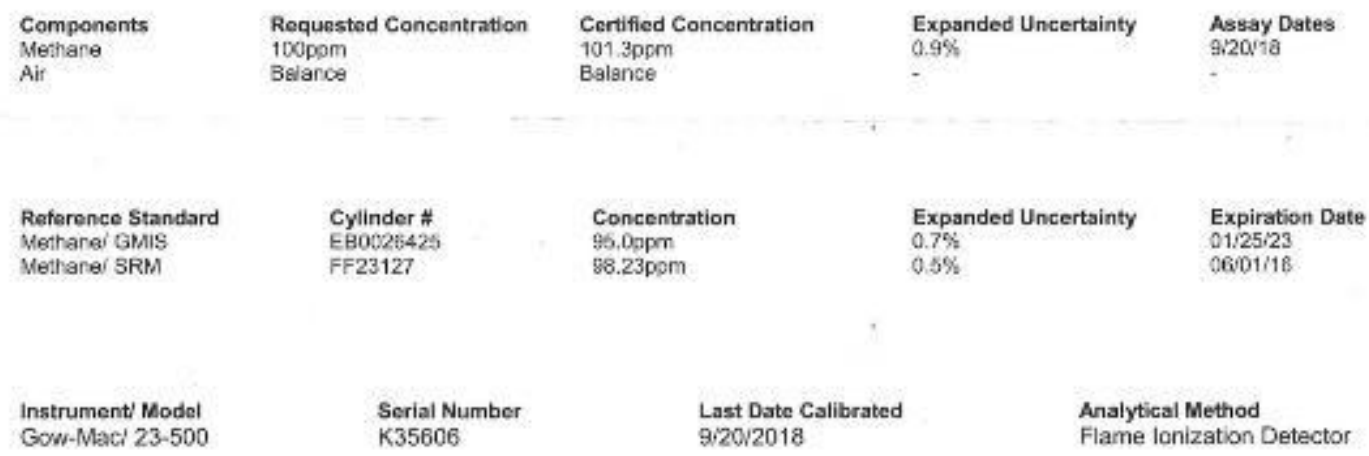

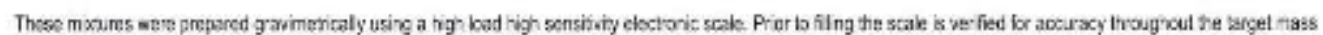

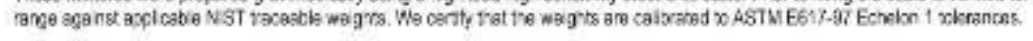

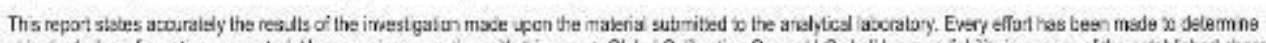

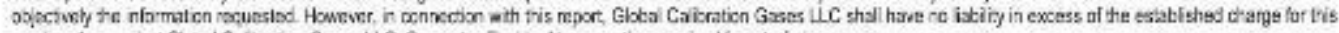

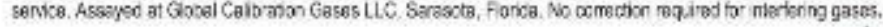

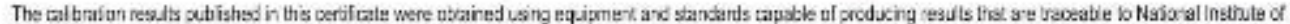

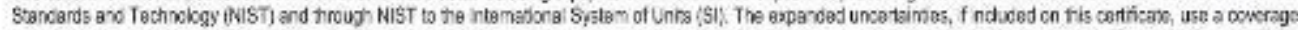

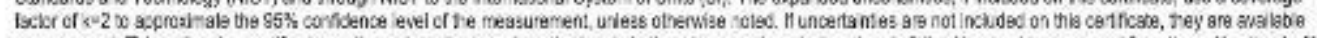

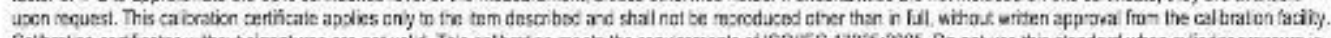

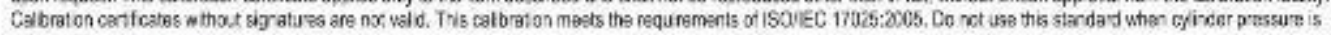
bstow 100 psig.

\section{Global}

CALIBRATION Produced by:

GASES LLC $\quad \begin{aligned} & 1000 \text { Commerce BNo N. } \\ & \text { Sarasola, Furida } 31243 \text { USh }\end{aligned}$

Principal Analyst: $1 / 4002$

Date:

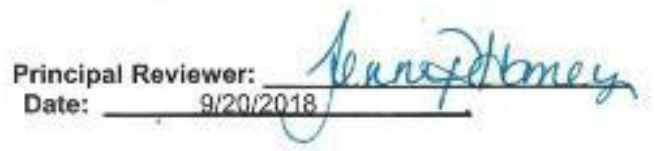

Figure 51: 101.3 ppmv Methane Bottle Calibration Certificate. 


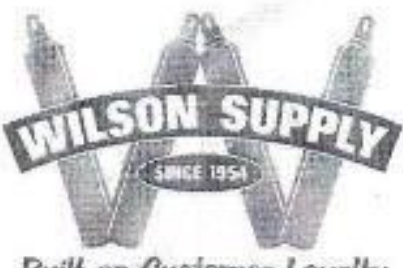

Builf on Customer Loyally

\section{Certificate of Analysis}

$\begin{array}{ll}\text { Certification Date: } & \begin{array}{l}28 \text { November } 2016 \\ \text { Air Ultra Zero }\end{array} \\ \text { Product: } & 28 \text { November } 2024 \\ \text { Expiration Date: } & 3156 \mathrm{~A}-01 \mathrm{~T} 5 \\ \text { Lot Number: } & \\ & \\ & \\ \text { Purity Specification } & \\ \text { Oxygen } & 19.5 \%-23.5 \% \\ \text { Carbon Monoxide } & <1.0 \mathrm{ppm} \\ \text { Carbon Dioxide } & <1.0 \mathrm{ppm} \\ \text { Moisture } & <3.0 \mathrm{ppm} \\ \text { Tatal Hydrocarbons } & <0.1 \mathrm{ppm}\end{array}$

The calbration results publichnd in this cetificate were obtained using equponent and stantarus capable of prodicing resubs thet are traceablo to N6tional insticute of Standards and Techrolagy (NIST) and through NIST to the intematienal Systam of Units iS!). The expanded uncertamies, if included on this cortificate. use a coverage fartar af $k=2$ to

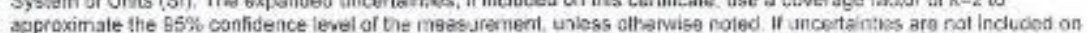
this certificste, they are availabe upon request. This calbratian certificgte spoles anly to the rem dascribed and shall not be rapecduced cher than in fult, wheut witten approval from the calbracion faclity. Calicration certicates wthou" signatures are rot valid. This calbration meets the requiramants of ISOMIEC 17025-2605.

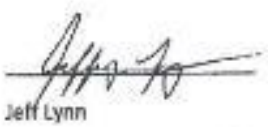

Figure 52: Ultra Zero Air Bottle Calibration Certificate. 


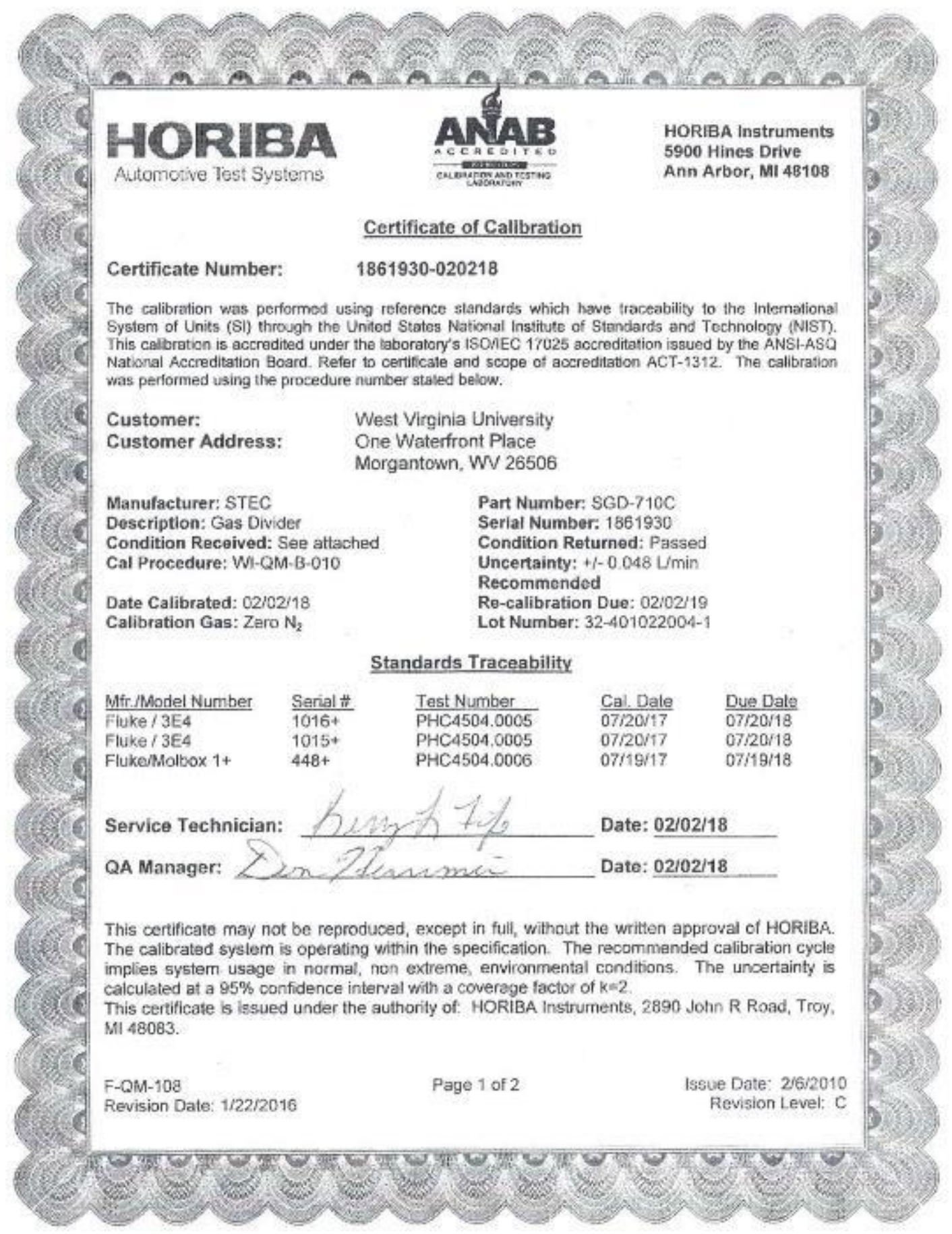

Figure 53: STEC SGD-710C Gas Divider Calibration Certificate. 
SGD-A10, SGD-710 GAS DIVIDERS VERIFICATION CHECK SHEET

CUSTOMER: WMU DATE: 02/02/18

MODEL: SGD-710C SERIAL NUMBER: 1881930

\begin{tabular}{|r|r|r|r|r|r|c|}
\hline $\begin{array}{c}\text { CUT } \\
\text { PT. }\end{array}$ & $\begin{array}{c}\text { COMP A } \\
\text { MixtURE GAS }\end{array}$ & $\begin{array}{c}\text { COMP B } \\
\text { DLUTANT GAS }\end{array}$ & $\begin{array}{c}\text { TOTAL FLOW } \\
\text { POINT }\end{array}$ & $\begin{array}{c}\text { MIXTURE } \\
\text { FLOW \% }\end{array}$ & $\begin{array}{c}\text { \%POINT } \\
\text { ERROR }>2.0 \%\end{array}$ & STATUS \\
\hline 0 & 0.0000 & 4.0193 & 4.0193 & 0.000 & 0.000 & Pass \\
\hline 10 & 0.3965 & 3.6067 & 4.0032 & 9.905 & 0.963 & Pass \\
\hline 20 & 0.7970 & 3.2051 & 4.0021 & 19.915 & 0.429 & Pass \\
\hline 30 & 1.2003 & 2.8038 & 4.0041 & 29.977 & 0.077 & Pass \\
\hline 40 & 1.5957 & 2.3982 & 3.9939 & 39.953 & 0.117 & Pass \\
\hline 50 & 1.9909 & 2.0045 & 3.9954 & 49.830 & 0.342 & Pass \\
\hline 60 & 2.3877 & 1.6028 & 3.9905 & 59.835 & 0.276 & Pass \\
\hline 70 & 2.7824 & 1.2066 & 3.9890 & 69.752 & 0.356 & Pass \\
\hline 80 & 3.1772 & 0.8053 & 3.9825 & 79.779 & 0.277 & Pass \\
\hline 90 & 3.5789 & 0.4044 & 3.9833 & 89.848 & 0.170 & Pass \\
\hline 100 & 3.9927 & 0.0000 & 3.9927 & 100.000 & 0.000 & Pass \\
\hline 100 & 3.9912 & 0.0000 & 3.9912 & 100.000 & 0.000 & Pass \\
\hline 90 & 3.5399 & 0.3957 & 3.9356 & 89.946 & 0.060 & Pass \\
\hline 80 & 3.1437 & 0.7950 & 3.9387 & 79.816 & 0.231 & Pass \\
\hline 70 & 2.7477 & 1.1885 & 3.9362 & 69.806 & 0.278 & Pass \\
\hline 60 & 2.3523 & 1.5825 & 3.9348 & 59.782 & 0.365 & Pass \\
\hline 50 & 1.9641 & 1.9683 & 3.9324 & 49.947 & 0.107 & Pass \\
\hline 40 & 1.5692 & 2.3579 & 3.9271 & 39.958 & 0.105 & Pass \\
\hline 30 & 1.1808 & 2.7417 & 3.9223 & 30.100 & -0.331 & Pass \\
\hline 20 & 0.7828 & 3.1340 & 3.9168 & 19.986 & 0.072 & Pass \\
\hline 10 & 0.3912 & 3.5167 & 3.9079 & 10.010 & -0.105 & Pass \\
\hline 0 & 0.0000 & 3.8976 & 3.8976 & 0.000 & 0.000 & Pass \\
\hline
\end{tabular}

STD. DEV. $\quad 0.0393$ LPM

MIXTURE GAS INLET PRESSURE TO DIVIDER: $\quad 21.0$ PSIG

DILUTION GAS INLET PRESSURE TO DIVIDER: $\quad 17.0$ PSIG

(AT $0.0 \%$ CUTPOINT)

OUTLET FLOW FROM GAS DIVIDER: $\quad 4.00$ LPM

Figure 54: STEC SGD-710C Gas Divider Verification Check Sheet. 


\section{Appendix III: Create Google ${ }^{\circledR}$ Earth File}

Given the data set inputs, the MATLAB $^{\odot}$ script called kml.m creates a Google ${ }^{\circledR}$ Earth map of the data.

Original codes developed by Dr. Marc Besch, Mr. Robert Heltzel, and Mr. Zachary Luzader were

reviewed and used as a foundation for this code. To make operational for the field testing data collected, the code was edited to account for errors with file creation and description display. In addition, mapping of the wind direction was implemented for possible source detection.

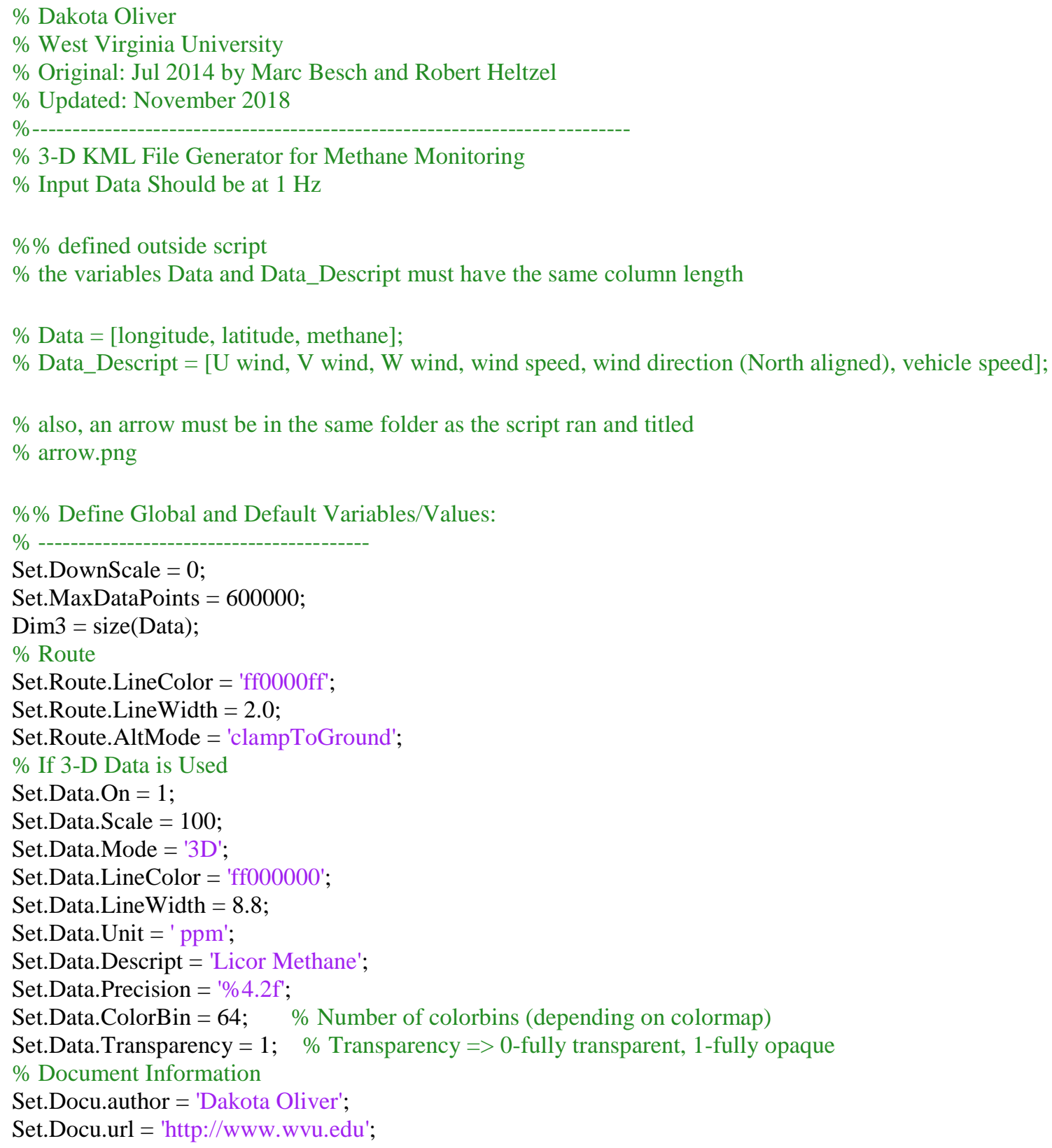


Set.Docu.visability $=1$;

Set.Docu.open $=1$;

Set.Docu.description = ' ';

Set.Docu.LookAt.longitude = 'Data_ $(1,1)$ ';

Set.Docu.LookAt.latitude = 'Data_ $(1,2)$ ';

Set.Docu. LookAt.altitude $=10000$;

Set.Docu.LookAt.heading $=0$;

Set.Docu.LookAt.tilt $=20$;

Set.Docu.LookAt.range $=40000$;

$\%$ Style Information

$\%$ Normal Data

Set.Style.Data.Normal.Label.color = 'ff00ffff';

Set.Style.Data.Normal.Label.scale $=0$;

Set.Style.Data.Normal.Line. width $=5$;

Set.Style.Data.Normal.Icon.scale $=0$;

$\%$ Highlight Data

Set.Style.Data.Highlight.Label.color = 'ff00ffff';

Set.Style.Data.Highlight.Label.scale $=0.75$;

Set.Style.Data.Highlight.Line. width $=10$;

Set.Style.Data.Highlight.Icon.scale $=0$;

$\%$ Route Data

Set.Style.Route.color $=$ Set.Data.LineColor;

Set.Style. Route. width $=$ Set.Data.LineWidth;

$\%$ Folder Information

$\%$ Route

Set.Folder.Route.styleUrl = '\#routestyle2';

Set.Folder. Route.tessellate $=1$;

Set.Folder.Route.altitudeMode = 'clampToSeaFloor';

$\%$ Data

Set.Folder.Data.styleUrl = '\#datastyle2';

Set.Folder.Data.Line.tessellate $=1$;

Set.Folder.Data.Point.altitudeMode = 'relativeToGround';

Set.Folder.Data.Line.altitudeMode = 'relativeToGround';

Set.Folder.Data.Line.extrude $=1$;

$\% \%$ Generating vector with color information for input data:

$\%$

$\%$ Scaled data parameter:

for $\mathrm{i}=1$ :length(Data(:,3))

if $\operatorname{Data}(\mathrm{i}, 3)<$ lowmet

$\operatorname{Data}(\mathrm{i}, 3)=$ lowmet;

$$
\text { end }
$$

end

$\operatorname{Data}(:, 4)=\operatorname{Data}(:, 3)^{*}($ Set.Data.Scale/max $(\operatorname{Data}(:, 3)))$;

clear i

$\%$ Evaluating $\min / \max$ data:

Set.Data.Min $=\min (\operatorname{Data}(:, 4))$;

Set.Data.Max $=\max (\operatorname{Data}(:, 4))$;

$\%$ Converting Matlab colormap into hexadecimal format for (Google Earth):

cmap_rgb3 = single $($ round $($ colormap $(' J e t ') * 255))$;

close gcf;

cmap_hex3 = cell(length(cmap_rgb3),1);

for $\mathrm{i}=1: 1$ :length(cmap_rgb3)

temp $=$ dec2hex $($ cmap_rgb3(i,:));

cmap_hex3 $\{\mathrm{i}, 1\}=[\operatorname{temp}(3,:)$, temp(2,:),temp(1,:)]; \% BGR (Google Earth) clear temp;

end 


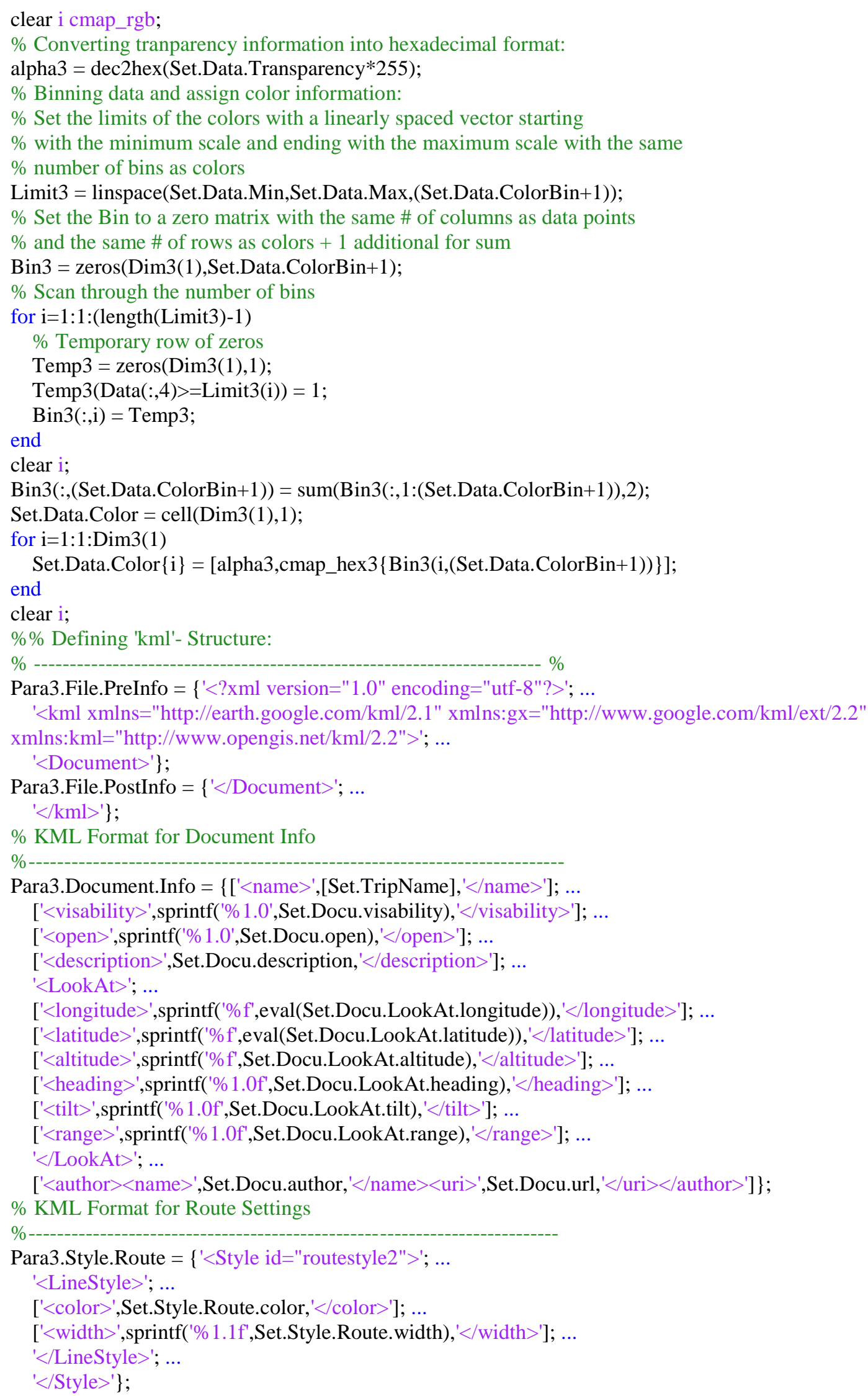




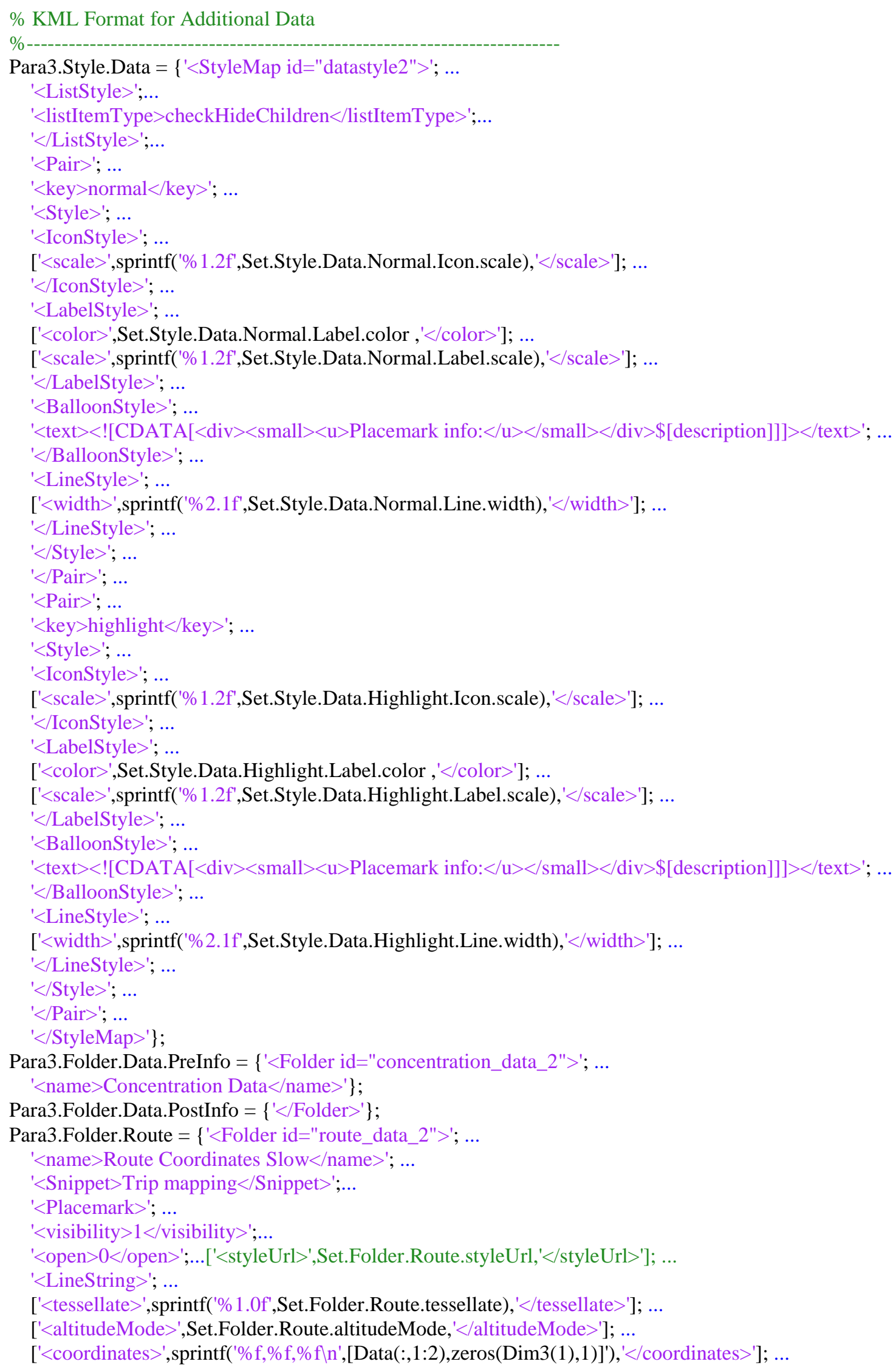




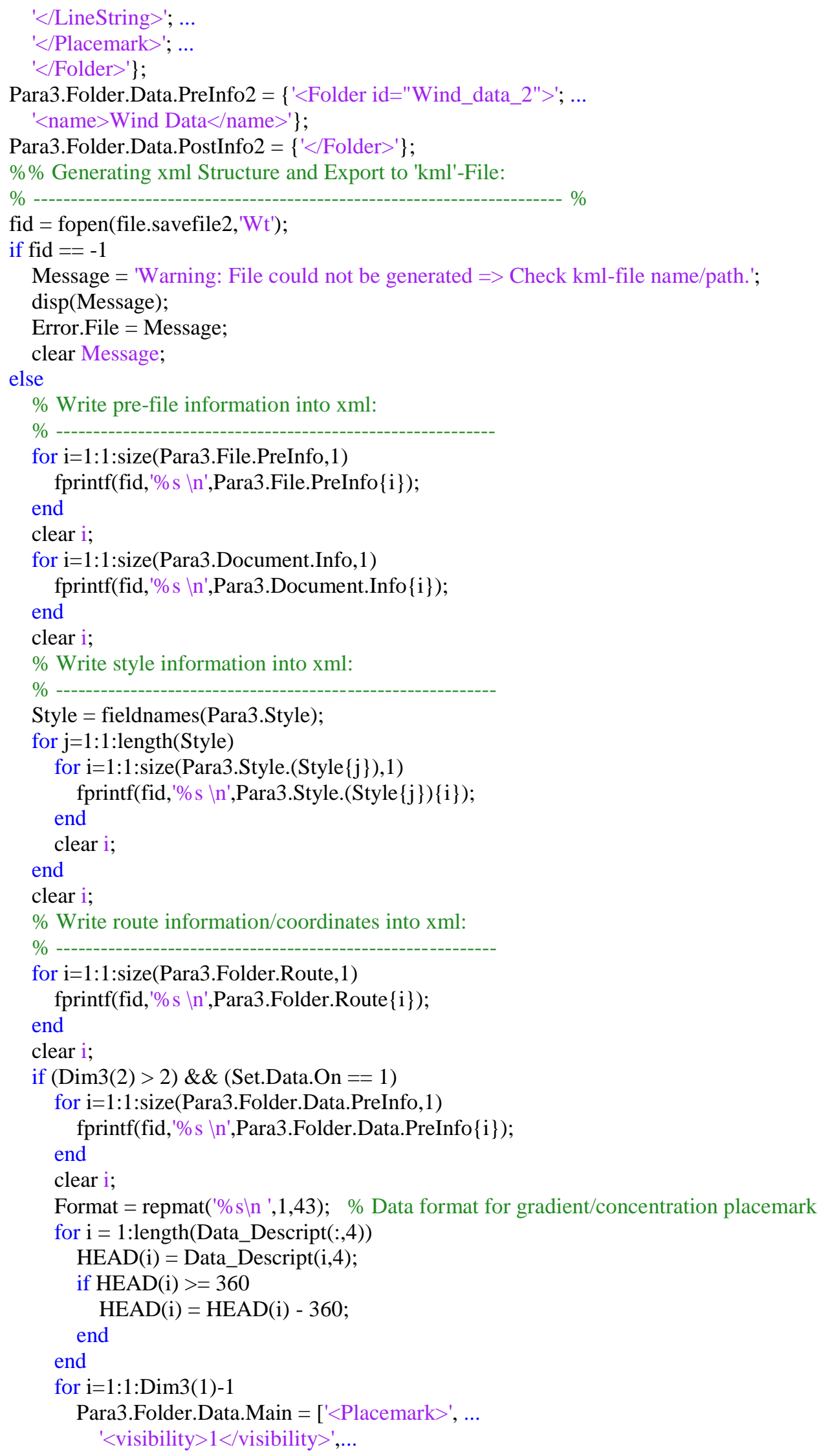


'<open $>0<$ /open $>$ ',...

'<name>',[sprintf(Set.Data.Precision,Data(i,3)),Set.Data.Unit],'</name>', ...

'<Snippet $>$ LGR Methane $</$ Snippet $>$ ',...

'<description $><$ ! [CDATA[',[sprintf('Longitude: \%2.2f deg <br $>$ Latitude: \%2.2f deg <br >

',[Data(i,1),Data(i,2)]),Set.Data.Descript,': ',sprintf(Set.Data.Precision,Data(i,3)),Set.Data.Unit, '<br>U wind: ', sprintf(Set.Data.Precision,Data_Descript(i,1)),' m/s<br $>$ V Wind: ', sprintf(Set.Data.Precision,Data_Descript(i,2)),' $\mathrm{m} / \mathrm{s}<$ br $>W$ wind: ',sprintf(Set.Data.Precision,Data_Descript(i,3)),' $\mathrm{m} / \mathrm{s}<$ br $>$ wind speed:

',sprintf(Set.Data.Precision,Data_Descript(i,4)),' m/s<br $>$ wind direction:

',sprintf(Set.Data.Precision,Data_Descript(i,5)),' theta $<$ br $>$ Vehicle speed:

',sprintf(Set.Data.Precision,Data_Descript(i,5)), ' mph' ],']] $></$ description $>$ ', ...

'<styleUrl>',Set.Folder.Data.styleUrl,'</styleUrl>', ...)',

$'<$ Style $>$ ', ...

'<LineStyle >', ...

'<color>',Set.Data.Color $\{\mathbf{i}\},{ }^{\prime}</$ color $>$ ', ...

'</LineStyle $>$ ', ...

$'</$ Style $>$ ', ...

'<MultiGeometry $>$ ', ...

'<LineString $>$ ', ...

'<tessellate>',sprintf('\%1.0f',Set.Folder.Data.Line.tessellate),'</tessellate>', ...

'<extrude>',sprintf('\%1.0f',Set.Folder.Data.Line.extrude), '</extrude>', ...

'<altitudeMode>',Set.Folder.Data.Line.altitudeMode,'</altitudeMode>', ...

'<coordinates>',sprintf('\%f,\%f, \%f

\%, \%f,\%fln',[Data(i,1:2),Data(i,4),Data(i+1,1:2),Data(i,4)]'),'</coordinates $>$ ', ...

'</LineString >', ...

'<Point $>$ ', ...

'<altitudeMode>',Set.Folder.Data.Point.altitudeMode, '</altitudeMode>', ...

'<coordinates>',sprintf('\%f,\%f,\%fln',[Data(i,1:2),Data(i,4)]'),'</coordinates > , ...

'</Point $>$ ', ...

'</MultiGeometry $>$ ', ...

'</Placemark $>$ '];

fprintf(fid,Format,Para3.Folder.Data.Main);

end

clear $\mathrm{i}$;

for $\mathrm{i}=1: 1$ :size(Para3.Folder.Data.PostInfo, 1)

fprintf(fid,'\%s $\backslash n$ ',Para3.Folder.Data.PostInfo $\{\mathrm{i}\})$; end

end

if $(\operatorname{Dim} 3(2)>2) \& \&($ Set.Data.On $==1)$

for $\mathrm{i}=1: 1$ :size(Para3.Folder.Data.PreInfo2,1)

fprintf(fid,'\%s $\backslash n$ ',Para3.Folder.Data.PreInfo2 $\{\mathrm{i}\})$;

end

clear i;

Format = repmat('\%s\n ',1,43); \% Data format for gradient/concentration placemark

for $\mathrm{i}=1$ :length(Data_Descript $(:, 4)$ )

HEAD $(\mathrm{i})=$ Data_Descript $(\mathrm{i}, 4)$;

if $\operatorname{HEAD}(\mathrm{i})>=360$

$\operatorname{HEAD}(\mathrm{i})=\operatorname{HEAD}(\mathrm{i})-360$;

end

end

for $\mathrm{i}=1: 1: \operatorname{Dim} 3(1)-1$

Para3.Folder.Data.Main2 $=\left[{ }^{\prime}<\right.$ Placemark $>$ ', ..

'<visibility $>1</$ visibility $>$ ',...

'<open $>0<$ /open $>$ ', ...

'<name>',sprintf(Set.Data.Precision,Data_Descript(i,10)),'</name >', ...

'<description> <! [CDATA[',[sprintf('Longitude: \%2.2f deg <br >Latitude: \% 2.2f deg <br >

',[Data(i,1),Data(i,2)]),Set.Data.Descript,': ',sprintf(Set.Data.Precision,Data(i,3)),Set.Data.Unit,'<br >U wind: ', 


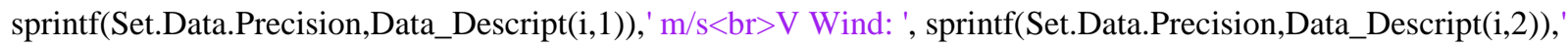
$\mathrm{m} / \mathrm{s}<\mathrm{br}>\mathrm{W}$ wind: ',sprintf(Set.Data.Precision,Data_Descript(i,3)),' m/s $<$ br $>$ wind speed:

',sprintf(Set.Data.Precision,Data_Descript(i,4)),' m/s<br $>$ wind direction:

',sprintf(Set.Data.Precision,Data_Descript(i,5)),' theta<br $>$ Vehicle speed:

',sprintf(Set.Data.Precision,Data_Descript(i,5)), ' mph' ],']] ></description>', ...

' $<$ Snippet $>$ Wind North Corrected $</$ Snippet $>$ ',...

'<StyleMap >',...

$'<$ Pair $>$ ', ...

'<key>normal $</$ key $>$ ', ...

'<Style>', ...

$'<$ IconStyle $>$ ',...

'<scale $>.5</$ scale $>$ ', ...

'<Icon>',...

'<href $>$ ' image $'</$ href $>$ ',...

'</Icon $>$ ',...

'<heading >',sprintf(Set.Data.Precision,HEAD(i)), '</heading $>$ ', ..

'<color $>$ FF00FFFF $</$ color $>$ ', ...

'</IconStyle $>$ ',...

'<BalloonStyle $>$ ', ...

$'<$ text $><![$ CDATA $[<$ div $><$ small $><$ u $>$ Placemark info: $</ \mathrm{u}></$ small $></$ div $>\$[$ description] $]]></$ text $>$ ', ..

'</BalloonStyle >', ...

'<LabelStyle $>$ ', ...

['<color>',Set.Style.Data.Normal.Label.color ,'</color >'], ...

['<scale>',sprintf('\%1.2f',Set.Style.Data.Normal.Label.scale), '</scale>'], ...

'</LabelStyle >', ...

'</Style $>$ ', ...

'</Pair >', ...

'<Pair >', ...

'<key>highlight $</$ key $>$ ', ...

'<Style>', ...

$'<$ IconStyle $>$ ',...

'<scale $>.75</$ scale $>$ ',...

$'<$ Icon $>$ ',...

'<href $>$ ' image ' $</$ href $>$ ', ...

'</Icon $>$ ',...

'<heading >',sprintf(Set.Data.Precision,HEAD(i)), '</heading $>$ ',...

'<color $>$ FF00FFFF $</$ color $>$ ', ...

'</IconStyle>',...

'<BalloonStyle $>$ ', ...

$'<$ text $\rangle<![$ CDATA $[<$ div $\rangle<$ small $><$ u $>$ Placemark info: $</ \mathrm{u}></$ small $></$ div $>\$[$ description] $]]></$ text $>$ ', ..

'</BalloonStyle $>$ ', ...

'<LabelStyle $>$ ', ...

['<color >',Set.Style.Data.Highlight.Label.color ,'</color >'], ...

['<scale>',sprintf('\%1.2f',Set.Style.Data.Highlight.Label.scale),'</scale>'], ...

'</LabelStyle>', ...

'</Style $>$ ', ...

'</Pair $>$ ',...

'</StyleMap $>$ ',...

'<Point $>$ ', ...

'<tessellate>',sprintf('\%1.0f',Set.Folder.Data.Line.tessellate),'</tessellate>', ...

'<altitudeMode>clamptoground $</$ altitudeMode $>$ ', ...

'<coordinates>',sprintf('\%f, \%f, \%f

$\%$ f, \%f, \%fln',[Data(i,1:2),Data(i,4),Data(i+1,1:2),Data(i,4)]'),'</coordinates $>$ ', ...

'</Point $>$ ', ...

'</Placemark $>$ '];

fprintf(fid,Format,Para3.Folder.Data.Main2); 


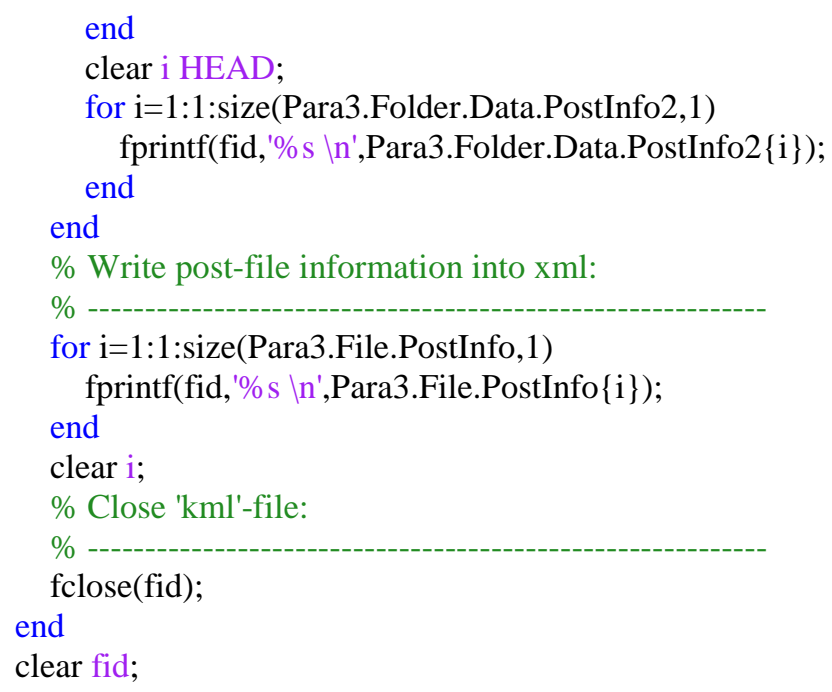




\section{Appendix IV: Initial PVs}

Table 18: Initial PVs of the Field Testing Data.

\begin{tabular}{|c|c|c|c|c|c|c|c|}
\hline File & UGGA Max (ppm) & LI-7700 Max (ppm) & PE & $\mathbf{r}^{2}$ & SEE & PIE & PV \\
\hline 533 & 2.771 & 2.739 & 0.326 & 0.615 & 0.061 & 0.045 & 0.687 \\
\hline 534 & 2.840 & 4.740 & 0.862 & 0.533 & 0.045 & 0.064 & 0.372 \\
\hline 535 & 5.292 & 6.572 & 0.829 & 0.737 & 0.039 & 0.017 & 0.466 \\
\hline 536 & 3.489 & 5.644 & 0.601 & 0.430 & 0.037 & 0.235 & 0.455 \\
\hline 537 & 4.821 & 8.349 & 0.730 & 0.417 & 0.115 & 0.032 & 0.405 \\
\hline 538 & 6.666 & 19.974 & 0.626 & 0.278 & 0.098 & 0.008 & 0.414 \\
\hline 539 & 7.013 & 13.429 & 0.430 & 0.361 & 0.117 & 0.050 & 0.542 \\
\hline 540 & 11.404 & 20.440 & 0.655 & 0.333 & 0.105 & 0.393 & 0.375 \\
\hline 541 & 3.272 & 5.941 & 0.667 & 0.310 & 0.098 & 0.007 & 0.403 \\
\hline 542 & 8.924 & 31.305 & 0.641 & 0.274 & 0.097 & 0.100 & 0.394 \\
\hline 543 & 5.573 & 13.065 & 0.559 & 0.329 & 0.021 & 0.006 & 0.468 \\
\hline 544 & 3.243 & 5.250 & 0.694 & 0.502 & 0.050 & 0.010 & 0.456 \\
\hline 545 & 14.396 & 25.545 & 0.414 & 0.606 & 0.048 & 0.054 & 0.636 \\
\hline 546 & 22.451 & 27.265 & 0.252 & 0.672 & 0.076 & 0.035 & 0.747 \\
\hline 549 & 3.698 & 3.361 & 0.085 & 0.981 & 0.082 & 0.077 & 0.939 \\
\hline 550 & 4.737 & 5.823 & 0.136 & 0.929 & 0.032 & 0.090 & 0.893 \\
\hline 551 & 4.412 & 7.318 & 0.586 & 0.602 & 0.035 & 0.007 & 0.549 \\
\hline 552 & 3.431 & 6.835 & 0.932 & 0.323 & 0.021 & 0.472 & 0.217 \\
\hline 553 & 27.358 & 43.372 & 0.953 & 0.739 & 0.034 & 0.026 & 0.401 \\
\hline 554 & 25.668 & 69.703 & 0.900 & 0.703 & 0.019 & 0.015 & 0.417 \\
\hline 555 & 18.909 & 37.650 & 0.903 & 0.666 & 0.044 & 0.038 & 0.400 \\
\hline 565 & 2.910 & 5.682 & 0.919 & 0.285 & 0.017 & 0.148 & 0.246 \\
\hline 575 & 2.481 & 2.385 & 0.414 & 0.478 & 0.071 & 0.142 & 0.582 \\
\hline 579 & 4.743 & 10.575 & 0.869 & 0.439 & 0.026 & 0.037 & 0.339 \\
\hline 580 & 10.329 & 21.949 & 0.811 & 0.467 & 0.106 & 0.090 & 0.373 \\
\hline 581 & 3.522 & 3.886 & 0.292 & 0.706 & 0.098 & 0.075 & 0.733 \\
\hline 582 & 3.182 & 2.969 & 0.071 & 0.877 & 0.106 & 0.057 & 0.912 \\
\hline 583 & 12.001 & 15.431 & 0.513 & 0.743 & 0.050 & 0.022 & 0.636 \\
\hline 584 & 35.819 & 56.272 & 0.238 & 0.629 & 0.116 & 0.093 & 0.733 \\
\hline 585 & 25.656 & 52.145 & 0.366 & 0.640 & 0.097 & 0.037 & 0.675 \\
\hline 586 & 10.195 & 17.334 & 0.662 & 0.359 & 0.136 & 0.076 & 0.415 \\
\hline 587 & 8.568 & 21.154 & 0.489 & 0.551 & 0.107 & 0.004 & 0.582 \\
\hline 588 & 6.372 & 19.504 & 0.867 & 0.338 & 0.096 & 0.067 & 0.301 \\
\hline 589 & 8.021 & 18.716 & 0.748 & 0.315 & 0.120 & 0.059 & 0.356 \\
\hline 590 & 11.413 & 32.812 & 0.548 & 0.328 & 0.093 & 0.044 & 0.469 \\
\hline 591 & 5.163 & 12.433 & 0.789 & 0.355 & 0.090 & 0.025 & 0.353 \\
\hline 592 & 5.874 & 10.012 & 0.701 & 0.546 & 0.091 & 0.024 & 0.466 \\
\hline 593 & 2.765 & 3.363 & 0.551 & 0.379 & 0.057 & 0.003 & 0.490 \\
\hline 594 & 9.762 & 9.842 & 0.568 & 0.939 & 0.047 & 0.074 & 0.669 \\
\hline 595 & 24.195 & 16.034 & 0.866 & 0.473 & 0.061 & 0.087 & 0.346 \\
\hline 596 & 35.789 & 45.284 & 0.806 & 0.746 & 0.034 & 0.039 & 0.479 \\
\hline 597 & 38.126 & 41.922 & 0.760 & 0.793 & 0.060 & 0.070 & 0.516 \\
\hline 598 & 2.727 & 3.299 & 0.246 & 0.669 & 0.073 & 0.500 & 0.698 \\
\hline
\end{tabular}




\section{Appendix V: DCM Self-Training PVs}

Table 19: PVs of the Field Testing Data Using DCM and Self-Training.

\begin{tabular}{|c|c|c|c|c|c|}
\hline File & PE & $\mathbf{r}^{2}$ & SEE & PIE & PV \\
\hline 533 & 0.176 & 0.828 & 0.041 & 0.027 & 0.843 \\
\hline 534 & 0.825 & 0.755 & 0.032 & 0.028 & 0.474 \\
\hline 535 & 0.779 & 0.655 & 0.046 & 0.028 & 0.463 \\
\hline 536 & 0.047 & 0.842 & 0.025 & 0.041 & 0.915 \\
\hline 537 & 0.561 & 0.915 & 0.053 & 0.066 & 0.665 \\
\hline 538 & 0.007 & 0.958 & 0.025 & 0.034 & 0.978 \\
\hline 539 & 0.055 & 0.771 & 0.070 & 0.053 & 0.884 \\
\hline 540 & 0.526 & 0.024 & 0.225 & 0.599 & 0.312 \\
\hline 541 & 0.002 & 0.743 & 0.077 & 0.382 & 0.866 \\
\hline 542 & 0.353 & 0.853 & 0.156 & 0.374 & 0.719 \\
\hline 543 & 0.299 & 0.576 & 0.016 & 0.007 & 0.692 \\
\hline 544 & 0.638 & 0.803 & 0.032 & 0.004 & 0.592 \\
\hline 545 & 0.371 & 0.921 & 0.021 & 0.013 & 0.774 \\
\hline 546 & 0.060 & 0.866 & 0.053 & 0.004 & 0.920 \\
\hline 549 & 0.358 & 0.996 & 0.021 & 0.002 & 0.809 \\
\hline 550 & 0.129 & 0.980 & 0.011 & 0.002 & 0.924 \\
\hline 551 & 0.540 & 0.879 & 0.020 & 0.012 & 0.670 \\
\hline 552 & 0.848 & 0.857 & 0.010 & 0.453 & 0.451 \\
\hline 553 & 0.945 & 0.932 & 0.017 & 0.032 & 0.472 \\
\hline 554 & 0.871 & 0.639 & 0.022 & 0.017 & 0.410 \\
\hline 555 & 0.890 & 0.841 & 0.030 & 0.012 & 0.471 \\
\hline 565 & 0.808 & 0.273 & 0.024 & 0.032 & 0.314 \\
\hline 575 & 0.266 & 0.566 & 0.113 & 0.077 & 0.698 \\
\hline 579 & 0.835 & 0.734 & 0.018 & 0.066 & 0.457 \\
\hline 580 & 0.754 & 0.264 & 0.128 & 0.053 & 0.336 \\
\hline 581 & 0.312 & 0.925 & 0.048 & 0.002 & 0.808 \\
\hline 582 & 0.017 & 0.940 & 0.073 & 0.006 & 0.969 \\
\hline 583 & 0.277 & 0.817 & 0.042 & 0.000 & 0.789 \\
\hline 584 & 0.000 & 0.907 & 0.060 & 0.005 & 0.966 \\
\hline 585 & 0.044 & 0.874 & 0.057 & 0.006 & 0.932 \\
\hline 586 & 0.526 & 0.701 & 0.094 & 0.119 & 0.603 \\
\hline 587 & 0.021 & 0.098 & 0.327 & 0.159 & 0.652 \\
\hline 588 & 0.649 & 0.758 & 0.059 & 0.029 & 0.568 \\
\hline 589 & 0.590 & 0.444 & 0.111 & 0.131 & 0.477 \\
\hline 590 & 0.329 & 0.494 & 0.081 & 0.051 & 0.643 \\
\hline 591 & 0.608 & 0.698 & 0.062 & 0.032 & 0.568 \\
\hline 592 & 0.567 & 0.051 & 0.270 & 0.340 & 0.328 \\
\hline 593 & 0.198 & 0.779 & 0.035 & 0.005 & 0.817 \\
\hline 594 & 0.549 & 0.803 & 0.065 & 0.008 & 0.639 \\
\hline 595 & 0.835 & 0.314 & 0.056 & 0.040 & 0.313 \\
\hline 596 & 0.786 & 0.877 & 0.023 & 0.034 & 0.537 \\
\hline 597 & 0.728 & 0.506 & 0.092 & 0.004 & 0.440 \\
\hline 598 & 0.482 & 0.464 & 0.109 & 0.012 & 0.554 \\
\hline
\end{tabular}




\section{Appendix VI: Average PVs of the Self-Trained DCM Applied to}

\section{Remaining Trip Files}

Table 20: Average PVs and its components of the Field Testing Data Using DCM Coefficients Created.

\begin{tabular}{|c|c|c|c|c|c|}
\hline File & PE & $\mathbf{r}^{2}$ & SEE & PIE & PV \\
\hline 533 & 0.474 & 0.739 & 0.053 & 0.071 & 0.649 \\
\hline 534 & 0.522 & 0.561 & 0.075 & 0.064 & 0.562 \\
\hline 535 & 0.497 & 0.415 & 0.100 & 0.084 & 0.522 \\
\hline 536 & 0.495 & 0.793 & 0.094 & 0.229 & 0.639 \\
\hline 537 & 0.482 & 0.770 & 0.052 & 0.096 & 0.653 \\
\hline 538 & 0.438 & 0.716 & 0.061 & 0.075 & 0.659 \\
\hline 539 & 0.513 & 0.346 & 0.108 & 0.592 & 0.433 \\
\hline 540 & 0.537 & 0.100 & 0.178 & 0.162 & 0.382 \\
\hline 541 & 0.543 & 0.600 & 0.178 & 0.379 & 0.529 \\
\hline 542 & 0.561 & 0.428 & 0.137 & 0.234 & 0.476 \\
\hline 543 & 0.492 & 0.719 & 0.057 & 0.065 & 0.633 \\
\hline 544 & 0.479 & 0.671 & 0.079 & 0.082 & 0.621 \\
\hline 545 & 0.461 & 0.813 & 0.046 & 0.071 & 0.682 \\
\hline 546 & 0.476 & 0.746 & 0.073 & 0.080 & 0.650 \\
\hline 549 & 0.455 & 0.750 & 0.051 & 0.074 & 0.663 \\
\hline 550 & 0.456 & 0.806 & 0.044 & 0.078 & 0.681 \\
\hline 551 & 0.466 & 0.806 & 0.045 & 0.070 & 0.677 \\
\hline 552 & 0.440 & 0.815 & 0.049 & 0.083 & 0.692 \\
\hline 553 & 0.479 & 0.743 & 0.052 & 0.071 & 0.648 \\
\hline 554 & 0.506 & 0.393 & 0.104 & 0.091 & 0.509 \\
\hline 555 & 0.486 & 0.709 & 0.061 & 0.062 & 0.634 \\
\hline 565 & 0.539 & 0.668 & 0.110 & 0.129 & 0.583 \\
\hline 575 & 0.513 & 0.809 & 0.111 & 0.218 & 0.636 \\
\hline 579 & 0.473 & 0.766 & 0.054 & 0.063 & 0.660 \\
\hline 580 & 0.523 & 0.385 & 0.100 & 0.071 & 0.499 \\
\hline 581 & 0.465 & 0.743 & 0.059 & 0.060 & 0.657 \\
\hline 582 & 0.480 & 0.729 & 0.054 & 0.075 & 0.642 \\
\hline 583 & 0.495 & 0.667 & 0.069 & 0.081 & 0.612 \\
\hline 584 & 0.508 & 0.782 & 0.050 & 0.096 & 0.644 \\
\hline 585 & 0.473 & 0.730 & 0.070 & 0.079 & 0.645 \\
\hline 586 & 0.484 & 0.663 & 0.077 & 0.120 & 0.612 \\
\hline 587 & 0.507 & 0.546 & 0.107 & 0.133 & 0.557 \\
\hline 588 & 0.481 & 0.734 & 0.071 & 0.078 & 0.643 \\
\hline 589 & 0.509 & 0.454 & 0.104 & 0.137 & 0.524 \\
\hline 590 & 0.525 & 0.528 & 0.084 & 0.083 & 0.547 \\
\hline 591 & 0.485 & 0.685 & 0.077 & 0.080 & 0.623 \\
\hline 592 & 0.504 & 0.146 & 0.235 & 0.384 & 0.390 \\
\hline 593 & 0.462 & 0.801 & 0.049 & 0.082 & 0.676 \\
\hline 594 & 0.583 & 0.147 & 0.118 & 0.084 & 0.383 \\
\hline 595 & 0.633 & 0.241 & 0.098 & 0.126 & 0.385 \\
\hline 596 & 0.506 & 0.734 & 0.055 & 0.080 & 0.630 \\
\hline 597 & 0.558 & 0.204 & 0.112 & 0.082 & 0.416 \\
\hline 598 & 0.531 & 0.224 & 0.301 & 0.504 & 0.389 \\
\hline
\end{tabular}




\section{Appendix VII: DCM Peak Sensitivity Analysis}

Table 21: Detection Thresholds of DCM Reconstruction Coefficients for 2.7 ppmv and 2.6 ppmv with $10 \mathrm{~Hz}$ and $1 \mathrm{~Hz} \mathrm{LI}-7700$.

\begin{tabular}{|c|c|c|c|c|c|c|}
\hline \multirow{2}{*}{ Trip Files } & \multicolumn{3}{|c|}{$10 \mathrm{~Hz}$ LI-7700 } & \multicolumn{3}{|c|}{$1 \mathrm{~Hz}$ LI-7700 } \\
\hline & False Reporting & False Positive & False Negative & False Reporting & False Positive & False Negative \\
\hline 533 & 0.099 & 0.059 & 0.177 & 0.047 & 0.038 & 0.069 \\
\hline 534 & 0.102 & 0.059 & 0.185 & 0.074 & 0.077 & 0.069 \\
\hline 535 & 0.146 & 0.138 & 0.161 & 0.080 & 0.088 & 0.059 \\
\hline 536 & 0.094 & 0.100 & 0.081 & 0.096 & 0.119 & 0.039 \\
\hline 537 & 0.102 & 0.067 & 0.169 & 0.074 & 0.077 & 0.069 \\
\hline 538 & 0.102 & 0.079 & 0.145 & 0.074 & 0.084 & 0.049 \\
\hline 539 & 0.121 & 0.079 & 0.202 & 0.091 & 0.080 & 0.118 \\
\hline 540 & 0.190 & 0.209 & 0.153 & 0.154 & 0.180 & 0.088 \\
\hline 541 & 0.251 & 0.351 & 0.056 & 0.231 & 0.310 & 0.029 \\
\hline 542 & 0.314 & 0.448 & 0.056 & 0.209 & 0.280 & 0.029 \\
\hline 543 & 0.105 & 0.067 & 0.177 & 0.080 & 0.077 & 0.088 \\
\hline 544 & 0.190 & 0.243 & 0.089 & 0.140 & 0.176 & 0.049 \\
\hline 545 & 0.099 & 0.063 & 0.169 & 0.072 & 0.077 & 0.059 \\
\hline 546 & 0.154 & 0.188 & 0.089 & 0.121 & 0.153 & 0.039 \\
\hline 549 & 0.088 & 0.029 & 0.202 & 0.030 & 0.015 & 0.069 \\
\hline 550 & 0.085 & 0.029 & 0.194 & 0.033 & 0.019 & 0.069 \\
\hline 551 & 0.124 & 0.071 & 0.226 & 0.063 & 0.057 & 0.078 \\
\hline 552 & 0.085 & 0.042 & 0.169 & 0.050 & 0.046 & 0.059 \\
\hline 553 & 0.099 & 0.059 & 0.177 & 0.047 & 0.038 & 0.069 \\
\hline 554 & 0.179 & 0.188 & 0.161 & 0.138 & 0.165 & 0.069 \\
\hline 555 & 0.110 & 0.084 & 0.161 & 0.083 & 0.088 & 0.069 \\
\hline 565 & 0.110 & 0.130 & 0.073 & 0.105 & 0.134 & 0.029 \\
\hline 575 & 0.080 & 0.079 & 0.081 & 0.096 & 0.123 & 0.029 \\
\hline 579 & 0.110 & 0.084 & 0.161 & 0.083 & 0.088 & 0.069 \\
\hline 580 & 0.165 & 0.163 & 0.169 & 0.127 & 0.138 & 0.098 \\
\hline 581 & 0.102 & 0.084 & 0.137 & 0.088 & 0.103 & 0.049 \\
\hline 582 & 0.091 & 0.017 & 0.234 & 0.033 & 0.015 & 0.078 \\
\hline 583 & 0.113 & 0.084 & 0.169 & 0.085 & 0.092 & 0.069 \\
\hline 584 & 0.094 & 0.042 & 0.194 & 0.044 & 0.019 & 0.108 \\
\hline 585 & 0.157 & 0.176 & 0.121 & 0.113 & 0.142 & 0.039 \\
\hline 586 & 0.118 & 0.100 & 0.153 & 0.094 & 0.107 & 0.059 \\
\hline 587 & 0.259 & 0.360 & 0.065 & 0.242 & 0.318 & 0.049 \\
\hline 588 & 0.176 & 0.209 & 0.113 & 0.143 & 0.184 & 0.039 \\
\hline 589 & 0.193 & 0.222 & 0.137 & 0.152 & 0.188 & 0.059 \\
\hline 590 & 0.135 & 0.113 & 0.177 & 0.085 & 0.088 & 0.078 \\
\hline 591 & 0.198 & 0.251 & 0.097 & 0.163 & 0.207 & 0.049 \\
\hline 592 & 0.077 & 0.050 & 0.129 & 0.069 & 0.077 & 0.049 \\
\hline 593 & 0.099 & 0.059 & 0.177 & 0.074 & 0.077 & 0.069 \\
\hline 594 & 0.110 & 0.013 & 0.298 & 0.063 & 0.008 & 0.206 \\
\hline 595 & 0.124 & 0.008 & 0.347 & 0.080 & 0.008 & 0.265 \\
\hline 596 & 0.102 & 0.059 & 0.185 & 0.063 & 0.057 & 0.078 \\
\hline 597 & 0.110 & 0.033 & 0.258 & 0.061 & 0.019 & 0.167 \\
\hline 598 & 0.154 & 0.188 & 0.089 & 0.121 & 0.153 & 0.039 \\
\hline
\end{tabular}


Table 22:The Best False Reporting Rates from 2.5 to 3.5 ppmv for the DCM Coefficients.

\begin{tabular}{|c|c|c|c|c|c|c|c|c|}
\hline \multirow[b]{2}{*}{$\begin{array}{l}\text { Trip } \\
\text { File }\end{array}$} & \multicolumn{4}{|c|}{$10 \mathrm{~Hz}$} & \multicolumn{4}{|c|}{$1 \mathrm{~Hz}$} \\
\hline & $\begin{array}{c}\text { Best False } \\
\text { Reporting } \\
\text { Rate }\end{array}$ & $\begin{array}{c}\text { Best } \\
\text { Detection } \\
\text { Threshold }\end{array}$ & $\begin{array}{c}\text { False } \\
\text { Positive } \\
\text { Rate }\end{array}$ & $\begin{array}{c}\text { False } \\
\text { Negative } \\
\text { Rate }\end{array}$ & $\begin{array}{c}\text { Best False } \\
\text { Reporting } \\
\text { Rate }\end{array}$ & $\begin{array}{c}\text { Best } \\
\text { Detection } \\
\text { Threshold }\end{array}$ & $\begin{array}{c}\text { False } \\
\text { Positive } \\
\text { Rate }\end{array}$ & $\begin{array}{c}\text { False } \\
\text { Negative } \\
\text { Rate }\end{array}$ \\
\hline 533 & 0.063 & 3.5 & 0.008 & 0.216 & 0.025 & 3.5 & 0.011 & 0.074 \\
\hline 534 & 0.069 & 3.5 & 0.023 & 0.196 & 0.036 & 3.1 & 0.022 & 0.077 \\
\hline 535 & 0.072 & 3.5 & 0.026 & 0.196 & 0.039 & 3.3 & 0.032 & 0.059 \\
\hline 536 & 0.083 & 3.5 & 0.083 & 0.082 & 0.088 & 2.9 & 0.110 & 0.030 \\
\hline 537 & 0.069 & 3.5 & 0.023 & 0.196 & 0.033 & 3.4 & 0.028 & 0.049 \\
\hline 538 & 0.061 & 3.5 & 0.030 & 0.144 & 0.033 & 3.5 & 0.039 & 0.012 \\
\hline 539 & 0.072 & 3.5 & 0.026 & 0.196 & 0.047 & 3.3 & 0.036 & 0.082 \\
\hline 540 & 0.099 & 3.5 & 0.064 & 0.196 & 0.069 & 3.4 & 0.071 & 0.061 \\
\hline 541 & 0.107 & 3.5 & 0.120 & 0.072 & 0.118 & 3.5 & 0.149 & 0.012 \\
\hline 542 & 0.096 & 3.5 & 0.105 & 0.072 & 0.107 & 3.5 & 0.135 & 0.012 \\
\hline 543 & 0.083 & 3.2 & 0.023 & 0.231 & 0.047 & 3.3 & 0.029 & 0.106 \\
\hline 544 & 0.091 & 3.5 & 0.090 & 0.093 & 0.091 & 3.3 & 0.115 & 0.012 \\
\hline 545 & 0.066 & 3.5 & 0.026 & 0.175 & 0.033 & 3.5 & 0.032 & 0.037 \\
\hline 546 & 0.094 & 3.5 & 0.098 & 0.082 & 0.088 & 2.9 & 0.106 & 0.040 \\
\hline 549 & 0.066 & 3.5 & 0.011 & 0.216 & 0.025 & 3.3 & 0.014 & 0.059 \\
\hline 550 & 0.063 & 3.4 & 0.011 & 0.200 & 0.019 & 3.4 & 0.014 & 0.037 \\
\hline 551 & 0.072 & 3.5 & 0.015 & 0.227 & 0.030 & 3.4 & 0.018 & 0.073 \\
\hline 552 & 0.055 & 3.5 & 0.011 & 0.175 & 0.022 & 3.5 & 0.018 & 0.037 \\
\hline 553 & 0.069 & 3.5 & 0.008 & 0.237 & 0.030 & 3.5 & 0.011 & 0.099 \\
\hline 554 & 0.083 & 3.5 & 0.041 & 0.196 & 0.055 & 3.5 & 0.050 & 0.074 \\
\hline 555 & 0.063 & 3.5 & 0.023 & 0.175 & 0.030 & 3.5 & 0.028 & 0.037 \\
\hline 565 & 0.077 & 3.5 & 0.075 & 0.082 & 0.083 & 3.5 & 0.103 & 0.012 \\
\hline 575 & 0.050 & 3.5 & 0.038 & 0.082 & 0.055 & 3.4 & 0.068 & 0.012 \\
\hline 579 & 0.066 & 3.5 & 0.026 & 0.175 & 0.033 & 3.5 & 0.032 & 0.037 \\
\hline 580 & 0.077 & 3.5 & 0.030 & 0.206 & 0.050 & 3.5 & 0.039 & 0.086 \\
\hline 581 & 0.080 & 3.5 & 0.068 & 0.113 & 0.069 & 3.5 & 0.085 & 0.012 \\
\hline 582 & 0.074 & 3.4 & 0.008 & 0.250 & 0.030 & 3.1 & 0.007 & 0.099 \\
\hline 583 & 0.077 & 3.5 & 0.038 & 0.186 & 0.044 & 3.5 & 0.043 & 0.049 \\
\hline 584 & 0.074 & 3.3 & 0.008 & 0.243 & 0.030 & 3.3 & 0.011 & 0.094 \\
\hline 585 & 0.091 & 3.5 & 0.090 & 0.093 & 0.088 & 2.9 & 0.106 & 0.040 \\
\hline 586 & 0.074 & 3.5 & 0.045 & 0.155 & 0.052 & 3.5 & 0.057 & 0.037 \\
\hline 587 & 0.107 & 3.5 & 0.109 & 0.103 & 0.107 & 3.4 & 0.135 & 0.012 \\
\hline 588 & 0.096 & 3.5 & 0.102 & 0.082 & 0.091 & 2.9 & 0.110 & 0.040 \\
\hline 589 & 0.096 & 3.5 & 0.075 & 0.155 & 0.080 & 3.5 & 0.089 & 0.049 \\
\hline 590 & 0.091 & 3.5 & 0.041 & 0.227 & 0.055 & 3.4 & 0.046 & 0.085 \\
\hline 591 & 0.099 & 3.5 & 0.098 & 0.103 & 0.091 & 3.3 & 0.115 & 0.012 \\
\hline 592 & 0.077 & 2.7 & 0.050 & 0.129 & 0.063 & 3.1 & 0.074 & 0.033 \\
\hline 593 & 0.063 & 3.5 & 0.026 & 0.165 & 0.033 & 3.1 & 0.029 & 0.044 \\
\hline 594 & 0.105 & 3.1 & 0.008 & 0.333 & 0.058 & 3.1 & 0.007 & 0.209 \\
\hline 595 & 0.121 & 2.9 & 0.000 & 0.383 & 0.077 & 3.1 & 0.000 & 0.308 \\
\hline 596 & 0.074 & 3.5 & 0.008 & 0.258 & 0.036 & 3.5 & 0.011 & 0.123 \\
\hline 597 & 0.088 & 3.5 & 0.004 & 0.320 & 0.047 & 3.1 & 0.007 & 0.165 \\
\hline 598 & 0.080 & 3.5 & 0.071 & 0.103 & 0.072 & 2.9 & 0.084 & 0.040 \\
\hline
\end{tabular}


Table 23: The Best False Reporting Rates from 2.5 to 5.5 ppmv for the DCM Coefficients.

\begin{tabular}{|c|c|c|c|c|c|c|c|c|}
\hline \multirow[b]{2}{*}{$\begin{array}{l}\text { Trip } \\
\text { File }\end{array}$} & \multicolumn{4}{|c|}{$10 \mathrm{~Hz}$} & \multicolumn{4}{|c|}{$1 \mathrm{~Hz}$} \\
\hline & $\begin{array}{c}\text { Best False } \\
\text { Reporting } \\
\text { Rate }\end{array}$ & $\begin{array}{c}\text { Best } \\
\text { Detection } \\
\text { Threshold }\end{array}$ & $\begin{array}{c}\text { False } \\
\text { Positive } \\
\text { Rate }\end{array}$ & $\begin{array}{c}\text { False } \\
\text { Negative } \\
\text { Rate }\end{array}$ & $\begin{array}{c}\text { Best False } \\
\text { Reporting } \\
\text { Rate }\end{array}$ & $\begin{array}{c}\text { Best Detection } \\
\text { Threshold }\end{array}$ & $\begin{array}{c}\text { False } \\
\text { Positive } \\
\text { Rate }\end{array}$ & $\begin{array}{c}\text { False } \\
\text { Negative } \\
\text { Rate }\end{array}$ \\
\hline 533 & 0.063 & 3.5 & 0.008 & 0.216 & 0.025 & 3.5 & 0.011 & 0.074 \\
\hline 534 & 0.061 & 4.6 & 0.004 & 0.253 & 0.028 & 5.3 & 0.003 & 0.158 \\
\hline 535 & 0.063 & 4.7 & 0.011 & 0.244 & 0.036 & 4.7 & 0.020 & 0.106 \\
\hline 536 & 0.044 & 4 & 0.030 & 0.087 & 0.044 & 3.9 & 0.053 & 0.013 \\
\hline 537 & 0.066 & 3.6 & 0.022 & 0.188 & 0.030 & 5.5 & 0.007 & 0.161 \\
\hline 538 & 0.055 & 4.9 & 0.011 & 0.210 & 0.028 & 4.1 & 0.021 & 0.053 \\
\hline 539 & 0.072 & 3.5 & 0.026 & 0.196 & 0.041 & 4.8 & 0.023 & 0.127 \\
\hline 540 & 0.069 & 4.9 & 0.014 & 0.259 & 0.047 & 4.7 & 0.027 & 0.136 \\
\hline 541 & 0.052 & 5.4 & 0.042 & 0.089 & 0.077 & 4.6 & 0.092 & 0.014 \\
\hline 542 & 0.039 & 5.2 & 0.032 & 0.063 & 0.061 & 4.6 & 0.075 & 0.000 \\
\hline 543 & 0.069 & 4.7 & 0.004 & 0.293 & 0.036 & 5.5 & 0.010 & 0.179 \\
\hline 544 & 0.055 & 4.4 & 0.026 & 0.146 & 0.039 & 4.1 & 0.042 & 0.027 \\
\hline 545 & 0.061 & 3.8 & 0.011 & 0.207 & 0.028 & 4.9 & 0.013 & 0.098 \\
\hline 546 & 0.044 & 4.9 & 0.028 & 0.099 & 0.041 & 4.4 & 0.048 & 0.014 \\
\hline 549 & 0.063 & 3.7 & 0.007 & 0.223 & 0.025 & 3.3 & 0.014 & 0.059 \\
\hline 550 & 0.063 & 3.4 & 0.011 & 0.200 & 0.019 & 3.4 & 0.014 & 0.037 \\
\hline 551 & 0.072 & 3.5 & 0.015 & 0.227 & 0.030 & 3.4 & 0.018 & 0.073 \\
\hline 552 & 0.055 & 3.5 & 0.011 & 0.175 & 0.019 & 3.6 & 0.014 & 0.037 \\
\hline 553 & 0.069 & 3.5 & 0.008 & 0.237 & 0.028 & 5.3 & 0.003 & 0.158 \\
\hline 554 & 0.069 & 4.9 & 0.014 & 0.259 & 0.044 & 4.7 & 0.027 & 0.121 \\
\hline 555 & 0.063 & 3.5 & 0.023 & 0.175 & 0.030 & 3.5 & 0.028 & 0.037 \\
\hline 565 & 0.041 & 4.2 & 0.033 & 0.067 & 0.052 & 4.5 & 0.065 & 0.000 \\
\hline 575 & 0.041 & 4.7 & 0.025 & 0.098 & 0.036 & 4.2 & 0.042 & 0.013 \\
\hline 579 & 0.061 & 3.8 & 0.026 & 0.163 & 0.033 & 3.5 & 0.032 & 0.037 \\
\hline 580 & 0.074 & 4.7 & 0.014 & 0.280 & 0.047 & 4.7 & 0.024 & 0.152 \\
\hline 581 & 0.055 & 3.8 & 0.026 & 0.141 & 0.033 & 3.7 & 0.032 & 0.037 \\
\hline 582 & 0.074 & 3.4 & 0.008 & 0.250 & 0.030 & 3.1 & 0.007 & 0.099 \\
\hline 583 & 0.066 & 3.6 & 0.022 & 0.188 & 0.036 & 3.6 & 0.028 & 0.062 \\
\hline 584 & 0.074 & 3.3 & 0.008 & 0.243 & 0.030 & 3.3 & 0.011 & 0.094 \\
\hline 585 & 0.050 & 4.7 & 0.028 & 0.122 & 0.039 & 4.2 & 0.042 & 0.027 \\
\hline 586 & 0.061 & 4.7 & 0.018 & 0.207 & 0.039 & 3.9 & 0.032 & 0.063 \\
\hline 587 & 0.055 & 5.2 & 0.028 & 0.150 & 0.063 & 5.5 & 0.065 & 0.054 \\
\hline 588 & 0.047 & 4.7 & 0.028 & 0.110 & 0.039 & 4.2 & 0.042 & 0.027 \\
\hline 589 & 0.063 & 5.2 & 0.014 & 0.238 & 0.052 & 5.5 & 0.042 & 0.107 \\
\hline 590 & 0.069 & 4.8 & 0.011 & 0.268 & 0.044 & 4.7 & 0.024 & 0.136 \\
\hline 591 & 0.052 & 4.6 & 0.029 & 0.133 & 0.047 & 4.4 & 0.048 & 0.042 \\
\hline 592 & 0.052 & 4.6 & 0.018 & 0.169 & 0.041 & 4.2 & 0.035 & 0.067 \\
\hline 593 & 0.055 & 3.8 & 0.011 & 0.185 & 0.025 & 3.7 & 0.014 & 0.062 \\
\hline 594 & 0.105 & 3.1 & 0.008 & 0.333 & 0.052 & 5.3 & 0.000 & 0.333 \\
\hline 595 & 0.116 & 3.8 & 0.000 & 0.457 & 0.063 & 5.3 & 0.000 & 0.404 \\
\hline 596 & 0.074 & 3.5 & 0.008 & 0.258 & 0.033 & 5.3 & 0.003 & 0.193 \\
\hline 597 & 0.088 & 3.5 & 0.004 & 0.320 & 0.047 & 3.1 & 0.007 & 0.165 \\
\hline 598 & 0.050 & 4.9 & 0.028 & 0.123 & 0.047 & 4.4 & 0.051 & 0.028 \\
\hline
\end{tabular}




\section{Appendix VIII: ANN Details}

The ANN created during training is shown in Figure 55. The ANN is a function fitting network with 10 nodes. The details of the weights and activation functions used are given in Table 24. The ANN can be recreated using these values.

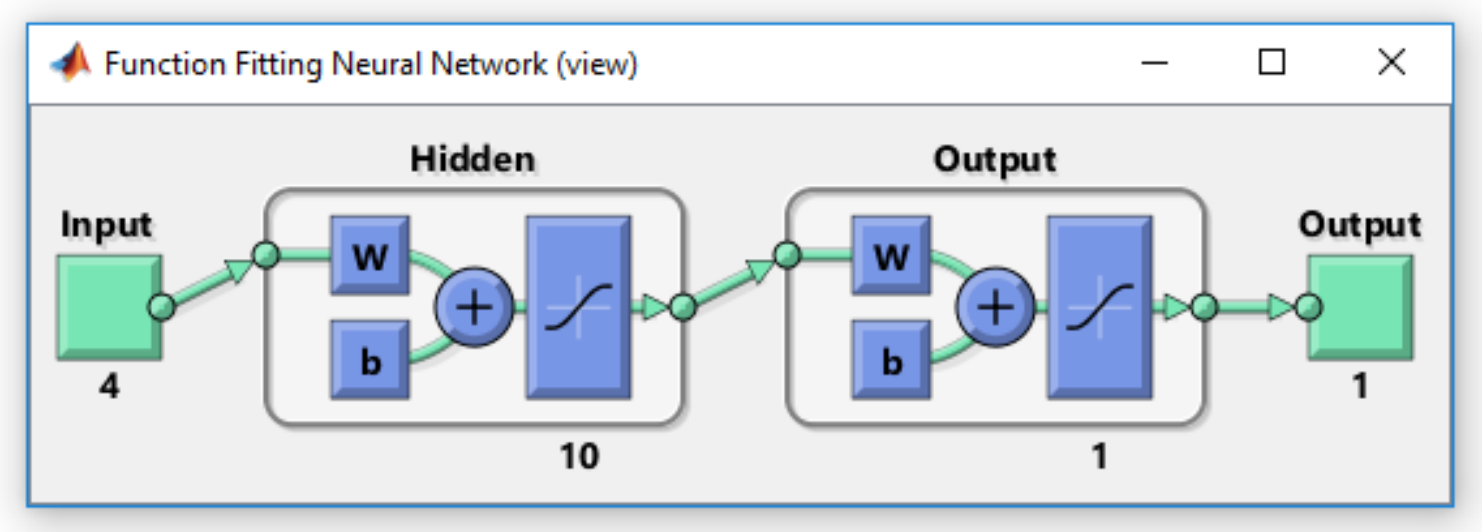

Figure 55: View of the ANN created.

Table 24: Detailed Values of the Weights of Each Node.

\begin{tabular}{|c|c|c|c|c|c|c|c|}
\hline \multicolumn{9}{|c|}{ Hidden Layer (tansig activation function) } & \multicolumn{2}{c|}{$\begin{array}{c}\text { Output Layer (tansig Activation } \\
\text { function) }\end{array}$} \\
\hline Node & Weights 1 & Weights 2 & Weights 3 & Weights 4 & Node Bias & Weights & $\begin{array}{c}\text { Output } \\
\text { Bias }\end{array}$ \\
\hline $\mathbf{1}$ & 0.325 & 1.732 & 1.768 & -3.36 & -0.42 & -310 & 60.92 \\
\hline $\mathbf{2}$ & 11.57 & 37.59 & -60.3 & -30.1 & 18.89 & 925.6 & 916.8 \\
\hline $\mathbf{3}$ & 22.33 & -45.5 & -15.9 & 137.1 & -29.3 & -267.2 & -105 \\
\hline $\mathbf{4}$ & 1.034 & -40.3 & 29.96 & -32.6 & -30.3 & -62.1 \\
\hline $\mathbf{5}$ & -2.35 & -10.5 & 8.156 & -5.84 & 0.372 & -68.3 \\
\hline $\mathbf{6}$ & 1.67 & 8.324 & 2.706 & -14.7 & 7.768 & 99.61 \\
\hline $\mathbf{7}$ & -1.56 & -7.79 & -3.12 & 14.32 & -7.38 & 116.5 \\
\hline $\mathbf{8}$ & -4.56 & -5.42 & 11.94 & -16.1 & -3.44 & -8.3 \\
\hline $\mathbf{9}$ & 4.491 & 5.476 & -12 & 15.81 & 3.597 & -1.52 & -1.5 \\
\hline $\mathbf{1 0}$ & -0.26 & -1.26 & -0.44 & 1.506 & & \\
\hline
\end{tabular}




\section{Appendix IX: DCM Self Training at $2 \mathrm{~Hz}$ PVs}

Table 25: PVs of the Field Testing Data Using DCM and Self-Training at $2 \mathrm{~Hz}$.

\begin{tabular}{|c|c|c|c|c|c|}
\hline File & PE & $\mathbf{r}^{2}$ & SEE & PIE & PV \\
\hline 533 & 0.463 & 0.207 & 0.077 & 0.071 & 0.468 \\
\hline 534 & 0.800 & 0.228 & 0.059 & 0.034 & 0.302 \\
\hline 535 & 0.797 & 0.491 & 0.040 & 0.038 & 0.395 \\
\hline 536 & 0.019 & 0.056 & 0.052 & 0.054 & 0.653 \\
\hline 537 & 0.576 & 0.004 & 0.109 & 0.421 & 0.299 \\
\hline 538 & 0.137 & 0.001 & 0.126 & 0.014 & 0.575 \\
\hline 539 & 0.247 & 0.121 & 0.120 & 0.320 & 0.525 \\
\hline 540 & 0.548 & 0.018 & 0.159 & 0.403 & 0.320 \\
\hline 541 & 0.740 & 0.011 & 0.263 & 0.654 & 0.187 \\
\hline 542 & 0.573 & 0.000 & 0.120 & 0.429 & 0.298 \\
\hline 543 & 0.590 & 0.009 & 0.024 & 0.495 & 0.286 \\
\hline 544 & 0.593 & 0.121 & 0.074 & 0.001 & 0.377 \\
\hline 545 & 0.477 & 0.222 & 0.062 & 0.015 & 0.473 \\
\hline 546 & 0.696 & 0.025 & 0.119 & 0.917 & 0.188 \\
\hline 549 & 0.693 & 0.939 & 0.075 & 0.005 & 0.610 \\
\hline 550 & 0.562 & 0.793 & 0.032 & 0.039 & 0.625 \\
\hline 551 & 0.754 & 0.056 & 0.055 & 0.419 & 0.223 \\
\hline 552 & 0.952 & 0.004 & 0.034 & 0.294 & 0.114 \\
\hline 553 & 0.957 & 0.575 & 0.042 & 0.074 & 0.336 \\
\hline 554 & 0.901 & 0.404 & 0.025 & 0.049 & 0.308 \\
\hline 555 & 0.940 & 0.361 & 0.064 & 0.000 & 0.277 \\
\hline 565 & 0.931 & 0.106 & 0.020 & 0.039 & 0.189 \\
\hline 575 & 0.512 & 0.001 & 0.103 & 0.906 & 0.279 \\
\hline 579 & 0.908 & 0.090 & 0.028 & 0.123 & 0.187 \\
\hline 580 & 0.698 & 0.011 & 0.152 & 0.158 & 0.265 \\
\hline 581 & 0.297 & 0.230 & 0.176 & 0.576 & 0.508 \\
\hline 582 & 0.134 & 0.625 & 0.193 & 0.055 & 0.790 \\
\hline 583 & 0.554 & 0.501 & 0.080 & 0.013 & 0.530 \\
\hline 584 & 0.038 & 0.196 & 0.154 & 0.030 & 0.694 \\
\hline 585 & 0.502 & 0.383 & 0.132 & 0.028 & 0.514 \\
\hline 586 & 0.512 & 0.000 & 0.209 & 0.256 & 0.348 \\
\hline 587 & 0.047 & 0.056 & 0.230 & 0.042 & 0.637 \\
\hline 588 & 0.703 & 0.008 & 0.161 & 0.320 & 0.244 \\
\hline 589 & 0.726 & 0.001 & 0.103 & 0.691 & 0.189 \\
\hline 590 & 0.665 & 0.003 & 0.151 & 0.209 & 0.274 \\
\hline 591 & 0.785 & 0.003 & 0.115 & 0.169 & 0.215 \\
\hline 592 & 0.633 & 0.027 & 0.119 & 0.955 & 0.218 \\
\hline 593 & 0.595 & 0.038 & 0.065 & 0.068 & 0.340 \\
\hline 594 & 0.661 & 0.880 & 0.041 & 0.027 & 0.604 \\
\hline 595 & 0.935 & 0.213 & 0.076 & 0.047 & 0.223 \\
\hline 596 & 0.896 & 0.545 & 0.049 & 0.028 & 0.362 \\
\hline 597 & 0.803 & 0.572 & 0.074 & 0.005 & 0.423 \\
\hline 598 & 0.674 & 0.411 & 0.069 & 0.052 & 0.430 \\
\hline
\end{tabular}

